\title{
Reperfusion cardiac arrhythmias and their relation to reperfusion induced cell death
}

Citation for published version (APA):

van der Weg, K. (2018). Reperfusion cardiac arrhythmias and their relation to reperfusion induced cell death. [Doctoral Thesis, Maastricht University]. Proefschriftmaken.nl II Uitgeverij Boxpress. https://doi.org/10.26481/dis.20181221kw

Document status and date:

Published: 01/01/2018

DOI:

$10.26481 / \mathrm{dis} .20181221 \mathrm{kw}$

Document Version:

Publisher's PDF, also known as Version of record

\section{Please check the document version of this publication:}

- A submitted manuscript is the version of the article upon submission and before peer-review. There can be important differences between the submitted version and the official published version of record.

People interested in the research are advised to contact the author for the final version of the publication, or visit the DOI to the publisher's website.

- The final author version and the galley proof are versions of the publication after peer review.

- The final published version features the final layout of the paper including the volume, issue and page numbers.

Link to publication

\footnotetext{
General rights rights.

- You may freely distribute the URL identifying the publication in the public portal. please follow below link for the End User Agreement:

www.umlib.nl/taverne-license

Take down policy

If you believe that this document breaches copyright please contact us at:

repository@maastrichtuniversity.nl

providing details and we will investigate your claim.
}

Copyright and moral rights for the publications made accessible in the public portal are retained by the authors and/or other copyright owners and it is a condition of accessing publications that users recognise and abide by the legal requirements associated with these

- Users may download and print one copy of any publication from the public portal for the purpose of private study or research.

- You may not further distribute the material or use it for any profit-making activity or commercial gain

If the publication is distributed under the terms of Article $25 \mathrm{fa}$ of the Dutch Copyright Act, indicated by the "Taverne" license above, 
Reperfusion cardiac arrhythmias and their relation to reperfusion induced cell death 
ISBN: 978-94-6380-140-9

Design by: Bregje Jaspers, ProefschriftOntwerp.nl

Printed by: ProefschriftMaken, www.proefschriftmaken.nl

(c) Kirian van der Weg 


\title{
Reperfusion cardiac arrhythmias and their relation to reperfusion induced cell death
}

\author{
PROEFSCHRIFT \\ ter verkrijging van de graad van doctor \\ aan de Universiteit Maastricht, \\ op gezag van Rector Magnificius, Prof. dr. Rianne M. Letschert, \\ volgens het besluit van het college van Decanen, \\ in het openbaar te verdedigen op \\ vrijdag 21 december 2018 om 12.00 uur \\ door \\ Kirian van der Weg \\ Geboren 23 november 1986 \\ te Rotterdam
}




\section{Promotores:}

Prof. dr. A.P.M. Gorgels

Prof. dr. M. Krucoff

Prof. dr. R.J. de Winter

\section{Beoordelingscommissie:}

Prof. dr. H.J.G.M. Crijns (voorzitter)

Prof. dr. P.A.F.M. Doevendans

Prof. dr. A.W.J. van 't Hof,

Dr. R. Nijveldt,

Prof. dr. P.G.A. Volders

This work was suppported by funding from the Hein Wellens Foundtion, Maastricht, The Netherlands and by the MUMC+ research fund, Maastricht, The Netherlands

Financial support by the Hartsvrienden RESCAR for the publication of this thesis is gratefully acknowledged

Financial support by the Dutch Hart Foundation for the publication of this thesis is gratefully acknowledged. 




\section{Table of contents}

$\begin{array}{ll}\text { Chapter 1: } \quad \text { Introduction } & 9\end{array}$

Chapter 2: $\quad$ Prospective evaluation of where reperfusion ventricular arrhythmia

"bursts" fit into optimal reperfusion in STEMI

Chapter 3: $\quad$ Ventricular arrhythmia Burst is an independent indicator of larger infarct size even in optimal reperfusion in STEMI.

Chapter 4: $\quad$ Reperfusion ventricular arrhythmia bursts identify larger infarct size in spite of optimal epicardial and microvascular reperfusion using cardiac magnetic resonance imaging

Chapter 5: $\quad$ Bursts of reperfusion arrhythmias occur independently of area at risk size and are the first marker of reperfusion injury

Chapter 6: $\quad$ Reperfusion cardiac arrhythmias and their relation to reperfusion induced cell death

Chapter 7: $\quad$ Summary and general discussion

Summary 


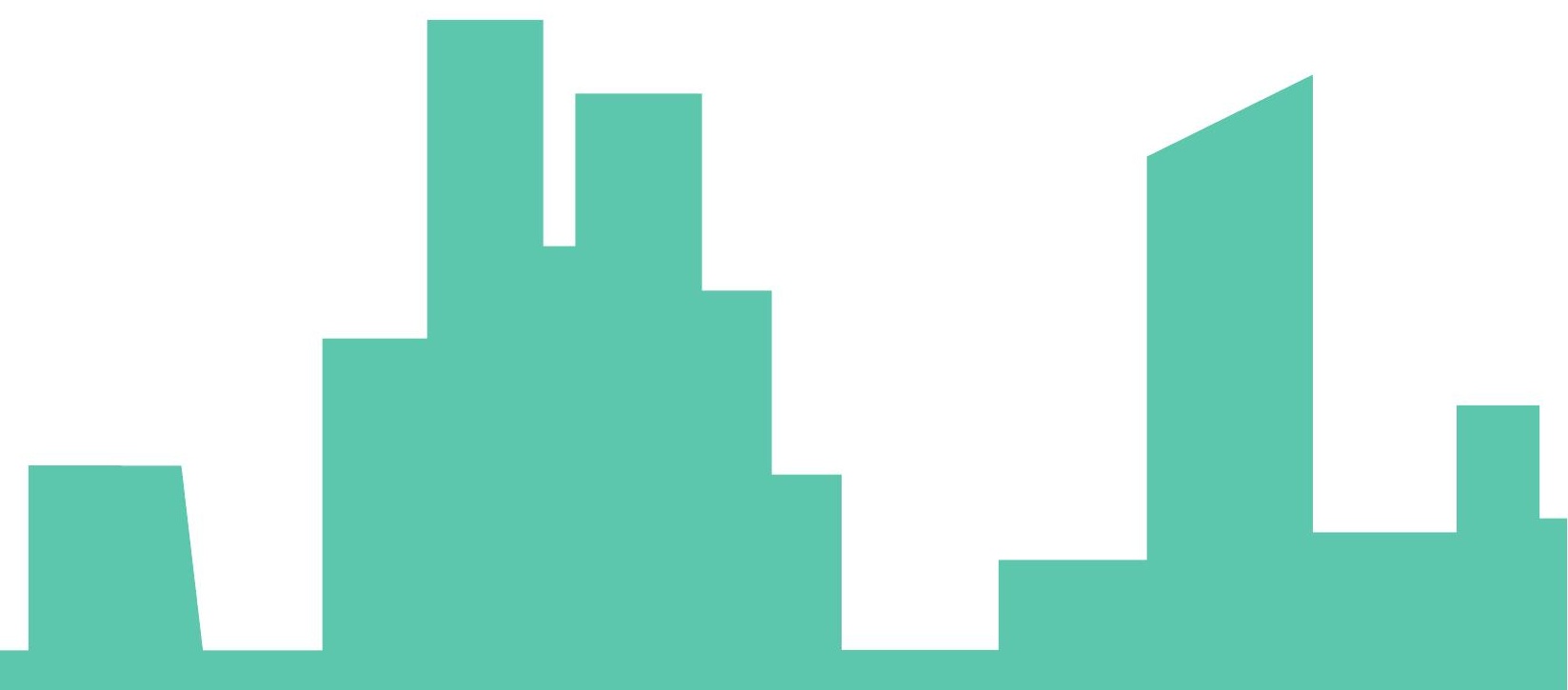




\section{Chapter 1}

Introduction

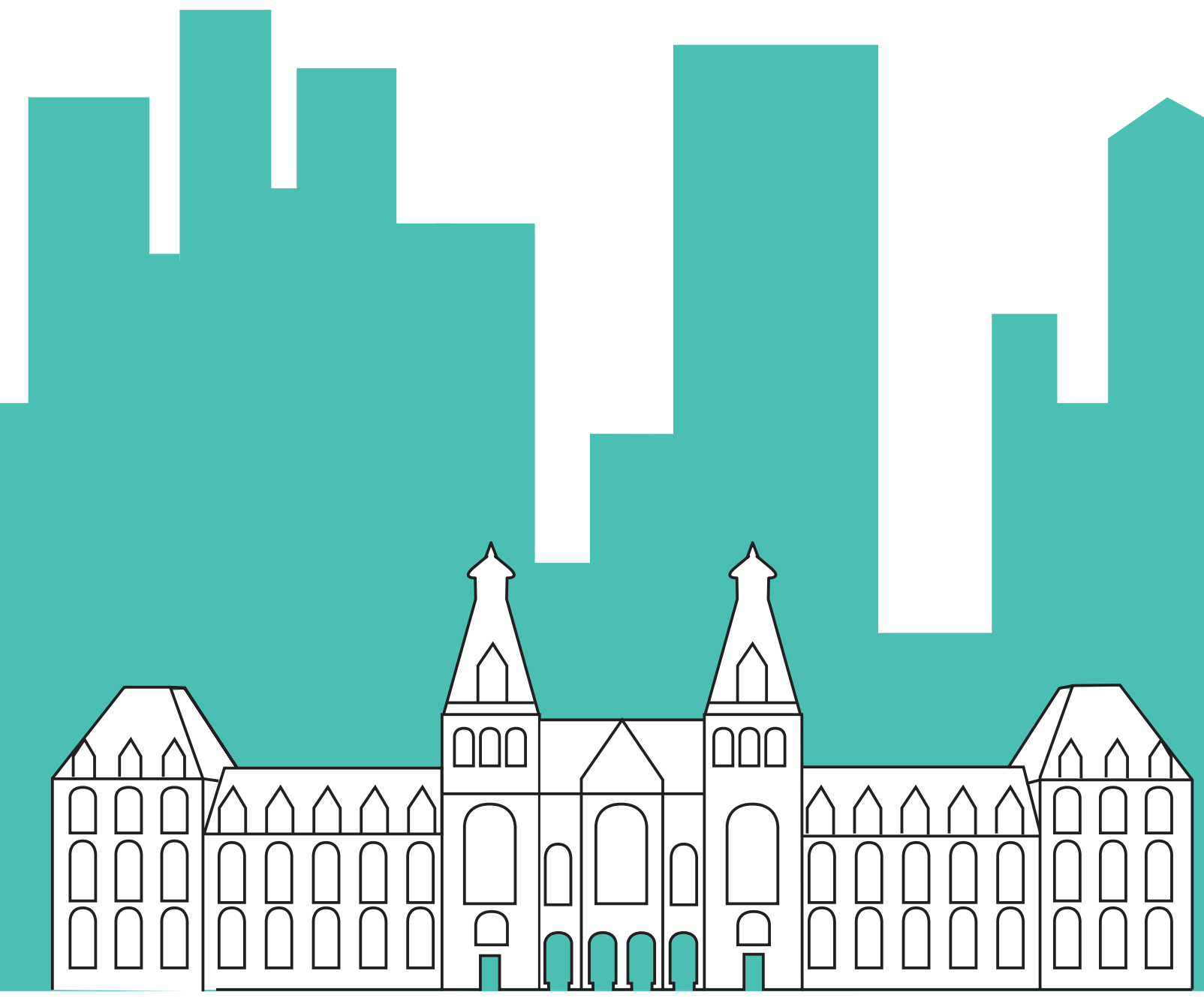




\section{Acute myocardial infarction}

George Dock and Sir William Osler were the first physicians to describe the diagnosis of myocardial infarction in a living patient in $1892^{1}$. At that time many physicians believed that acute myocardial infarction (AMI) inevitably let to sudden cardiac death. James Herrick challenged this notion of AMI as being uniformly fatal and described the signs and symptoms of AMI in $1912^{2}$. His observations formed the basis of AMI research. This allowed physicians in the early 1920's to know the fundamental clinical and electrocardiographic features of AMI and coronary occlusion being the immediate precipitate. In the more than 50 years that followed important research focused on the pathophysiology of myocardial infarction (MI). Using a dog model Jennings et al. developed the concept of the wavefront-like spread of transmural ischemia and subsequent necrosis ${ }^{3-7}$ : Cell death upon ischemia starts subendocardially and progresses as a wave front toward the epicardium causing a transmural infarct with sufficient duration of sustained ischemia. Occlusion of a coronary artery puts the area of the myocardium that it provides at risk of necrosis. The longer occlusion and ischemia persist, the more of the area at risk will become necrotic and form final infarct size. These observations emphasized the importance of interrupting ischemia to stop this progressive process of myocardial cell death and obtain optimal myocardial salvage.

Based on these fundamental observations many therapeutic strategies were developed to improve diagnosis and treatment during the acute phase of $\mathrm{Ml}$ and to reduce complications and recurrences. This work has resulted in a substantial decrease in mortality as previously reviewed by our group (8). Contributions to this improvement comprised new diagnostic, monitoring and treatment strategies, such as the coronary care unit ${ }^{9}$, IV thrombolytic therapy ${ }^{10,11}$, coronary bypass surgery ${ }^{12}$, percutaneous coronary intervention ${ }^{13}$, and hemodynamic monitoring ${ }^{14}$.

An essential breakthrough consisted of the advent of means to reopen the culprit vessel in the very early stage of AMI, first with fibrinolytic agents and later with percutaneous coronary interventions. Though already in 1957 streptokinase administration in patients with AMI was suggested to reduce in-hospital mortality if administered early enough ${ }^{15}$, it was not till the late nineteen seventies ${ }^{16}$ that this approach received new attention and till the nineteen eighties that the first large scale thrombolytic trials were published ${ }^{11,17-20}$.

Though thrombolytic therapy greatly improved mortality after AMI, its use was associated with an increased risk of bleeding, especially hemorrhagic cerebral stroke as a rare but major complication ${ }^{21}$. In addition, thrombolytic therapy failed to produce epicardial reperfusion with normal flow in about $20-50 \%$ of patients ${ }^{11}$. Furthermore, in those in whom successful reperfusion was obtained, about $20 \%$ experienced early re-occlusion of the infarct vesse ${ }^{21}$. These limitations led to investigations of mechanical reperfusion with balloon angioplasty and later with coronary stents, and primary percutaneous coronary intervention (PCI) for acute STEMI has become the contemporary standard of care as a safer and more successful method of restoring stable and sustained perfusion ${ }^{13,22-25}$. 
Systematic adoption of primary $\mathrm{PCl}$ reducing door-to-balloon time has resulted in even lower mortality and morbidity ${ }^{23}$. The development of new adjunctive platelet inhibiting agents and improved stents has further contributed to a better short and long-term prognosis with ischemic coronary syndromes ${ }^{26-33}$.

\section{Reperfusion arrhythmias}

Arrhythmias with reperfusion of the occluded coronary artery either by fibrinolytic therapy or $\mathrm{PCl}$ has been observed in both animal models and human patients, as described by our group and others ${ }^{17,34-40}$. These arrhythmias include isolated ventricular premature beats with long coupling interval, accelerated idioventricular rhythms (AIVR), ventricular fibrillation, and acute sinus bradycardia and/or AV-block.

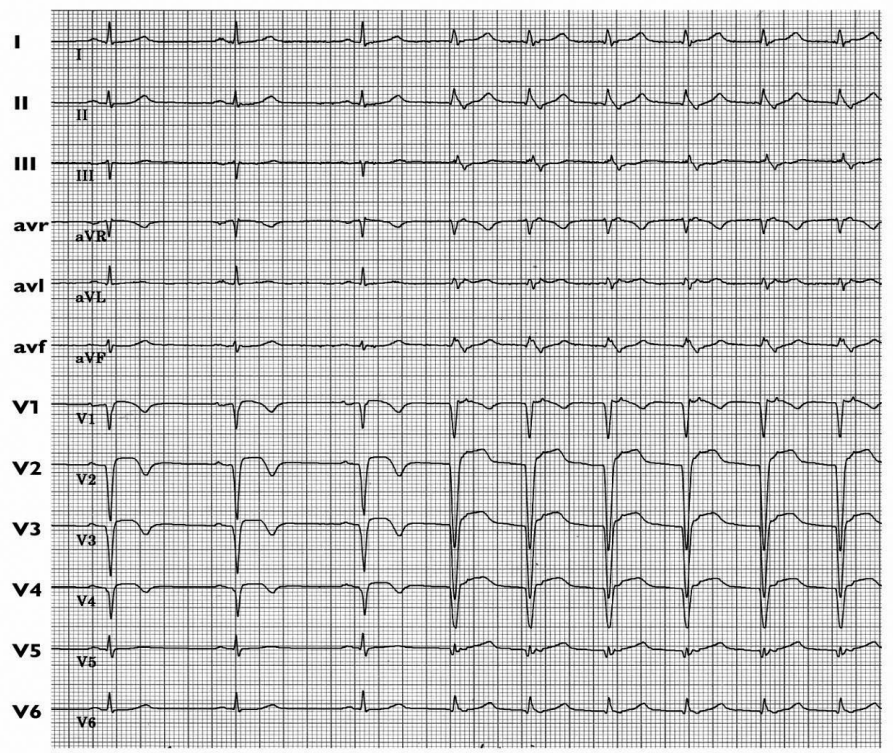

Figure 1: Example of an accelerated idiopathic ventricular rhythm.

Slow sinus rhythm with QRS/T complexes consistent with a reperfused anterior wall infarction is interrupted after the $3 \mathrm{~d}$ beat by a ventricular rhythm of about 100/min. The ventricular origin is supported by the widening of the QRS complexes and the 1:1 retrograde conduction to the atria. The configuration of the QRS complexes of this AIVR is consistent with an origin from the reperfused area.

In the setting of AMI AIVR in particular was described in the pre-thrombolytic era ${ }^{41-46}$ but its pathophysiological and clinical significance remained speculative ${ }^{47}$. With the advent of thrombolytic therapy and later of $\mathrm{PCl}$ it was observed that these arrhythmias occurred simultaneously with signs of reopening of the culprit vessel, such as relieve of chest pain and normalization of ST segment deviation ${ }^{17,34,40}$. While first thought of as a positive sign of reperfusion, later research has associated reperfusion ventricular arrhythmias with increased infarct size and decreased ventricular functioning ${ }^{48}$. Reperfusion ventricular arrhythmias "bursts" are quantitatively characterized by a high density of ventricular arrhythmias (VA) occurring within a small time window and two standard deviations 
apart from the previous baseline VA density, as illustrated by figure $1+2^{17,49}$. As mentioned, these arrhythmias are typically ventricular premature beats with long coupling intervals and AIVRs $s^{50-53}$. Their QRS configuration is consistent with an origin from the reperfused territory and they are usually transient, hemodynamically well tolerated and occur closely related to the time of reopening of the infarct vessel.

\section{Reperfusion injury and the possible relation with VA bursts}

As mentioned above the primary objective of both thrombolytic and mechanical reperfusion is to interrupt ischemia and thus "salvage" myocardium at risk, reducing infarct size and improving clinical outcome in patients presenting with STEMI. However, chemical injury from restoration of oxygenated blood flow and worsening of ischemia from mechanical distal vessel embolization have also been associated with reperfusion therapies. The potential deleterious effect of reperfusion injury is defined as additional myocyte apoptosis as a result of reperfusion of ischemic but still viable myocytes and is termed lethal reperfusion injury ${ }^{54}$. Illustrative of this process is the frequently observed increase in chest pain after opening of the occluded vessel and concomitant increase of ST-elevation on the ECG ${ }^{55}$. Besides the increase in chest pain and ST-elevation, reperfusion injury is also characterized by VA bursts

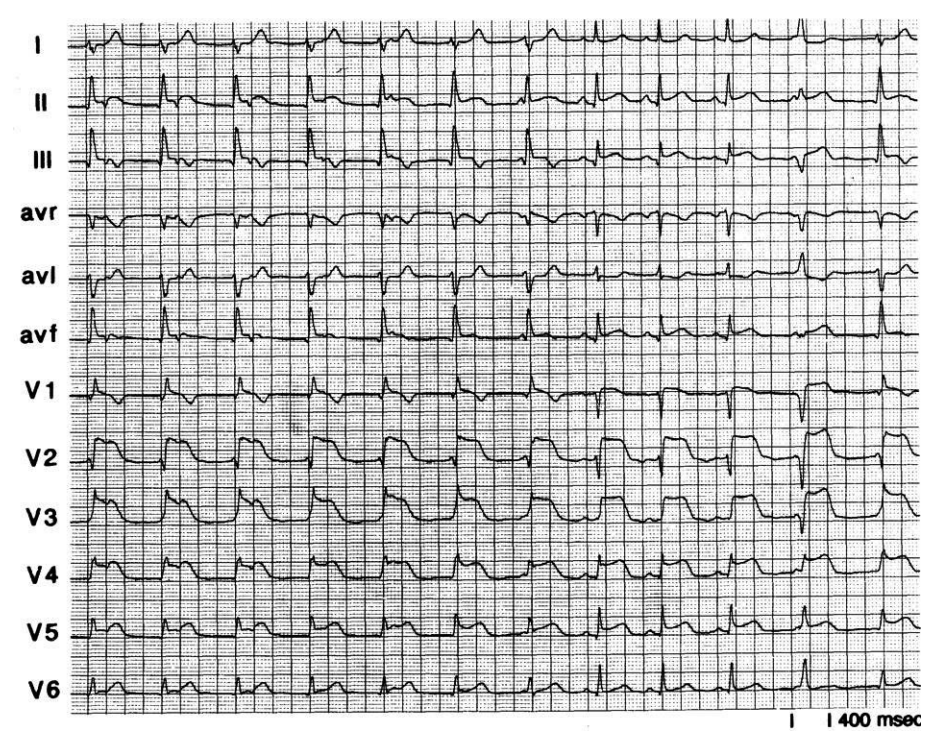

Figure 2: Example of a complex AIVR

The rhythm strip starts with an AIVR in the setting of a reperfusing anterior wall infarction. The ventricular origin is supported by retrograde VA conduction to the atria, as visualized by the negative deflections after the QRS complexes in leads II, III and aVF before the onset of the T waves. Retrograde conduction disappears starting from the 4th AIVR complex and turns with $P$ fusions to overt sinus $P$ waves. This results in fusions and sinus captures (QRS complexes 7-10). AIVR restarts at QRS 11 with a fusion beat.

These findings led us to postulate that the pathophysiological mechanisms for lethal reperfusion injury and reperfusion arrhythmias might be intertwined and therefore this thesis focuses on the 
hypothesis of VA burst being a marker for lethal reperfusion injury.

\section{Objectives of this thesis}

1. To confirm previous findings that a burst of ventricular arrhythmias is associated with larger infarct size, using CMR to assess infarct size

2. To relate ventricular arrhythmia burst to cellular damage downstream of intact epicardial and microvascular flow independent of the size of myocardial area at risk, eg that VA burst is not simply the end result of large MI.

3. To correlate our evidence with the literature reporting similar pathophysiological basis of reperfusion arrhythmias and reperfusion injury.

\section{Outline of the thesis}

In chapter 2, to confirm previous findings, the correlation of VA burst with larger infarct size is tested in an independent cohort, using cardiac magnetic resonance (CMR).

In chapter 3, the relation of VA burst with infarct size is reported in the presence of optimal angiographic blush.

In chapter 4, the relation of VA burst with infarct size is reported in the absence of microvascular obstruction using CMR.

In chapter 5, the relation between VA burst and infarct size is reported as dependent on the size of the initial area at risk.

In chapter 6, the pathophysiological basis for lethal reperfusion injury and for reperfusion arrhythmias are reviewed and compared.

In chapter 7 the results of this thesis and the relation between VA burst as a potential marker for lethal reperfusion injury will be discussed and directions for future research will be given. 


\section{References}

1. Osler W. The Principle and Practice of Medicine. New York: D. Appleton; 1892.

2. Herrick JB. Clinical features of sudden obstruction of the coronary arteries. JAMA : the journal of the American Medical Association. 1912;59:2015-20.

3. Reimer KA, Jennings RB. The "wavefront phenomenon" of myocardial ischemic cell death. II. Transmural progression of necrosis within the framework of ischemic bed size (myocardium at risk) and collateral flow. Laboratory investigation; a journal of technical methods and pathology. 1979;40(6):633-44. Epub 1979/06/01.

4. Reimer KA, Jennings RB. The changing anatomic reference base of evolving myocardial infarction. Underestimation of myocardial collateral blood flow and overestimation of experimental anatomic infarct size due to tissue edema, hemorrhage and acute inflammation. Circulation. 1979;60(4):866-76. Epub 1979/10/01.

5. Reimer KA, Lowe JE, Rasmussen MM, Jennings RB. The wavefront phenomenon of ischemic cell death. 1. Myocardial infarct size vs duration of coronary occlusion in dogs. Circulation. 1977;56(5):786-94. Epub 1977/11/01.

6. Jennings RB, Murry C, Reimer KA. Myocardial effects of brief periods of ischemia followed by reperfusion. Advances in cardiology. 1990;37:7-31. Epub 1990/01/01.

7. Jennings RB, Sommers HM, Smyth GA, Flack HA, Linn H. Myocardial necrosis induced by temporary occlusion of a coronary artery in the dog. Archives of pathology. 1960;70:68-78. Epub 1960/07/01.

8. de Vreede JJ, Gorgels AP, Verstraaten GM, Vermeer F, Dassen WR, Wellens HJ. Did prognosis after acute myocardial infarction change during the past 30 years? A meta-analysis. Journal of the American College of Cardiology. 1991;18(3):698-706. Epub 1991/09/01.

9. Lown B, Fakhro AM, Hood WB, Jr., Thorn GW. The coronary care unit. New perspectives and directions. JAMA : the journal of the American Medical Association. 1967;199(3):188-98. Epub 1967/01/16.

10. The Thrombolysis in Myocardial Infarction (TIMI) trial. Phase I findings. TIMI Study Group. The New England journal of medicine. 1985;312(14):932-6. Epub 1985/04/04.

11. investigators G. An international randomized trial comparing four thrombolytic strategies for acute myocardial infarction. The New England journal of medicine. 1993;329(10):673-82. Epub 1993/09/02.

12. Effler DB. Myocardial revascularization surgery since 1945 A.D. Its evolution and its impact. The Journal of thoracic and cardiovascular surgery. 1976;72(6):823-8. Epub 1976/12/01.

13. Grines CL, Browne KF, Marco J, Rothbaum D, Stone GW, O'Keefe J, et al. A comparison of immediate angioplasty with thrombolytic therapy for acute myocardial infarction. The Primary Angioplasty in Myocardial Infarction Study Group. The New England journal of medicine. 1993;328(10):673-9. Epub 1993/03/11.

14. Forrester JS, Diamond G, Chatterjee K, Swan HJ. Medical therapy of acute myocardial infarction by application of hemodynamic subsets (first of two parts). The New England journal of medicine. 1976;295(24):1356-62. Epub 1976/12/09.

15. Sherry S, Fletcher AP, Alkajersig N, Smyrniotis FE. An approach to intravascular fibrinolysis in man. Transactions of the Association of American Physicians. 1957;70:288-95; discussion 95-6. Epub 
1957/01/01.

16. Rentrop KP, Blanke H, Karsch KR, Wiegand V, Kostering H, Oster H, et al. Acute myocardial infarction: intracoronary application of nitroglycerin and streptokinase. Clinical cardiology. 1979;2(5):354-63. Epub 1979/10/01.

17. Gorgels AP, Vos MA, Letsch IS, Verschuuren EA, Bar FW, Janssen JH, et al. Usefulness of the accelerated idioventricular rhythm as a marker for myocardial necrosis and reperfusion during thrombolytic therapy in acute myocardial infarction. The American journal of cardiology. 1988;61(4):231-5. Epub 1988/02/01.

18. Simoons ML, Serruys PW, van den Brand M, Res J, Verheugt FW, Krauss XH, et al. Early thrombolysis in acute myocardial infarction: limitation of infarct size and improved survival. Journal of the American College of Cardiology. 1986;7(4):717-28. Epub 1986/04/01.

19. Effectiveness of intravenous thrombolytic treatment in acute myocardial infarction. Gruppo Italiano per lo Studio della Streptochinasi nell'Infarto Miocardico (GISSI). Lancet. 1986;1(8478):397-402. Epub $1986 / 02 / 22$.

20. Maroo A, Topol EJ. The early history and development of thrombolysis in acute myocardial infarction. Journal of thrombosis and haemostasis : JTH. 2004;2(11):1867-70. Epub 2004/11/20.

21. Indications for fibrinolytic therapy in suspected acute myocardial infarction: collaborative overview of early mortality and major morbidity results from all randomised trials of more than 1000 patients. Fibrinolytic Therapy Trialists' (FTT) Collaborative Group. Lancet. 1994;343(8893):311-22. Epub 1994/02/05.

22. Zijlstra F, de Boer MJ, Hoorntje JC, Reiffers S, Reiber JH, Suryapranata H. A comparison of immediate coronary angioplasty with intravenous streptokinase in acute myocardial infarction. The New England journal of medicine. 1993;328(10):680-4. Epub 1993/03/11.

23. Global Use of Strategies to Open Occluded Coronary Arteries in Acute Coronary Syndromes Angioplasty Substudy I. A clinical trial comparing primary coronary angioplasty with tissue plasminogen activator for acute myocardial infarction. The New England journal of medicine. 1997;336(23):1621-8. Epub 1997/06/05.

24. Grines CL, Marsalese DL, Brodie B, Griffin J, Donohue B, Costantini CR, et al. Safety and cost-effectiveness of early discharge after primary angioplasty in low risk patients with acute myocardial infarction. PAMI-II Investigators. Primary Angioplasty in Myocardial Infarction. Journal of the American College of Cardiology. 1998;31(5):967-72. Epub 1998/04/30.

25. Tcheng JE, Kandzari DE, Grines CL, Cox DA, Effron MB, Garcia E, et al. Benefits and risks of abciximab use in primary angioplasty for acute myocardial infarction: the Controlled Abciximab and Device Investigation to Lower Late Angioplasty Complications (CADILLAC) trial. Circulation. 2003;108(11):131623. Epub 2003/08/27.

26. Randomized trial of intravenous streptokinase, oral aspirin, both, or neither among 17,187 cases of suspected acute myocardial infarction: ISIS-2.ISIS-2 (Second International Study of Infarct Survival) Collaborative Group. Journal of the American College of Cardiology. 1988;12(6 Suppl A):3A-13A. Epub 1988/12/01.

27. Schwartz L, Bourassa MG, Lesperance J, Aldridge HE, Kazim F, Salvatori VA, et al. Aspirin and dipyridamole in the prevention of restenosis after percutaneous transluminal coronary angioplasty. The New England 
journal of medicine. 1988;318(26):1714-9. Epub 1988/06/30.

28. Committee CS. A randomised, blinded, trial of clopidogrel versus aspirin in patients at risk of ischaemic events (CAPRIE). CAPRIE Steering Committee. Lancet. 1996;348(9038):1329-39. Epub 1996/11/16.

29. Brener SJ, Barr LA, Burchenal JE, Katz S, George BS, Jones AA, et al. Randomized, placebo-controlled trial of platelet glycoprotein Ilb/llla blockade with primary angioplasty for acute myocardial infarction. ReoPro and Primary PTCA Organization and Randomized Trial (RAPPORT) Investigators. Circulation. 1998;98(8):734-41. Epub 1998/09/04.

30. Antoniucci D, Santoro GM, Bolognese L, Valenti R, Trapani M, Fazzini PF. A clinical trial comparing primary stenting of the infarct-related artery with optimal primary angioplasty for acute myocardial infarction: results from the Florence Randomized Elective Stenting in Acute Coronary Occlusions (FRESCO) trial. Journal of the American College of Cardiology. 1998;31(6):1234-9. Epub 1998/05/15.

31. Rodriguez A, Bernardi V, Fernandez M, Mauvecin C, Ayala F, Santaera O, et al. In-hospital and late results of coronary stents versus conventional balloon angioplasty in acute myocardial infarction (GRAMI trial). Gianturco-Roubin in Acute Myocardial Infarction. The American journal of cardiology. 1998;81(11):128691. Epub 1998/06/19.

32. Suryapranata H, van 't Hof AW, Hoorntje JC, de Boer MJ, Zijlstra F. Randomized comparison of coronary stenting with balloon angioplasty in selected patients with acute myocardial infarction. Circulation. 1998;97(25):2502-5. Epub 1998/07/10.

33. Stone GW, Grines CL, Browne KF, Marco J, Rothbaum D, O'Keefe J, et al. Predictors of in-hospital and 6-month outcome after acute myocardial infarction in the reperfusion era: the Primary Angioplasty in Myocardial Infarction (PAMI) trail. Journal of the American College of Cardiology. 1995;25(2):370-7. Epub 1995/02/01.

34. Goldberg S, Greenspon AJ, Urban PL, Muza B, Berger B, Walinsky P, et al. Reperfusion arrhythmia: a marker of restoration of antegrade flow during intracoronary thrombolysis for acute myocardial infarction. American heart journal. 1983;105(1):26-32. Epub 1983/01/01.

35. Gressin V, Gorgels AP, Louvard Y, Lardoux H, Bigelow RH. Is arrhythmogenicity related to the speed of reperfusion during thrombolysis for myocardial infarction? European heart journal. 1993;14(4):516-20. Epub 1993/04/01.

36. Gressin V, Gorgels AP, Louvard Y, Lardoux H, Bigelow RH. [Is sudden reperfusion more arrhythmogenic during thrombolysis for myocardial infarction?]. Archives des maladies du coeur et des vaisseaux. 1993;86(10):1475-81. Epub 1993/10/01. Une reperfusion plus soudaine est-elle plus arythmogene au cours de la thrombolyse pour infarctus du myocarde?

37. Gressin V, Louvard Y, Gorgels AP, Pezzano M, Lardoux H. [Reperfusion arrhythmia]. Archives des maladies du coeur et des vaisseaux. 1993;86 Spec No 4:69-77. Epub 1993/07/01. Arythmies de reperfusion.

38. Gressin V, Gorgels A, Louvard Y, Lardoux H, Bigelow R. ST-segment normalization time and ventricular arrhythmias as electrocardiographic markers of reperfusion during intravenous thrombolysis for acute myocardial infarction. The American journal of cardiology. 1993;71(16):1436-9. Epub 1993/06/15.

39. Gressin V, Gorgels A, Louvard Y, Maison-Blanche P. Reconsidering arrhythmias as markers of reperfusion. Combined arrhythmia and ST-segment analysis during myocardial infarction. Journal of electrocardiology. 1993;26 Suppl:262-9. Epub 1993/01/01. 
40. Buckingham TA, Devine JE, Redd RM, Kennedy HL. Reperfusion arrhythmias during coronary reperfusion therapy in man. Clinical and angiographic correlations. Chest. 1986;90(3):346-51. Epub 1986/09/01.

41. Rothfeld EL, Zucker JR, Parsonnet V, Alinsonorin CA. Idioventricular rhythm in acute myocardial infarction. Circulation. 1968;27:203-9.

42. Castellanos A, Jr., Lemberg L, Arcebal AG. Mechanisms of slow ventricular tachycardias in acute myocardial infarction. Diseases of the chest. 1969;56(6):470-6. Epub 1969/12/01.

43. Norris RM, Mercer CJ, Yeates SE. Idioventricular rhythm complicating acute myocardial infarction. British heart journal. 1970;32(5):617-21. Epub 1970/09/01.

44. Norris RM, Mercer CJ. Significance of idioventricular rhythms in acute myocardial infarction. Progress in cardiovascular diseases. 1974;16(5):455-68. Epub 1974/03/01.

45. de Soyza N, Bissett JK, Kane JJ, Murphy ML, Doherty JE. Association of accelerated idioventricular rhythm and paroxysmal ventricular tachycardia in acute myocardial infarction. The American journal of cardiology. 1974;34(6):667-70. Epub 1974/11/01.

46. Lichstein E, Ribas-Meneclier C, Gupta PK, Chadda KD. Incidence and description of accelerated ventricular rhythm complicating acute myocardial infarction. The American journal of medicine. 1975;58(2):192-8. Epub 1975/02/01.

47. Talbot S, Greaves M. Association of ventricular extrasystoles and ventricular tachycardia with idioventricular rhythm. British heart journal. 1976;38(5):457-64. Epub 1976/05/01.

48. Engelen DJ, Gressin V, Krucoff MW, Theuns DA, Green C, Cheriex EC, et al. Usefulness of frequent arrhythmias after epicardial recanalization in anterior wall acute myocardial infarction as a marker of cellular injury leading to poor recovery of left ventricular function. The American journal of cardiology. 2003;92(10):1143-9. Epub 2003/11/12.

49. Majidi M, Kosinski AS, Al-Khatib SM, Lemmert ME, Smolders L, van Weert A, et al. Reperfusion ventricular arrhythmia 'bursts' in TIMI 3 flow restoration with primary angioplasty for anterior STelevation myocardial infarction: a more precise definition of reperfusion arrhythmias. Europace : European pacing, arrhythmias, and cardiac electrophysiology : journal of the working groups on cardiac pacing, arrhythmias, and cardiac cellular electrophysiology of the European Society of Cardiology. 2008;10(8):988-97. Epub 2008/05/17.

50. Terkelsen CJ, Sorensen JT, Kaltoft AK, Nielsen SS, Thuesen L, Botker HE, et al. Prevalence and significance of accelerated idioventricular rhythm in patients with ST-elevation myocardial infarction treated with primary percutaneous coronary intervention. The American journal of cardiology. 2009;104(12):1641-6. Epub 2009/12/08.

51. Gorgels A, Vos MA, Brugada P, Wellens HJ. The clinical relevance of abnormal automaticity and triggered activity. Cardiac arrhythmias: Where to go frome here? Mount Kisco, NY: Futura Publishing company; 1987. p. 147-69.

52. Rosen MR, Fisch C, Hoffman BF, Danilo P, Jr., Lovelace DE, Knoebel SB. Can accelerated atrioventricular junctional escape rhythms be explained by delayed afterdepolarizations? The American journal of cardiology. 1980;45(6):1272-84. Epub 1980/06/01.

53. Ferrier GR, Moffat MP, Lukas A. Possible mechanisms of ventricular arrhythmias elicited by ischemia 
followed by reperfusion. Studies on isolated canine ventricular tissues. Circulation research. 1985;56(2):184-94. Epub 1985/02/01.

54. Yellon DM, Hausenloy DJ. Myocardial reperfusion injury. The New England journal of medicine. 2007;357(11):1121-35. Epub 2007/09/15.

55. Doevendans PA, Gorgels AP, van der Zee R, Partouns J, Bar FW, Wellens HJ. Electrocardiographic diagnosis of reperfusion during thrombolytic therapy in acute myocardial infarction. The American journal of cardiology. 1995;75(17):1206-10. Epub 1995/06/15. 


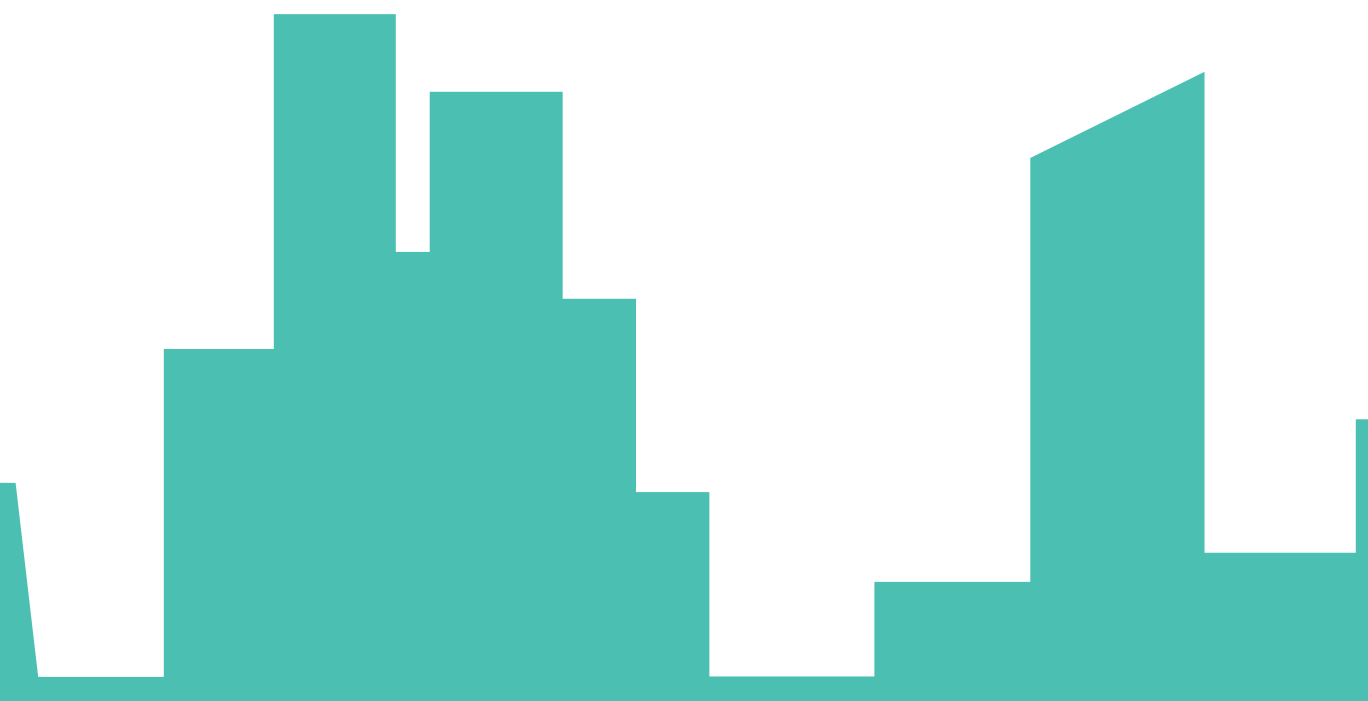

First author: K. van der Weg, MD

Authors: Kirian van der Weg, MD* $\neq$, Wichert J. Kuijt, MD †, Jan G.P. Tijssen, PhD †, Sebastiaan C.A.M. Bekkers, MD, PhD*, Joost D.E. Haeck, MD, PhD †, Cynthia L. Green, PhD ¥, Miguel E. Lemmert, MD* ,Robbert J. de Winter, MD, PhD †, Anton P.M. Gorgels, MD, PhD, *, Mitchell W. Krucoff, MD, PhD $\neq$

Work was performed in:

* Maastricht University Medical Centre, Maastricht, The Netherlands + Academic Medical Centre, Amsterdam, The Netherlands

‡ Duke University Medical Center, Durham, United States of America

Published in

International journal of cardiology 2015; 195: 136-42.s 


\section{Chapter 2}

Prospective evaluation of where reperfusion ventricular arrhythmia "bursts" fit into optimal reperfusion in STEMI

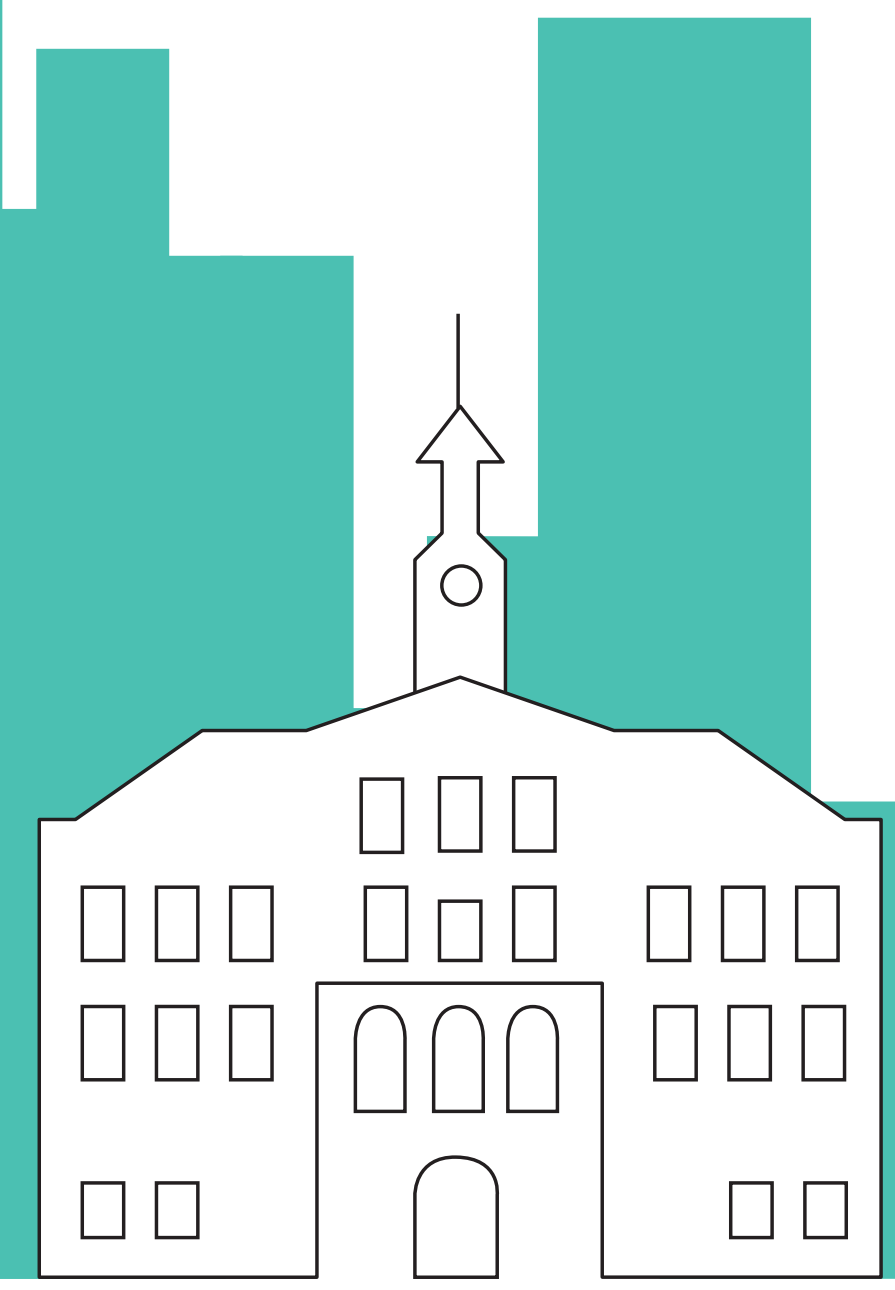




\section{Abstract}

\section{Background:}

Early reperfusion of ischemic myocytes is essential for optimal salvage in acute myocardial infarction. VA (ventricular arrhythmia) bursts after recanalization of the culprit vessel have been found to be related to larger infarct size (IS), using SPECT.

\section{Objective:}

The hypothesis was tested that this finding could be confirmed in an independent cohort using a more accurate technique, i.e. delayed-enhancement cardiovascular magnetic resonance imaging (DE-CMR).

\section{Methods:}

All 196 patients from the PREPARE and MAST studies who had 24-hour, continuous, 12-lead Holter, started before primary percutaneous coronary intervention resulting in brisk TIMI (thrombolysis in myocardial infarction) 3 flow and stable ST-recovery were included. VA bursts were identified against subject-specific background VA rates using a previously published statistical outlier method. IS was assessed using DE-CMR. Angiography, Holter and DE-CMR results were assessed in core laboratories, blinded to all other data.

\section{Results:}

VA bursts were present in 154/196 (79\%) of patients. Baseline characteristics between the groups with and without bursts were similar. VA burst was associated with significantly larger infarct size in the population as a whole (median $11.3 \%$ vs $5.3 \% ; \mathrm{p}=0.001$ ) and also when divided in non-anterior (median 9.9\% vs 4.9\%; $\mathrm{p}=0.003$ ) and anterior myocardial infarction (median $21.4 \%$ vs $12.0 \% ; \mathrm{p}=$ 0.48 ), the latter not reaching statistical significance due to the small subset of patients.

\section{Conclusion:}

Beyond the classical markers of "optimal" reperfusion such as TIMI 3 flow and stable ST-segment recovery, VA bursts occurring during the reperfusion phase are an early electrobiomarker of larger IS. Clinical trial registration: PREPARE: ISRCTN71104460 http://www.controlled-trials.com/ISRCTN71104460. 


\section{Introduction}

Ventricular arrhythmias (VA) upon reperfusion are recognized as a typical phenomenon since the advent of recanalization techniques in acute ST-elevation myocardial infarction (STEMI). However, not much is known about their pathophysiological and prognostic significance ${ }^{1}$. Morphologically, these reperfusion VAs include ventricular premature beats with long coupling intervals and accelerated idioventricular rhythms. They occur (almost) directly at the moment of reperfusion, are hemodynamically well tolerated and originate within the reperfusion zone (Fig. 1$)^{2}$. In conjunction with thrombolytic therapy, reperfusion VA were considered a positive event as a non-invasive marker of infarct artery recanalization ${ }^{2}$. In the more contemporary era of direct percutaneous coronary intervention ( $\mathrm{PCI}$ ), where TIMI 3 epicardial flow is restored in $>90 \%$ of STEMI's and mortality has been reduced to less than $5 \%{ }^{3}$, the hypothesis that VA "bursts" are associated with larger infarct size (IS) and worsened outcomes in the setting of anterior MI has been proposed by our group, based on retrospective modeling ${ }^{4-7}$.

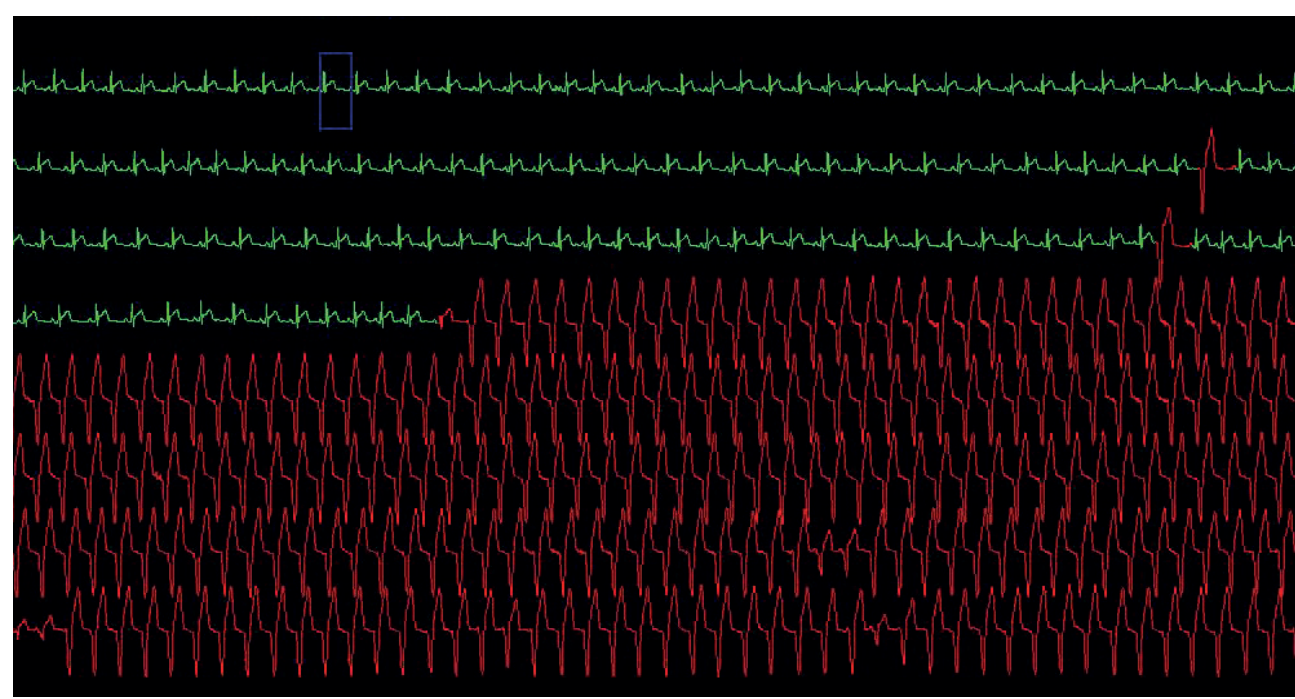

Figure 1: Full disclosure format of a 24 hour ambulatory recording illustrating the onset and perpetuation of a reperfusion ventricular arrhythmia burst.

Green waveforms: Sinus beats still showing some ST segment elevation. Red waveforms: accelerated idioventricular rhythm interrupting the sinus rhythm.

Over the last years, it has become clear that clinically beneficial reperfusion in STEMI is dependent on both the clinical context and on a series of key mechanistic steps defining "optimal" reperfusion per se. Clinically, the timing of presentation relative to the ongoing irreversible injury or "wavefront" of cell death has been addressed with emphasis on early diagnosis and time to intervention and results in smaller IS and lower morbidity ${ }^{8-10}$. IS as an endpoint was traditionally measured with SPECT imaging, but can now be measured with greater precision using delayed enhancement cardiovascular magnetic resonance imaging $(\mathrm{DE}-\mathrm{CMR})^{11}$. 
In this report, we pursued to prospectively test the hypothesis generated by observations from Majidi et al $\mathrm{al}^{4,5} 12$ to a unique patient population with not only anterior STEMI but also non-anterior STEMI and the use of DE-CMR, the current gold standard, for IS measurement. In this population we examined whether it could be confirmed that VA burst adds significantly to IS in patients with optimal reperfusion in an independent, larger population consisting of both anterior and nonanterior $\mathrm{MI}$ and correlated to final IS as determined by CMR.

\section{Methods}

\section{Study population}

Patients included in the Maastricht ST-Elevation Myocardial Infarction (MAST) cohort $^{13}$ and the Proximal embolic protection study in patients undergoing primary angioplasty for acute myocardial infarction (PREPARE) cohort were included for analyses. The protocols of both studies, specifically including Holter recording and CMR imaging, were prospectively designed to answer the questions of the study at hand. Since the PROXIS device used in the PREPARE trial did not influence the final infarct size, all patients from that study were included in this analysis ${ }^{14}$. Approval of both studies was granted by the Medical Ethical Committee of corresponding hospitals (MAST p06.0032L and PREPARE ISRCTN71104460) and written informed consent was obtained from all patients included. Both studies included patients enrolled between August 2006 and June 2008. Inclusion criteria for both studies were as follows: (1) symptoms consistent with an acute STEMI lasting for more than $30 \mathrm{~min}$ but less than $6 \mathrm{~h}$ and (2) ST-elevation of more than $1 \mathrm{~mm}$ in anatomically adjacent leads in the initial electrocardiogram (ECG), and (3) primary PCI. Exclusion criteria were as follows: (1) age below 18 years, (2) cardiogenic shock, (3) pregnancy, (4) inability to obtain informed consent, (5) any contraindications to the use of glycoprotein Ilb/Illa receptor antagonists, (6) a co-existent condition associated with a limited life expectancy, (7) prior coronary artery bypass grafting or fibrinolytics, and (8) standard contra-indications for CMR.

In both studies, 24-hour, continuous, digital 12-lead ECG-Holter monitoring was started at the time of admission, and CMR imaging was scheduled 3 months after the acute event for analyses of final infarct size after remodeling ${ }^{9}$. Technical exclusion criteria for this VA burst study were as follows: (1) poor quality ECG-Holter recording, (2) previous myocardial infarction (MI), and (3) poor quality CMR imaging. Clinical exclusion criteria for the current study were (1) absence of successful epicardial flow restoration defined as TIMI flow $\leq 2$, (2) failure to achieve complete and stable ST recovery within 240 min or (3) late ST re-elevation on continuous ECG-Holter. These exclusion criteria were formed because we were interested in the additional value of VA burst in patients with optimal epicardial reperfusion and brisk ST-recovery. Therefore, we did not perform statistical analyses of the groups excluded. 

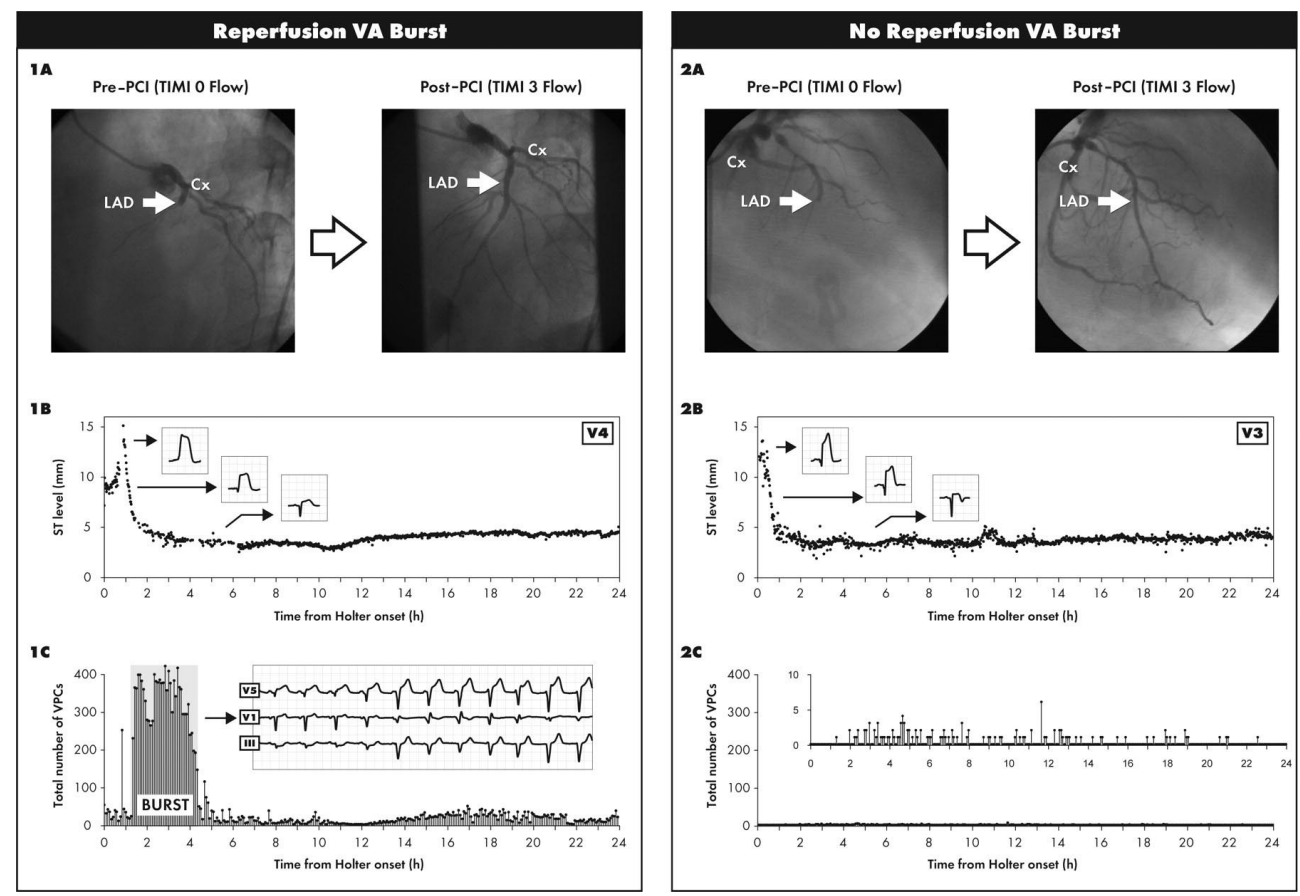

Figure 2: Example of a patient with and a patient without VA burst

Concomitantly acquired coronary angiography assessments of pre- and post-primary percutaneous coronary intervention TIMI flow grades in two study subjects ( $1 \mathrm{~A}$ and $2 \mathrm{~A}$ ) with a total occlusion in the proximal left anterior descending artery proximal (LAD); continuous digital 12-lead electrocardiography monitoring for ST-segment recovery analysis with both subjects having $\geq 50 \%$ stable ST-segment recovery (1B and $2 \mathrm{~B}$ ); and complete beat-to-beat Holter monitoring for quantitative rhythm analysis identifying (1C) or not identifying (2C) patient-specific ventricular arrhythmia 'bursts' by using independent statistical outlier detection methodology. Cx, circumflex artery; LMA, left marginal artery. Note the burst versus the background VA as depicted in IC and 2 C. (reproduced with permission from: Majidi et al. Eur. Heart J 2009;30:757-764)

\section{Angiographic TIMI flow assessment}

TIMI flow grade assessment was performed by the angiographic core laboratories (Academic Medical Centre, Amsterdam, The Netherlands and Maastricht University Medical Centre, Maastricht, The Netherlands) blinded to all patient and other core laboratory data. TIMI flow was graded according to the TIMI trial classification ${ }^{15}$.

\section{ECG data acquisition}

Continuous, high fidelity, digital, 12-lead ECG-Holter recording (NEMON 180+, Northeast Monitoring, Maynard,MA,USA)was started at the time of admission prior to $\mathrm{PCl}$ and continued for an average of $24 \mathrm{~h}$. This system provided the source data for both continuous STsegment recovery and ventricular arrhythmia burst analysis. Quantitative ST-segment recovery analysis was performed on 60 second median beat 12-lead ECGs. Quantitative ventricular arrhythmia (VA) analysis was performed on 3-lead beat-to-beat Holter. ST and VA analyses were performed by independent experts blinded to all other patient and core laboratory data through the collaborative eECG core laboratory program 
(Duke Clinical Research Institute/Maastricht University Medical Center eECG Core, Durham, North Carolina, USA and Maastricht, The Netherlands), using NEMON Holter for Windows software.

\section{Continuous ST recovery analysis}

Methods and criteria for continuous 12-lead ST-segment recovery analysis and reperfusion of the culprit lesion have been described in detail previously ${ }^{16}$. In short, peak ST-segment deviation is determined based on the lead with the greatest baseline deviation taken from themost abnormal ECG recorded duringmonitoring. Stable and complete ST-segment recovery is defined as $\geq 50 \%$ recovery from previous peak ST-segment levels in the most deviated lead within 240 min, lasting N4 $\mathrm{h}$ without further ST-segment evolution (N100 $\mu \mathrm{V})$. Late ST (re-)elevation defining epicardial vessel reocclusion ( $\mathrm{N} 150 \mu \mathrm{V}$ re-elevation in the most abnormal lead evolving in b60 $\mathrm{min}$ ) or microvascular insufficiency (N50\% peak ST levels persisting N6 h in the most abnormal lead) were used to exclude patients from the "optimal reperfusion biosignature" group included in the current analysis.

\section{Quantitative rhythm analysis and defining VA burst}

For beat-to-beat quantitative rhythm analysis on all digital 3-lead Holter recordings, Holter 5 software (Northeast Monitoring, Maynard, MA, USA) was used ${ }^{4}$. All automatically assigned waveform labels were manually verified for each cardiac cycle from each subject to ensure accurate VA capture according to predefined criteria for ECG interpretation of VAs $s^{4,5}$. To generate quantitative VA rates over a 24 hour period, total VPC counts, for which no distinction between the types of VPC was made, were bundled into 5 minute blocks for temporal correlation with stable ST-segment recovery and angiographic observations (Fig. 2). Quantitative VA rates over the course of Holter recordings were incorporated in a statistical outlier detection method to automatically separate outlier events of VA rates (VA burst), if present, from patient-specific baseline VA counts. VA bursts were defined as "reperfusion VA bursts" if concomitant with or subsequent to angiographic documentation of re-established TIMI 3 flow in the infarct related artery. Study subjects were dichotomously classified into the'reperfusion VA burst' group or the'no burst' group. Statistical definition and characterization of reperfusion VA bursts has been described in detail by Majidi et $\mathrm{al}^{4}$.

\section{CMR imaging protocol}

CMR was performed 3 to 6 months after the myocardial infarction. Images were acquired on clinical 1.5-T scanners (Philips Intera, Philips Medical Systems, Best, The Netherlands) and Siemens Sonato/ Avanto (Siemens, Erlangen, Germany) using phased-array receiver coils according to the routine scan protocol at each site. Localizers were acquired to identify the cardiac position and the standard long- and short-axis of the heart. Cine images were acquired in the vertical and horizontal long axis, and multiple short-axis slices completely covering the left ventricle, using a steady-state freeprecession sequence. DE-CMR images were obtained 10-15 min after the intravenous administration of $0.2 \mathrm{mmol} / \mathrm{kg}$ body weight Gadolinium-based contrast agent (Gd-DTPA, Magnevist ${ }^{\oplus}$, Schering, Germany) in horizontal and vertical long axis, and multiple short axis views completely covering the left ventricle, using a segmented inversion recovery gradient-echo sequence (either $2 \mathrm{D}$ or 
3D). DE-CMR images were analyzed off-line independently by a single experienced observer per trial, blinded to the clinical and ECG data, using commercially available software (CAAS MRV 3.0, Pie Medical Imaging, Maastricht, The Netherlands for MAST study or MASS 5.1, Medis, Leiden, The Netherlands for PREPARE trial). Both laboratories used the standardized methods for CMR analyses which have shown to have excellent reproducibility ${ }^{17}$. Statistical comparisons showed no significant trial difference for IS $(p=0.48)$ Endocardial and epicardial contours were manually traced on the DE-CMR images. Final left ventricular IS was quantified using a SI threshold of N5 SDabove a remote non-infarcted region and expressed as a percentage of total left ventricular mass. Areas of microvascular obstruction (central hypoenhancement within hyperenhanced area) were included in IS assessment. Left ventricular end-diastolic volumes, end-systolic volumes, and ejection fraction (LVEF) were determined by planimetry of all short axis images in each patient.

\section{Statistical analysis}

Univariable comparisons for baseline characteristics and outcomes for subjects with and without VA burst were made using the student t-test for continuous variables that were normally distributed, the Wilcoxon rank sum test for non-normally distributed continuous variables, and Fisher's exact test for dichotomous variables. A p-value of 0.05 was considered statistically significant and all tests were two sided. Medians are provided with their corresponding upper and lower quartiles. Multivariable linear regression analysis was performed to assess whether VA burst remained an independent predictor for infarct size when corrected for baseline covariates. Covariates were selected by including known predictors for infarct size, study origin, and treatment assignment in the multivariable model and excluding those with $p$-values of $\geq 0.15$. Covariates were added to a regression model starting with VA burst. Data were analyzed using IBM SPSS statistics software version 19. (IBM, Armonk, New York, USA)

\section{Results}

\section{Patient characteristics}

Of the 327 available patients that gave informed consent ( $n=106$ MAST and $n=221$ PREPARE), 196 were included in the final analysis population of patients with optimal reperfusion $(n=56$ MAST and $n=140$ PREPARE). Reasons for exclusions were previous MI $(n=17)$, presented with TIMI 3 flow before PCI $(n=19)$, TIMI 3 flow could not be established after $\mathrm{PCI}(\mathrm{n}=27)$, no CMR was performed ( $n=26)$, CMR study quality was insufficient to determine IS $(n=19)$, stable ST reperfusion was not achieved ( $n=19)$, and occurrence of late ST re-elevation $(n=4)$ (Fig. 3).

Reperfusion VA burst was observed in 154/196 (79.8\%) of "optimal reperfusion" patients. Table 1 compares the baseline characteristics between the burst and no burst groups. Other than a lower incidence of nitrate use before reperfusion in the VA burst group ( $p=0.045)$, the two groups were comparable. Reperfusion VA burst was observed in 75.5\% (111/147) of non-anterior MI patients and 
in $87.8 \%$ (43/49) of patients with anterior MI location ( $p=0.07)$. CMR was performed a median of 141 days (range of 111-317) after admission.

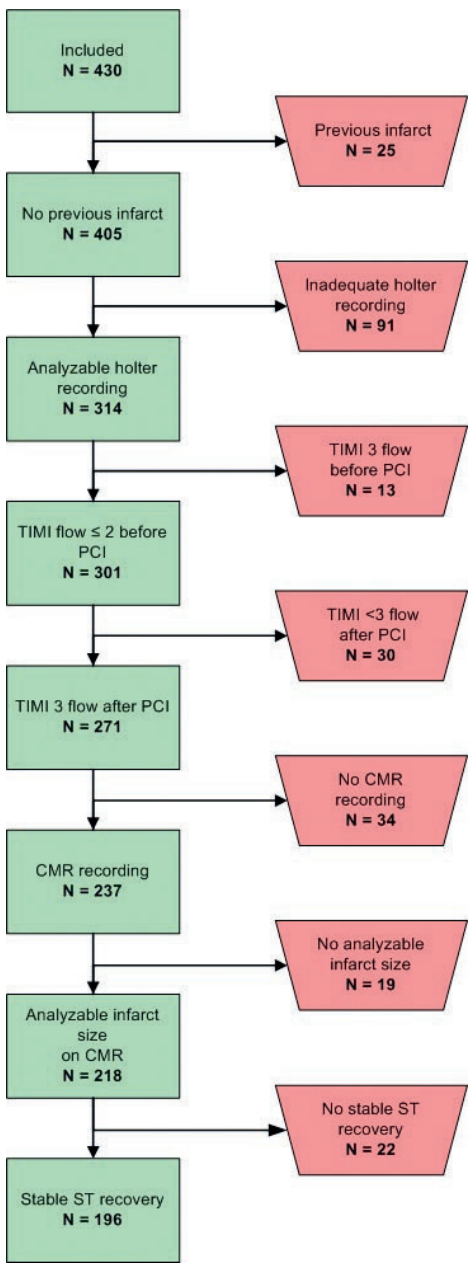

\section{Figure 3: Patient selection}

Patient selection of combined dataset with reasons for exclusion.

$\mathrm{TIMI}=$ thrombolysis in myocardial infarction, $\mathrm{CMR}=$ cardiac magnetic resonance, $\mathrm{PCI}$ = percutaneous coronary intervention 


\begin{tabular}{|c|c|c|c|}
\hline & Burst $\mathbf{N}=154$ & No burst $\mathbf{N}=42$ & $\mathbf{p}$ \\
\hline \multicolumn{4}{|l|}{ Demographics } \\
\hline Age (years) & $58.2 \pm 11.3$ & $58.1 \pm 9.3$ & 0.94 \\
\hline Male & $121(78.6 \%)$ & $38(90.5 \%)$ & 0.12 \\
\hline \multicolumn{4}{|l|}{ Comorbidities } \\
\hline BMI & $26.9 \pm 3.7$ & $27.1 \pm 3.9$ & 0.75 \\
\hline Smoking current & 89 (57.8\%) & 25 (59.5\%) & 0.51 \\
\hline Previous & $27(17.5 \%)$ & $10(23.8 \%)$ & \\
\hline History of hypertension & $36(23.4 \%)$ & $13(31.0 \%)$ & 0.32 \\
\hline Diabetes mellitus & $10(6.5 \%)$ & $3(7.1 \%)$ & 1.00 \\
\hline Hypercholesteremia & 30 (19.5\%) & $8(19.0 \%)$ & 1.00 \\
\hline Positive family history & $62(40.3 \%)$ & $17(40.5 \%)$ & 1.00 \\
\hline Pre-existent AP & $18(11.7 \%)$ & $9(21.4 \%)$ & 0.13 \\
\hline History of stroke & $4(2.6 \%)$ & $2(4.8 \%)$ & 0.61 \\
\hline History of peripheral artery disease & $5(3.2 \%)$ & $3(7.1 \%)$ & 0.37 \\
\hline \multicolumn{4}{|l|}{ Medication } \\
\hline$\beta$-blocker & $16(10.4 \%)$ & $6(14.3 \%)$ & 0.58 \\
\hline Acetyl salisylic acid & 15 (9.7\%) & $7(16.7 \%)$ & 0.27 \\
\hline ADP-antagonist & $1(0.6 \%)$ & $0(0.0 \%)$ & 1.00 \\
\hline Statin & $20(13.0 \%)$ & $8(19.0 \%)$ & 0.33 \\
\hline Nitrates & $0(0.0 \%)$ & $2(4.8 \%)$ & $0.045^{*}$ \\
\hline ACE-inhibitor & $6(3.9 \%)$ & $2(4.8 \%)$ & 0.68 \\
\hline AT-Il antagonist & $9(5.8 \%)$ & $5(11.9 \%)$ & 0.18 \\
\hline Calcium-antagonist & $8(5.2 \%)$ & $6(14.3 \%)$ & 0.08 \\
\hline \multicolumn{4}{|l|}{ PCI } \\
\hline Duration of symptoms (minutes) & $186.2 \pm 82.6$ & $184.6 \pm 64.8$ & 0.91 \\
\hline Anterior location & $43(27.9 \%)$ & $6(14.3 \%)$ & 0.07 \\
\hline Multiple vessel disease & $51(33.1 \%)$ & $18(42.9 \%)$ & 0.28 \\
\hline $\mathrm{PCl}$ of $>1$ lesion & $8(5.2 \%)$ & $1(2.4 \%)$ & 0.69 \\
\hline Side branch occlusion & $2(1.3 \%)$ & $0(0.0 \%)$ & 1.00 \\
\hline Distal embolization & $15(9.7 \%)$ & $7(16.7 \%)$ & 0.27 \\
\hline Presence of collaterals & $8(5.2 \%)$ & $4(9.5 \%)$ & 0.29 \\
\hline \multicolumn{4}{|l|}{ CMR } \\
\hline Time to CMR & $124(100-326)$ & $144(113-297)$ & 0.15 \\
\hline LVEF & $51.1 \pm 9.5$ & $53.6 \pm 9.1$ & 0.11 \\
\hline \multicolumn{4}{|l|}{ Laboratory results } \\
\hline CK-MB max & $210(127-400)$ & $134(59-183)$ & $0.001^{*}$ \\
\hline
\end{tabular}

* significant difference.

Results presented as mean \pm standard deviation, median with quartiles ( .....), or $\mathrm{N}(\%)$. ACE $=$ angiotensine converting enzyme, $\mathrm{ADP}=$ adenosine diphosphate, $\mathrm{AP}=$ angina pectoris, $\mathrm{AT}=$ angiotensine, $\mathrm{BMI}=$ body mass index, $\mathrm{PCl}=$ percutaneous coronary intervention. 


\section{Burst, infarct location, ST-recovery, and final infarct size}

As shown in figure 4, the presence of VA burst was associated with a IS twice as large compared to patients without VA burst ( $11.3 \%$ vs. $5.3 \%$, respectively; $p=0.001)$. In multivariable analyses, this correlation between VA burst and IS remained significant $(B=3.3 ; p=0.02)$ when correcting for other factors related to IS, including anterior location, age, and stroke history (Table 2). In stratified analyses based on MI location, non-anterior IS was significantly higher in patients with VA burst compared to no VA burst (9.9\% vs. $4.9 \%$, respectively; $p=0.003)$, and also in anterior infarct location ( $21.4 \%$ vs. $12.0 \%$, respectively) although not statistically significant due to the small number of patients $(p=0.48)$. An interaction test for VA burst and anterior infarct location did not reach statistical

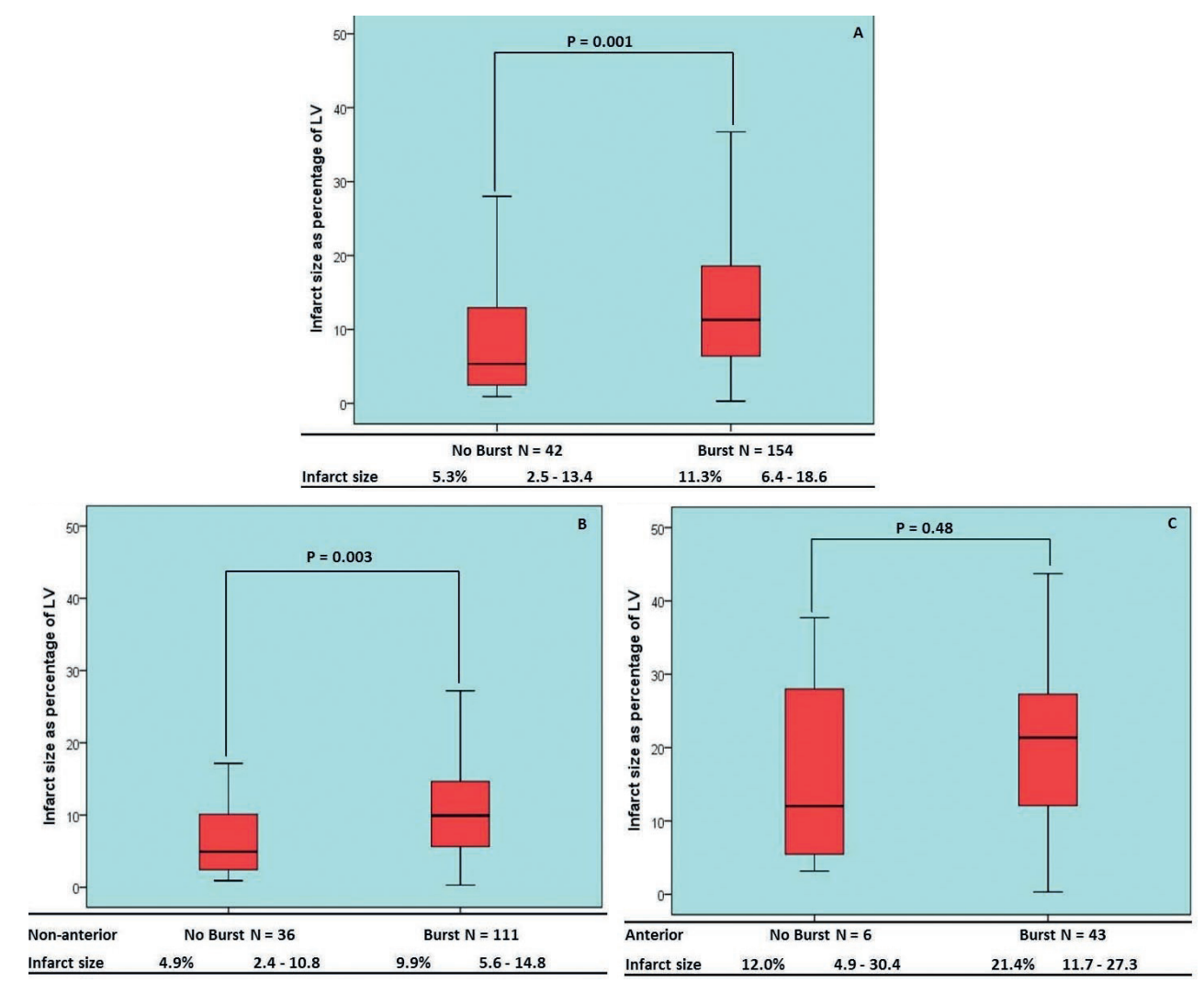

Figure 4: Effect of VA burst on infarct size

Box plots with corresponding medians and quartiles displaying the effect of VA burst for (A) Infarct size for total population, (B) infarct size ${ }^{*}$ of non-anterior myocardial infarctions, and (C) infarct size of anterior myocardial infarctions. 


\begin{tabular}{lccc}
\hline & Coefficient & $95 \% \mathrm{Cl}$ & $P$-value \\
\hline Presence of VA burst & 3.3 & $(0.5,6.1)$ & $0.02^{*}$ \\
Anterior location & 8.9 & $(6.3,11.5)$ & $<0.001^{*}$ \\
Age (years) & 0.1 & $(-0.1,0.2)$ & 0.09 \\
History of stroke & -5.5 & $(-12.1,1.1)$ & 0.10 \\
Constant & 2.3 & $(0.5,6.1)$ & $0.02^{*}$ \\
\hline
\end{tabular}

*significant difference. $\mathrm{R}^{2}=0.25$

Constant $=$ the constant in the regression analyses of $y=a x+b$ The constant being $b$

significance indicating that burst did not occur more often in the anterior population versus the non-anterior population. IS in patients with late and/or incomplete ST-segment recovery who were excluded from the "optimal reperfusion" cohort analyzed in this study is shown in figure 5. As can be seen, IS in the absence of ST recovery was significantly higher than in patients with ST recovery ( $23.5 \%$ and $19.1 \%$ vs. $5.3 \%$ and $11.3 \%$, respectively; $p=0.002$ ). When patients with ST recovery were further grouped by the presence or absence of VA burst, patients with ST recovery and VA burst had larger IS, more comparable to the no ST recovery group. This suggests that the lack of ST recovery leads to larger IS anyway due to the poor reperfusion quality as a result of mechanisms such as distal embolization. Furthermore, our results show that although TIMI 3 flow and ST recovery are optimal, the occurrence of VA bursts is associated with similarly sized IS as patients without ST-recovery. Left ventricular ejection fraction did not differ between the two groups due to small infarct size but the enzymatic surrogate for infarct size, CK-MB max, was significantly higher in the population with VA burst ( 210 vs $134 ; p=0.001)$.

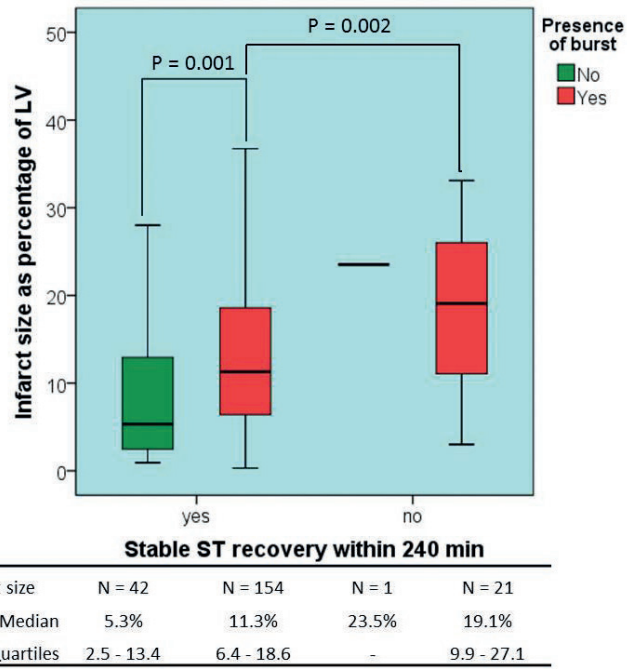

Figure 5: Effect of stable or non ST-recovery in combination with VA burst on infarct size

Box plot with corresponding median and quartiles displaying the effect of stable ST-recovery and the presence of VA burst for infarct size. 


\section{Discussion}

This study provides prospective confirmation in an independent patient population of the hypothesis that the presence of reperfusion VA burst further stratifies IS in patients who otherwise have an optimal mechanistic biosignature of brisk epicardial TIMI flow and rapid and complete STsegment recovery. In addition to these confirmatory findings, this study is the first to also explore VA burst in non-anterior MI cohorts, and is the first to report serial surrogate mechanistic modeling of angiographic flow, ST-segment recovery and reperfusion VA burst arrhythmia using DE-CMR as a uniquely precise measure of IS.

Previous models of reperfusion VA burst depended on core laboratory SPECT to quantify an independent IS endpoint. SPECT is well validated in larger MI, however is less reliable in smaller $\mathrm{MI}^{18}$. DE-CMR, on the other hand, has superior spatial resolution and is superior in detecting subendocardial infarcts and infarcts in non-anterior locations which are smaller than anterior infarcts in general ${ }^{11,19}$. The use of this imaging technology is particularly important in the current study with non-anterior STEMI. While it is noteworthy that in our data IS in anterior STEMI was not significantly different in patients with and without VA burst, we do not feel the change in imaging technology explains this difference from previous reports. IS of anterior STEMI in our data was numerically double in patients with VA burst compared to those with no burst. In our data set only 6 patients with anterior STEMI location did not have VA burst, leaving numerical differences in IS in this subset statistically underpowered especially with the large heterogeneity in infarct size for anterior infarctions. The reason for this low incidence in anterior STEMI in our population can be partly explained by the exclusion of proximal LAD occlusion in the PREPARE data set secondary to the inability to place the PROXIS device in those patients. But incidence of anterior MI in the MAST data set was similar and no other reason except pure coincidence could be found. Surrogate markers for infarct size supported the findings of IS using DE-CMR. LVEF did not significantly differ between the two groups. This might be because though IS was significantly larger in the VA burst population, they were relatively small and therefore had minor effects on LVEF. The low incidence of anterior infarcts might be additional factor for the preserved LVEF found. Enzymatic infarct size estimated using CK-MB max values did significantly differ as DE-CMR results showed. We acknowledge the limitations of CK-MB max levels for estimating infarct size and included this outcome to illustrate our findings. The population existed out of homogenous group with brisk optimal reperfusion (TIMI 3 flow) increasing the reliability of CK-MB max values as an indicating marker for final IS.

\section{Clinical relevance of reperfusion VA Burst}

Even as knowledge has advanced that it is not simply the infarct artery opening but a series of key mechanistic steps that define optimal reperfusion, each of these steps has come to provide potential therapeutic targets to improve STEMI outcomes ${ }^{8}$. The availability of quantifiable surrogates for each of the key mechanistic steps thus provides a potentially important construct of a profile or "biosignature" of optimal reperfusion"12. In the Majidi model reproduced for this 
analysis, brisk angiographic TIMI flow through the epicardial artery, rapid and complete ST recovery reflecting microvascular flow to the reversibly ischemic territory downstream, and freedom from arrhythmias reflecting chemical toxicity at the cellular level constitute the extension of the optimal biosignature. While a number of other surrogate markers, including serial cardiac enzyme curve areas, contrast echocardiography and other imaging technologies, have interest in STEMI patients after reperfusion, angiography for TIMI flow and ECG-based ST-segment recovery and VA burst provide pragmatic advantages. First, angiography and ECG monitoring are fundamental for STEMI patients, and so are routinely available technologies in the clinical care setting. Secondly, TIMI flow, ST recovery and freedom from VA burst following reperfusion are all "day zero" surrogates that can be interpreted in virtual realtime, either for clinical or for clinical research applications.

\section{Limitations}

There are several limitations to our data. First, only $50 \%$ of the patients from these combined studies had both optimal recanalization by angiography and ST-segment recovery and all surrogates markers analyzable for our model (Holter and DE-CMR imaging). This resulted in a cohort too small to power subgroup observations, such as the anterior MI location group. However, in this relatively small population, with a high incidence of smaller infarct that were accurately analyzed by $D E-C M R$, the results are clear and confirmative for the correlation between larger IS in the event of VA burst. Furthermore this study is a pooled cohort from two clinical trials. Combining the two trials increased sample size but also has potentially confounding features. In the multivariable model, however, study origin did not interact with the final IS determination. Finally, while IS has utility as an endpoint for testing the information content of additional surrogate markers to the biosignature of "optimal" reperfusion, clinical endpoints such as heart failure, need for defibrillators or mortality would be very meaningful as further asses its clinical relevance.

\section{Conclusion}

Our study uniquely confirms our hypothesis that VA bursts predict larger infarct size in patients presenting with both anterior and non-anterior STEMI and treated with primary PCI resulting in brisk epicardial flow restoration (TIMI 3 flow) and rapid and complete ST-segment resolution, using CMR to determine final IS. Future work should concentrate on analyzing the pathophysiological mechanisms of VA burst with one possibility being a sign of reperfusion injury. This would open the way to new treatment targets such as interventional methods and drugs to prevent or treat reperfusion injury.

\section{Acknowledgements}

The authors wish to thank the Hein Wellens Foundation, which supported this work. 


\section{Funding Sources}

This work was supported by the Hein Wellens Foundation, Maastricht, The Netherlands, the MUMC ${ }^{+}$ Research Fund, Maastricht, The Netherlands, and the Academic medical centre - University of Amsterdam, the Netherlands.

\section{Disclosures}

No disclosures to be reported 


\section{References}

1. Terkelsen CJ, Sorensen JT, Kaltoft AK, Nielsen SS, Thuesen L, Botker HE, Lassen JF. Prevalence and significance of accelerated idioventricular rhythm in patients with st-elevation myocardial infarction treated with primary percutaneous coronary intervention. The American journal of cardiology. 2009;104:1641-1646

2. Gorgels AP, Vos MA, Letsch IS, Verschuuren EA, Bar FW, Janssen JH, Wellens HJ. Usefulness of the accelerated idioventricular rhythm as a marker for myocardial necrosis and reperfusion during thrombolytic therapy in acute myocardial infarction. The American journal of cardiology. 1988;61:231235

3. Braunwald E. The rise of cardiovascular medicine. European heart journal. 2012;33:838-845, 845a

4. Majidi M, Kosinski AS, Al-Khatib SM, Lemmert ME, Smolders L, van Weert A, Reiber JH, Tzivoni D, Bar FW, Wellens HJ, Gorgels AP, Krucoff MW. Reperfusion ventricular arrhythmia 'bursts' in timi 3 flow restoration with primary angioplasty for anterior st-elevation myocardial infarction: A more precise definition of reperfusion arrhythmias. Europace : European pacing, arrhythmias, and cardiac electrophysiology : journal of the working groups on cardiac pacing, arrhythmias, and cardiac cellular electrophysiology of the European Society of Cardiology. 2008;10:988-997

5. Majidi M, Kosinski AS, Al-Khatib SM, Lemmert ME, Smolders L, van Weert A, Reiber JH, Tzivoni D, Bar FW, Wellens HJ, Gorgels AP, Krucoff MW. Reperfusion ventricular arrhythmia 'bursts' predict larger infarct size despite timi 3 flow restoration with primary angioplasty for anterior st-elevation myocardial infarction. European heart journal. 2009;30:757-764

6. Engelen DJ, Gressin V, Krucoff MW, Theuns DA, Green C, Cheriex EC, Maison-Blanche P, Dassen WR, Wellens HJ, Gorgels AP. Usefulness of frequent arrhythmias after epicardial recanalization in anterior wall acute myocardial infarction as a marker of cellular injury leading to poor recovery of left ventricular function. The American journal of cardiology. 2003;92:1143-1149

7. Remmelink M, Delewi R, Yong ZY, Piek JJ, Baan J, Jr. More pronounced diastolic left ventricular dysfunction in patients with accelerated idioventricular rhythm after reperfusion by primary percutaneous coronary intervention. The Journal of invasive cardiology. 2010;22:574-578

8. Ibanez B, Heusch G, Ovize M, Van de Werf F. Evolving therapies for myocardial ischemia/reperfusion injury. Journal of the American College of Cardiology. 2015;65:1454-1471

9. Grover S, Bell G, Lincoff M, Jeorg L, Madsen PL, Huang S, Leow S, Figtree G, Chakrabarty A, Leong DP, Woodman RJ, Selvanayagam JB. Utility of $\mathrm{cmr}$ markers of myocardial injury in predicting Iv functional recovery: Results from protection ami cmr sub-study. Heart, lung \& circulation. 2015

10. Eitel I, de Waha S, Wohrle J, Fuernau G, Lurz P, Pauschinger M, Desch S, Schuler G, Thiele H. Comprehensive prognosis assessment by $\mathrm{cmr}$ imaging after st-segment elevation myocardial infarction. Journal of the American College of Cardiology. 2014;64:1217-1226

11. Wagner A, Mahrholdt H, Holly TA, Elliott MD, Regenfus M, Parker M, Klocke FJ, Bonow RO, Kim RJ, Judd RM. Contrast-enhanced mri and routine single photon emission computed tomography (spect) perfusion imaging for detection of subendocardial myocardial infarcts: An imaging study. Lancet. 2003;361:374379 
12. Majidi M, Kosinski AS, Al-Khatib SM, Smolders L, Cristea E, Lansky AJ, Stone GW, Mehran R, Gibbons RJ, Crijns HJ, Wellens HJ, Gorgels AP, Krucoff MW. Implications of ventricular arrhythmia "bursts" with normal epicardial flow, myocardial blush, and st-segment recovery in anterior st-elevation myocardial infarction reperfusion: A biosignature of direct myocellular injury "downstream of downstream". European heart journal. Acute cardiovascular care. 2015;4:51-59

13. Bekkers SC, Backes WH, Kim RJ, Snoep G, Gorgels AP, Passos VL, Waltenberger J, Crijns HJ, Schalla S. Detection and characteristics of microvascular obstruction in reperfused acute myocardial infarction using an optimized protocol for contrast-enhanced cardiovascular magnetic resonance imaging. European radiology. 2009;19:2904-2912

14. Haeck JD, Kuijt WJ, Koch KT, Bilodeau L, Henriques JP, Rohling WJ, Baan J, Jr., Vis MM, Nijveldt R, van Geloven N, Groenink M, Piek JJ, Tijssen JG, Krucoff MW, De Winter RJ. Infarct size and left ventricular function in the proximal embolic protection in acute myocardial infarction and resolution of st-segment elevation (prepare) trial: Ancillary cardiovascular magnetic resonance study. Heart (British Cardiac Society). 2010;96:190-195

15. The thrombolysis in myocardial infarction (timi) trial. Phase i findings. Timi study group. The New England journal of medicine. 1985;312:932-936

16. Krucoff MW, Croll MA, Pope JE, Pieper KS, Kanani PM, Granger CB, Veldkamp RF, Wagner BL, Sawchak ST, Califf RM. Continuously updated 12-lead st-segment recovery analysis for myocardial infarct artery patency assessment and its correlation with multiple simultaneous early angiographic observations. The American journal of cardiology. 1993;71:145-151

17. McAlindon E, Pufulete M, Lawton C, Angelini GD, Bucciarelli-Ducci C. Quantification of infarct size and myocardium at risk: Evaluation of different techniques and its implications. European heart journal cardiovascular Imaging. 2015

18. Alpert JS, Thygesen K, Antman E, Bassand JP. Myocardial infarction redefined--a consensus document of the joint european society of cardiology/american college of cardiology committee for the redefinition of myocardial infarction. Journal of the American College of Cardiology. 2000;36:959-969

19. Ibrahim T, Bulow HP, Hackl T, Hornke M, Nekolla SG, Breuer M, Schomig A, Schwaiger M. Diagnostic value of contrast-enhanced magnetic resonance imaging and single-photon emission computed tomography for detection of myocardial necrosis early after acute myocardial infarction. Journal of the American College of Cardiology. 2007;49:208-216 


\section{Sublemental table}

Supplemental table 1: Baseline and oucomvariables in the study group with stable ST recovery versus the incomplete and/or non stable ST-recovery group

\begin{tabular}{|c|c|c|c|}
\hline & $\begin{array}{c}\text { Stable ST-recovery } \\
\qquad(\mathrm{N}=196)\end{array}$ & $\begin{array}{l}\text { No Stable ST-recovery } \\
\qquad(\mathrm{N}=\mathbf{2 2})\end{array}$ & $\mathbf{p}$ \\
\hline \multicolumn{4}{|l|}{ Demographics } \\
\hline Age (years) & $58.2 \pm 10.9$ & $58.2 \pm 11.4$ & 0.98 \\
\hline Male & $159(81 \%)$ & $19(86 \%)$ & 0.55 \\
\hline \multicolumn{4}{|l|}{ Comorbidities } \\
\hline BMI & $26.9 \pm 3.7$ & $27.1 \pm 3.1$ & 0.99 \\
\hline Smoking current & $114(58 \%)$ & $12(54 \%)$ & 0.58 \\
\hline Previous & $37(19 \%)$ & $2(9 \%)$ & \\
\hline History of hypertension & $39(25 \%)$ & $5(23 \%)$ & 0.82 \\
\hline Diabetes mellitus & $13(7 \%)$ & $2(9 \%)$ & 0.67 \\
\hline Hypercholesteremia & $38(19 \%)$ & $2(9 \%)$ & 0.24 \\
\hline Positive family history & $79(40 \%)$ & $8(36 \%)$ & 0.83 \\
\hline Pre-existent AP & $27(14 \%)$ & $2(9 \%)$ & 0.54 \\
\hline History of stroke & $6(3 \%)$ & $0(0 \%)$ & 0.41 \\
\hline History of peripheral artery disease & $8(4 \%)$ & $0(0 \%)$ & 0.34 \\
\hline \multicolumn{4}{|l|}{ Medication } \\
\hline$\beta$-blocker & $22(11 \%)$ & $3(14 \%)$ & 0.74 \\
\hline Acetyl salisylic acid & $22(11 \%)$ & $0(0 \%)$ & 0.10 \\
\hline ADP-antagonist & $1(0.5 \%)$ & $0(0 \%)$ & 0.74 \\
\hline Statin & $28(14 \%)$ & $1(5 \%)$ & 0.20 \\
\hline Nitrates & $2(1 \%)$ & $0(0 \%)$ & 0.64 \\
\hline ACE-inhibitor & $8(4 \%)$ & $2(9 \%)$ & 0.29 \\
\hline AT-Il antagonist & $14(7 \%)$ & $1(5 \%)$ & 0.65 \\
\hline Calcium-antagonist & $14(7 \%)$ & $1(5 \%)$ & 0.65 \\
\hline \multicolumn{4}{|l|}{$\mathbf{P C l}$} \\
\hline Duration of symptoms (minutes) & $185.9 \pm 79.0$ & $212.6 \pm 101.5$ & 0.09 \\
\hline Anterior location & $49(25 \%)$ & $10(46 \%)$ & $0.04^{*}$ \\
\hline Multiple vessel disease & $69(35 \%)$ & $12(55 \%)$ & 0.08 \\
\hline $\mathrm{PCl}$ of $>1$ lesion & $9(5 \%)$ & $1(5 \%)$ & 0.99 \\
\hline Side branch occlusion & $2(1 \%)$ & $1(5 \%)$ & 0.18 \\
\hline Distal embolization & $22(11 \%)$ & $4(18 \%)$ & 0.34 \\
\hline Presence of collaterals & $12(6 \%)$ & $0(0 \%)$ & 0.23 \\
\hline \multicolumn{4}{|l|}{ CMR } \\
\hline Final infarct size & $12.3 \pm 9.2$ & $18.6 \pm 9.5$ & $0.002 *$ \\
\hline LVEF & $52.3 \pm 9.2$ & $46.9 \pm 9.9$ & $0.021^{*}$ \\
\hline
\end{tabular}

* significant difference.

Results presented as mean \pm standard deviation, median with quartiles (.....), or $\mathrm{N}(\%) . \mathrm{ACE}=$ angiotensine converting enzyme, $\mathrm{ADP}=$ adenosine diphosphate, $\mathrm{AP}=$ angina pectoris, $\mathrm{AT}=$ angiotensine, $\mathrm{BMI}=$ body mass index, $\mathrm{PCl}=$ percutaneous coronary intervention. 


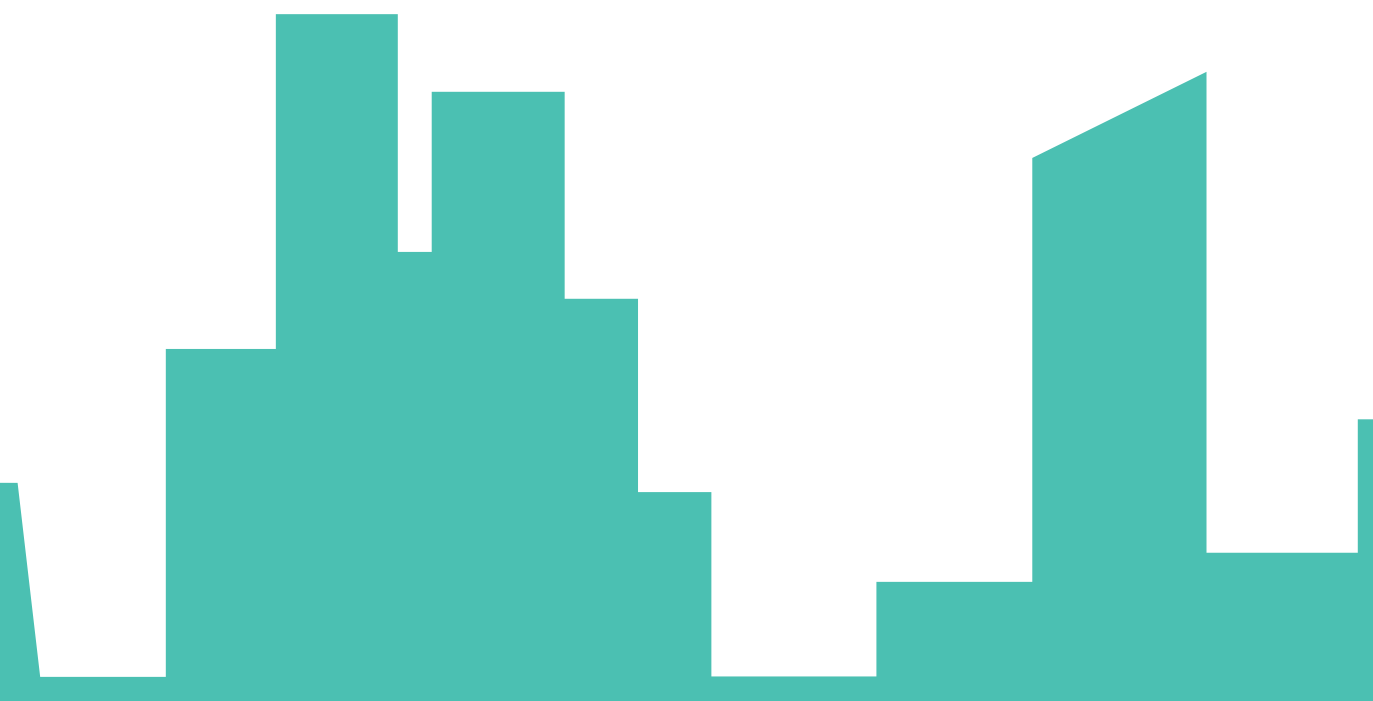

Authors:

Kirian van der Weg, MD, (a,b), Mohamed Majidi, MD, (a,b), Joost D.E, Haeck, MD, PhD, (c), Jan G.P. Tijssen, PhD, (c), Cynthia L. Green, PhD, (b) Karel T. Koch, MD, PhD, (c), Wichert J. Kuijt, MD, (c), Mitchell

W. Krucoff, MD, PhD, (b), Anton P.M. Gorgels, MD, PhD, (a), Robbert J. de Winter, MD, PhD, (c)

\section{Work was performed in:}

a Maastricht University Medical Centre, Maastricht, The Netherlands

b Duke University Medical center and Duke Clinical Research Institute, Durham, United States of America

c Academic Medical Centre, Amsterdam, The Netherlands

Published in

Journal of Electrocardiology 2016; 49 : 345 - 352 


\section{Chapter 3}

Ventricular arrhythmia Burst is an independent indicator of larger infarct size even in optimal reperfusion in STEMI.

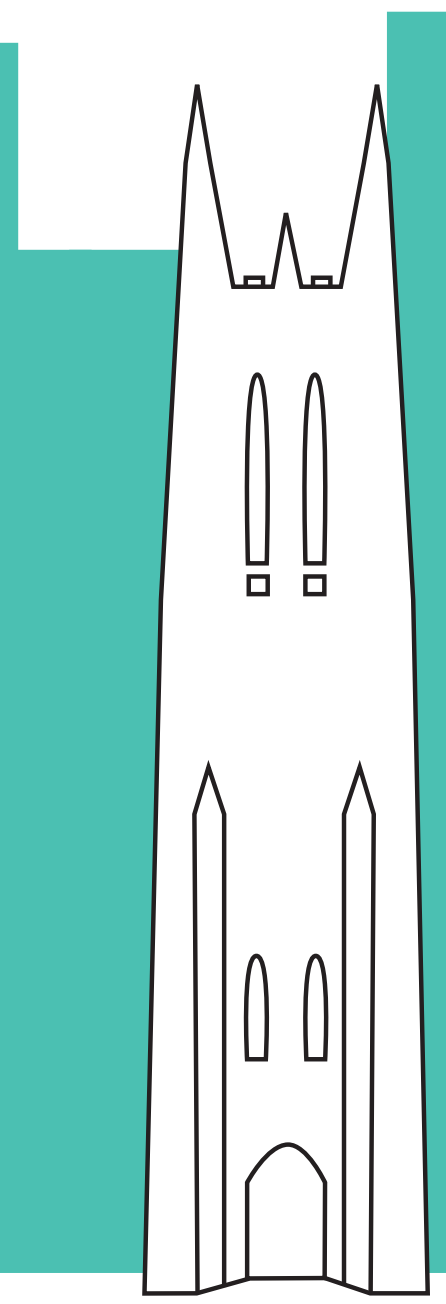




\section{Abstract}

\section{Objective:}

We hypothesized that ventricular arrhythmia (VA) bursts during reperfusion phase are a marker of larger infarct size despite optimal epicardial and microvascular perfusion.

\section{Methods:}

126 STEMI patients were studied with $24 \mathrm{~h}$ continuous, 12-lead Holter monitoring. Myocardial blush grade (MBG) was determined and VA bursts were identified against subject-specific background VA rates in core laboratories. Delayed-enhancement cardiovascular magnetic resonance imaging was used to determine infarct size.

\section{Results:}

In the group with MBG 3 no significant differences were found for baseline characteristics between burst versus no burst (102 vs. 24). In those with optimal epicardial and microvascular reperfusion (TIMI 3, stable ST-recovery, and MBG 3), VA burst was associated with larger infarct size (N=102/126; median 11.0 vs. $5.1 \%$; $p=0.004)$.

\section{Conclusion:}

In the event of MBG 3, VA bursts were associated with significantly larger infarct size even if optimal epicardial and microvascular reperfusion was present. 


\section{Manuscript}

In the thrombolytic era, ventricular arrhythmias (VA) concomitant with ST segment normalization in ST elevation myocardial infarction (STEMI) were recognized as a sign of reperfusion'. These reperfusion arrhythmias typically consist of bursts of single or double ventricular premature beats (with long coupling intervals to the preceding normally conducted beats) and accelerated idioventricular rhythms. Their QRS configuration is consistent with an origin from the reperfused territory ${ }^{1}$. When primary $\mathrm{PCl}$ became available it was found that in complete epicardial recanalization with TIMI 3 flow, these bursts of ventricular reperfusion arrhythmias (VA bursts) were associated with larger infarct size and decreased left ventricular function². Since the advent of coronary revascularization it was realized that just TIMI 3 flow was not sufficient to warrant optimal recovery at myocellular level. Phenomena such as distal embolization and damage at the microvascular level may interfere with recurrence of myocellular function. Therefore, although optimal epicardial recanalization (i.e. TIMI 3 flow) was present, it was found that infarct size also depended from more downstream existing markers, such as blush, microvascular obstruction (MVO) and ST segment recovery ${ }^{3-7}$. Clinically, inadequate microvascular perfusion is independently associated with left ventricular remodeling and mortality ${ }^{8}$. Myocardial blush grade (MBG) is an angiographic classification to assess the microvascular integrity status after epicardial flow restoration (Fig. 1) and lower MBG is associated with larger infarct size, decreased left ventricular ejection fraction (LVEF), and increased mortality ${ }^{9,10}$.

\footnotetext{
Myocardial Blush Grades

Grade 0 Failure of dye to enter the microvasculature. Either minimal or no ground glass appearance ("blush") or (MBG-0) opacification of the myocardium in the distribution of the culprit artery indicating lack of tissue-level perfusion.

Grade 1 Dye slowly enters but fails to exit the microvasculature. There is the ground glass appearance ("blush") or

(MBG-1) opacification of the myocardium in the distribution of the culprit lesion that fails to clear from the microvasculature, and dye staining is present on the next injection (approximately 30 seconds between injections).

Grade 2 Delayed entry and exit of dye from the microvasculature. There is the ground glass appearance ("blush")

(MBG-2) or opacification of the myocardium in the distribution of the culprit lesion that is strongly persistent at the end of the washout phase (i.e., dye is strongly persistent after three cardiac cycles of the washout phase and either does not or only minimally diminishes in intensity during washout).
}

Grade 3 Normal entry and exit of dye from the microvasculature. There is the ground glass appearance ("blush")

(MBG-3) or opacification of the myocardium in the distribution of the culprit lesion that clears normally and is either gone or only mildly/moderately persistent at the end of the washout phase (i.e., dye is gone or is mildly/moderately persistent after three cardiac cycles of the washout phase and noticeably diminishes in intensity during the washout phase), similar to that in an uninvolved artery. Blush that is of only mild intensity throughout the washout phase but fades minimally is also classified as grade 3.

Figure 1: Classification of myocardial blush grades 
The hypothesis of this study was, by exploring the relation between MBG, VA bursts and final infarct size measured by cardiac MRI, that even in patients with optimal epicardial and microvascular recanalization VAs indicate larger infarct size, identifying a more downstream, at the myocellular level existing, source of cell death in reperfused STEMI.

\section{Methods}

\section{Study population}

Patients included in the "proximal embolic protection study in patients undergoing primary angioplasty for acute myocardial infarction" (PREPARE) trial were used for the analyses. Since the Proxis $^{\mathrm{TM}}$ proximal protection system used in the PREPARE trial did not influence final infarct size and $\mathrm{LVEF}^{11}$ no distinction was made between the treatment and control group. Approval was granted by the Medical Ethical Committee of the Academic Medical Center (ISRCTN71104460) and written informed consent was obtained from all patients included. To study the ST-segment and ventricular arrhythmia behavior, 24-h holter recording starting before $\mathrm{PCl}$ was part of the study protocol.

The design of the PREPARE trial has been published earlier ${ }^{11}$. In brief, in the PREPARE trial, primary $\mathrm{PCl}$ was performed in patients with STEMI at the Academic Medical Centre in Amsterdam, The Netherlands, between December 2006 and June 2008. Inclusion criteria were: (1) age 18 years and above, (2) onset of symptoms of myocardial infarction less than six hours before presentation, (3) persistent ST-segment elevation of at least $2 \mathrm{~mm}$ in two or more contiguous leads on initial ECG, and (4) TIMI-graded flow 0 to 1 on diagnostic angiography.

Exclusion criteria were: (1) any contraindication to the use of glycoprotein Illb/Illa receptor antagonists, (2) a co-existent condition associated with a limited life expectancy, (3) prior coronary artery bypass grafting or administration of thrombolytic agents, (4) the presenting STEMI being a recurrence in the same myocardial area, and (5) proximal LAD occlusion causing inability for the PROXIS device to be used. Exclusion criteria for ECG analysis were: (1) insufficient holter recording quality for determining presence or absence of VA burst either because of reperfusion before start of holter recording or excess noise, (2) previous $\mathrm{MI}$, (3) inability to obtain cardiac magnetic resonance (CMR) recordings or inconclusive CMR recording for infarct size determination, (4) absence of successful epicardial flow restoration defined as TIMI flow $\leq 2,(5)$ inability to obtain stable ST recovery within $240 \mathrm{~min}$, (6) late ST re-elevation, and (7) MBG $\leq 2$.

\section{Angiographic TIMI flow and blush grade assessment}

At the end of each primary $\mathrm{PCl}$, a final coronary angiogram was obtained. This post-procedural angiogram was used to assess TIMI flow, angiographic signs of distal embolization and the MBG by an independent observer at a corelab (Cordinamo, Wezep, The Netherlands). Epicardial coronary flow was assessed according the TIMI trial classification ${ }^{12}$. Angiographic distal embolization was 
defined as a filling defect, with an abrupt cut-off in the vessel located distally from the infarctrelated coronary lesion. The assessment of myocardial blush grade was performed according to van 't Hof et al. ${ }^{10}$ (Fig 1).

\section{ECG data acquisition}

Continuous 12-lead ECG Holter recording (NEMON 180+, Northeast Monitoring, Maynard, MA, USA) was started immediately after admission and prior to the first angiogram. The NEMON system records a standard digital simultaneously archiving beat-to-beat Holter rhythm on a digital clock synchronized to the catheterization laboratory clock for accurate correlation of ECG changes, and holter rhythm changes. Continuous digital ECG and Holter data were encrypted and blinded to the clinical team and sent to the eECG core laboratory (eECG Core Laboratory, Maastricht University Medical Centre, Maastricht, The Netherlands) for independent blinded quantitative rhythm analysis.

\section{Continuous ST recovery analysis}

Method and criteria for continuous 12-lead ST-segment recovery analysis and reperfusion of the culprit lesion have been described in detail previously ${ }^{6}$. In short, peak ST-segment deviation is determined based on the lead with the greatest deviation taken from the most abnormal ECG recorded during monitoring. Steady state recovery was determined as $\geq 50 \%$ recovery from previous peak ST-segment levels in the most deviated lead, lasting N4 $\mathrm{h}$ without further ST-segment evolution (N100 uV) and patients were excluded from further analysis if time from last contrast injection to steady state was $\mathbf{2 4 0} \mathrm{min}$ or more. Late ST elevation was diagnosed when recurrent ischemia following the first sustained $50 \%$ recovery (stable reperfusion) occurs with re-elevation of $150 \mathrm{uV}$, relative to the immediate previous recovery or baseline ST level in the most abnormal lead, occurring after stable reperfusion.

\section{Quantitative rhythm analysis}

For beat-to-beat quantitative rhythm analysis on all digital 3-lead holter recordings, holter 5 software (Northeast Monitoring, Maynard, MA, USA) was used ${ }^{13}$. All automatically assigned waveform labels were manually verified for each cardiac cycle from each subject to ensure accurate VA capture according to predefined criteria for ECG interpretation of VAs ${ }^{13,14}$. Fusion beats (normally conducted ventricular activation fused with ventricular premature complex (VPC) morphology) were also considered VPC's. To generate quantitative VA rates over a $24 \mathrm{~h}$ period, total VPC counts were bundled into 5 min blocks for temporal correlation with stable ST-segment recovery and angiographic observations (Fig 2).

\section{Defining VA burst}

Quantitative VA rates over the course of Holter recordings were incorporated in a statistical outlier detection method to automatically separate outliers of VA rates ('VA bursts'), from subject-specific background VA counts. Reperfusion VA bursts were identified as such if they occurred concomitantly with or subsequently to angiographic documentation of re-established TIMI 3 flow in the infarct 
related artery. Study subjects were dichotomously classified into the 'reperfusion VA burst' group or the 'no-VA burst' group based on having a significantly higher incidence of ventricular arrhythmias than background ventricular arrhythmias. This is illustrated in figure 2 panel $1 \mathrm{C}$ and $2 \mathrm{C}$ where over $24 \mathrm{~h}$ continuous ventricular activation is observed ("background arrhythmias"), but in panel 1C interrupted by a sudden increase in ventricular arrhythmias ("VA burst"), which was statistically identified using an outlier methodology as outlined in the supplement to this manuscript ${ }^{13}$.

A

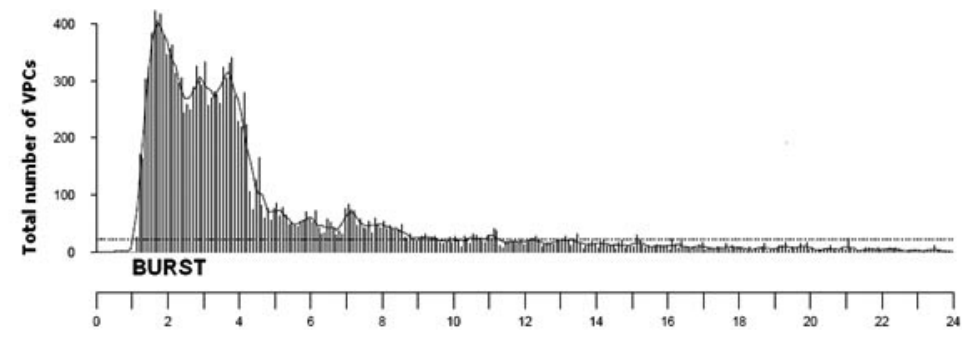

B

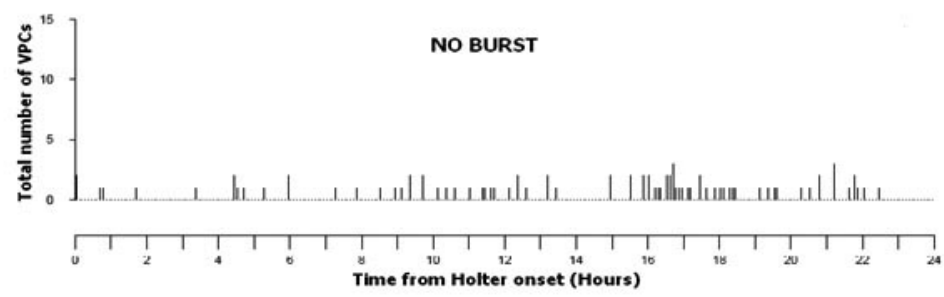

Figure 2: Example of a patient with and a patient without VA burst

Examples of a patient with and a patient without VA burst. The X-axis displays the time from the onset of reperfusion till 24 hours after in 5 minute timeframes. The $Y$-axis displays the amount of ventricular beats within a certain 5 minute timeframe. Figure $2 a$ shows a high count of ventricular beats within the first 4 hours after reperfusion after which it slowly drops below background level as illustrated by the horizontal dotted line. This figure is a clear image of a burst of ventricular arrhythmias. This is in contrast with figure $2 \mathrm{~B}$ that shows a constant low level of ventricular beats in the 24 hours after reperfusion never reaching above 5 beats per 5 minutes. This patient doesn't have a burst of ventricular arrhythmias.

\section{Cardiac Magnetic Resonance protocol}

CMR examination was performed on a $1.5 \mathrm{~T}$ clinical scanner (Sonato/Avanto, Siemens, Erlangen, Germany), with the patient in a supine position, using a phased array cardiac receiver coil. ECG-gated cine images were acquired using a breath-hold segmented steady-state free precession sequence (echo time/repetition time of 1.2/3.2 ms; spatial resolution of $1.331 .835 \mathrm{~mm}$ ). Per patient short-axis views were obtained every $10 \mathrm{~mm}$ starting from base to apex and including the entire left ventricle. Late gadolinium enhancement images were obtained 10-15 min after the administration of a gadoliniumbased contrast agent (Magnevist, Schering AG, Berlin, Germany; $0.2 \mathrm{mmol} / \mathrm{kg}$ ) using a two-dimensional 
segmented inversion recovery gradient echopulse sequence (repetition time/echo time $9.6 / 4.4 \mathrm{~ms}$, spatial resolution $1.631 .335 .0 \mathrm{~mm}$ ), with slice position identical to the cine images. The inversion time was set to null the signal of viable myocardium and typically ranged from 250 to $300 \mathrm{~ms}$. All data were analyzed using a dedicated software package (MASS 5.1) and by one experienced investigator who was blinded to the patient data. Left ventricular volumes were determined by planimetry of all short axis images in each patient and the left ventricular ejection fraction was calculated. The delayed gadolinium enhancement (DE)-CMR images and final infarct size were assessed described previously ${ }^{15}$. In brief, final infarct size was calculated by automatic summation of all slice volumes of hyper enhancement (signal intensity $>6 \mathrm{SD}$ above the mean signal intensity of remote myocardium).

\section{Statistical analysis}

Univariable comparisons for patient characteristics and outcomes between patients with and patients without VA bursts were made using independent student $t$-test for parametric variables, Wilcoxon rank sum test for nonparametric variables, and Fisher exact test for dichotomous variables. The same was done in subgroup analysis of patients with blush 3 grade. A p value of $<0.05$ was considered statistically significant and all statistical tests were two-sided. Multivariable linear regression analysis was performed to assess whether VA burst remained an independent predictor for infarct size and LVEF if corrected for covariates. The dependent variable was infarct size determined by DE-CMR. Covariates were selected by including known predictors for infarct size, displayed in Table 1 , in the multivariate model and using the backwards stepwise model excluding those with $p$ values $\geq 0.15$. Covariates were added to a regression model starting with VA burst and presence or absence of blush grade 3 . Data were analyzed using IBM SPSS statistics software version 19.

\section{Results}

The PREPARE study population consists of 206 patients, of whom 7 were excluded because of previous myocardial infarction, 15 patients had inadequate Holter recordings for VA burst determination, 13 patients did not obtain TIMI 3flow after $\mathrm{PCl}, 12$ were excluded because of insufficient CMR quality for infarct size determination, 19 had no stable ST recovery within 240 min or had late ST re-elevation, and 14 had MBG $\leq 2$ (Fig. 3). The remaining 126 patients were used for analysis.

Table 1 shows patients characteristics according to the presence or absence of VA burst. The mean age was between 56 and 58 years in the respective groups and did not significantly differ. Most of the patients were male (80-96\%) and VA burst occurred in $81.0 \%(102 / 126)$. No significant differences were found regarding baseline characteristics between the presence or absence of VA burst, except for the use of calcium antagonists. Patients who used a calcium antagonist before STEMI had on average a lower incidence of VA burst ( $4 \%$ vs $17 \% ; p=0.04$ ). DE-CMR was performed within a median of 207 days (25\%-75\% quartiles; $135-365$ days). 


\begin{tabular}{|c|c|c|c|c|c|}
\hline & \multicolumn{5}{|c|}{ MBG 3} \\
\hline & \multicolumn{2}{|c|}{$\begin{array}{l}\text { Burst not present } \\
\qquad(\mathrm{N}=24)\end{array}$} & \multicolumn{2}{|c|}{$\begin{array}{l}\text { Burst present } \\
(\mathrm{N}=102)\end{array}$} & $P$ \\
\hline age (years) & 56.0 & SD 8.5 & 57.8 & SD 11.2 & 0.46 \\
\hline Male & 23 & $95.8 \%$ & 82 & $80.4 \%$ & 0.08 \\
\hline \multicolumn{6}{|l|}{ Comorbidities } \\
\hline BMI & 27.2 & SD 4.0 & 26.7 & SD 3.8 & 0.60 \\
\hline Smoking current & 14 & $58.3 \%$ & 64 & $62.7 \%$ & 0.80 \\
\hline Previous & 5 & $20.8 \%$ & 17 & $16.7 \%$ & \\
\hline History of hypertension & 6 & $25.0 \%$ & 21 & $20.6 \%$ & 0.59 \\
\hline Diabetes mellitus & 2 & $8.3 \%$ & 6 & $5.9 \%$ & 0.65 \\
\hline Hypercholesteremia & 3 & $12.5 \%$ & 14 & $13.7 \%$ & 1.00 \\
\hline Positive family history & 7 & $29.2 \%$ & 41 & $40.2 \%$ & 0.36 \\
\hline Pre-existent AP & 2 & $8.3 \%$ & 3 & $2.9 \%$ & 0.24 \\
\hline History of stroke & 0 & $0.0 \%$ & 2 & $2.0 \%$ & 1.00 \\
\hline Peripheral artery disease & 0 & $0.0 \%$ & 2 & $2.0 \%$ & 1.00 \\
\hline \multicolumn{6}{|l|}{ Medication } \\
\hline$\beta$-blocker & 3 & $12.5 \%$ & 10 & $9.8 \%$ & 0.71 \\
\hline acetyl salic acid & 2 & $8.3 \%$ & 9 & $8.8 \%$ & 1.00 \\
\hline ADP-antagonist & 0 & $0.0 \%$ & 1 & $1.0 \%$ & 1.00 \\
\hline Statin & 4 & $16.7 \%$ & 10 & $9.8 \%$ & 0.47 \\
\hline Nitrates & 0 & $0.0 \%$ & 0 & $0.0 \%$ & \\
\hline ACE-inhibitor & 1 & $4.2 \%$ & 4 & $3.9 \%$ & 1.00 \\
\hline AT-II antagonist & 2 & $8.3 \%$ & 7 & $6.9 \%$ & 0.68 \\
\hline Calcium-antagonist & 4 & $16.7 \%$ & 4 & $3.9 \%$ & $0.04 *$ \\
\hline \multicolumn{6}{|l|}{ PCI } \\
\hline Anterior MI & 4 & $16.7 \%$ & 27 & $26.5 \%$ & 0.43 \\
\hline Multiple vessel disease & 10 & $41.7 \%$ & 30 & $29.4 \%$ & 0.38 \\
\hline $\mathrm{PCl}$ of $>1$ lesion & 0 & $0.0 \%$ & 1 & $1.0 \%$ & 1.00 \\
\hline Distal embolization & 2 & $8.3 \%$ & 11 & $10.8 \%$ & 1.000 \\
\hline Duration of symptoms (min) & 173.0 & SD 69.0 & 184.8 & SD 91.5 & 0.57 \\
\hline
\end{tabular}

* significant difference

a duration of symptoms from onset till first balloon time

$\mathrm{ACE}=$ angiotensin converting enzyme, $\mathrm{ADP}=$ adenosine diphosphate, $\mathrm{AP}=$ angina pectoris, $\mathrm{AT}=$ angiotensin, $\mathrm{BMI}=$ body mass index, $\mathrm{CMR}=$ cardiovascular magnetic resonance imaging, $\mathrm{MBG}=$ myocardial blush grade, $\mathrm{MVO}=$ microvascular obstruction, $\mathrm{PCl}=$ percutaneous coronary intervention 


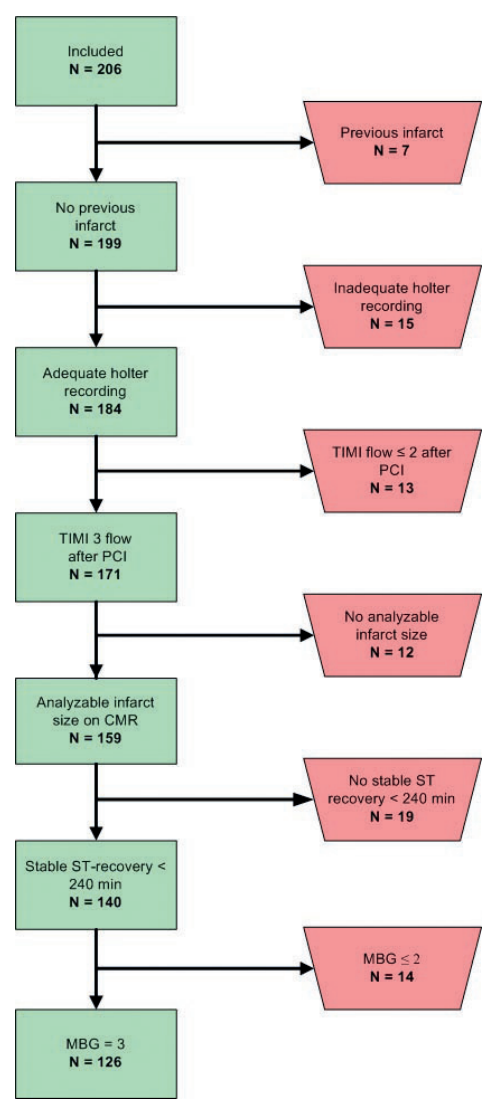

Figure 3: Patient selection

Patient selection of combined dataset with reasons for exclusion. $C M R=$ cardiac magnetic resonance, $M B G=$ myocardial blush grade, $\mathrm{PCl}=$ percutaneous coronary intervention, $\mathrm{TIMI}=$ thrombolysis in myocardial infarction

In case of optimal microvascular reperfusion (MBG 3), but with VA burst, infarct size doubled (11.0 vs. $5.1 \% ; p=0.004$ ) compared to no VA burst (Fig. 4). Due to the relatively small infarcts in this study population LVEF was not significantly affected by the all or none presence of VA burst. In multivariable analysis the correlation between VA burst and infarct size remained significant $(B=3.8$; $p=0.04$ ) when correcting for other known predictors of infarct size, such as anterior wall location, age, and the use of $\beta$-blockers or ACE-inhibitors before the event (Table 2). In the multivariable analyses there was no significant effect of the use of calcium-antagonists before the event. 


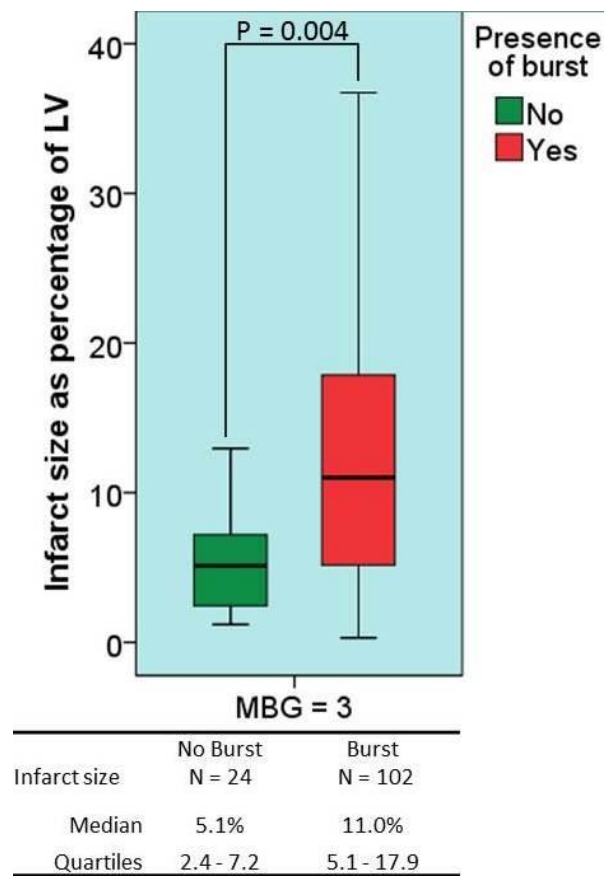

Figure 4 : Differences between VA burst present or absent

Box plots with corresponding medians and quartiles displaying the effect VA burst in the presence of optimal myocardial blush grade (MBG 3).

Table 2: Multivariable analysis for final infarct size in patients with optimal blush grade

\begin{tabular}{lccc}
\hline & Coefficient & $95 \% \mathrm{Cl}$ & $P$-value \\
\hline Presence of VA burst & 3.8 & $0.2-7.4$ & 0.040 \\
Anterior location & 8.7 & $5.4-12.0$ & 0.000 \\
$\beta$-blocker use before event & -4.8 & $-9.5--0.1$ & 0.045 \\
ACE-inhibitor used before & 7.7 & $0.4-15.0$ & 0.039 \\
Patient's age in years & 0.1 & $-0.01-0.25$ & 0.080 \\
Constant & -8.9 & $-17.8--0.1$ & 0.048 \\
\hline
\end{tabular}

$\mathrm{R}^{2}=0.27$

$\mathrm{ACE}=$ angiotensin converting enzyme 


\section{Discussion}

This study shows that in the case of TIMI-3 flow and optimal microvascular reperfusion as indicated by TIMI-3 flow, stable ST-recovery and MBG 3, in patients with VA burst, infarct size was twice as large as those without VA burst.

ST-segment resolution has been accepted as an important electrobiomarker for the success of reperfusion and infarct size after recanalization attempts in STEMI ${ }^{6,7}$. This study suggests that addition of the presence of VA burst further refines the prognostic model that identifies myocardial salvage and infarct size. VA burst has been shown to be a marker for larger infarct size, as measured by SPECT, in anterior wall STEMI ${ }^{14,16}$. Our results confirm previous findings using the more accurate measurement of DE-CMR ${ }^{17}$. Previous models of reperfusion VA burst depended on 99mTc-sestamibi SPECT to quantify the infarct size endpoint. SPECT is well validated in larger Ml's, however is less reliable in smaller Ml's with lower sensitivity for scintigraphic defects below $10 \mathrm{gr}$. of infarcted tissue $^{18}$. DE-CMR, on the other hand, has superior spatial resolution and is superior in detecting smaller infarcts, such as subendocardial infarcts and infarcts in non-anterior locations ${ }^{19,20}$. Our results show that final infarct size is was in general relatively small, especially in non-anterior infarcts, in the setting of fast ST-recovery and optimal TIMI flow and blush grade. By using a more accurate method such as DE-CMR we could confirm results from a previous study that used SPECT for anterior MI but also show that the correlation is valid for non-anterior $\mathrm{Ml}$, a population with generally smaller infarcts $^{16}$.

Until now it was not known whether VA bursts were markers either of suboptimal microvascular reperfusion, larger areas at risk or another pathophysiological mechanism such as reperfusion injury. This is the first study to describe that VA bursts indicate larger infarct size in the presence of not only optimal epicardial but also optimal (MBG determined) microvascular reperfusion directly after reperfusion by $\mathrm{PCl}$ using DE-CMR. There are nevertheless experimental reports showing a progression of microvascular obstruction (MVO) over the hours after reperfusion ${ }^{2121,22}$. However CMR was performed after the (sub)acute phase and the difference in infarct size between the burst and no burst group remained. To exclude the involvement of suboptimal microvascular perfusion in the presence of VA burst and its correlation with infarct size, the hypothesis should also be tested in a population using MVO diagnosed by DE-CMR as a marker of impaired microvascular integrity. Moreover, the influence of the initial area at risk on the presence of VA burst should be tested to exclude an interaction for the outcome of infarct size. These questions are currently being studied by our group in ongoing research.

In the event of optimal epicardial reperfusion and optimal MBG, the occurrence of VA burst appeared a marker for larger infarct size. As such VA burst may be a potential useful biomarker for larger infarct size and worse outcome next to current markers of TIMI flow, stable ST recovery within $240 \mathrm{~min}$, and myocardial blush grade. Such an additional biomarker could be useful in the early identification of 
patients at higher risk following recanalization attempts. "VA burst in our study was defined by a statistical outlier method, a burst of ventricular arrhythmias being differentiated from background arrhythmias using a $24 \mathrm{~h}$ holter recording. In clinical practice such a long recording time will likely not be needed as the occurrence of reperfusion arrhythmia burst can already be readily observed in the cath lab. However it is desirable to develop a robust algorithm enabling automatic assessment of "burst" or "no burst". Therefore, further research studying shorter observation times to quantify background arrhythmias should be done."

\section{Limitations}

One of the limitations of our study was a relatively small study population, yet, VA bursts were accurately assessed using continuous Holter monitoring and manual validation and infarct size was assessed using the current standard MRI. We did not have sufficient data regarding enzymatic infarct size because more than $50 \%$ of the population was referred back to the non-intervention hospitals in the region shortly after the recanalizati

In procedure and enzymatic data from those hospitals was limited. The number of patients with an anterior myocardial infarction was small in our study population. This is probably due to the exclusion of proximal LAD infarcts because of the inability to use the Proxis device in these laesions. Although the use of the Proxis device did not influence infarct size it did however exclude a part of the anterior infarctions.

We did not analyze the additional effect of medication given post myocardial infarction on final infarct size at the time of CMR. Because medication given after myocardial infarction is protocollized according to the ESC guidelines throughout the Netherlands we assume that it did not cause significant effect on infarct size between patients. However, we did not test this assumption.

For unknown reasons our study group showed a marked male preponderance. Therefore it is not certain whether the results can be transponed to a female population.

MBG as a marker for microvascular obstruction has some limitations and MVO on DE-CMR is currently being considered the preferred method. However, MBG directly after $\mathrm{PCl}$ is an intrinsically and early obtainable angiographic marker, while MVO on DE-CMR requires additional equipment and patient related suitability. 


\section{Conclusion}

This is the first study to show that infarct size as measured by CMR is significantly larger in the occurrence of VA burst upon reperfusion in both anterior and non-anterior myocardial infarction, not only in the presence of optimal epicardial reperfusion but also when optimal microvascular reperfusion is present as defined by MBG 3. This suggests the cause of the larger damage to be localized at the myocellular level.

\section{Acknowledgements}

The authors wish to thank the Hein Wellens Foundation for their support in this project.

\section{Funding Sources}

This work was supported by funding from the Hein Wellens Foundation, Maastricht, and from the Academic Medical Center - University of Amsterdam, the Netherlands.

\section{Disclosures}

The authors have no conflicts of interest to declare. 


\section{References}

1. Gorgels AP, Vos MA, Letsch IS, et al. Usefulness of the accelerated idioventricular rhythm as a marker for myocardial necrosis and reperfusion during thrombolytic therapy in acute myocardial infarction. The American journal of cardiology. Feb 1 1988;61(4):231-235.

2. Engelen DJ, Gressin V, Krucoff MW, et al. Usefulness of frequent arrhythmias after epicardial recanalization in anterior wall acute myocardial infarction as a marker of cellular injury leading to poor recovery of left ventricular function. The American journal of cardiology. Nov 15 2003;92(10):1143-1149.

3. Ibanez B, Heusch G, Ovize M, Van de Werf F. Evolving Therapies for Myocardial Ischemia/Reperfusion Injury. Journal of the American College of Cardiology. Apr 14 2015;65(14):1454-1471.

4. Eitel I, de Waha S, Wohrle J, et al. Comprehensive prognosis assessment by CMR imaging after ST-segment elevation myocardial infarction. Journal of the American College of Cardiology. Sep 23 2014;64(12):12171226.

5. Krucoff MW, Croll MA, Pope JE, et al. Continuous 12-lead ST-segment recovery analysis in the TAMI 7 study. Performance of a noninvasive method for real-time detection of failed myocardial reperfusion. Circulation. Aug 1993;88(2):437-446.

6. Krucoff MW, Croll MA, Pope JE, et al. Continuously updated 12-lead ST-segment recovery analysis for myocardial infarct artery patency assessment and its correlation with multiple simultaneous early angiographic observations. The American journal of cardiology. Jan 15 1993;71(2):145-151.

7. Sattur S, Sarwar B, Sacchi TJ, Brener SJ. Correlation between markers of reperfusion and mortality in ST-elevation myocardial infarction: a systematic review. The Journal of invasive cardiology. Nov 2014;26(11):587-595.

8. Wong DT, Leung MC, Richardson JD, et al. Cardiac magnetic resonance derived late microvascular obstruction assessment post ST-segment elevation myocardial infarction is the best predictor of left ventricular function: a comparison of angiographic and cardiac magnetic resonance derived measurements. The international journal of cardiovascular imaging. Dec 2012;28(8):1971-1981.

9. Hoffmann R, Haager P, Arning J, et al. Usefulness of myocardial blush grade early and late after primary coronary angioplasty for acute myocardial infarction in predicting left ventricular function. The American journal of cardiology. Nov 1 2003;92(9):1015-1019.

10. van 't Hof AW, Liem A, Suryapranata H, Hoorntje JC, de Boer MJ, Zijlstra F. Angiographic assessment of myocardial reperfusion in patients treated with primary angioplasty for acute myocardial infarction: myocardial blush grade. Zwolle Myocardial Infarction Study Group. Circulation. Jun 16 1998;97(23):23022306.

11. Haeck JD, Kuijt WJ, Koch KT, et al. Infarct size and left ventricular function in the PRoximal Embolic Protection in Acute myocardial infarction and Resolution of ST-segment Elevation (PREPARE) trial: ancillary cardiovascular magnetic resonance study. Heart (British Cardiac Society). Feb 2010;96(3):190-195.

12. The Thrombolysis in Myocardial Infarction (TIMI) trial. Phase I findings. TIMI Study Group. The New England journal of medicine. Apr 4 1985;312(14):932-936.

13. Majidi M, Kosinski AS, Al-Khatib SM, et al. Reperfusion ventricular arrhythmia 'bursts' in TIMI 3 flow restoration with primary angioplasty for anterior ST-elevation myocardial infarction: a more 
precise definition of reperfusion arrhythmias. Europace : European pacing, arrhythmias, and cardiac electrophysiology : journal of the working groups on cardiac pacing, arrhythmias, and cardiac cellular electrophysiology of the European Society of Cardiology. Aug 2008;10(8):988-997.

14. Majidi M, Kosinski AS, Al-Khatib SM, et al. Reperfusion ventricular arrhythmia 'bursts' predict larger infarct size despite TIMI 3 flow restoration with primary angioplasty for anterior ST-elevation myocardial infarction. European heart journal. Apr 2009;30(7):757-764.

15. Hirsch A, Nijveldt R, Haeck JD, et al. Relation between the assessment of microvascular injury by cardiovascular magnetic resonance and coronary Doppler flow velocity measurements in patients with acute anterior wall myocardial infarction. Journal of the American College of Cardiology. Jun 10 2008;51(23):2230-2238.

16. Majidi M, Kosinski AS, Al-Khatib SM, et al. Implications of ventricular arrhythmia "bursts" with normal epicardial flow, myocardial blush, and ST-segment recovery in anterior ST-elevation myocardial infarction reperfusion: A biosignature of direct myocellular injury "downstream of downstream". European heart journal. Acute cardiovascular care. Feb 2015;4(1):51-59.

17. van der Weg K, Kuijt WJ, Tijssen JG, et al. Prospective evaluation of where reperfusion ventricular arrhythmia "bursts" fit into optimal reperfusion in STEMI. International journal of cardiology. 2015;accepted for publication.

18. Alpert JS, Thygesen K, Antman E, Bassand JP. Myocardial infarction redefined--a consensus document of The Joint European Society of Cardiology/American College of Cardiology Committee for the redefinition of myocardial infarction. Journal of the American College of Cardiology. Sep 2000;36(3):959-969.

19. Ibrahim T, Bulow HP, Hackl T, et al. Diagnostic value of contrast-enhanced magnetic resonance imaging and single-photon emission computed tomography for detection of myocardial necrosis early after acute myocardial infarction. Journal of the American College of Cardiology. Jan 16 2007;49(2):208-216.

20. Wagner A, Mahrholdt H, Holly TA, et al. Contrast-enhanced MRI and routine single photon emission computed tomography (SPECT) perfusion imaging for detection of subendocardial myocardial infarcts: an imaging study. Lancet. Feb 1 2003;361(9355):374-379.

21. Reffelmann T, Kloner RA. Microvascular reperfusion injury: rapid expansion of anatomic no reflow during reperfusion in the rabbit. American journal of physiology. Heart and circulatory physiology. Sep 2002;283(3):H1099-1107.

22. Rochitte CE, Lima JA, Bluemke DA, et al. Magnitude and time course of microvascular obstruction and tissue injury after acute myocardial infarction. Circulation. Sep 8 1998;98(10):1006-1014. 


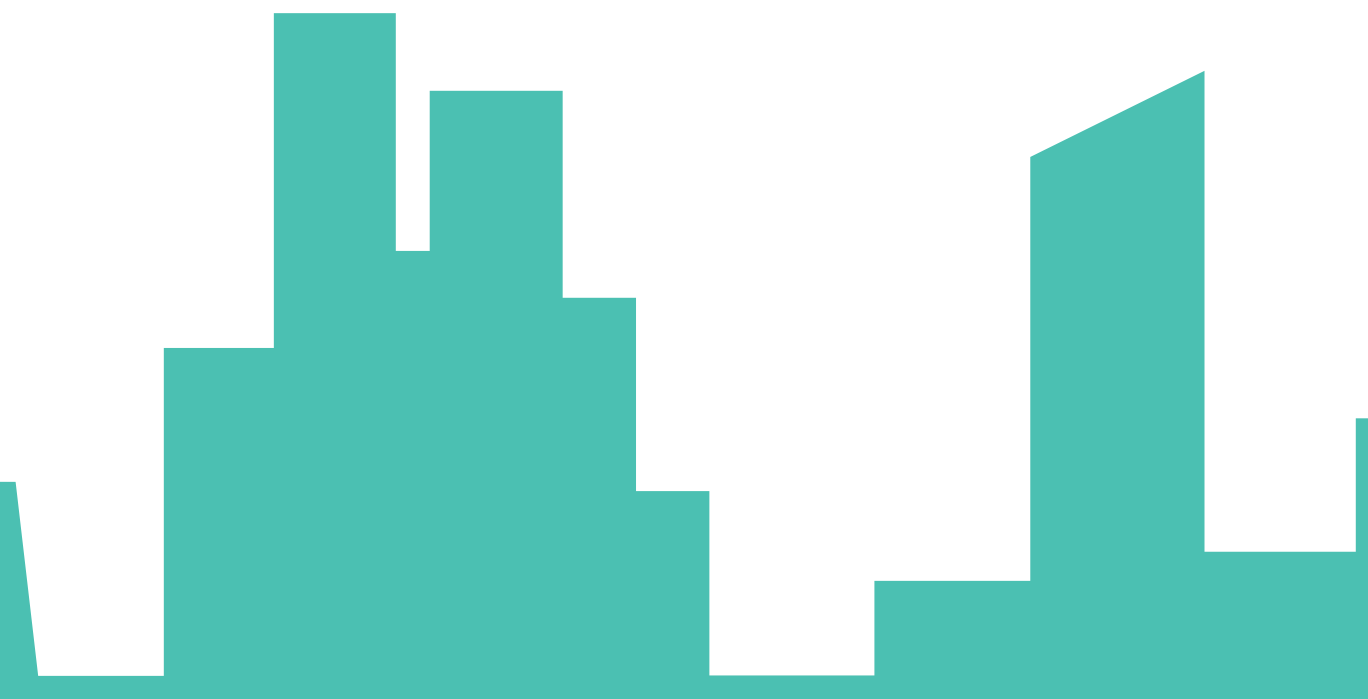

Authors:

Kirian van der Weg, MD *†, Wichert J. Kuijt, MD $\neq$, Sebastiaan C.A.M. Bekkers, MD, PhD*, Jan G.P. Tijssen, PhD $\neq$, Cynthia L. Green, PhD †, Miguel E. Lemmert, MD *, Mitchell W. Krucoff, MD, PhD †,

Anton P.M. Gorgels, MD, PhD *

Work was performed in:

* Maastricht University Medical Centre, Maastricht, The Netherlands

† Duke University Medical Center and Duke Clinical Research Institute, Durham, United States of America

¥ Academic Medical Centre, Amsterdam, The Netherlands

Published in

European Heart Journal: Acute Cardiovascular Care 2018; 7: 246-256 


\section{Chapter 4}

Reperfusion ventricular arrhythmia bursts identify larger infarct size in spite of optimal epicardial and microvascular reperfusion using cardiac magnetic resonance imaging.

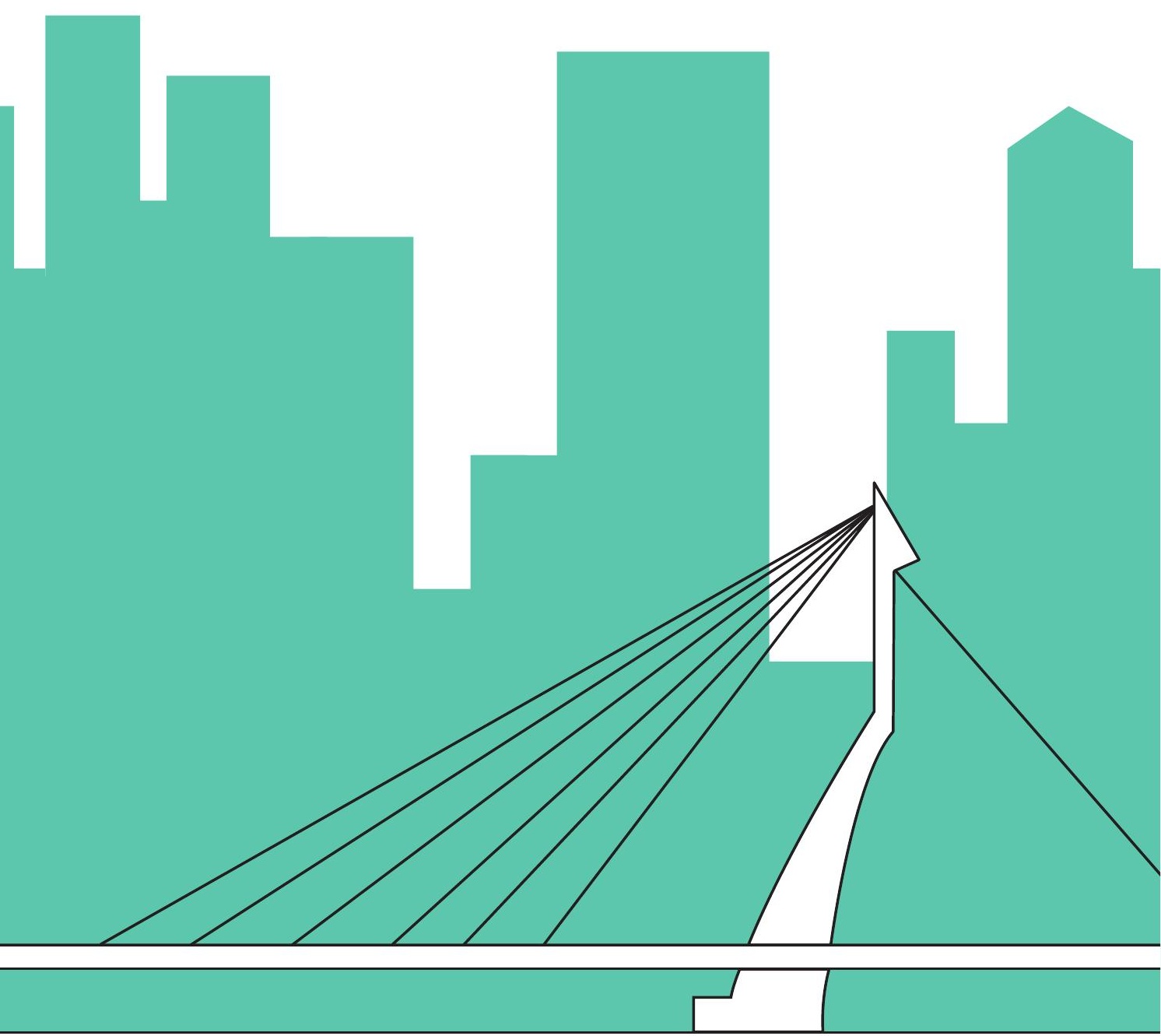




\section{Abstract}

\section{Aims:}

Ventricular arrhythmia (VA) bursts following recanalisation in acute ST-elevation myocardial infarction (STEMI) are related to larger infarct size (IS). Inadequate microvascular reperfusion, as determined by microvascular obstruction MVO) using cardiac magnetic resonance imaging (CMR), is also known to be associated with larger IS. This study aimed to test the hypothesis that VA bursts identify larger infarct size in spite of optimal microvascular reperfusion.

\section{Methods:}

All 65 STEMI patients from the Maastricht ST elevation (MAST) study with brisk epicardial flow (TIMI 3), complete ST recovery post-percutaneous coronary intervention and early CMR were included. Using 24-hour Holter registrations from the time of admission, VA bursts were identified against subject-specific Holter background VA rates using a statistical outlier method. MVO and final IS were determined using delayed enhancement CMR.

\section{Results:}

MVO was present in 37/65 (57\%) of patients. IS was significantly smaller in the group without MVO (median 9.4\% vs. 20.5\%; $<$ < 0.001). IS in the group with MVO did not differ depending on VA burst ( $n=28 / 37$; median $20.8 \%$ vs. $19.7 \% ; p=0.64$ ). However, in the group without MVO, VA burst was associated with significantly larger IS ( $n=17 / 28$; median $10.5 \%$ vs. $4.1 \% ; p=0.037$ ). In multivariable analyses, VA burst as well as anterior infarct location remained independent predictors of larger infarct size.

\section{Conclusion:}

In the presence of suboptimal reperfusion with MVO by CMR, VA burst does not further define MI size. However, with optimal TIMI 3 reperfusion and optimal microvascular perfusion (i.e. no MVO), VA burst is associated with larger IS, indicating that VA burst is a marker of additional cell death. 


\section{Introduction}

Since the advent of recanalization techniques in acute ST-elevation myocardial infarction (STEMI), ventricular arrhythmias (VAs) upon reperfusion are a frequently recognised phenomenon. Such VAs include ventricular premature beats with long coupling intervals and accelerated idioventricular rhythms (fig 1). They are hemodynamically well tolerated and originate within the reperfusion zone'. In the thrombolytic era, reperfusion VAs were considered to be a favourable non-invasive marker of reperfusion. However, with direct percutaneous coronary intervention (PCI) for STEMI establishing TIMI 3 flow in $>90 \%$ of patients, reperfusion VAs have been shown to be associated with larger infarct size $(I S)^{2}$. statistical objectification of these reperfusion VAs, in which they were quantified against a subject-specific background VA rate as a new 'burst' of VA following angiographic recanalisation of the infarct artery, has confirmed these findings ${ }^{3-7}$.

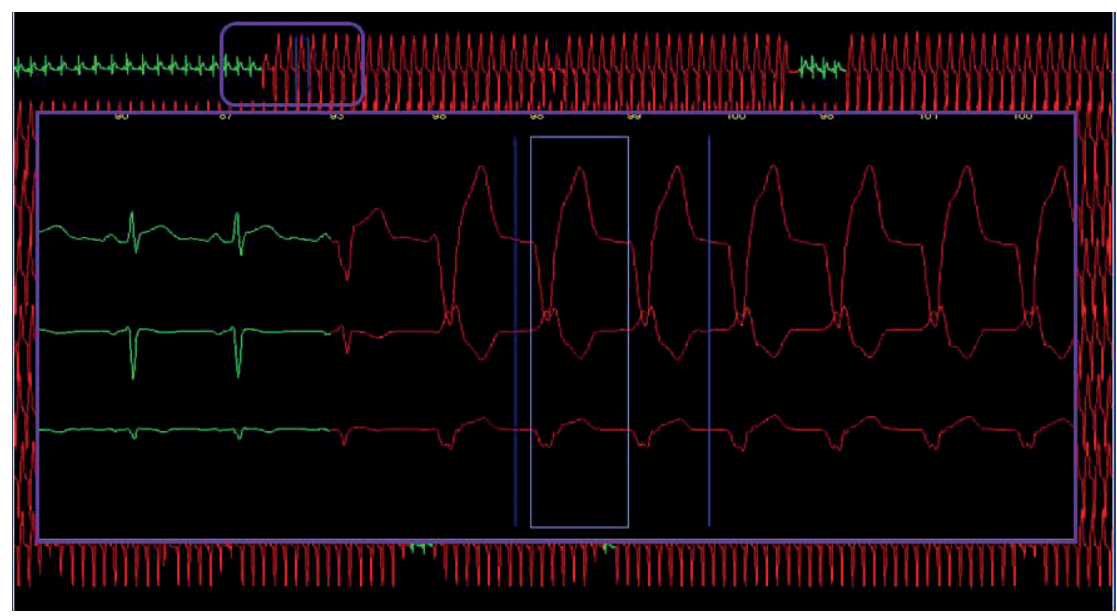

Figure 1: Example of a patient with an accelerated ventricular rhythm

Holter recording of a patient with a run of accelerated ventricular rhythm initiated by a characteristic fusion beat and sometimes interrupted by a captured beat

The involvement of microvascular obstruction (MVO) in the pathogenesis of VA burst is unknown and has never been studied. MVO is a known marker of additional extensive injury and larger IS, worse left ventricle ejection fraction (LVEF), left ventricle (LV) remodelling and a higher incidence of cardiovascular complications ${ }^{8-11}$. MVO can be assessed angiographically, characterized by a lower myocardial blush grade (MBG $<3$ ), or by using cardiac magnetic resonance imaging (CMR) for MVO. The latter has been found to be a better marker, but is also more difficult to obtain due to the limited availability of magnetic resonance imaging (MRI) equipment and patient factors such as heart failure or claustrophobia ${ }^{12}$. 
The purpose of our study was to test the hypothesis that VA burst is an additional independent marker of larger IS in the presence of optimal microvascular perfusion from a prospectively gathered, discrete set of patients in whom independent core laboratory assessments of MVO by CMR were available in conjunction with other key mechanistic surrogates such as epicardial recanalisation (TIMI flow) and continuous digital 12-lead electrocardiogram (ECG) for ST recovery and quantitative ventricular rhythm capture.

\section{Methods}

\section{Study population}

Consecutive patients included in the Maastricht ST-elevation myocardial infarction (MAST) cohort were studied. These patients presented with a first acute STEMI at Maastricht University Medical Center from August 2006 to March 2008 and gave consent to participate in the MAST study. STEMI was defined according to ECG and enzymatic criteria according to the active consensus document during the study time period ${ }^{13}$. Approval of the study was granted by the Medical Ethical Committee of corresponding hospital (MAST p06.0032), and written informed consent was obtained from all patients. The study protocol conforms to the ethical guidelines of the 1975 Declaration of Helsinki as reflected in a priori approval by the institution's human research committee.

Inclusion criteria for the MAST cohort were: (1) symptoms consistent with an acute STEMI lasting for more than 30 minutes but less than 6 hours; (2) ST-elevation of more than $1 \mathrm{~mm}$ in anatomically adjacent leads in the initial ECG; (3) primary PCl; and (4) availability of CMR images. Exclusion criteria included: (1) age below 18 years; (2) cardiogenic shock; (3) pregnancy; (4) inability to obtain informed consent; and (5) contraindications for CMR.

Additional exclusion criteria for the purpose of this study were: (1) absence of or poor-quality ECG Holter recording; (2) and/or CMR imaging; (3) previous myocardial infarction (MI); (4) absence of successful epicardial flow restoration defined as TIMI flow $\leq 2$; (5) and/or stable ST recovery within $240 \mathrm{~min}$; and (6) late ST re-elevation.

\section{Angiographic TIMI flow assessment}

TIMI flowe grading is a well validated classification system going from $0-3$. It is used to semiquantitatively assess coronary artery perfusion beyond point of occlusion on coronary angiography. TIMI flow grade assessment was performed by the angiographic core laboratory (Maastricht University Medical Center, Maastricht, The Netherlands) post-procedurally and blinded to all patient and other core laboratory data. TIMI flow was graded according to the TIMI trial classification $^{14}$. 


\section{ECG data acquisition}

Continuous, high-fidelity, digital, 12-lead ECG Holter recording (NEMON 180+, Northeast Monitoring, Inc., Maynard, MA, USA) was started before $\mathrm{PCl}$ and continued for an average of 24 hours. This system provided the source data for both continuous ST-segment recovery and VA burst analyses. Quantitative ST-segment recovery analysis was performed on 60-second median beat 12-lead ECGs. Quantitative VA analysis was performed on three-lead beat-to-beat Holter device. ST and VA analyses were performed by independent experts blinded to all other patient and core laboratory data through the collaborative eECG core laboratory program (Duke Clinical Research Institute/ Maastricht University Medical Center eECG Core, Durham, NC, USA and Maastricht, The Netherlands) using NEMON Holter for Windows software (NorthEast Monitoring, Inc., Maynard, MA, USA).

\section{Continuous ST recovery analysis}

Methods and criteria for continuous 12-lead ST-segment recovery analysis and reperfusion of the culprit lesion have been described in detail previously ${ }^{4}$. In short, peak ST-segment deviation is determined based on the lead with the greatest deviation taken from the most abnormal ECG recorded during monitoring. Stable and complete ST-segment recovery is defined as $\geq 50 \%$ recovery from previous peak ST-segment levels in the most deviated lead within 240 minutes, lasting $>4$ hours without further ST-segment evolution $(>100 \mu \mathrm{V})$. Late ST (re-)elevation defining epicardial vessel re-occlusion ( $>150 \mu \mathrm{V}$ re-elevation in the most abnormal lead evolving in $<60$ minutes) or microvascular insufficiency $>50 \%$ peak ST levels persisting $>6$ hours in the most abnormal lead) were used to exclude patients from the "optimal reperfusion biosignature" group included in the current analysis.

\section{Quantitative rhythm analysis}

For beat-to-beat quantitative rhythm analysis on all digital three-lead Holter recordings, Holter 5 software (Northeast Monitoring, Inc., Maynard, MA, USA) was used ${ }^{5}$. All automatically assigned waveform labels were manually verified for each cardiac cycle from each subject in order to ensure accurate VA capture according to predefined criteria for ECG interpretation of VAs ${ }^{3,5}$. Fusion beats (normally conducted ventricular activation fused with ventricular premature complex [VPC] morphology) were also considered to be VPCs. Ventricular fibrillation was excluded from the analysis; every ventricular complex was counted independent of the length of the arrhythmia. To generate quantitative VA rates over a 24-hour period, total VPC counts, for which no distinction between the types of VPC was made, were bundled into 5-minute blocks for temporal correlation with stable ST-segment recovery and angiographic observations ( Fig 2 chapter 2).

\section{Defining VA burst}

Quantitative VA rates over the course of Holter recordings were incorporated into a statistical outlier detection method in order to automatically separate outliers of VA rates ('VA bursts') from subject-specific background VA counts. Reperfusion VA bursts were defined as VA bursts if they were concomitant with or subsequent to angiographic documentation of re-established TIMI 3 flow 
in the infarct related artery. Study subjects were dichotomously classified into the 'reperfusion VA burst' group or the 'no burst' group. More detailed description of the characterization of reperfusion VA bursts has been published Majidi et al. ${ }^{5}$

\section{Cardiovascular magnetic resonance imaging protocol}

CMR was performed at $5 \pm 2$ days and $111 \pm 11$ days after admission. Images were acquired on a 1.5-Tesla MRI system (Intera, Philips Medical Systems, Best, The Netherlands) with a dedicated fiveelement phased array surface coil. For functional analysis, ECG-gated cine images were obtained in the LV short-axis plane covering the entire LV using a segmented, balanced, steady-state, free precession sequence (slice thickness $6 \mathrm{~mm}$, slice gap $4 \mathrm{~mm}$, average repetition time [TR] and echo time [TE] 3.8/1.9 ms, respectively, flip angle $50^{\circ}$, field of view (FOV) $350 \mathrm{~mm}$, matrix $256 \times 256$, typically 22-25 phases per cardiac cycle). Delayed enhancement (DE) imaging was performed 10 minutes after an intravenous bolus of $0.2 \mathrm{mmol} / \mathrm{kg}$ body weight gadolinium-diethylenetriaminepentaacetic acid (Magnevist ${ }^{\oplus}$, Bayer Schering Pharma, Berlin, Germany) using a breath-hold three-dimensional inversionrecovery gradient-echo sequence (acquired slice thickness $12 \mathrm{~mm}$, reconstructed slice thickness $6 \mathrm{~mm}$, average TR/TE 3.9/2.4 ms, multi-shot [50 profiles/shot] segmented partial echo readout every heart beat [TFE, turbo gradient echo], flip angle $15^{\circ}$, FOV $400 \mathrm{~mm}$, matrix $256 \times 256$, acquired and reconstructed pixel size $1.56 \times 1.56 \mathrm{~mm}$ ). The inversion time that optimally suppressed the signal of the noninfarcted myocardium (typical range 200-280 ms) was determined with a preceding Look-Locker sequence.

\section{DE-CMR image analysis}

Two observers who were blinded to clinical data independently analysed the DE-CMR images using commercially available software (CAAS MRV 3.0, Pie Medical Imaging, Maastricht, The Netherlands). The inter-observer agreement was excellent $(\kappa=0.9)$. Discrepancies were resolved by consensus. Endocardial and epicardial borders were manually traced, excluding the papillary muscles, in the end-diastolic and end-systolic short-axis phases in order to determine left ventricular enddiastolic volume, endsystolic volume, stroke volume, ejection fraction and enddiastolic mass. These parameters were indexed for body surface area. Likewise, endocardial and epicardial contours were manually traced on the DE images, which were viewed as separate sets. IS was quantified on the DE images using an SI threshold of $>5$ SD above a remote non-infarcted reference region, including areas of MVO (central hypoenhancement within a hyperenhanced area) and expressed as a percentage of LV mass. MVO was quantified by manually tracing the central hypoenhanced area and expressed as a percentage of LV mass (Fig 2). 


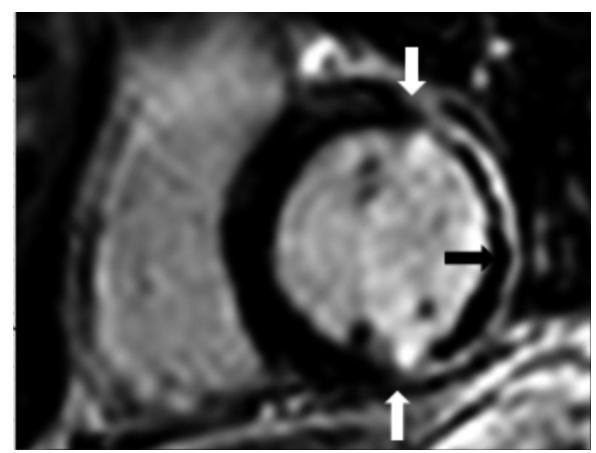

Figure 2: Microvascular obstruction on CMR

DE-CMR image showing an inferolateral and lateral wall infarction (between white arrows) with microvascular obstruction (see black arrow).

\section{Statistical analysis}

Univariable comparisons for baseline characteristics and outcomes in the burst and no burst groups were made using the Student t-test for normally distributed continuous variables, the Wilcoxon rank sum test for non-normally distributed continuous variables and Fisher's exact test for categorical variables. Multivariable linear regression analysis was performed in order to assess whether VA burst remained an independent predictor of IS when corrected for confounders in the population without MVO. Due to the small population size, we were limited to including only one covariate, which was selected by performing univariable regression analyses for known predictors for IS, study origin and treatment assignment. Significant results were included in the multivariable model and the final model was generated by a backward stepwise elimination. The regression model was checked for assumptions, outliers and multicollinearity. Discrepancies were recorded. A p-value of $<0.05$ was considered statistically significant, and all tests were twosided. Data were analysed using IBM SPSS statistics software version 19 (IBM, Armonk, NY, USA).

\section{Results}

\section{Patient characteristics}

According to the nature of the reperfusion arrhythmias (ventricular premature beats (VPBs) and accelerated idioventricular rhythms (AIVRs)), the arrhythmia bursts were well tolerated and none of the patients experienced symptomatic VAs. Patient characteristics according to MVO status and burst are shown in Table 1. Most descriptors were comparable across VA burst groups and representative of a typical STEMI population, except for an overall high incidence of current smoking or history of smoking (89-100\%) and a relatively low incidence of anterior MI (11-32\%). 


\begin{tabular}{|c|c|c|c|c|c|c|}
\hline & \multicolumn{3}{|c|}{ No MVO (N = 28) } & \multicolumn{3}{|c|}{ MVO $(\mathrm{N}=37)$} \\
\hline & $\begin{array}{c}\text { Burst } \\
\text { present } \\
\mathrm{N}=17\end{array}$ & $\begin{array}{c}\text { Burst not } \\
\text { present } \\
\mathrm{N}=11\end{array}$ & $\mathrm{P}$ & $\begin{array}{c}\text { Burst } \\
\text { present } \\
\mathrm{N}=28\end{array}$ & $\begin{array}{c}\text { Burst not } \\
\text { present } \\
\mathrm{N}=9\end{array}$ & $\mathrm{p}$ \\
\hline \multicolumn{7}{|l|}{ Demographics } \\
\hline Age (years) & $62.3 \pm 7.9$ & $59.6 \pm 11.0$ & 0.46 & $56.1 \pm 12.6$ & $63.2 \pm 9.5$ & 0.13 \\
\hline Male & $11(64.7 \%)$ & $10(90.9 \%)$ & 0.19 & $20(71.4 \%)$ & $7(77.8 \%)$ & 1.00 \\
\hline \multicolumn{7}{|l|}{ Comorbidities } \\
\hline BMI & $26.1 \pm 2.9$ & $26.9 \pm 3.8$ & 0.55 & $27.7 \pm 4.8$ & $26.9 \pm 3.9$ & 0.64 \\
\hline Smoking (current or history) & $16(94.1 \%)$ & $10(90.9 \%)$ & 1.00 & $25(89.3 \%)$ & $9(100.0 \%)$ & 0.56 \\
\hline Hypertension & $6(35.3 \%)$ & $6(54.5 \%)$ & 0.45 & $7(25.0 \%)$ & $4(44.4 \%)$ & 0.40 \\
\hline Diabetes mellitus & $2(11.8 \%)$ & $1(9.1 \%)$ & 1.00 & $1(3.6 \%)$ & $1(11.1 \%)$ & 0.43 \\
\hline Hypercholesteremia & $5(29.4 \%)$ & $1(9.1 \%)$ & 0.33 & $11(39.3 \%)$ & $3(33.3 \%)$ & 1.00 \\
\hline Positive family history & $6(35.3 \%)$ & $6(54.5 \%)$ & 0.44 & $15(53.6 \%)$ & $5(55.6 \%)$ & 1.00 \\
\hline Pre-existent AP & $5(29.4 \%)$ & $3(27.3 \%)$ & 0.44 & $13(46.4 \%)$ & $3(33.3 \%)$ & 0.71 \\
\hline AP 24h preceding AMI & $6(35.3 \%)$ & $6(54.5 \%)$ & 1.00 & $13(46.4 \%)$ & $5(55.6 \%)$ & 0.70 \\
\hline Previous Stroke & $2(11.8 \%)$ & $1(9.1 \%)$ & 1.00 & $1(3.6 \%)$ & $0(0.0 \%)$ & 1.00 \\
\hline Peripheral artery disease & $0(0.0 \%)$ & $1(9.1 \%)$ & 0.39 & $3(10.7 \%)$ & $1(11.1 \%)$ & 1.00 \\
\hline \multicolumn{7}{|l|}{ Medication } \\
\hline$\beta$-blocker & $0(0.0 \%)$ & $4(36.4 \%)$ & $0.02^{*}$ & $4(14.3 \%)$ & $1(11.1 \%)$ & 1.00 \\
\hline Acetyl salic acid & $3(17.6 \%)$ & $2(18.2 \%)$ & 1.00 & $2(7.1 \%)$ & $2(22.2 \%)$ & 0.24 \\
\hline ADP-antagonist & $0(0.0 \%)$ & $0(0.0 \%)$ & n.a & $0(0.0 \%)$ & $0(0.0 \%)$ & n.a. \\
\hline Statin & $3(17.6 \%)$ & $2(18.2 \%)$ & 1.00 & $7(25.0 \%)$ & $2(22.2 \%)$ & 1.00 \\
\hline Nitrates & $0(0.0 \%)$ & $1(9.1 \%)$ & 0.39 & $0(0.0 \%)$ & $0(0.0 \%)$ & n.a. \\
\hline ACE-inhibitor & $2(11.8 \%)$ & $1(9.1 \%)$ & 1.00 & $0(0.0 \%)$ & $0(0.0 \%)$ & n.a. \\
\hline AT-Il antagonist & $1(5.9 \%)$ & $1(9.1 \%)$ & 1.00 & $2(7.1 \%)$ & $2(22.2 \%)$ & 0.24 \\
\hline Calcium-antagonist & $2(11.8 \%)$ & $1(9.1 \%)$ & 1.00 & $2(7.1 \%)$ & $2(22.2 \%)$ & 0.24 \\
\hline \multicolumn{7}{|l|}{$\mathrm{PCl}$} \\
\hline Anterior location & $2(11.8 \%)$ & $2(18.2 \%)$ & 1.00 & $9(32.1 \%)$ & $1(11.1 \%)$ & 0.39 \\
\hline Multiple vessel disease & $10(58.8 \%)$ & $3(27.3 \%)$ & 0.49 & $10(35.71 \%)$ & $6(66.7 \%)$ & 0.041 \\
\hline $\mathrm{PCl}$ of $>1$ lesion & $2(11.8 \%)$ & $1(9.1 \%)$ & 1.00 & $5(17.9 \%)$ & $0(0.0 \%)$ & 0.31 \\
\hline Side branch occlusion & $1(5.9 \%)$ & $0(0.0 \%)$ & 1.00 & $1(3.6 \%)$ & $0(0.0 \%)$ & 1.00 \\
\hline Distal embolization & $2(11.8 \%)$ & $2(18.2 \%)$ & 1.00 & $5(17.9 \%)$ & $0(0.0 \%)$ & 0.31 \\
\hline Duration of symptoms (min) & $201(173-307)$ & $217(165-248)$ & 0.97 & $180(142-238)$ & $226(196-307)$ & 0.054 \\
\hline \multicolumn{7}{|l|}{ CMR } \\
\hline Days to first CMR & $5(4.0-7.0)$ & $4(3.0-5.0)$ & 0.18 & $5(4.0-5.8)$ & $4(3.0-5.0)$ & 0.19 \\
\hline Days to late CMR & $105(101-114)$ & $99(91-105)$ & $0.02 *$ & $112(101-114)$ & $103(99-113)$ & 0.38 \\
\hline Percentage of MVO & n.a. & n.a. & n.a. & $1.2 \%(0.9-3.2)$ & $2.5 \%(1.4-4.5)$ & 0.14 \\
\hline
\end{tabular}

* significant difference

Results presented as mean \pm standard deviation, median with quartiles or as $\mathrm{N}(\%)$. ACE $=$ angiotensin converting enzyme, $\mathrm{ADP}=$ adenosine diphosphate, $\mathrm{AP}=$ angina pectoris, $\mathrm{AT}=$ angiotensin, $\mathrm{BMI}=$ body mass index, $\mathrm{CMR}=$ cardiovascular magnetic resonance imaging, $\mathrm{MVO}=$ microvascular obstruction, $\mathrm{PCl}$ = percutaneous coronary intervention 
For the whole population, the median duration of ischaemia (time in minutes from onset of symptoms to first balloon inflation) was 201 minutes, the incidence of anterior MI was $21.5 \%$ and the median days to first and second CMR were 5 and 106, respectively. For the subgroups of MVO versus no MVO, the median duration of ischaemia was 201 versus 210 minutes, and the incidence of anterior MI was $27 \%$ versus $14.3 \%$. Finally, for the subgroup without MVO, the median duration of ischaemia was 201 versus 217 minutes for burst versus no burst, respectively, and the incidence of anterior MI was $11.2 \%$ versus $18.2 \%$. VA burst occurred less frequently in patients who used $\beta$-blockers before STEMI if MVO was absent $(p=0.02)$. There were no significant differences in characteristics between the presence or absence of MVO.

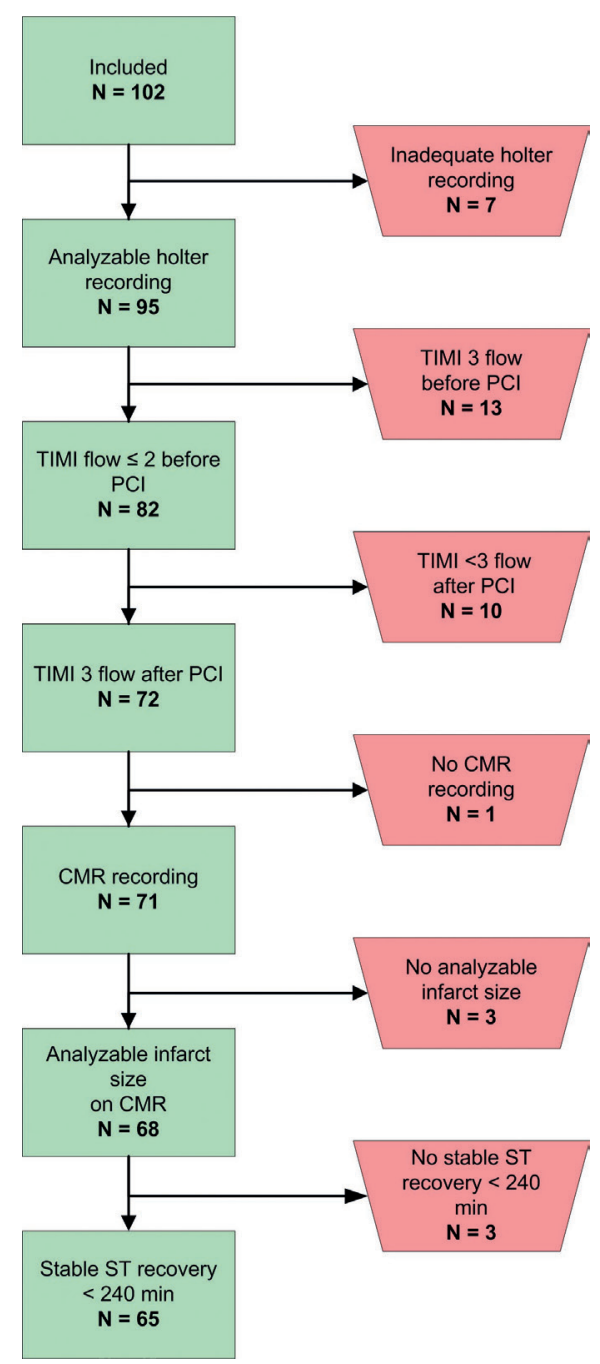

Figure 3: Patient selection

$\mathrm{CMR}=$ cardiac magnetic resonance imaging, $\mathrm{PCl}=$ percutaneous coronary intervention 


\section{MVO and IS}

IS was larger in patients with MVO found on their first DE-CMR $(20.2 \%$ vs. 9.5\%; $p<0.001)$ (Fig. 4), and this difference remained, as observed at the second DE-CMR (15.8\% vs. $5.8 \% ; p<0.001)$. Accordingly, LVEF was significantly lower in the presence of MVO (49.9\% vs. $57.3 \% ; p<0.001)$. In the presence of MVO, the presence of VA burst was not associated with a further increase in IS or a lower LVEF.

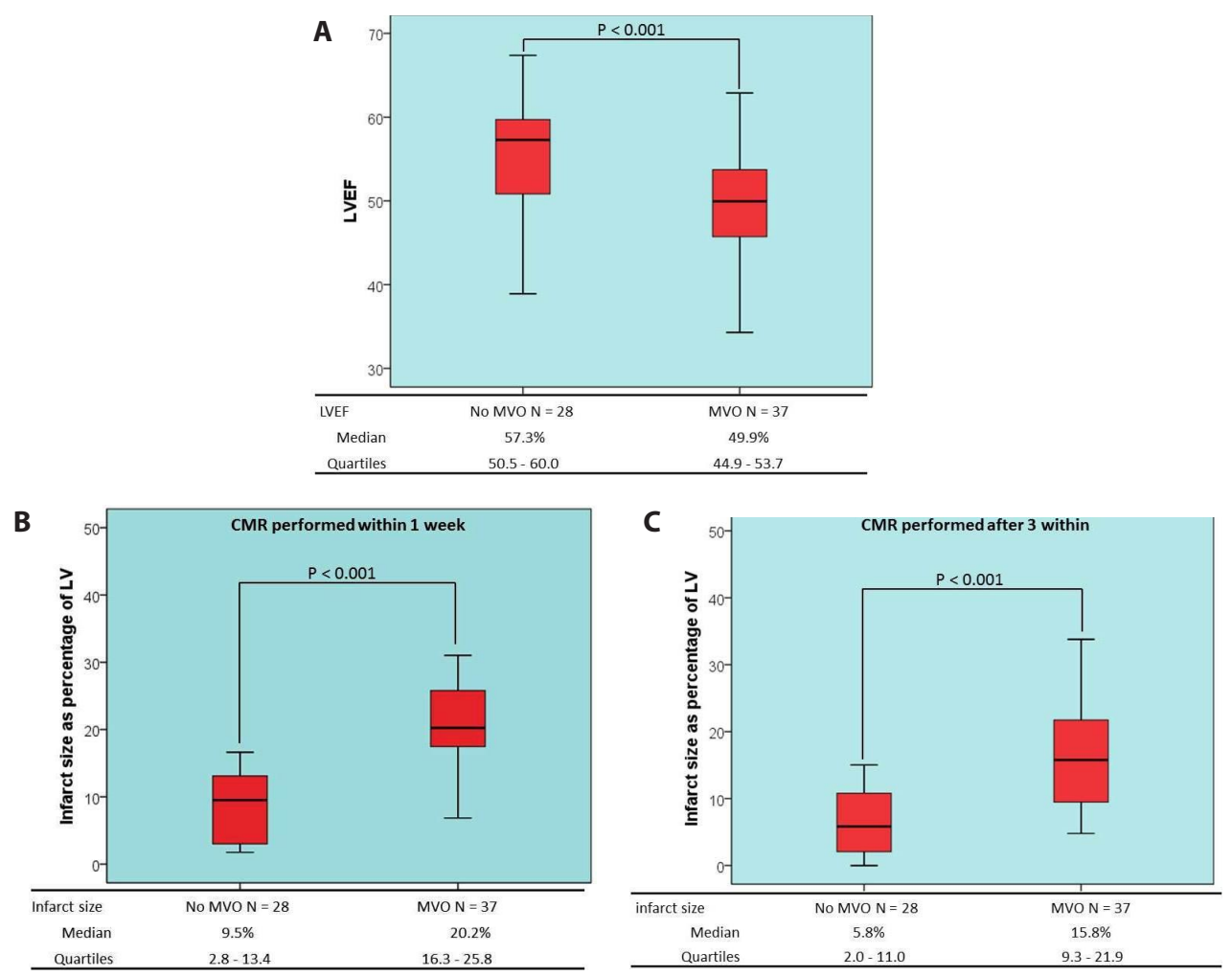

Figure 4: Boxplots displaying the differences between presence or absence of MVO

$A$ : Difference in infarct size determined with first DE-CMR reported as median and quartiles. $B$ : Difference in infarct size determined with late DE-CMR reported as median and quartiles. C: Difference in LVEF determined with CMR reported as median and quartiles.

However, in the absence of MVO but with VA burst, IS was twice as large (10.5\% vs. $4.1 \% ; p=0.037)$ (Fig. 5 ) at the first DE-CMR and three times as large at the second DE-CMR (8.4\% vs. $2.5 \% ; p=0.048)$. Univariable regression analyses for patients without MVO showed significant correlations between final IS for VA burst, anterior infarct location, use of $\beta$-blockade and gender for both early and late $\mathrm{DE}-\mathrm{CMR}$ (Table 2). Angina in the 24 hours proceeding MI had a significant correlation for IS on late DE-CMR. In multivariable analyses, the correlation between VA burst and IS remained significant ( $B=6.3, p=0.02$ for early $D E-C M R$ and $B=5.3, p=0.03$ for late $D E-C M R$ ) when correcting for the 
most significant predictor of IS in multivariable analyses, anterior location (Table 3). Due to the relatively small infarcts in this study population, LVEF was not significantly affected by the all-or none presence of VA burst.
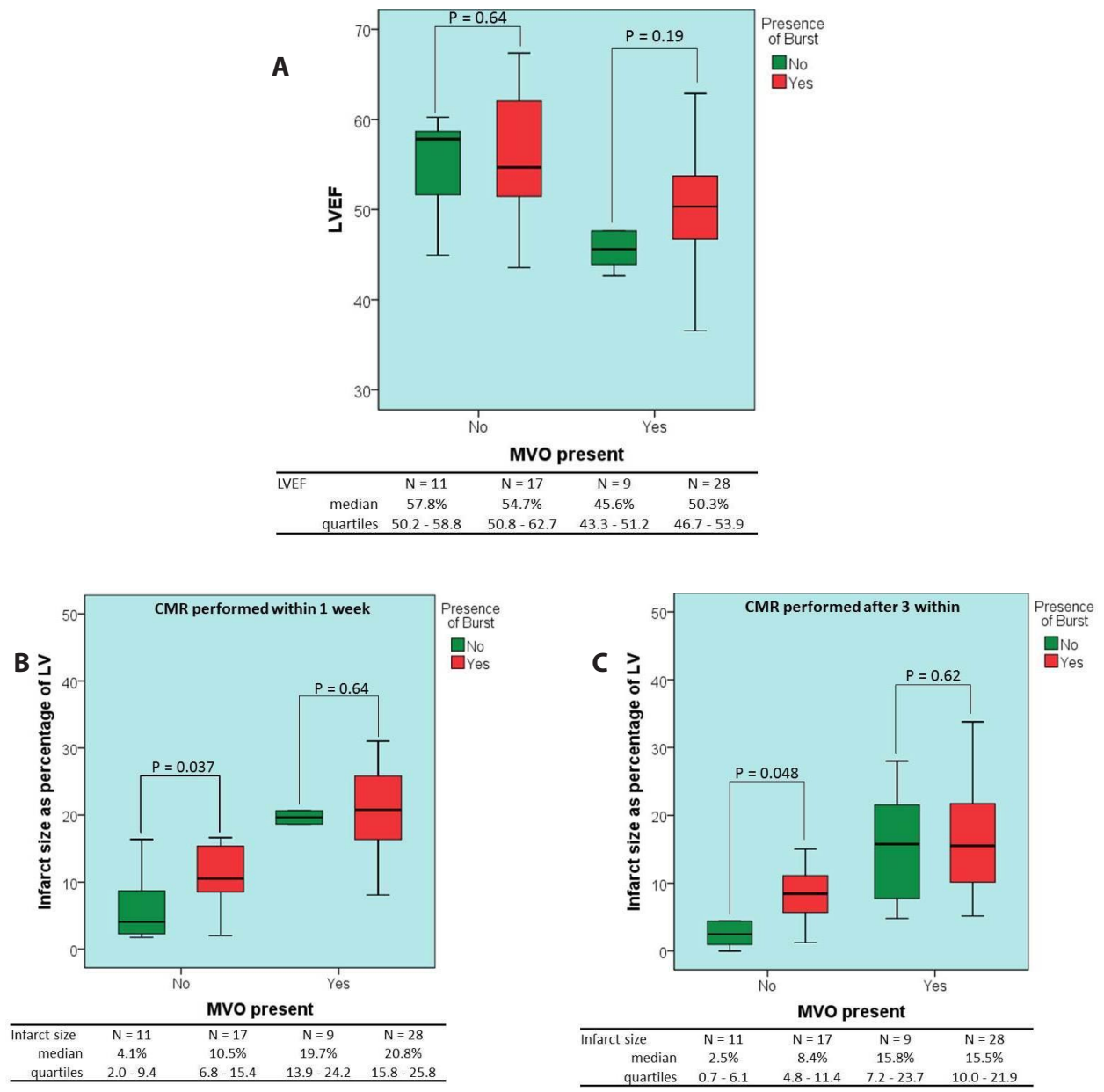

Figure 5: Boxplots displaying the differences between presence or absence of VA burst conditional on presence or absence of MVO

$A$ : Difference in infarct size determined with first DE-CMR. B: Difference in infarct size determined with late DE-CMR. C: Difference in LVEF 
Infarct size on early CMR (\% of LV) Infarct size on late CMR (\% of LV)

$\mathrm{R}$

\section{Demographics}

Age (years)

Male

0.33

0.42

0.06

0.16

$-0.29$

$-0.04$

0.18

$-0.19$

$-0.11$

$-0.31$

0.07

$-0.19$

$-0.38$

$-0.02$

$-0.18$

$-0.21$

$-0.01$

$-0.20$

Calcium-antagonist

PCI

Anterior location

Multiple vessel disease

$\mathrm{PCl}$ of $>1$ lesion

Side branch occlusion

Distal embolization

Duration of symptoms (min)

\section{CMR}

Days to CMR after AMI

0.16

$-0.29$

$-0.18$

$-0.09$

0.20
$\mathrm{P}$

0.084

$0.027^{*}$

0.759

0.03

0.17

$-0.19$

$-0.09$

0.24

$-0.07$

$-0.12$

$-0.45$

0.27

$-0.15$

0.341

$0.049 *$

$-0.42$

0.15

$-0.14$

$-0.19$

0.14

$-0.17$

0.310

$0.014^{*}$

0.41

$0.047^{*}$

0.421

0.24

0.264

0.133

$-0.32$

0.131

0.383

$-0.17$

0.434

0.649

$-0.20$

0.352

0.397

0.00

0.993

* significant difference

$\mathrm{ACE}=$ angiotensin converting enzyme, $\mathrm{ADP}=$ adenosine diphosphate, $\mathrm{AP}=$ angina pectoris, $\mathrm{AT}=$ angiotensin, $\mathrm{BMI}=$ body mass index, $\mathrm{CMR}=$ cardiovascular magnetic resonance imaging, $\mathrm{MVO}=$ microvascular obstruction, $\mathrm{PCl}=$ percutaneous coronary intervention 


\section{A. Early cardiac MRI}

\begin{tabular}{lccc}
\hline & Coefficient & $\mathbf{9 5 \%} \mathbf{~ C l}$ & P-value \\
\hline Constant & 4.28 & $-0.08-8.64$ & 0.05 \\
Presence of VA burst & 6.29 & $0.95-11.62$ & $0.02 *$ \\
Anterior location & 11.10 & $3.65-18.55$ & $0.01^{*}$ \\
\hline
\end{tabular}

${ }^{*}$ significant difference. $\mathrm{R} 2=0.360$

B. Late cardiac MRI after 3 months

\begin{tabular}{lccc}
\hline & Coefficient & $\mathbf{9 5 \%} \mathbf{C l}$ & $\boldsymbol{P}$-value \\
\hline Constant & 2.71 & $-1.04-6.46$ & 0.15 \\
Presence of VA burst & 5.32 & $0.67-9.97$ & $0.03^{*}$ \\
Anterior location & 7.35 & $1.20-13.51$ & $0.02^{*}$ \\
\hline
\end{tabular}

*significant difference. $\mathrm{R} 2=0.344$

\section{Discussion}

Our findings confirm previous findings of MVO being correlated with larger IS and lower LVEF. Moreover, this study is the first to show that VA burst sub-stratifies patients with TIMI 3 flow, ST recovery and absence of MVO in relation to final IS. This suggests VA burst to be an early additional marker that is complementary to TIMI flow, ST-segment resolution and MVO in assessing IS. In the presence of MVO and its associated larger IS, VA burst appears to have no additional substratifying value. This is likely due to the already deleterious effect of a destroyed microvasculature as indicated by the presence of MVO.

\section{MVO}

Significantly larger IS and lower LVEF that were observed in the presence of MVO occurred in the event of stable ST recovery within 240 minutes and no re-elevation of the ST segment. This confirms previous findings that, while correlated, MVO is a strong and additional predictor of IS in addition to ST-segment recovery and TIMI flow alone ${ }^{10,15}$.

Microvascular disperfusion can also be assessed by a $M B G \leq 2$, but recent studies have shown that MBG underestimates the presence of $\mathrm{MVO}^{12,16}$. MVO has shown to be a dynamic process that continues to develop up to 48 hours after reperfusion ${ }^{17-19}$. This is because MVO is not only the result of long, intensive ischaemia and angioplasty induced distal coronary embolization, but is also brought on by the reperfusion process, leading to oedema, inflammation and oxidative stress, among others ${ }^{20}$. The effects of reperfusion will become apparent directly after $\mathrm{PCl}$, but will accumulate in the first days after reperfusion. This may also go some way to explaining why MBG, as assessed early during reperfusion, misses cases of MVO that are later found on DE-CMR. In the presence of MVO, the 
additional presence of VA burst did not significantly influence IS. This observation suggests that the more upstream damage of the microvasculature that causes a larger IS prevents the downstream myocellular tissue from recovering. However, this does not exclude reperfusion arrhythmias from being likely to occur in the area without microvascular occlusion. There was, however, a visible trend showing that bursts occurred more frequently when the area of MVO was smaller.

\section{VA burst}

Our results show that VA burst distinguishes patients with larger infarcts from those with smaller infarcts if optimal epicardial perfusion (TIMI 3 flow), optimal microvascular perfusion and stable ST recovery without re-elevation are present. Our results demonstrate that IS is significantly larger in the first days after the event and that the difference becomes more apparent after more than 3 months if VA burst was present. This latter change in difference over time might be attributed to clearing of necrotic myocardium, inflammatory cells, residual oedema and haemorrhage, as well as replacement by scar tissue. Because of the influence of these factors, previous studies have shown that the majority of infarct healing occurs within the first 3-4 months after the event and continues at a slower rate up to 1 year ${ }^{21-24}$. Recent research has shown that ticagrelor might have a protective effect on MVO. Our study only included clopidogrel as was per protocol at the time of inclusion. It would be interesting to study whether ticagrelor could influence the incidence of VA burst ${ }^{25}$.

\section{Biosignature of "optimal" reperfusion}

Rapid, complete, and stable ST-segment resolution without re-elevation is a well-validated, electrocardiographic biomarker of high quality reperfusion ${ }^{4,26-28}$. Over 30 years of experimental and clinical research, much evidence has emerged regarding what constitutes 'optimal' reperfusion. This constitutes a series of mechanistic events: epicardial flow, distal embolisation, microvascular flow, reversal of the ischaemic zone and recovery of the still viable but severely damaged myocytes. The combination of these factors results in the creation of an advancing 'signature' of surrogate biomarkers using angiography, ECG, echocardiography, single-photon emission computed tomography and, more recently, $\mathrm{CMR}^{2-4,6,7}$. This report is the first to use the more sensitive and specific CMR imaging as a way to define MVO and select only those patients with full microvascular reperfusion. This subset comprises every optimal perfusion stage up to reversal of the ischaemic zone, however leaving the question as to whether the severely damaged myocytes recovered or died by the reperfusion process.

Our results indicate that VA burst is a marker of additional cell death in the presence of optimal epicardial and microvascular reperfusion. This finding is of clinical and experimental importance. VA burst not only identifies larger infarcts at an early stage following the recanalization attempt, but also enables research aimed at preventing additional myocellular injury. VA burst has the potential to provide an inexpensive diagnostic tool that can guide medical decision making, for example regarding time to discharge. Furthermore, it can also be used as a measure for additional injury of 
which the pathophysiology is not yet fully clear. Our results suggest a more downstream myocellular mechanism such as reperfusion injury.

\section{Limitations}

This is a small but thoroughly studied population that is useful for insight into strategic approaches using a signature of surrogate markers reflective of key mechanistic steps of reperfusion after STEMI, but is in need of much expanded and prospective work in order to confirm these findings and to understand their prognostic implications and relevance to testing new therapies. This small population limited our ability to conduct a more elaborate multivariable analysis and also to draw confirmative conclusions.

Furthermore, we found a significant difference between the occurrence of VA burst and the use of $\beta$-blockers before STEMI. This could be a coincidence because many variables were analysed in a small population and only few used $\beta$-blockade. Furthermore, the significant relationship was only present in univariate analyses and did not hold in the multivariate analyses. At most, we can hypothesise that the impact of $\beta$-blockade before an ischaemic event may have a relevant impact in patients with otherwise optimal reperfusion.

Late CMR was performed significantly earlier in the population without MVO and without VA burst in comparison to the group without MVO but with VA burst. We consider this to be a chance observation that did not influence IS because of the time between the event and CMR recording.

\section{Conclusion}

This is the first study to show that in the presence of optimal epicardial and microvascular reperfusion (TIMI 3 flow and absence of MVO on DE-CMR), VA bursts identify significantly larger IS in STEMI patients. VA burst has the potential to provide an inexpensive diagnostic tool that can guide medical decision making, for example regarding time to discharge. Furthermore, it can also be used as a measure for additional injury of which the pathophysiology is not yet fully clear. Our results suggest a more downstream myocellular mechanism such as reperfusion injury. In addition, this study confirms previous findings that the presence of MVO on DE-CMR is correlated with larger IS.

\section{Funding Sources}

This work was supported by funding from the Hein Wellens Foundation, Maastricht, the The Netherlands, and by the MUMC+ Research Fund, Maastricht, The Netherlands

\section{Acknowledgements}

The authors wish to thank the Hein Wellens Foundation for their support in this project. 


\section{Conflict of interest and competing interests}

None 


\section{References}

1. Gorgels AP, Vos MA, Letsch IS, et al. Usefulness of the accelerated idioventricular rhythm as a marker for myocardial necrosis and reperfusion during thrombolytic therapy in acute myocardial infarction. The American journal of cardiology. 1988; 61: 231-5.

2. Engelen DJ, Gressin V, Krucoff MW, et al. Usefulness of frequent arrhythmias after epicardial recanalization in anterior wall acute myocardial infarction as a marker of cellular injury leading to poor recovery of left ventricular function. The American journal of cardiology. 2003; 92: 1143-9.

3. Majidi M, Kosinski AS, Al-Khatib SM, et al. Reperfusion ventricular arrhythmia 'bursts' predict larger infarct size despite TIMI 3 flow restoration with primary angioplasty for anterior ST-elevation myocardial infarction. European heart journal. 2009; 30: 757-64.

4. Krucoff MW, Croll MA, Pope JE, et al. Continuously updated 12-lead ST-segment recovery analysis for myocardial infarct artery patency assessment and its correlation with multiple simultaneous early angiographic observations. The American journal of cardiology. 1993; 71: 145-51.

5. Majidi M, Kosinski AS, Al-Khatib SM, et al. Reperfusion ventricular arrhythmia 'bursts' in TIMI 3 flow restoration with primary angioplasty for anterior ST-elevation myocardial infarction: a more precise definition of reperfusion arrhythmias. Europace : European pacing, arrhythmias, and cardiac electrophysiology : journal of the working groups on cardiac pacing, arrhythmias, and cardiac cellular electrophysiology of the European Society of Cardiology. 2008; 10: 988-97.

6. Majidi M, Kosinski AS, Al-Khatib SM, et al. Implications of ventricular arrhythmia "bursts" with normal epicardial flow, myocardial blush, and ST-segment recovery in anterior ST-elevation myocardial infarction reperfusion: A biosignature of direct myocellular injury "downstream of downstream". European heart journal Acute cardiovascular care. 2015; 4: 51-9.

7. van der Weg K, Kuijt WJ, Tijssen JG, et al. Prospective evaluation of where reperfusion ventricular arrhythmia "bursts" fit into optimal reperfusion in STEMI. International journal of cardiology. 2015; accepted for publication.

8. Bekkers SC, Smulders MW, Passos VL, et al. Clinical implications of microvascular obstruction and intramyocardial haemorrhage in acute myocardial infarction using cardiovascular magnetic resonance imaging. European radiology. 2010; 20: 2572-8.

9. Bogaert J, Kalantzi M, Rademakers FE, Dymarkowski S and Janssens S. Determinants and impact of microvascular obstruction in successfully reperfused ST-segment elevation myocardial infarction. Assessment by magnetic resonance imaging. European radiology. 2007; 17: 2572-80.

10. Nijveldt R, Beek AM, Hirsch A, et al. Functional recovery after acute myocardial infarction: comparison between angiography, electrocardiography, and cardiovascular magnetic resonance measures of microvascular injury. Journal of the American College of Cardiology. 2008; 52: 181-9.

11. Wu KC, Zerhouni EA, Judd RM, et al. Prognostic significance of microvascular obstruction by magnetic resonance imaging in patients with acute myocardial infarction. Circulation. 1998; 97: 765-72.

12. Wong DT, Leung MC, Richardson JD, et al. Cardiac magnetic resonance derived late microvascular obstruction assessment post ST-segment elevation myocardial infarction is the best predictor of left ventricular function: a comparison of angiographic and cardiac magnetic resonance derived 
measurements. The international journal of cardiovascular imaging. 2012; 28: 1971-81.

13. Thygesen K, Alpert JS and White HD. Universal definition of myocardial infarction. Journal of the American College of Cardiology. 2007; 50: 2173-95.

14. The Thrombolysis in Myocardial Infarction (TIMI) trial. Phase I findings. TIMI Study Group. The New England journal of medicine. 1985; 312: 932-6.

15. Poli A, Fetiveau R, Vandoni P, et al. Integrated analysis of myocardial blush and ST-segment elevation recovery after successful primary angioplasty: Real-time grading of microvascular reperfusion and prediction of early and late recovery of left ventricular function. Circulation. 2002; 106: 313-8.

16. Vicente J, Mewton N, Croisille P, et al. Comparison of the angiographic myocardial blush grade with delayed-enhanced cardiac magnetic resonance for the assessment of microvascular obstruction in acute myocardial infarctions. Catheterization and cardiovascular interventions : official journal of the Society for Cardiac Angiography \& Interventions. 2009; 74: 1000-7.

17. Rochitte CE, Lima JA, Bluemke DA, et al. Magnitude and time course of microvascular obstruction and tissue injury after acute myocardial infarction. Circulation. 1998; 98: 1006-14.

18. Ambrosio G, Weisman HF, Mannisi JA and Becker LC. Progressive impairment of regional myocardial perfusion after initial restoration of postischemic blood flow. Circulation. 1989; 80: 1846-61.

19. Reffelmann T and Kloner RA. Microvascular reperfusion injury: rapid expansion of anatomic no reflow during reperfusion in the rabbit. American journal of physiology Heart and circulatory physiology. 2002; 283: H1099-107.

20. Jaffe R, Charron T, Puley G, Dick A and Strauss BH. Microvascular obstruction and the no-reflow phenomenon after percutaneous coronary intervention. Circulation. 2008; 117: 3152-6.

21. Reimer KA and Jennings RB. The changing anatomic reference base of evolving myocardial infarction. Underestimation of myocardial collateral blood flow and overestimation of experimental anatomic infarct size due to tissue edema, hemorrhage and acute inflammation. Circulation. 1979; 60: 866-76.

22. Ingkanisorn WP, Rhoads KL, Aletras AH, Kellman P and Arai AE. Gadolinium delayed enhancement cardiovascular magnetic resonance correlates with clinical measures of myocardial infarction. Journal of the American College of Cardiology. 2004; 43: 2253-9.

23. Fieno DS, Hillenbrand HB, Rehwald WG, et al. Infarct resorption, compensatory hypertrophy, and differing patterns of ventricular remodeling following myocardial infarctions of varying size. Journal of the American College of Cardiology. 2004; 43: 2124-31.

24. Pokorney SD, Rodriguez JF, Ortiz JT, Lee DC, Bonow RO and Wu E. Infarct healing is a dynamic process following acute myocardial infarction. Journal of cardiovascular magnetic resonance : official journal of the Society for Cardiovascular Magnetic Resonance. 2012; 14: 62.

25. Park SD, Lee MJ, Baek YS, et al. Randomised trial to compare a protective effect of Clopidogrel Versus Tlcagrelor on coronary Microvascular injury in ST-segment Elevation myocardial infarction (CV-TIME trial). Eurolntervention : journal of EuroPCR in collaboration with the Working Group on Interventional Cardiology of the European Society of Cardiology. 2016; 12: e964-e71.

26. Gibson CM, Karha J, Giugliano RP, et al. Association of the timing of ST-segment resolution with TIMI myocardial perfusion grade in acute myocardial infarction. American heart journal. 2004; 147: 847-52.

27. Anderson RD, White HD, Ohman EM, et al. Predicting outcome after thrombolysis in acute myocardial 
infarction according to ST-segment resolution at 90 minutes: a substudy of the GUSTO-III trial. Global Use of Strategies To Open occluded coronary arteries. American heart journal. 2002; 144: 81-8.

28. Shah A, Wagner GS, Granger CB, et al. Prognostic implications of TIMI flow grade in the infarct related artery compared with continuous 12-lead ST-segment resolution analysis. Reexamining the "gold standard" for myocardial reperfusion assessment. Journal of the American College of Cardiology. 2000; 35: 666-72. 


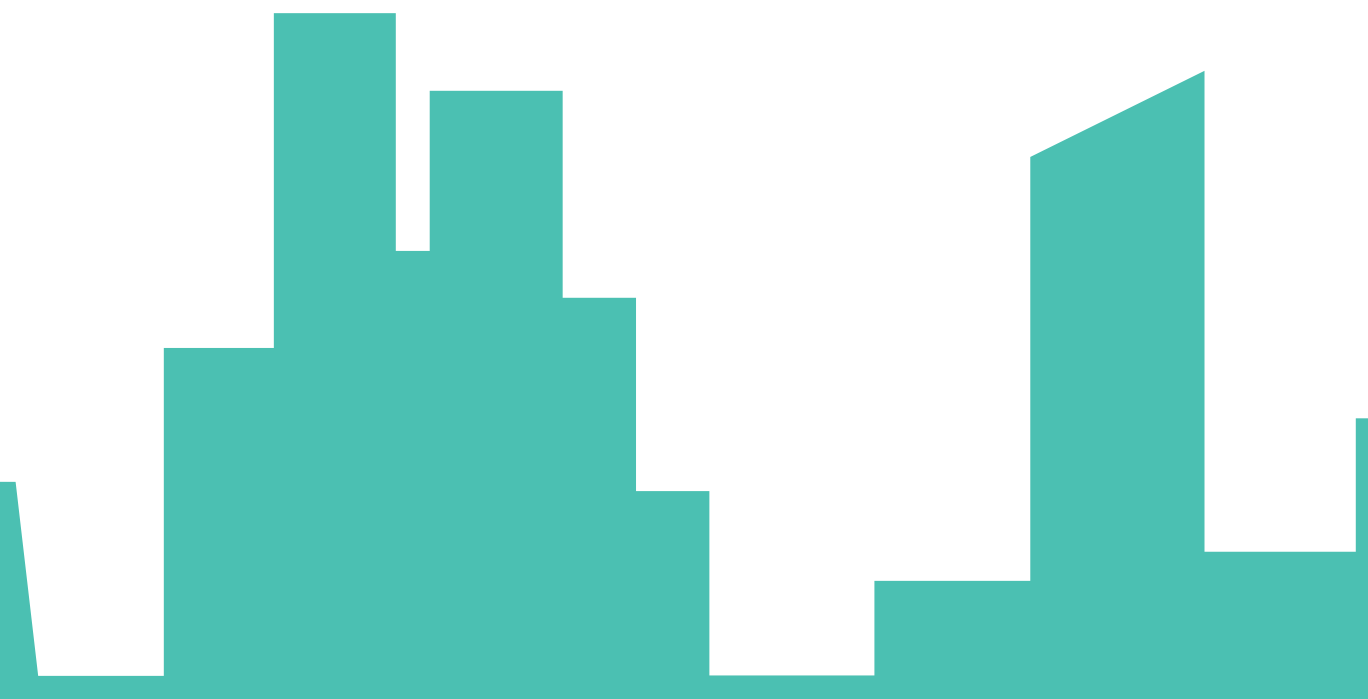

Authors:

Kirian van der Weg, MD *†, Wichert J. Kuijt, MD ¥, Sebastiaan C.A.M. Bekkers, MD, PhD *, Jan G.P. Tijssen, PhD $\neq$, Cynthia L. Green, PhD †, Martijn W. Smulders, MD*, Miguel E. Lemmert, MD, PhD*,

Mitchell W. Krucoff, MD, PhD †, Anton P.M. Gorgels, MD, PhD*

Work was performed in:

* Maastricht University Medical Centre, Maastricht, The Netherlands

† Duke University Medical Center and Duke Clinical Research Institute, Durham, United States of America

‡Academic Medical Centre, Amsterdam, The Netherlands

Published in

International Journal of Cardiology 2018;271:240-246 


\section{Chapter 5}

Bursts of reperfusion arrhythmias occur independently of area at risk size and are the first marker of reperfusion injury.

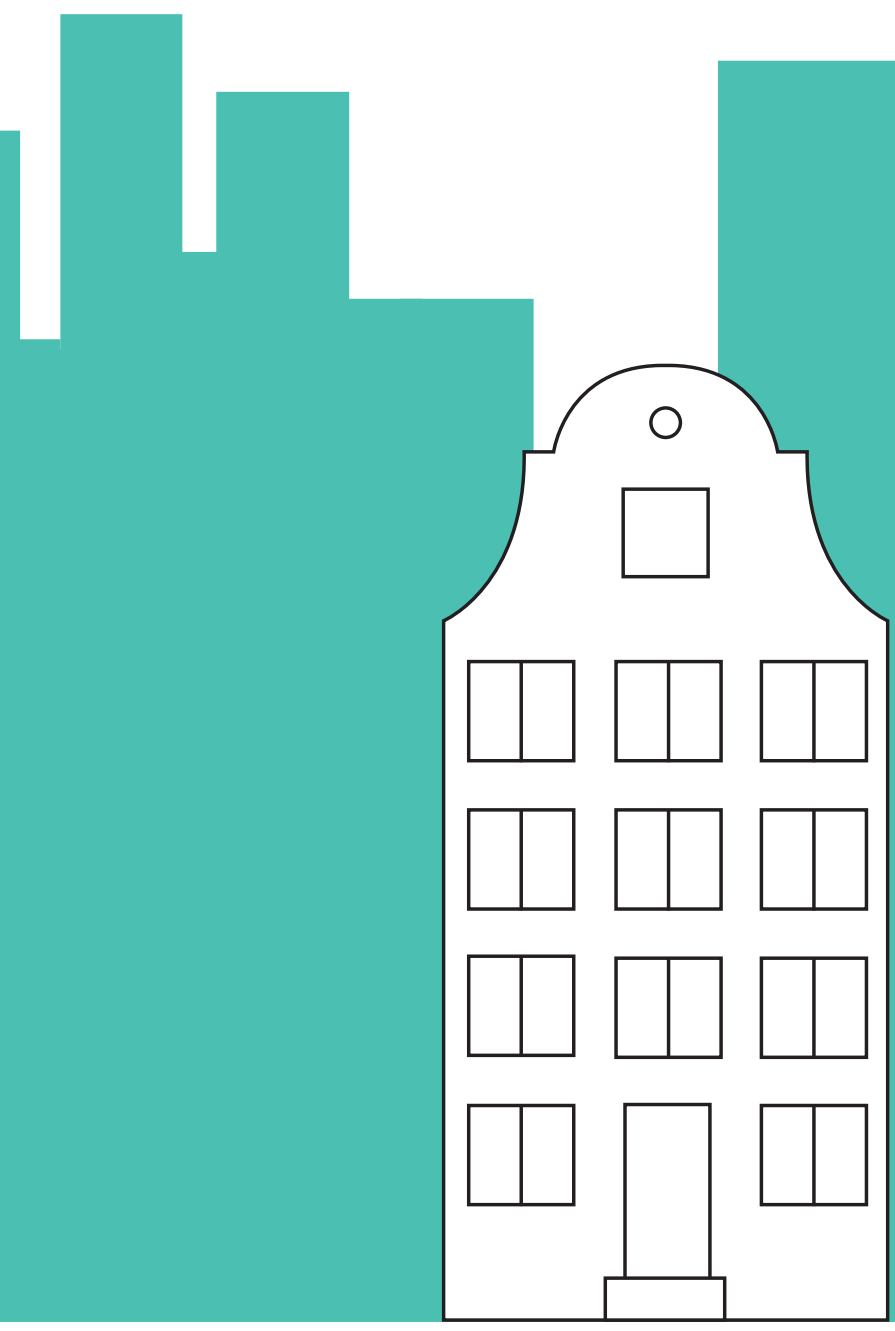




\section{Abstract}

\section{Background:}

The presence of reperfusion ventricular arrhythmias (VA) has been shown to correlate with larger infarct size (IS). However it is unclear whether the initial area at risk (AAR), also a determining factor for IS, is responsible for this correlation. We hypothesized that IS would be significantly larger in the presence of VA, while AAR would not differ.

\section{Methods:}

68 STEMI patients from the MAST study with 24-hour, continuous, 12-lead Holter monitoring initiated prior to primary percutaneous coronary intervention (PCI) resulting in TIMI 3 flow post $\mathrm{PCl}$ were included. VA bursts were identified against subject-specific background VA rates using a previously validated statistical outlier method. IS, and infarct endocardial surface area (ESA) were obtained using CMR at mean 4.9 days after admission. Holter and CMR results were determined in core laboratories blinded to all other data.

\section{Results:}

VA bursts were present in $69 \%(45 / 65)$ of patients. No significant differences were found for demographic characteristics, comorbidities, infarct location, number of diseased coronary vessels, or duration of ischemia between groups with and without VA burst. IS was significantly smaller in the group without VA bursts (median $9.3 \%$ vs $17.0 \% ; p=0.025$ ). Infarct ESA did not significantly differ between the population with and without VA burst; median $24.3 \%$ vs $20.0 \%$; $p=0.15$.

\section{Conclusion:}

VA bursts are a marker for larger IS independent of AAR, assessed by surrogate markers. These findings support the hypothesis that VA bursts are a marker of reperfusion damage occurring downstream at myocellular level. 


\section{Introduction}

Historically ventricular arrhythmias (VA) after thrombolytic therapy were considered a favorable non-invasive marker of reperfusion'. More recent studies in the era of primary percutaneous intervention ( $\mathrm{PCI}$ ) have shown that reperfusion VA bursts are related to larger infarct size (IS) and worse left ventricular function ${ }^{2-8}$. Such VA bursts include mostly ventricular premature beats with long coupling intervals and accelerated idioventricular rhythms (fig. 1). They are usually transient, hemodynamically well tolerated and occur closely related to the time of reopening of the infarct vessel ${ }^{9}$.

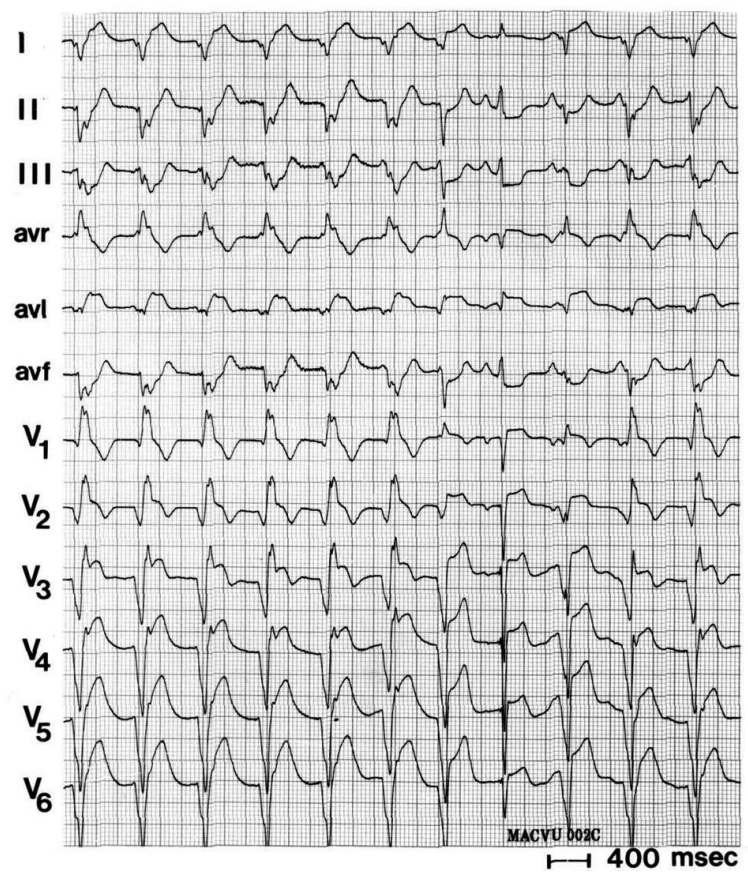

Figure 1: Example of Accelerated idioventricular rhythm

ECG of a patient with an accelerated ventricular rhythm (AIVR) followed by a captured beat and fusion beat after which the AIVR continues. This ECG shows the characteristic ventricular rhythm of $100 \mathrm{bpm}$ in combination without visible $p$-waves until a ventricular beat originated from another part of the ventricles after which a captured beat is visible followed by a fusion beat.

Our group developed a quantitative method to distinguish reperfusion VA bursts from background arrhythmias during STEMI and reperfusion². VA bursts correlates significantly with larger IS even in the absence of microvascular obstruction (MVO) or with optimal myocardial blush grade ${ }^{6,8}$, consistently suggesting they are a signal of injury occurring further downstream at myocellular level ${ }^{3}$. It has been suggested that the initial area at risk (AAR) is related to the occurrence of VA bursts and therefore the correlation with larger infarct size. 
AAR is a known determinant for final infarct size, in combination with factors such as the duration of infarction, the extent of collateral flow and the success of revascularization attempt ${ }^{10-12}$. Because $A A R$ is an important prognostic marker, its accurate measurement has been pursued using various imaging modalities, including SPECT imaging and, more recently, cardiovascular magnetic resonance imaging (CMR). One such method is the endocardial surface area (ESA), the percentage of infarcted endocardial border of the left ventricle measured on delayed enhancement (DE-)CMR images. DE-CMR allows accurate measurement of irreversible myocardial injury ${ }^{13}$. ESA is based on the principle that the lateral extent of irreversible injury is completed within 40 minutes after coronary occlusion and therefore matches the lateral boundaries of the $\mathrm{AAR}^{10}$. Longer duration of ischemia will only result in progression of irreversible injury towards the epicardium as a transmural wave front, while ESA won't change ${ }^{14,15}$.

We sought to investigate whether VA burst is related to larger AAR. If not, VA burst might be a marker of injury on a cellular level after reperfusion i.e. reperfusion injury.

\section{Methods}

\section{Study population}

Consecutive patients included in the Maastricht ST-Elevation Myocardial Infarction (MAST) database were studied, presenting with a first acute STEMI at Maastricht University Medical Centre from August 2006 to March 2008. STEMI was defined according to ECG and enzymatic criteria according to active consensus document ${ }^{16}$. As an enzymatic marker we used the cardiac troponin T test of Roche Diagnostics (Basel, Switzerland) which is elevated if $\geq 0.05 \mathrm{ng} / \mathrm{ml}$.

As previously described ${ }^{17}$, inclusion criteria were: (1) symptoms consistent with an acute STEMI lasting for more than 30 minutes but less than 6 hours, (2) ST-elevation of more than $1 \mathrm{~mm}$ in anatomically adjacent leads in the initial ECG, (3) primary $\mathrm{PCl}$, (4) availability of CMR images. Exclusion criteria were: (1) age below 18 years, (2) cardiogenic shock, (3) pregnancy, (4) inability to obtain informed consent, (5) standard contra-indications for CMR, (6) absence or poor quality ECG-Holter recording, (7) previous myocardial infarction, (8) absence of or poor quality CMR images unreliable for infarct determination, (9) absence of successful epicardial flow restoration defined as TIMI flow $\leq 2$, (10) inability to obtain stable ST recovery within $240 \mathrm{~min}$, and (11) late ST re-elevation.

Approval of the study was granted by the Medical Ethical Committee of corresponding hospital (MAST, MEC 05-199) and written informed consent was obtained from all patients included.

\section{Angiographic TIMI flow assessment}

TIMI flow grade assessment was performed by the angiographic core laboratories (Academic Medical Centre, Amsterdam, The Netherlands and Maastricht University Medical Centre, Maastricht, 
The Netherlands) post-procedural and blinded to all other data. TIMI flow was graded according to the TIMI trial classification ${ }^{18}$.

\section{ECG data acquisition}

Continuous, high-fidelity, digital, 12-lead ECG Holter recording (NEMON 180+, Northeast Monitoring, Maynard, MA, USA) was started before $\mathrm{PCl}$ and continued for an average of 24 hours. This system provided the source data for both continuous ST-segment recovery and ventricular arrhythmia burst analyses on a single time track. Quantitative ST-segment recovery analysis was performed on median beat 12-lead ECGs every 60 seconds. Quantitative ventricular arrhythmia analysis was performed on 3-lead beat-to-beat Holter. ST and VA analyses were performed by independent experts blinded to all other patient and core laboratory data through the collaborative eECG core laboratory program (ST-analyses Duke Clinical Research Institute core lab Durham, North Carolina, USA / VA analyses Maastricht University Medical Centre eECG Core lab Maastricht, The Netherlands) using NEMON Holter for Windows software (NorthEast Monitoring, Inc. Maynard, Massachusetts, USA)

\section{Continuous ST recovery analysis}

Methods and criteria for continuous 12-lead ST-segment recovery analysis and reperfusion of the culprit lesion have been described in detail previously ${ }^{19}$. In short, peak ST-segment deviation is determined based on the lead with the peak deviation taken from the most abnormal ECG recorded during monitoring. Stable and complete ST-segment recovery is defined as $\geq 50 \%$ recovery from previous peak ST-segment levels in the most deviated lead within 240 minutes, lasting $>4$ hours without further ST-segment re-elevation (>100 uV). Late ST (re-)elevation defining epicardial vessel re-occlusion ( $>150 \mathrm{uV}$ re-elevation in the most abnormal lead evolving in $<60$ minutes) or $<50 \%$ ST-segment recovery indicating microvascular insufficiency were used to exclude patients with suboptimal reperfusion in the current analysis.

\section{Quantitative rhythm analysis}

For beat-to-beat quantitative rhythm analysis on all digital 3-lead Holter recordings, Holter 5 software (Northeast Monitoring, Maynard, MA, USA) was used ${ }^{2}$. All automatically assigned waveform labels were manually verified for each cardiac cycle from each subject to ensure accurate VA capture according to predefined criteria for ECG interpretation of VAs ${ }^{2,3}$. Fusion beats (normally conducted ventricular activation fused with ventricular premature complex (VPC) morphology) were also considered VPCs. Ventricular fibrillation was excluded from the analysis; every ventricular complex was counted independent of the length of the arrhythmia. To generate quantitative VA rates over a $24 \mathrm{~h}$ period, total VPC counts, for which no distinction between the types of VPC was made, were bundled into 5 min blocks for temporal correlation with stable ST-segment recovery and angiographic observations. (Fig. 1) 


\section{Defining VA burst}

Quantitative VA rates over the course of Holter recordings were incorporated in a statistical outlier detection method to automatically separate outliers of VA rates ('VA bursts'), from subject-specific background VA counts. Reperfusion VA bursts were defined as VA bursts if concomitant with or subsequent to angiographic documentation of re-established TIMI 3 flow in the infarct related artery. Study subjects were dichotomously classified into the 'reperfusion VA burst' group or the 'no burst' group. More detailed description of the characterization of reperfusion VA bursts has been published by Majidi et al $^{2}$.

\section{Cardiovascular magnetic resonance imaging protocol}

CMR was performed $5 \pm 2$ days days after admission. Images were acquired on a 1.5T MRI system (Intera, Philips Medical Systems, Best, The Netherlands) with a dedicated five-element phased array surface coil. For functional analysis, ECG-gated cine images were obtained in the short axis plane covering the entire LV using a segmented steady-state free precession sequence [average repetition (TR) and echo time (TE) 3.8/1.9 ms, respectively, flip angle $50^{\circ}$, pixel size $1.36 \times 1.36 \mathrm{x}$ $6 \mathrm{~mm}$ (slice gap $4 \mathrm{~mm}$ ), typically 22-25 phases per cardiac cycle]. Delayed enhancement (DE-) CMR was performed $10 \mathrm{~min}$ after an intravenous bolus of $0.2 \mathrm{mmol} / \mathrm{kg}$ body weight gadoliniumdiethylenetriaminepentaacetic acid (Magnevist ${ }^{\circledR}$, Bayer Schering Pharma, Berlin, Germany) using a breath-hold three-dimensional inversion-recovery gradient-echo sequence [average TR/TE 3.9/2.4 $\mathrm{ms}$, multi-shot (50 profiles/shot) segmented partial echo readout every heart beat (TFE), flip angle $15^{\circ}$, reconstructed pixel size $1.56 \times 1.56 \times 6 \mathrm{~mm}$ ]. The inversion time that optimally suppressed signal of non-infarcted myocardium (typical range $200-280 \mathrm{~ms}$ ) was determined with a preceding LookLocker sequence.

\section{DE-CMR image analysis}

All CMR images were analysed independently by two observers and blinded to clinical data, using commercially available software (CAAS MRV 4.3, Pie Medical Imaging, Maastricht, The Netherlands). Interobserver agreement was excellent ( $\mathrm{K}$ value 0.9 ). Discrepancies were resolved in consensus. On all short-axis cine slices, endocardial and epicardial borders were manually traced, excluding the papillary muscles, in the end-diastolic and end-systolic phases to determine left ventricular enddiastolic volume (LVEDV), end-systolic volume (LVESV), stroke volume (LVSV), ejection fraction (LVEF) and end-diastolic mass (LV mass). These parameters were indexed for body surface area.

Likewise, endocardial and epicardial contours were manually traced on all DE-CMR images covering the whole LV. Infarct size (IS) was quantified using an SI threshold of $>5$ SD above a remote non-infarcted region and, if present, included central area of hypoenhancement within the hyperenhanced area (i.e. microvascular obstruction). IS was expressed as a percentage of total LV mass. The transmural extent of infarction was calculated by dividing the hyperenhanced volume by the total volume of the segment involving the infarct. MVO was calculated separately as the difference in IS with and without exclusion of any central dark hypoenhanced areas and was 
expressed as a percentage of total LV mass. In each DE-CMR short axis slice, ttotal endocardial border length and of the hyperenhanced (infarcted) border length were measured manually to determine ESA. Total LV infarct ESA was calculated as a percentage of all summed single slice hyperenhanced endocardial border lengths (including areas of microvascular obstruction) divided by all summed single slice total endocardial length of the whole left ventricle. (See supplement 1 , showing tracings of only a single slice)

\section{Statistical analysis}

Univariable comparisons for baseline characteristics and outcomes for subjects with and without VA burst were made using the student t-test for continuous variables that were normally distributed, the Wilcoxon rank sum test for non-normally distributed continuous variables, and Fisher's exact test for dichotomous variables. A p- value of $<0.05$ was considered statistically significant and all tests were two-sided. Data were analyzed using IBM SPSS statistics software version 19. (IBM, Armonk, New York, USA)

Because of population size and the amount of covariates necessary to provide additional information, multivariable analyses were not performed.

\section{Results}

\section{Patient characteristics}

Study population consisted of all 65 analyzable "optimal reperfusion" patients from a total of 102 included in the MAST study. Reasons for exclusion were, inadequate holter recordings $(n=7)$, presented with TIMI 3 flow before PCI $(n=13)$, TIMI 3 flow could not be established after PCI $(n=$ 10), withdrawal of informed consent before CMR recording $(n=1)$, poor quality CMR study $(n=3)$, stable ST reperfusion was not achieved $(n=3)$, and occurrence of late ST re-elevation ( $N=1)($ Fig. 2$)$. 


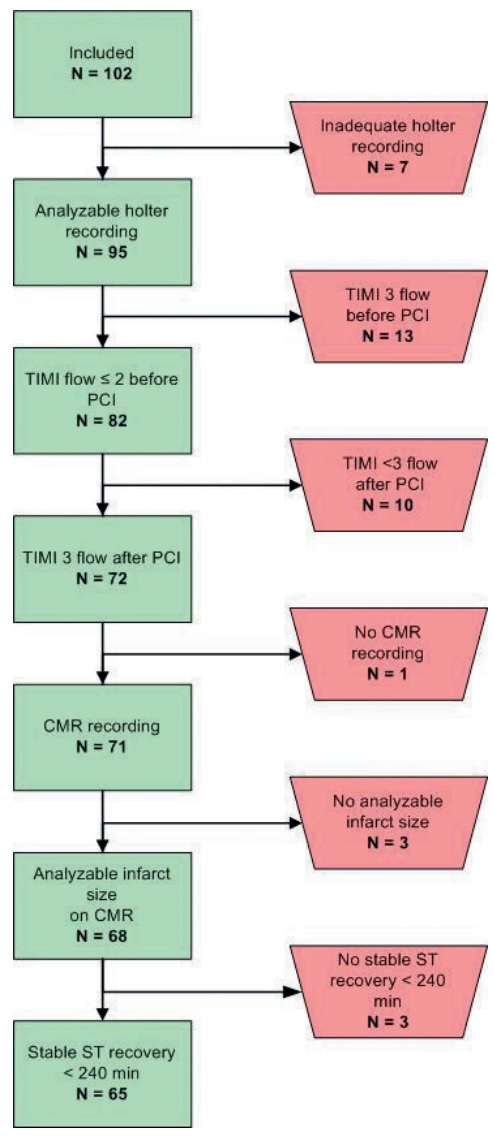

Figure 2: Patient selection

$\mathrm{CMR}=$ cardiac magnetic resonance imaging, $\mathrm{PCl}=$ percutaneous coronary intervention

VA burst was present in 69\% (45/65). Groups with and without VA bursts had a mean age of 58 and 61 years (table 1). In both groups the majority consisted of men (69\% and $85 \%)$ and the rate of (previous) smokers was high (91\% and 95\%). Anterior infarction was present in a minority (15\% and $24 \%)$. 


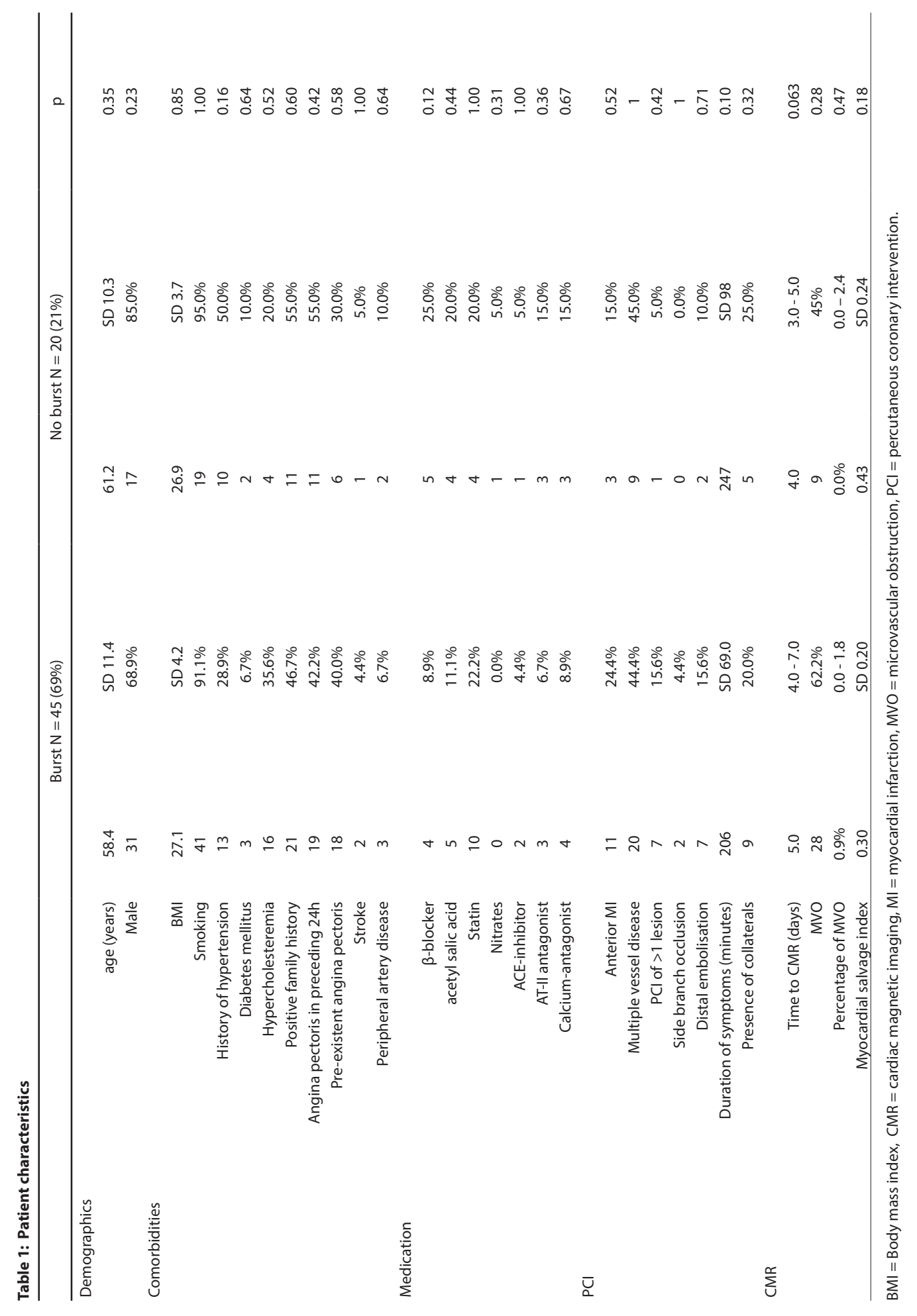




\section{VA bursts}

IS as recorded by CMR (median at day 5) was significantly larger in the optimal reperfusion group with VA burst than with no VA burst (16.6\% vs. 9.3\%; $p=0.03$ ). (Fig. 3 )

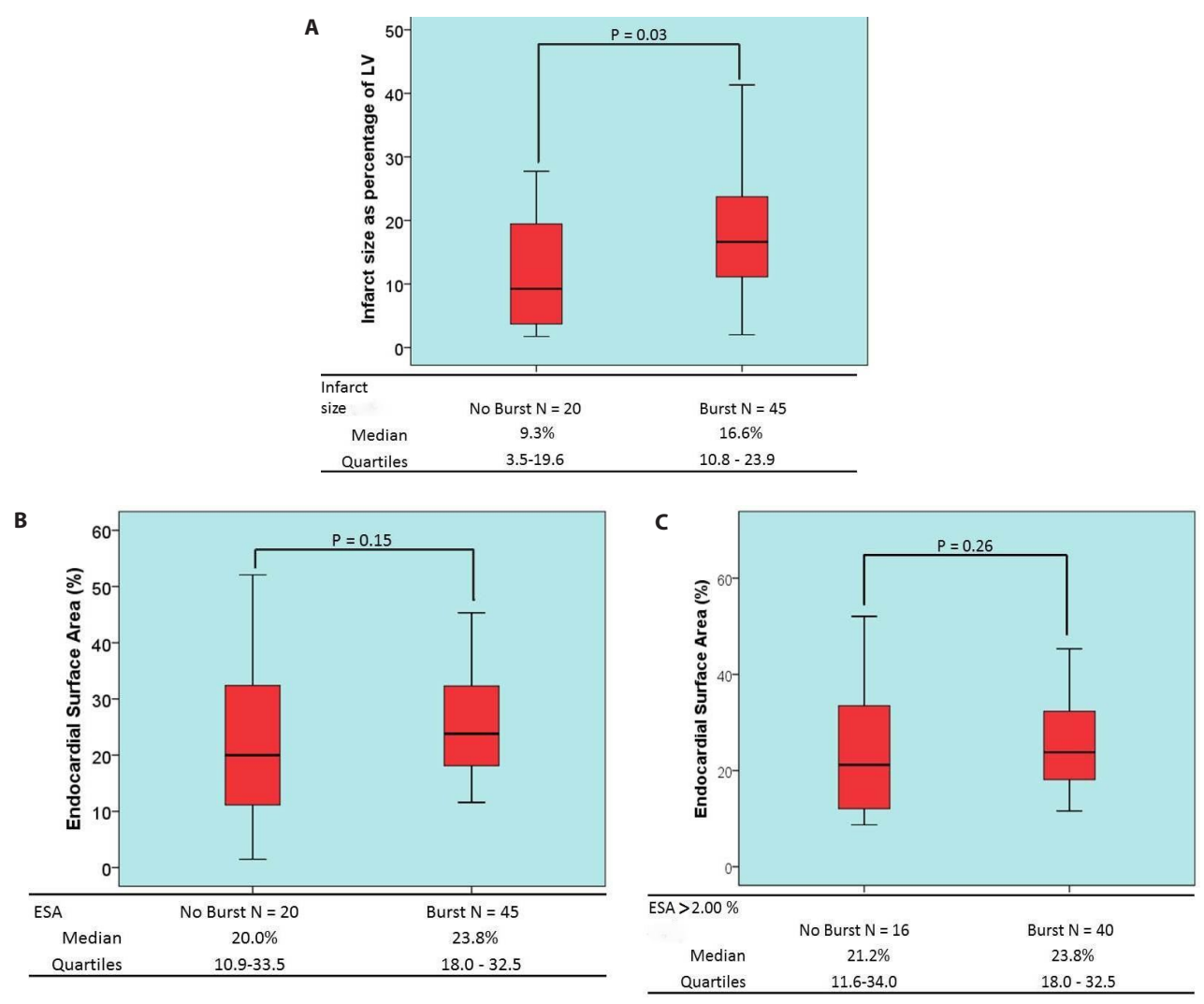

Figure 3: Boxplots displaying the differences in infarct size and area at risk between presence or absence of VA Burst A Difference in infarct size determined with DE-CMR reported as median and quartiles.

B: Difference in Area at risk determined with endocardial surface area reported as median and quartiles

C: Difference in Area at risk determined with endocardial surface area when excluding infarcts $<2 \%$ on DE-CMR reported as median and quartiles

In contrast, AAR by infarct ESA showed no significant differences between the groups with and without VA burst (20.0\% vs $23.8 \% ; p=0.15)$ (Fig. 3). Because infarct ESA has shown poor correlations for small infarcts or for short periods of ischemia, a secondary analysis excluding patients with small infarcts (<2.00\%) on DE-CMR was performed excluding 4 patients with VA burst and 5 without. Within this subgroup infarct ESA still did not differ between the group with and without VA burst ( $21.2 \%$ vs $23.8 \% ; p=0.26)$. Not only did AAR measurements show no significant differences between both study groups, neither did MVO size $(0.0 \%$ vs $0.9 \% ; p=0.47)$ on CMR. 


\section{Discussion}

These data confirm previous findings that in patients with optimal reperfusion by angiographic and ST-segment recovery, larger IS is found in the patients with VA burst ${ }^{2-4,6-8}$. More importantly, this is the first study to show that even though IS is significantly larger if VA burst is present, AAR did not significantly differ between both groups. (as illustrated in supplement 1) These findings in combination with previous findings suggest that VA bursts correlation with larger IS is not caused by larger AAR or MVO but by a process further downstream at the myocellular level i.e. reperfusion injury

\section{Area at risk assessment}

The most commonly used and therefore considered to be the gold standard for AAR assessment is SPECT with technetium as tracer. It provides information on zones with reduced perfusion regardless of anatomy and it accounts for collateral flow what can limit the ischemic area. However, the method has some important limitations. The perfusion defects that are contributed to the culprit artery may as well be increased or decreased depending on the characteristics of the other coronary arteries $^{20}$. In addition to the analytical limitations, the method is logistically challenging because it requires injection of the tracer before $\mathrm{PCl}$ and imaging needs to be performed within the first hours after the procedure. Such a sequence may interfere with patient care and may be challenging during night time ${ }^{20}$. Furthermore, the radiation dose using this technique is relatively high ${ }^{21}$.

Presently, the gold standard for IS determination is DE-CMR because of its high imaging quality, accuracy, and reproducibility ${ }^{22}$. This technique enables accurate assessment of the lateral borders and of the transmural extent of the myocardial infarct ${ }^{13,23}$. Experimental studies have shown that the endocardial extent of (possible) necrosis is established already at 40 minutes after coronary occlusion. This determines the lateral boundaries of the AAR. The subsequent increases of IS is determined by the transmural wavefront progression of ischemia from the endo- to the epicardial layers. Early revascularisation stops this process and reduces final IS ${ }^{10,24}$. The use of ESA for AAR assessment is based on this "wavefront" mechanism of infarct formation. Good correlations with both angiographic, BARI and APPROACH, scores, SPECT, T2-weighted CMR imaging and pathology findings have been reported ${ }^{15,21,25-28}$. Furthermore, ESA has shown the highest correlation with near transmural infarcts, $R=0.93$, in comparison with other techniques for assessing $A A R^{14}$. However, some studies showed conflicting results ${ }^{29-31}$. The majority of studies found an underestimation by ESA which might be explained by a couple of mechanisms. As previously mentioned is the ESAmethod based of the wave front progression with the border being formed after 40 minutes. $A$ short time between onset of symptoms and reperfusion will result in a border smaller than the extent of AAR. Secondly, a recent study by van der Pals et al. showed a lateral perfusion gradient at the border of the infarct resulting in a smaller border zone measured by $\mathrm{DE}-\mathrm{CM} \mathrm{R}^{32}$. To limit underestimation by ESA we also performed sub-analyses with comparable findings where we excluded patients with IS $<2 \%$ on DE-CMR. A small possible trend towards larger infarct 
size was visible when small infarcts were included in the analyses. However, this possible trend completely disappeared when removing the small infarcts for which the ESA method has shown to be inadequate.

Another method for assessing AAR using CMR is T2-weighted hyperenhanced imaging. This method is based on the concept of increased oedema in the AAR versus necrotic and non-ischemic tissue after reperfusion as found by histopathological animal studies ${ }^{26,27,33-36}$. However, there is disagreement in the cardiovascular imaging community whether the T2-weighted hyperintense area really corresponds with the $A A R^{37-43}$. Reasons for the disagreement may be the different protocols used, the absence of clear borders in water content between AAR and healthy tissue, or whether oedema is detectable beyond the AAR border zone resulting in overestimation of $A A R^{25,38}$. Kim et al also found that T2-weighted hyperintense regions corresponded better with IS than $A A R^{37}$. Because of this controversy regarding the validity of using T2-weighted imaging as a marker for AAR we preferred ESA for AAR assessment.

\section{Mechanism of VA burst as a marker of reperfusion injury}

Our results show that in patients with otherwise apparently optimal reperfusion, final infarct size was significantly larger in the group with VA bursts, while AAR assessment did not significantly differ. This finding makes it unlikely for larger AAR to be pathophysiological related to a burst of reperfusion VA. In a previous study we have found that in the absence of MVO, VA burst predicts larger infarct size excluding microvascular obstruction as the culprit for VA burst ${ }^{6-8}$. The combination of the latter and the present study provides a new insight i.e. that VA burst is neither a marker of larger AAR nor of MVO but of a process happening further downstream at the myocellular level. We have also found that the occurrence of ST recovery is not related to the occurrence of VA burst and that it presence even in a well ST recovered population results in larger infarct size; this finding also excludes ischemia as a mechanism for VA bursts. Taken together, the most straightforward explanation would be that VA burst occurs as the result of reperfusion injury; a phenomenon well described both in the experimental and clinical literature but for which a reliable marker is not yet clinically available ${ }^{44-47}$.

\section{Clinical implications}

Our findings suggest that the occurrence of VA bursts after revascularization in STEMI is an early marker of reperfusion injury. In the PCl era, combining angiography and continuous ECG ST-segment recovery and VA burst creates a quantifiable definition of reperfusion injury suitable for research and even real-time clinical instrumentation applications in catheterisation lab during primary $\mathrm{PCI}$. This implies VA burst to be a new electrobiomarker for early risk assessment after revascularization and a tool to monitor interventions to prevent reperfusion injury. Recently multiple reviews have been published addressing the struggles and failures in finding treatment options to prevent reperfusion injury $^{48-50}$. 


\section{Limitations}

The study population for this sub study was relatively small due to the added in- and exclusion criteria and an extensive study protocol using early and late CMR and 24 hour holter recording. Due to this small population, no multivariable analysis was performed. Nevertheless, already in this small population, AAR did not significantly differ in contrast to significant differences in final infarct size.

Regarding the burst group, we observed shorter duration of ischemia, although larger final infarct size. This finding may be due to chance due to relatively small study groups, but may suggest that the effect of reperfusion injury is more marked than the damage due to ischemia. If correct, this finding underscores the importance of reperfusion injury and means of reducing its effect in the clinical arena.

Finally our findings were done in STEMI patients with TIMI 3 flow and stable ST-recovery after PCI. Therefore the results cannot be translated to populations with other characteristics.

\section{Conclusion}

This is the first study to show that the relation of VA burst with larger final IS is independent from AAR. These results combined with previous information imply that VA burst is a sign of a damaging process occurring further downstream of the microvascular bed independent of AAR, namely of reperfusion injury. This suggests VA burst to be an early clinical electrobiomarker for reperfusion injury.

\section{Funding Sources}

This work was supported by funding from the Hein Wellens Foundation, Maastricht, The Netherlands, and by the MUMC+ Research Fund, Maastricht, The Netherlands

\section{Acknowledgements}

The authors wish to thank the Hein Wellens Foundation and the MUMC+ Research Fund for their support in this project.

\section{Conflict of interest and competing interests}

None 


\section{References}

1 Gorgels A, Vos MA, Brugada P, Wellens HJ. The clinical relevance of abnormal automaticity and triggered activity. Cardiac arrhythmias: Where to go frome here? Mount Kisco, NY: Futura Publishing company; 1987. p. 147-69.

2 Majidi M, Kosinski AS, Al-Khatib SM, Lemmert ME, Smolders L, van Weert A, et al. Reperfusion ventricular arrhythmia 'bursts' in TIMI 3 flow restoration with primary angioplasty for anterior ST-elevation myocardial infarction: a more precise definition of reperfusion arrhythmias. Europace : European pacing, arrhythmias, and cardiac electrophysiology : journal of the working groups on cardiac pacing, arrhythmias, and cardiac cellular electrophysiology of the European Society of Cardiology. 2008;10:98897.

Majidi M, Kosinski AS, Al-Khatib SM, Lemmert ME, Smolders L, van Weert A, et al. Reperfusion ventricular arrhythmia 'bursts' predict larger infarct size despite TIMI 3 flow restoration with primary angioplasty for anterior ST-elevation myocardial infarction. European heart journal. 2009;30:757-64.

4 Majidi M, Kosinski AS, Al-Khatib SM, Smolders L, Cristea E, Lansky AJ, et al. Implications of ventricular arrhythmia "bursts" with normal epicardial flow, myocardial blush, and ST-segment recovery in anterior ST-elevation myocardial infarction reperfusion: A biosignature of direct myocellular injury "downstream of downstream". European heart journal Acute cardiovascular care. 2015;4:51-9.

Engelen DJ, Gressin V, Krucoff MW, Theuns DA, Green C, Cheriex EC, et al. Usefulness of frequent arrhythmias after epicardial recanalization in anterior wall acute myocardial infarction as a marker of cellular injury leading to poor recovery of left ventricular function. The American journal of cardiology. 2003;92:1143-9. van der Weg K, Kuijt WJ, Bekkers SC, Tijssen JG, Green CL, Lemmert ME, et al. Reperfusion ventricular arrhythmia bursts identify larger infarct size in spite of optimal epicardial and microvascular reperfusion using cardiac magnetic resonance imaging. European heart journal Acute cardiovascular care. 2017:2048872617690887.

van der Weg K, Kuijt WJ, Tijssen JG, Bekkers SC, Haeck JD, Green CL, et al. Prospective evaluation of where reperfusion ventricular arrhythmia "bursts" fit into optimal reperfusion in STEMI. International journal of cardiology. 2015;195:136-42.

van der Weg K, Majidi M, Haeck JD, Tijssen JG, Green CL, Koch KT, et al. Ventricular arrhythmia burst is an independent indicator of larger infarct size even in optimal reperfusion in STEMI. Journal of electrocardiology. 2016;49:345-52.

Gorgels AP, Vos MA, Letsch IS, Verschuuren EA, Bar FW, Janssen JH, et al. Usefulness of the accelerated idioventricular rhythm as a marker for myocardial necrosis and reperfusion during thrombolytic therapy in acute myocardial infarction. The American journal of cardiology. 1988;61:231-5.

Reimer KA, Jennings RB. The "wavefront phenomenon" of myocardial ischemic cell death. II. Transmural progression of necrosis within the framework of ischemic bed size (myocardium at risk) and collateral flow. Laboratory investigation; a journal of technical methods and pathology. 1979;40:633-44. Reimer KA, Jennings RB. The changing anatomic reference base of evolving myocardial infarction. Underestimation of myocardial collateral blood flow and overestimation of experimental anatomic 
infarct size due to tissue edema, hemorrhage and acute inflammation. Circulation. 1979;60:866-76. Reimer KA, Lowe JE, Rasmussen MM, Jennings RB. The wavefront phenomenon of ischemic cell death. 1. Myocardial infarct size vs duration of coronary occlusion in dogs. Circulation. 1977;56:786-94. Kim RJ, Fieno DS, Parrish TB, Harris K, Chen EL, Simonetti O, et al. Relationship of MRI delayed contrast enhancement to irreversible injury, infarct age, and contractile function. Circulation. 1999;100:19922002. Versteylen MO, Bekkers SC, Smulders MW, Winkens B, Mihl C, Winkens MH, et al. Performance of angiographic, electrocardiographic and MRI methods to assess the area at risk in acute myocardial infarction. Heart (British Cardiac Society). 2012;98:109-15.

Lonborg J, Engstrom T, Mathiasen AB, Vejlstrup N. Myocardial area at risk after ST-elevation myocardial infarction measured with the late gadolinium enhancement after scar remodeling and T2-weighted cardiac magnetic resonance imaging. The international journal of cardiovascular imaging. 2012;28:145564.

Thygesen K, Alpert JS, White HD. Universal definition of myocardial infarction. Journal of the American College of Cardiology. 2007;50:2173-95.

Bekkers SC, Backes WH, Kim RJ, Snoep G, Gorgels AP, Passos VL, et al. Detection and characteristics of microvascular obstruction in reperfused acute myocardial infarction using an optimized protocol for contrast-enhanced cardiovascular magnetic resonance imaging. European radiology. 2009;19:2904-12. Ganz W. The thrombolysis in myocardial infarction (TIMI) trial. The New England journal of medicine. 1985;313:1018.

Krucoff MW, Croll MA, Pope JE, Pieper KS, Kanani PM, Granger CB, et al. Continuously updated 12-lead ST-segment recovery analysis for myocardial infarct artery patency assessment and its correlation with multiple simultaneous early angiographic observations. The American journal of cardiology. 1993;71:145-51.

Sechtem U. Imaging myocardial area at risk and final infarct size. European Heart Journal Supplements. 2001;3:C36-C46.

Ortiz-Perez JT, Meyers SN, Lee DC, Kansal P, Klocke FJ, Holly TA, et al. Angiographic estimates of myocardium at risk during acute myocardial infarction: validation study using cardiac magnetic resonance imaging. European heart journal. 2007;28:1750-8.

Wagner A, Mahrholdt H, Holly TA, Elliott MD, Regenfus M, Parker M, et al. Contrast-enhanced MRI and routine single photon emission computed tomography (SPECT) perfusion imaging for detection of subendocardial myocardial infarcts: an imaging study. Lancet. 2003;361:374-9.

Wu E, Judd RM, Vargas JD, Klocke FJ, Bonow RO, Kim RJ. Visualisation of presence, location, and transmural extent of healed Q-wave and non-Q-wave myocardial infarction. Lancet. 2001;357:21-8. Maruoka Y, Tomoike H, Kawachi Y, Noguchi K, Nakamura M. Relations between collateral flow and tissue salvage in the risk area after acute coronary occlusion in dogs: a topographical analysis. British journal of experimental pathology. 1986;67:33-42. area at risk with pre- versus post-reperfusion imaging techniques in the pig model. Basic research in cardiology. 2011;106:1247-57. 

by magnetic resonance imaging early after coronary artery occlusion with or without reperfusion. Cardiovascular research. 1993;27:1462-9.

Aletras AH, Tilak GS, Natanzon A, Hsu LY, Gonzalez FM, Hoyt RF, Jr., et al. Retrospective determination of the area at risk for reperfused acute myocardial infarction with $\mathrm{T} 2$-weighted cardiac magnetic resonance imaging: histopathological and displacement encoding with stimulated echoes (DENSE) functional validations. Circulation. 2006;113:1865-70.

Carlsson M, Ubachs JF, Hedstrom E, Heiberg E, Jovinge S, Arheden H. Myocardium at risk after acute infarction in humans on cardiac magnetic resonance: quantitative assessment during follow-up and validation with single-photon emission computed tomography. JACC Cardiovascular imaging. 2009;2:569-76.

Fuernau G, Eitel I, Franke V, Hildebrandt L, Meissner J, de Waha S, et al. Myocardium at risk in ST-segment elevation myocardial infarction comparison of T2-weighted edema imaging with the MR-assessed endocardial surface area and validation against angiographic scoring. JACC Cardiovascular imaging. 2011;4:967-76.

Ubachs JF, Engblom H, Erlinge D, Jovinge S, Hedstrom E, Carlsson M, et al. Cardiovascular magnetic resonance of the myocardium at risk in acute reperfused myocardial infarction: comparison of T2weighted imaging versus the circumferential endocardial extent of late gadolinium enhancement with transmural projection. Journal of cardiovascular magnetic resonance : official journal of the Society for Cardiovascular Magnetic Resonance. 2010;12:18.

31 Wright J, Adriaenssens T, Dymarkowski S, Desmet W, Bogaert J. Quantification of myocardial area at risk with T2-weighted CMR: comparison with contrast-enhanced CMR and coronary angiography. JACC Cardiovascular imaging. 2009;2:825-31. van der Pals J, Hammer-Hansen S, Nielles-Vallespin S, Kellman P, Taylor J, Kozlov S, et al. Temporal and spatial characteristics of the area at risk investigated using computed tomography and T1-weighted magnetic resonance imaging. European heart journal cardiovascular Imaging. 2015;16:1232-40. Jennings RB, Schaper J, Hill ML, Steenbergen C, Jr., Reimer KA. Effect of reperfusion late in the phase of reversible ischemic injury. Changes in cell volume, electrolytes, metabolites, and ultrastructure. Circulation research. 1985;56:262-78.

Whalen DA, Jr., Hamilton DG, Ganote CE, Jennings RB. Effect of a transient period of ischemia on myocardial cells. I. Effects on cell volume regulation. The American journal of pathology. 1974;74:381-97. Jennings RB, Murry C, Reimer KA. Myocardial effects of brief periods of ischemia followed by reperfusion. Advances in cardiology. 1990;37:7-31. Boxt LM, Hsu D, Katz J, Detweiler P, McLaughlin S, Kolb TJ, et al. Estimation of myocardial water content using transverse relaxation time from dual spin-echo magnetic resonance imaging. Magnetic resonance imaging. 1993;11:375-83.

37 Kim HW, Van Assche L, Jennings RB, Wince WB, Jensen CJ, Rehwald WG, et al. Relationship ofT2-Weighted MRI Myocardial Hyperintensity and the Ischemic Area-At-Risk. Circulation research. 2015;117:254-65. Croisille P, Kim HW, Kim RJ. Controversies in cardiovascular MR imaging: T2-weighted imaging should not be used to delineate the area at risk in ischemic myocardial injury. Radiology. 2012;265:12-22. 

imaging to evaluate myocardial salvage and myocardial hemorrhage after acute reperfused STelevation myocardial infarction. Expert review of cardiovascular therapy. 2016;14:843-54. Wince WB, Suranyi P, Schoepf UJ. Contemporary cardiovascular imaging methods for the assessment of at-risk myocardium. Journal of the American Heart Association. 2013;3:e000473.

Bulluck H, White SK, Rosmini S, Bhuva A, Treibel TA, Fontana M, et al. T1 mapping and T2 mapping at 3T for quantifying the area-at-risk in reperfused STEMI patients. Journal of cardiovascular magnetic resonance : official journal of the Society for Cardiovascular Magnetic Resonance. 2015;17:73. Bulluck H, White SK, Frohlich GM, Casson SG, O'Meara C, Newton A, et al. Quantifying the Area at Risk in Reperfused ST-Segment-Elevation Myocardial Infarction Patients Using Hybrid Cardiac Positron Emission Tomography-Magnetic Resonance Imaging. Circulation Cardiovascular imaging. 2016;9:e003900. Mangion K, Berry C. Advances in Magnetic Resonance Imaging of the Myocardial Area at Risk and Salvage. Circulation Cardiovascular imaging. 2016;9.

Turer AT, Hill JA. Pathogenesis of myocardial ischemia-reperfusion injury and rationale for therapy. The American journal of cardiology. 2010;106:360-8.

Prasad A, Stone GW, Holmes DR, Gersh B. Reperfusion injury, microvascular dysfunction, and cardioprotection: the "dark side" of reperfusion. Circulation. 2009;120:2105-12. Moens AL, Claeys MJ, Timmermans JP, Vrints CJ. Myocardial ischemia/reperfusion-injury, a clinical view on a complex pathophysiological process. International journal of cardiology. 2005;100:179-90. Yellon DM, Hausenloy DJ. Myocardial reperfusion injury. The New England journal of medicine. 2007;357:1121-35. Hausenloy DJ, Garcia-Dorado D, Botker HE, Davidson SM, Downey J, Engel FB, et al. Novel targets and future strategies for acute cardioprotection: Position Paper of the European Society of Cardiology Working Group on Cellular Biology of the Heart. Cardiovascular research. 2017;113:564-85. Rossello X, Yellon DM. A critical review on the translational journey of cardioprotective therapies! International journal of cardiology. 2016;220:176-84. Hausenloy DJ, Yellon DM. Ischaemic conditioning and reperfusion injury. Nature reviews Cardiology. 2016;13:193-209. 


\section{Suplemental figure}

\section{DE-CMR: acute inferior MI}

A

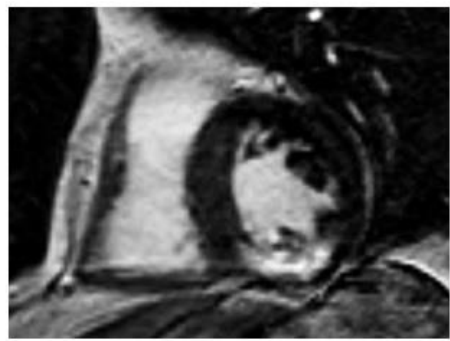

B

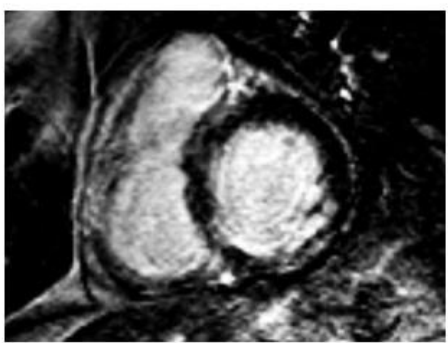

\section{Definitions and measurements}
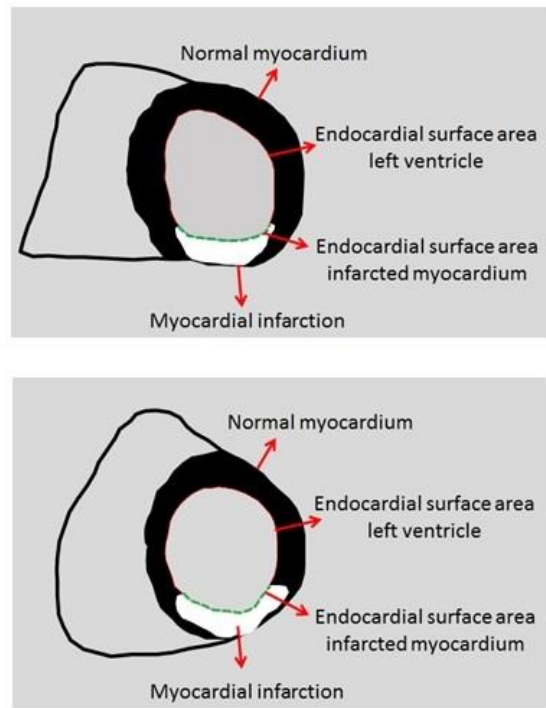

Endocardial surface area $=\frac{\text { Endocardial surface area infarcted myocardium }}{\text { Endocardial surface area left ventricle }} * 100 \%$

Supplement 1: Example of area at risk (AAR) measurement using endocardial surface area (ESA) for 2 different patients Both patients had an AAR of $20 \%$ and an acute inferior wall myocardial infarction. Baseline characteristics were roughly equal; both male, 70 years at the time of infarction and equal time to reperfusion. However patient $A$ did not have VA burst and a final infarct size of $9 \%$, patient B did have VA burst and had a final infarct size of $15 \%$.

In this figure only one slice was used to better visualise the difference between a patient with VA burst vs one without while both having the same AAR and baseline characteristics. For analyses all slices of the left ventricle were used to determine ESA, AAR, and final infarct size. 


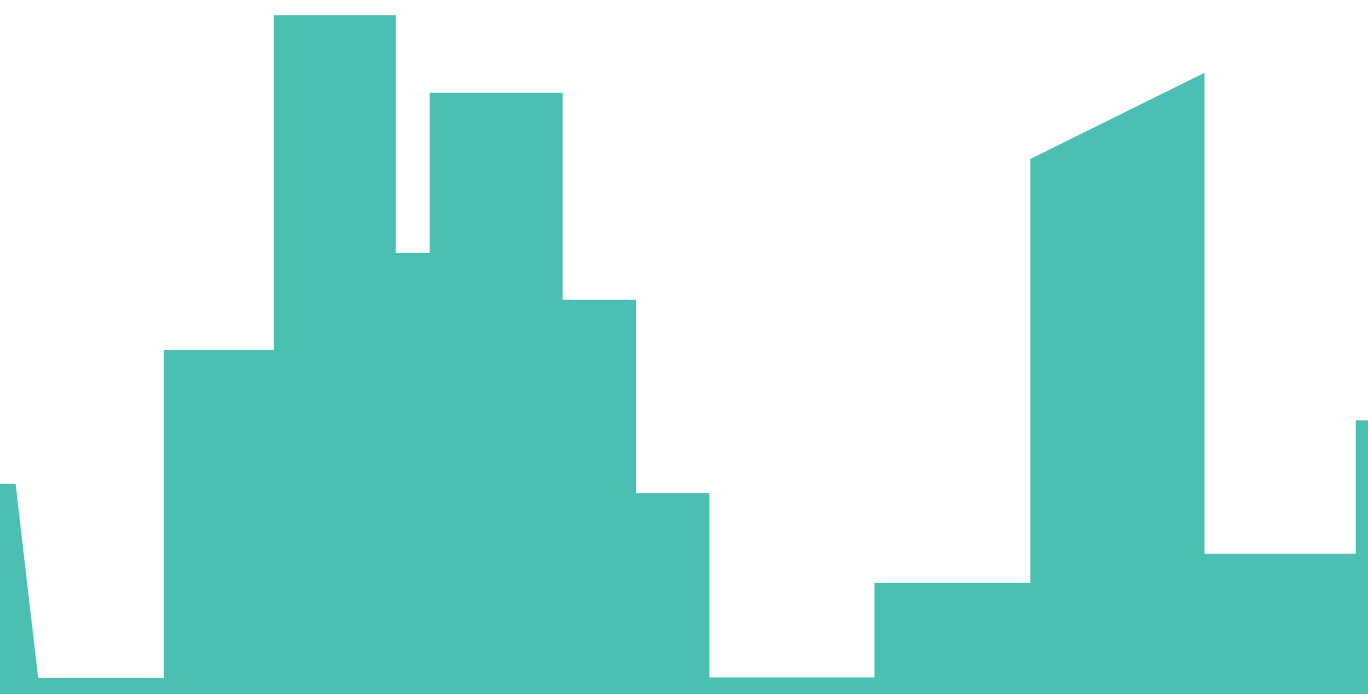

Authors:

Kirian van der Weg, MD*, Frits W. Prinzen, PhDt, Anton P.M. Gorgels, MD, PhD*†

\section{Work was performed in:}

* Maastricht University Medical Centre, Maastricht, The Netherlands

† Cardiovascular Research Institute Maastricht (CARIM), Maastricht University, Maastricht, The Netherlands

Published online ahead of press in the

European Heart Journal Acute Cardiovascular Care 


\section{Chapter 6}

Reperfusion cardiac arrhythmias and their relation to reperfusion induced cell death

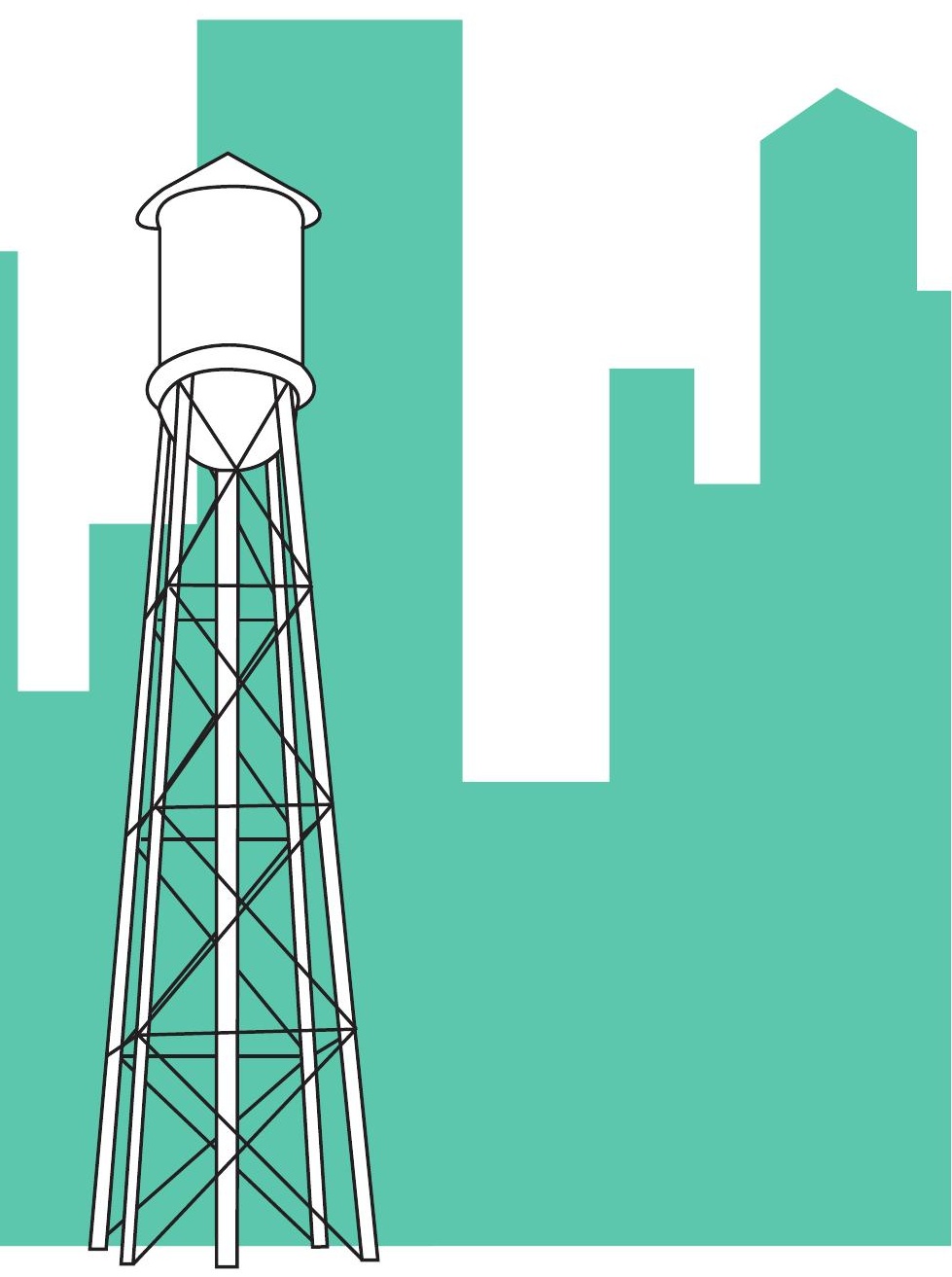




\section{Abstract}

Reperfusion does not only salvage ischemic myocardium but also can cause additional cell death which is called lethal reperfusion injury. The time of reperfusion is often accompanied by ventricular arrhythmias i.e. reperfusion arrhythmias. While both conditions are seen as separate processes, recent research has shown that reperfusion arrhythmias are related to larger infarct size. The pathophysiology of fatal reperfusion injury revolves around intracellular calcium overload and reactive oxidative species inducing apoptosis by opening of the mitochondrial protein transition pore. The pathophysiological basis for reperfusion arrhythmias is the same intracellular calcium overload that is causing fatal reperfusion injury. Therefore both conditions should not be seen as separate entities but as one and the same process resulting in two different visible effects. Reperfusion arrhythmias could therefore be seen as a potential marker for fatal reperfusion injury. 


\section{Introduction}

Reperfusion injury is the damage caused by inflammation, oxidative injury, and electronic imbalance as the result of the return of blood flow to previous ischemic tissue. Reperfusion of ischemic myocardial tissue by thrombolysis or percutaneous coronary intervention ( $\mathrm{PCI})$ is essential to effectively reduce infarct size and increase clinical outcomes in patients presenting with acute myocardial infarction (AMI). However restoration of oxygenated blood flow also induces reperfusion injury'. Lethal reperfusion injury is defined as myocardial cell damage and/or death occurring as a result of the reperfusion of ischemic but still viable cells. Clinical characteristics include an increase in chest pain and/or ST elevation, and a secondary plasma enzyme level rise after revascularization ${ }^{2}$. Reperfusion can be accompanied by a high density of ventricular arrhythmias, typically consisting of ventricular premature beats with long coupling intervals and accelerated idioventricular rhythms typically starting within the first 20 minutes of reperfusion (Fig. 1) 3. $^{3}$

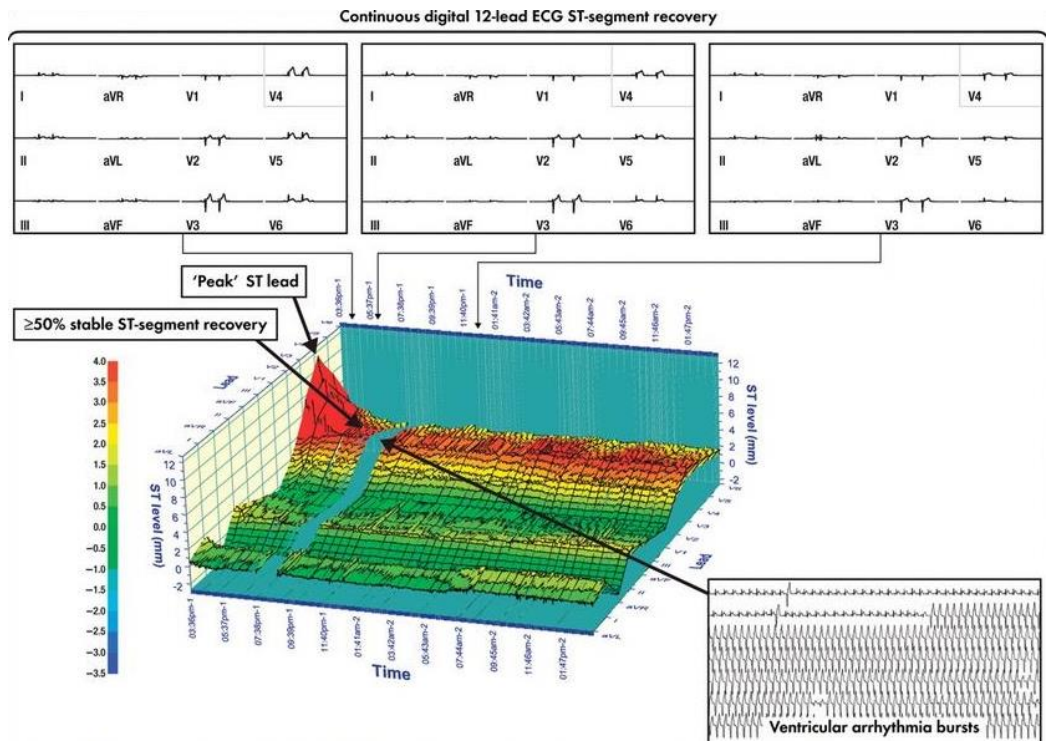

\section{Figure 1:}

Three-dimensional graphic output from 12-lead digital ECG monitor (NEMON 180+, NorthEast Monitoring, Inc.), showing STsegment level $(\mathrm{mm})(\boldsymbol{Y}$-axis) for all 12 leads ( $\boldsymbol{Z}$-axis) with respect to time ( $\boldsymbol{X}$-axis) in a study subject with anterior STEMI treated with primary PCI presented as abrupt ST-segment resolution anterior myocardial wall leads V2-V6; V4 is the peak ST lead. The three upper panels show representative 12 lead-ECG's with resolving ST-elevation, best seen in lead V4. The substantial data gap in the graphic at the time of ST-elevation resolution was caused by a sudden increase ('bursts') of VAs from which ST-segment levels were excluded for graphic three-dimensional continuous ST-segment recovery visualization (from Majidi et al. Europace 2008;10:988-997)

In the thrombolytic era, without the support of angiographic imaging these arrhythmias were considered a beneficial sign i.e. reopening of the infarct vessel by solution of the occluding clot. 
With the advent of percutaneous coronary intervention of the culprit coronary vessel it was found that ventricular reperfusion arrhythmias were associated with increased infarct size and decreased ventricularfunctioning despiteoptimalepicardialandmicrovascularflowand equalarea atrisk (AAR) ${ }^{3-9}$. These findings suggest that the pathophysiological mechanisms of lethal reperfusion injury at the cellular level and reperfusion arrhythmias are intertwined. This review will focus on the pathophysiological mechanisms behind these occurrences and the clinical implications.

\section{Myocellular death in ischemic heart disease}

Cell death in the setting of acute myocardial infarction and reperfusion can occur as a result of 3 different mechanisms. First because of ischemia induced necrosis after extended time of ischemia; furthermore because of microvascular obstruction(MVO) occurring after epicardial reperfusion or third as a result of injury caused by reperfusion of ischemic but viable myocardium, i.e. lethal reperfusion injury ${ }^{1,10-15}$. For the purpose of this review we will focus on lethal reperfusion injury but also give a short overview of the changes during ischemia and the pathophysiology of MVO.

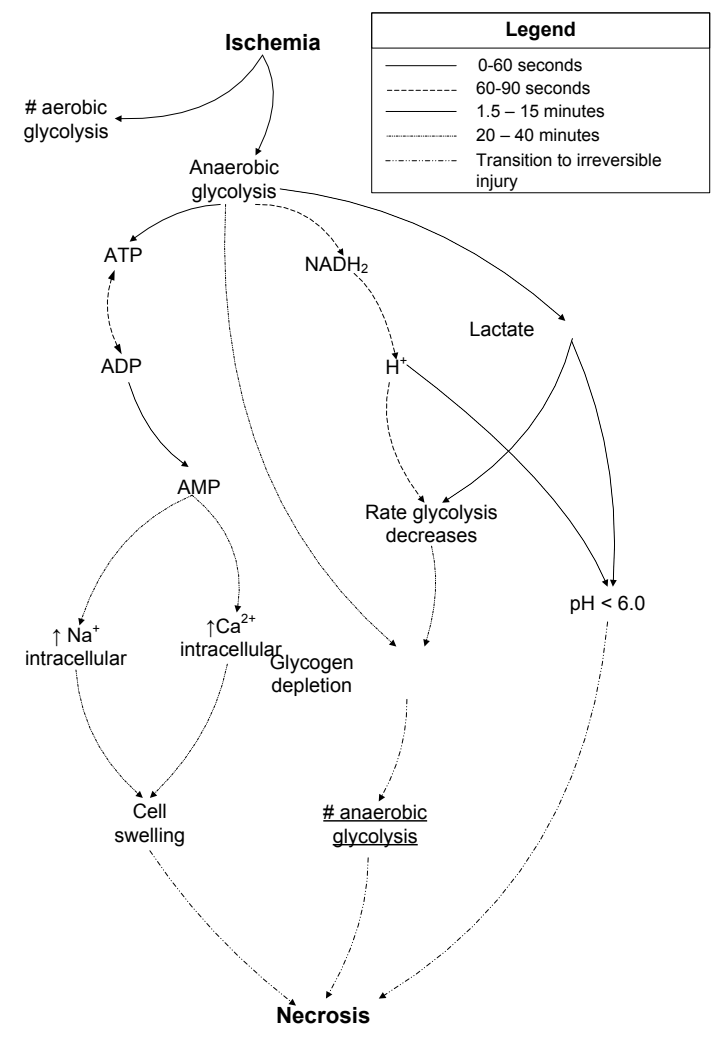

Figure 2: Schematic representation of the sequence of events following onset of ischemia 


\section{Ischemic changes}

In the first 10 seconds of ischemia oxyhemoglobin is exhausted and aerobic metabolism ceases (Fig. 2) ${ }^{16,17}$. After 15 to 20 seconds anaerobic glycolysis supervenes as the only source of high energy phosphate. At the same time formation of $\mathrm{NADH} 2$ is favored above NAD formation and extracellular potassium concentrations start to rise, inducing arrhythmias ${ }^{16-19}$. After 60 to 90 seconds the glycolysis starts to slow markedly because of the sarcosplasmic NADH2/NAD ratio and low $\mathrm{pH}$. At this time the majority of available ATP is used for mitochondrial ATPase and myocardial contraction ceases $^{15,20-22}$. As ischemia persists for 10-15 minutes, $\mathrm{Na} / \mathrm{K}$ ATPase activity causes a slight decrease in intracellular sodium while anaerobic glycolysis causes formation of xanthine and hypoxanthine and $\mathrm{pH}$ lowering below 6 due to the intracellular rise in lactate and $\mathrm{H}^{+23}$. After 20-40 minutes of ischemia, myocytes reach the last phase of reversible injury characterized by glycogen depletion, swelling of mitochondria, and further rise of intracellular sodium and calcium ${ }^{16-18,20-24}$.

Necrosis will extend from endocardium to epicardium in a wavefront manner finally causing transmural necrosis the longer ischemia persists ${ }^{25,26}$.

\section{Microvascular obstruction}

MVO is caused by two different processes, first by obstruction of the microvasculature by micro particles coming from the atherosclerotic plaque at the obstruction site that can become detached during $\mathrm{PCl}^{27}$. The second process involves cellular changes at the microvascular and myocellular level and is induced by the local ischemia followed by reperfusion process (Fig. 3A). Experimental research in rabbits has shown that expansion of MVO occurs during the first 8 hours after reperfusion with almost a tripling between 2 and 120 minutes after reperfusion ${ }^{28-30}$. MVO due to cellular changes induced by reperfusion can cause luminal obstruction either from internal or by external compression of the capillaries ${ }^{14,31,32}$. The internal obstruction is related to processes such as edema of the endothelium and leukocyte plugging. External compression is due to swelling of myocytes, interstitial edema and hemorrhage. The latter is caused by leakage of ischemic injured capillary walls, while myocyte swelling is related to potassium efflux aggravated by reperfusion. Ischemia followed by reperfusion also activates Inflammation. Endothelial edema is not the only result of inflammation that incites MVO. Damage associated molecular pattern molecules (DAMPs), produced as a result of necrosis, enter the circulation upon reperfusion and activate toll like receptors (TLRs) which in turn produce cytokines (IL-1, IL-6, and TNFa) causing IL-8 production and neutrophil accumulation (Fig. 3B) 31,33-37. At the same time accumulation of neutrophils is triggered by reactive oxygen species (ROS) ${ }^{15,32}$. IL-8 causes vasoconstriction via decrease of nitric oxide (NO), damage of $\beta$-adrenergic receptors and prostacyclin production. Vasoconstriction is further amplified by the

production of platelet activating factor by neutrophils and IL-8 that activates thromboxane $A_{2}{ }^{15,37,38}$. This decrease in blood flow will aid the luminal obstruction of vessels by neutrophil plugging or thrombus formation by platelet activating factor and complement activation. 
A

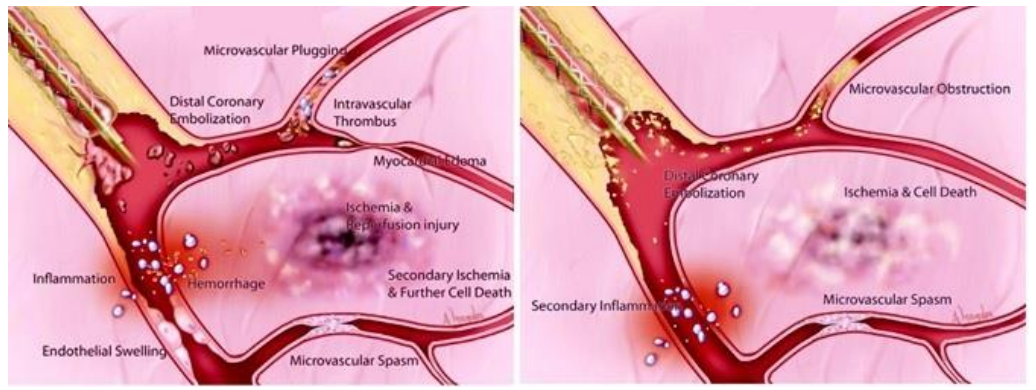

B

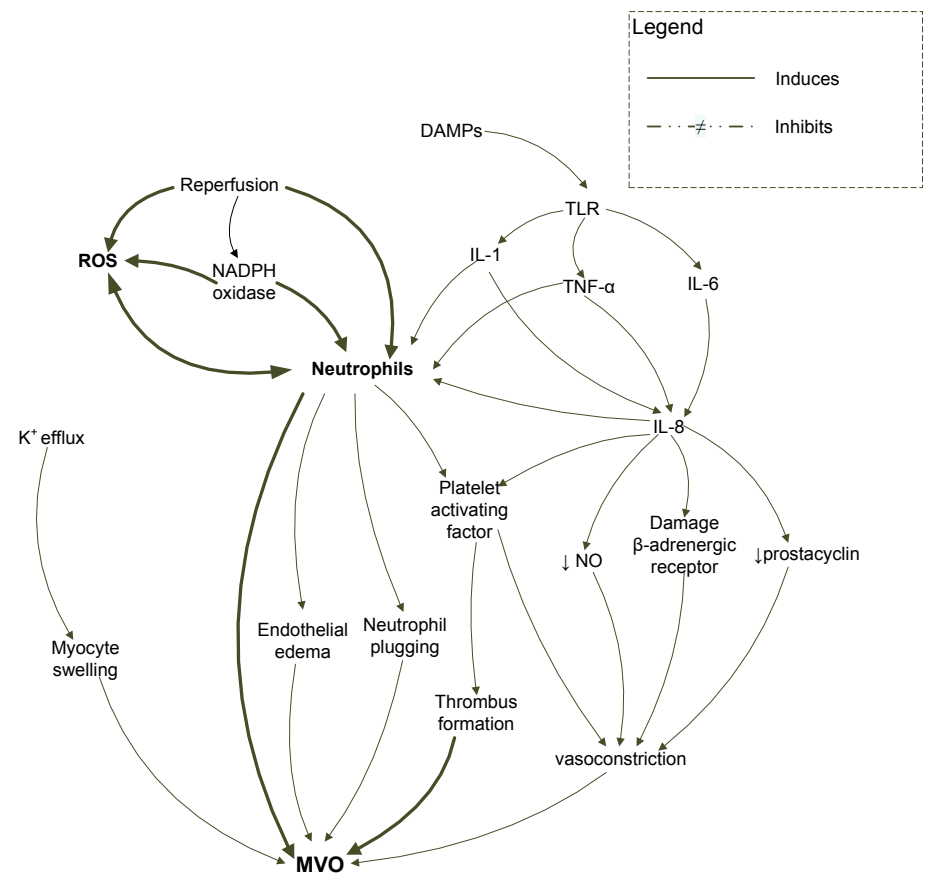

Figure 3:

A Schematic representation of pathophysiological mechanisms that may contribute to reperfusion no reflow in the setting of primary angioplasty for AMI. The vasculature within the necrotic zone is subjected to additional injury after reperfusion. Microvascular spasm and plugging, intravascular thrombus, endothelial swelling, and capillary compression by edema within the adjacent myocardial tissue may lead to microvascular obstruction. Angioplasty-induced distal coronary embolization of plaque and thrombus may compound the vascular obstruction. An inflammatory response may exacerbate this process, which leads to further myocardial ischemia and cell death. Right: Interventional no reflow after non infarct angioplasty is induced by distal coronary embolization of plaque components. Mechanical obstruction of the microvasculature may be accompanied by an inflammatory vascular response that leads to vascular spasm. These mechanisms result in myocardial ischemia and cell death ${ }^{27}$.

B Schematic changes MVO induced by reperfusion 


\section{Reperfusion at the myocellular level}

Irreversible myocellular injury during reperfusion induces necrosis and apoptosis, the latter being an ATP dependent process that is impossible to occur during ischemia. The pathophysiology behind reperfusion injury is roughly based on 3 mutually interfering mechanisms. These mechanisms include intracellular calcium overload, the production of reactive oxygen species (ROS) and neutrophil accumulation (Fig. 4A).

\section{Intracellular calcium overload}

Reperfusion of previous ischemic tissue causes a wash out of extracellular electrolytes and leads to correction of intracellular acidosis with the help of the $\mathrm{H}^{+} / \mathrm{Na}^{+}$exchanger resulting in an increased intracellular sodium concentration. Due to the still present shortage of ATP, correction of the intracellular sodium concentration using $\mathrm{Na}^{+} / \mathrm{K}^{+}$ATPase is deficient and is taken over by the reversed $\mathrm{Na}^{+} / \mathrm{Ca}^{2+}$ exchanger causing an intracellular calcium overload while enhancing potassium efflux ${ }^{1}$ 14, 39. Alongside the correction of acidosis, reperfusion enhances intracellular calcium overload by activation of renin-angiotensin system (RAS) that triggers angiotensin II release which, in combination with the catecholamines released during ischemia and reperfusion, induces further intracellular calcium release $\mathrm{e}^{33,40}$. Moreover, the reperfusion initiated production of ROS increases calcium overload directly by damaging the sarcoplasmic reticulum. Finally the interaction of ROS with free fatty acids leads to alpha-1 adrenergic receptor stimulation which causes calcium overload via interaction with catecholamines ${ }^{1,39,41}$.

\section{ROS production}

Under normal circumstances ROS are only produced in small amounts, being immediately eradicated. However, large amounts are produced under stressful circumstances, such as after myocardial ischemia ${ }^{15}$. Throughout ischemia xanthine oxidase and hypoxanthine are formed and upon reperfusion, oxygen starts to interact with xanthine oxidase and hypoxanthine producing $\mathrm{ROS}^{1,42-44}$. Furthermore, ROS formation is also stimulated by intracellular $\mathrm{Ca}^{2+}$ overload and catecholamines $^{45}$. Moreover, the activation of the mitochondrial benzodiazepine receptor (mBzR) by ROS activates the inner membrane ion channel (IMAC) stimulating ROS formation, known as ROS induced ROS formation ${ }^{46}$. Finally, neutrophils at the site of reperfusion are a major source of ROS, directly and through leukocyte-mediated activation of NADPH oxidase'.

\section{Neutrophil accumulation}

Neutrophils are present around the border of ischemic tissue. Reperfusion enables neutrophils to infiltrate the area at risk. Neutrophil accumulation in non-reperfused myocardium is associated with slow infiltration into the area at risk in the first 12-24 hours of ischemia and reaching peak concentrations after 2 to 4 days and mainly present around the border zone of the infarct ${ }^{47}$. However, neutrophil accumulation is accelerated and increased in reperfused myocardium though still occurring later than ROS formation and intracellular calcium overload, with higher concentrations 
found in the subendocardium compared to subepicardium ${ }^{35}$. Neutrophils are activated via cytokines and ROS. The inflammatory response triggered by the activation and presence of neutrophils directly activates apoptosis, increasing final infarct size.

\section{Opening mitochondrial permeability transition pore}

It has been found that one of the most important key stones in lethal reperfusion injury is the opening of the mitochondrial permeability transition pore (MPTP), the latter being due to large amounts of ROS and intracellular calcium overload $139,41,43-46$. The MPTP is located in the inner membrane of mitochondria. The slight increase of intracellular calcium and ROS during ischemia is not enough to open the pore because of the inhibitory effect acidosis has on the pore. After reperfusion, acidosis is resolved and concentrations of ROS and intracellular calcium increase causing opening of MPTP. Indirectly ROS causes opening of MPTP via activation of inner membrane ion channel (IMAC) and via the induced collapse of mitochondrial membrane potential ${ }^{14,48}$. Besides their stimulatory function in the production of ROS and intracellular calcium, catecholamines also promote mPTP opening. The opening of the mPTP pore causes a decrease of $\mathrm{pH}$, and increases intracellular calcium overload and ROS production (ROS induced ROS production). MPTP opening causes the influx of other molecules inducing an increase of osmotic load with mitochondrial swelling as result in addition to the increase in ROS and intracellular calcium. The swelling eventually causes the mitochondria to rupture and apoptotic proteins to be released. Cytochrome $C$ released via mPTP opening activates the caspase cascade inducing apoptosis ${ }^{49}$. Furthermore, mPTP opening and intracellular calcium overload induce the uncoupling of oxidative phosphorylation. Uncoupling of oxidative phosphorylation triggers apoptosis via ATP hydrolyses leading to activation of degradative enzymes ${ }^{50}$. Finally, intracellular calcium overload can cause myocyte hypercontracture. Excessive hypercontracture can cause myocytes to tear away from tight intercellular junctions during hypercontracture damaging the sarcolemmal of adjacent cells and can cause damage to cytoskeletal elements resulting in apoptosis. This manifests on histological examination as contraction band necrosis ${ }^{51}$.

\section{Reperfusion arrhythmias}

Clinically, reperfusion arrhythmias consist of ventricular arrhythmias, ranging from premature ventricular complexes (PVCs) to VF but mainly consist of accelerated idioventricular rhythms (AIVRs). These arrhythmias have a configuration consistent with an origin from the ischemic (reperfused) area. While first thought of as a beneficial sign, i.e. reopening of the infarct vessel, more recent studies showed that reperfusion without arrhythmias resulted in smaller infarcts in spite of equal initial areas at risk ${ }^{3-8}$. 


\section{Pathophysiologic mechanisms underlying reperfusion arrhythmias}

The pathophysiological process behind reperfusion arrhythmias is not yet fully understood, but some relevant processes are known. Delayed afterdepolarizations (DADs) are likely the most common electrophysiological cause of reperfusion arrhythmias. DADs are oscillations of the membrane potential, occurring after complete repolarization of the preceding action potential. As is also the case in other pathologies, DADs after reperfusion are due to intracellular calcium overload and further amplified via calcium release by the sarcoplasmic reticulum upon the inflow of calcium into the cell ${ }^{44,52-54}$. When the threshold is reached for the depolarizing current, a spontaneous action potential will occur. This action potential can again induce an afterpotential resulting in self-sustaining

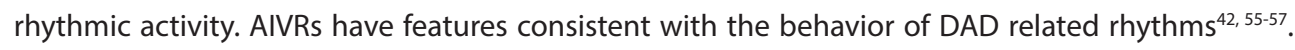
In addition, intracellular calcium overload can cause reperfusion arrhythmias by uncoupling of oxidative phosphorylation, as described above ${ }^{41,44,58}$. Uncoupling of oxidative phosphorylation results in reduced concentrations of ATP, inducing shortening of action potential by closure of $\mathrm{K}_{\text {ATP }}^{+}$ channels ${ }^{48,59}$.

\section{Correlation between fatal reperfusion injury and reperfusion arrhy- thmias}

The pathophysiology of reperfusion arrhythmias has not yet been described in detail. The above described pathophysiology shows a process were intracellular calcium overload is in the center of triggering reperfusion arrhythmias. At the same time is intracellular calcium overload also a key component for inducing cell death in fatal reperfusion injury. It is therefore likely that reperfusion arrhythmias and fatal reperfusion injury aren't two independent processes but two different outcomes of one and the same process as is shown in figure 4A. Consequently, reperfusion arrhythmias can be seen and used as a marker of lethal reperfusion injury.

This connection is supported by previous findings by our group ${ }^{3-9}$. We found, in several independent cohorts, the presence of a "burst" of ventricular reperfusion arrhythmias (VA burst) to be related to clinically significant larger infarct size. This increase remained while correcting for other known factors of increased infarct size. In the presence of optimal epicardial and microvascular reperfusion the significant difference persisted. We tested whether VA burst was related to larger area at risk but no relation was found.

Reperfusion arrhythmias as an electrobiomarker of reperfusion injury are rarely reported in clinical trials focusing on infarct size reducing strategies. The above mentioned pathophysiology and our clinical observations suggest that they could be an important early and unique marker for reperfusion injury. As such reperfusion arrhythmias could become an early marker for risk stratification and for strategies to reduce reperfusion injury. 


\section{Treatment}

\section{Treatment of reperfusion injury}

Prompt restoration of blood flow to the ischemic tissue is essential for optimal salvage and to reduce mortality and morbidity in patients presenting with AMI. However, this does not prevent lethal reperfusion injury that can consist up to $50 \%$ of final infarct size ${ }^{14}$. To prevent and reduce reperfusion injury, knowledge regarding its pathophysiology is essential. Various treatments have been tested and though different in site of action most of them have one common feature: although promising in preclinical trials, phase II and III clinical trials have rarely shown to be successful. Recently, a number of reviews have been published where the various recent trials and controversies are discussed ${ }^{10,13,14,60-62}$. Figure $4 B$ illustrates the different points of action of potential treatment options and how they fit into the pathophysiologic mechanism of reperfusion injury. Above we described the pathophysiological relation between lethal reperfusion injury and reperfusion arrhythmias. However, most studies only focused on limiting final infarct size without taking into account the all or none presence of reperfusion injury. The occurrence of ventricular arrhythmias were not reported in the majority of trials, though those who did showed a reduction in arrhythmias when final infarct size was reduced $33,36,42,53,63-69$.

Reduction of intracellular calcium overload has been an important focus in the prevention of reperfusion injury. Animal trials exist for fast $\mathrm{Na}^{+} / \mathrm{H}^{+}$inhibitors, sodium-channel inhibitors, $\mathrm{Na}^{+} /$ $\mathrm{Ca}^{2+}$ inhibitors, calcium antagonists, NMDA antagonists, and ACE inhibitors ${ }^{33,40,42,52,63,70-74}$. Most have been carried out in rats, though also rabbits, dogs, guinea pig and swine models have been used. The drugs used reduced the incidence of VPBs, VT, and/or VF while at the same time reducing infarct size. In most trials, drugs were administered before induction of ischemia. If administered during ischemia treatments were less effective if effective at all for both arrhythmias as infarct size. Another important factor in reperfusion injury is the production of ROS. Administration of ROS scavengers has shown to reduce VF and infarct size in rats and in some cases even ventricular tachycardia and mortality ${ }^{66,67,71,75,76}$. However in all studies drug administration was done before ischemia induction and the application of ROS scavengers in phase II and III trials did not reduce infarct size.

As discussed above, opening of MPTP is a key component in reperfusion injury and is induced via intracellular calcium overload and ROS. Blockage of this pore by cyclosporine A, a strong MPTP inhibitor, reduced infarct size in animal studies. Also in a recent human pilot clinical trial it has shown to reduce infarct size by $40 \%$ compared to control patients ${ }^{77}$. However, the larger CIRCUS trial found no significant reduction in infarct size ${ }^{78,79}$. None of these trials reported the incidence of reperfusion arrhythmias; therefore the percentage of cases with reperfusion injury, possibly profiting from the intervention was not known. In addition beta-blockers have been used to reduce reperfusion injury, but results have been conflicting. This could have been due to different factors, which were extensively discussed in 
recent reviews ${ }^{80,81}$. Both trials only focused on ventricular fibrillation and none on the incidence of reperfusion arrhythmias.

A

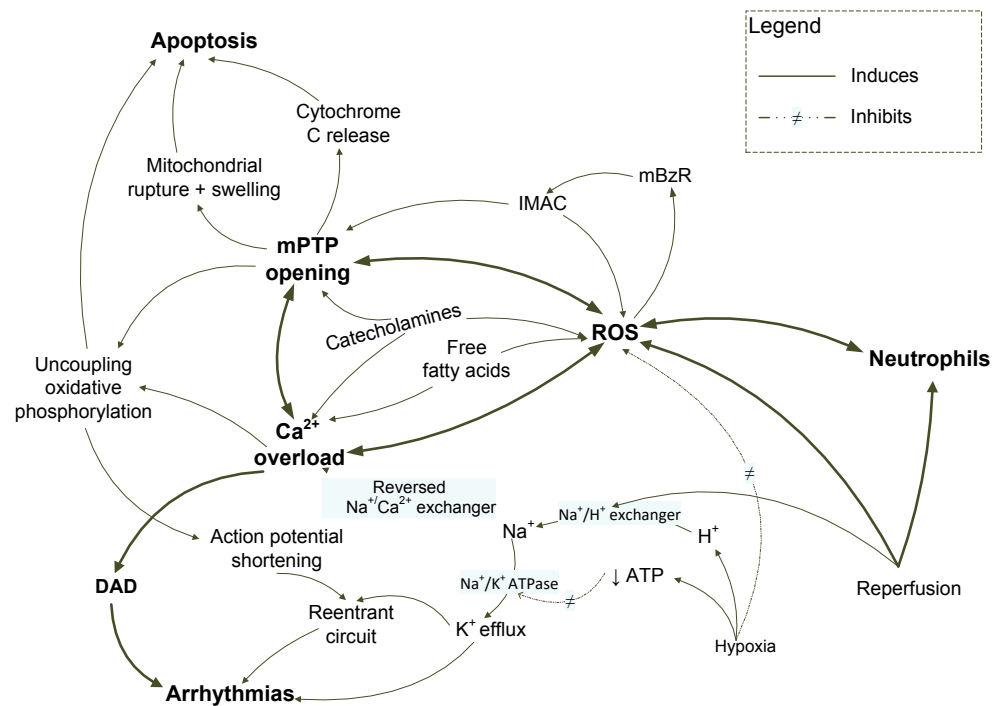

B

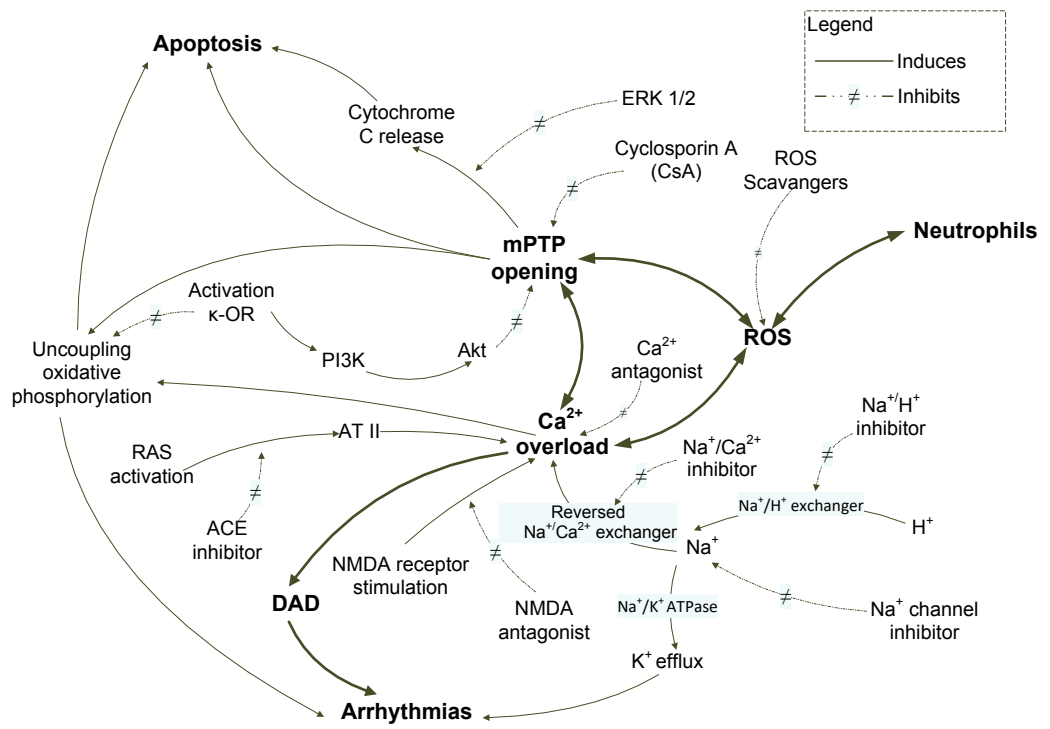

Figure 4:

A Schematic changes lethal reperfusion injury and relation with reperfusion arrhythmias (see text for explanation)

B Locations where trials have tried to prevent lethal reperfusion injury (see text for explanation) 


\section{Pre-, per- and postconditioning}

Pre- per- and postconditioning comprise a particular niche in the prevention and treatment of reperfusion injury, because these interventions were not only beneficial in animal studies but also in human trials ${ }^{62,82-85}$. Preconditioning involves the administration of short periods of ischemia or other interventions to the heart preceding a longer period of ischemia. Indeed, the action of preconditioning seems to be supported by the observation of smaller infarct size in patients with angina in the 24 hours preceding AMI and has shown to reduce morbidity and mortality after coronary artery bypass graft surgery ${ }^{86-89}$. Its "anticipatory" aspect allows possible application in patients receiving cardiopulmonary bypass surgery ${ }^{90}$ but clearly precludes $\mathrm{AMI}$ as an indication. The administration of short periods of ischemia during or after ischemia (peri- and postconditioning) resulted in the same beneficial effects as preconditioning with the advantage of being applicable in patients presenting with AMI. These interventions were applied mechanically by balloon re-inflation after balloon angioplasty, pharmacologically and by brief periods of ventricular pacing ${ }^{91}$. In addition, "remote conditioning" has been studied: ischemic stimuli applied to other parts of the human body, for example by brachialis compression via cuff inflation ${ }^{92-95}$. Infarct size reduction reportedly was as high as $50 \%$ in animal studies ${ }^{39}, 96-99$. However, most clinical trials have been neutral, currently preventing implementation into daily practice ${ }^{100}$. The disappointing translation from experimental studies to clinical trials could be caused be a number of reasons and are thoroughly discussed by Heusch ${ }^{62}$. Peri- and postconditioning could be promising in humans, but conflicting results remain and the optimal protocol is still unknown. A different approach in translating results of experimental studies in to clinical trials, as suggested by Heusch, might be a way to reduce current inconsistencies.

\section{Possible explanations for failure of treatment in patients}

As discussed before, numerous potential treatments have failed to be effective in patients presenting with AMI while being effective in animal studies. Multiple explanations have been proposed such as; difference animals and humans, duration of ischemia and other variabilities in clinical setting i.e. pharmacological intervention only possible after onset ischemia. Another important fact is that reperfusion injury can't be explained as one simple mechanism but consists of redundant mechanisms induced by a sudden change from ischemic to reperfused tissue. Therefore prevention of reperfusion injury is unlikely to be obtained by manipulation of one single mechanism and multiple pathways should be targeted simultaneously. Finally, for yet unknown reasons, reperfusion injury does not occur in every patient leading to dilution of the treatment effect in clinical trials.

\section{Conclusion}

Reperfusion of ischemic tissue is a double edged sword by also causing additional damage to myocardial cells. The genesis of lethal reperfusion injury and reperfusion arrhythmias concentrates around intracellular calcium overload for both events. This conformity in their pathological basis 
led us to conclude that reperfusion arrhythmias and fatal reperfusion injury should be considered to have the same underlying pathophysiology. Reperfusion arrhythmias can therefore be seen as a marker of fatal reperfusion injury instead of an independent entity.

\section{Funding Sources}

This work was supported by funding from the Hein Wellens Foundation, Maastricht, the The Netherlands.

\section{Acknowledgements}

The authors wish to thank the Hein Wellens Foundation for its support in this project.

\section{Conflict of interest and competing interests}

None 


\section{References}

1. Yellon DM and Hausenloy DJ. Myocardial reperfusion injury. N Engl J Med. 2007; 357: 1121-35.

2. Doevendans PA, Gorgels AP, van der Zee R, Partouns J, Bar FW and Wellens HJ. Electrocardiographic diagnosis of reperfusion during thrombolytic therapy in acute myocardial infarction. Am J Cardiol. 1995; 75: 1206-10.

3. Majidi M, Kosinski AS, Al-Khatib SM, et al. Reperfusion ventricular arrhythmia 'bursts' in TIMI 3 flow restoration with primary angioplasty for anterior ST-elevation myocardial infarction: a more precise definition of reperfusion arrhythmias. Europace. 2008; 10: 988-97.

4. Majidi M, Kosinski AS, Al-Khatib SM, et al. Reperfusion ventricular arrhythmia 'bursts' predict larger infarct size despite TIMI 3 flow restoration with primary angioplasty for anterior ST-elevation myocardial infarction. Eur Heart J. 2009; 30: 757-64.

5. Majidi M, Kosinski AS, Al-Khatib SM, et al. Implications of ventricular arrhythmia "bursts" with normal epicardial flow, myocardial blush, and ST-segment recovery in anterior ST-elevation myocardial infarction reperfusion: A biosignature of direct myocellular injury "downstream of downstream". Eur Heart J Acute Cardiovasc Care. 2015; 4: 51-9.

6. van der Weg K, Kuijt WJ, Bekkers SC, et al. Reperfusion ventricular arrhythmia bursts identify larger infarct size in spite of optimal epicardial and microvascular reperfusion using cardiac magnetic resonance imaging. Eur Heart J Acute Cardiovasc Care. 2017: 2048872617690887.

7. van der Weg K, Kuijt WJ, Tijssen JG, et al. Prospective evaluation of where reperfusion ventricular arrhythmia "bursts" fit into optimal reperfusion in STEMI. Int J Cardiol. 2015; 195: 136-42.

8. van der Weg K, Majidi M, Haeck JD, et al. Ventricular arrhythmia burst is an independent indicator of larger infarct size even in optimal reperfusion in STEMI. J Electrocardiol. 2016; 49: 345-52.

9. Engelen DJ, Gressin V, Krucoff MW, et al. Usefulness of frequent arrhythmias after epicardial recanalization in anterior wall acute myocardial infarction as a marker of cellular injury leading to poor recovery of left ventricular function. Am J Cardiol. 2003; 92: 1143-9.

10. Hausenloy DJ, Barrabes JA, Botker HE, et al. Ischaemic conditioning and targeting reperfusion injury: a 30 year voyage of discovery. Basic Res Cardiol. 2016; 111: 70.

11. Hausenloy DJ and Yellon DM. Myocardial ischemia-reperfusion injury: a neglected therapeutic target. $J$ Clin Invest. 2013; 123: 92-100.

12. Hausenloy DJ and Yellon DM. Ischaemic conditioning and reperfusion injury. Nat Rev Cardiol. 2016; 13: 193-209.

13. Heusch G and Gersh BJ. The pathophysiology of acute myocardial infarction and strategies of protection beyond reperfusion: a continual challenge. Eur Heart J. 2017; 38: 774-84.

14. Ibanez B, Heusch G, Ovize M and Van de Werf F. Evolving Therapies for Myocardial Ischemia/Reperfusion Injury. J Am Coll Cardiol. 2015; 65: 1454-71.

15. Monassier JP. Reperfusion injury in acute myocardial infarction. From bench to cath lab. Part I: Basic considerations. Arch Cardiovasc Dis. 2008; 101: 491-500.

16. Jennings RB and Reimer KA. The cell biology of acute myocardial ischemia. Annu Rev Med. 1991; 42: 22546. 
17. Jennings RB, Murry CE, Steenbergen C, Jr. and Reimer KA. Development of cell injury in sustained acute ischemia. Circulation. 1990; 82: II2-12.

18. Jennings RB, Murry $C$ and Reimer KA. Myocardial effects of brief periods of ischemia followed by reperfusion. Adv Cardiol. 1990; 37: 7-31.

19. Klabunde RE. Cardiac electrophysiology: normal and ischemic ionic currents and the ECG. Adv Physiol Educ. 2017; 41: 29-37.

20. Reimer KA, Jennings RB and Tatum AH. Pathobiology of acute myocardial ischemia: metabolic, functional and ultrastructural studies. Am J Cardiol. 1983; 52: 72A-81A.

21. Jennings RB, Schaper J, Hill ML, Steenbergen C, Jr. and Reimer KA. Effect of reperfusion late in the phase of reversible ischemic injury. Changes in cell volume, electrolytes, metabolites, and ultrastructure. Circ Res. 1985; 56: 262-78.

22. Jennings RB and Reimer KA. Acute myocardial ischemia: effects of reperfusion with arterial blood. Artif Cells Blood Substit Immobil Biotechnol. 1994; 22: 253-78.

23. Jennings RB and Reimer KA. Lethal myocardial ischemic injury. Am J Pathol. 1981; 102: 241-55.

24. Reimer KA and Jennings RB. The changing anatomic reference base of evolving myocardial infarction. Underestimation of myocardial collateral blood flow and overestimation of experimental anatomic infarct size due to tissue edema, hemorrhage and acute inflammation. Circulation. 1979; 60: 866-76.

25. Reimer KA and Jennings RB. The "wavefront phenomenon" of myocardial ischemic cell death. II. Transmural progression of necrosis within the framework of ischemic bed size (myocardium at risk) and collateral flow. Lab Invest. 1979; 40: 633-44.

26. Reimer KA, Lowe JE, Rasmussen MM and Jennings RB. The wavefront phenomenon of ischemic cell death. 1. Myocardial infarct size vs duration of coronary occlusion in dogs. Circulation. 1977; 56: 786-94.

27. Jaffe R, Charron T, Puley G, Dick A and Strauss BH. Microvascular obstruction and the no-reflow phenomenon after percutaneous coronary intervention. Circulation. 2008; 117: 3152-6.

28. Ambrosio $\mathrm{G}$ and Tritto I. Reperfusion injury: experimental evidence and clinical implications. Am Heart J. 1999; 138: S69-75.

29. Rochitte CE, Lima JA, Bluemke DA, et al. Magnitude and time course of microvascular obstruction and tissue injury after acute myocardial infarction. Circulation. 1998; 98: 1006-14.

30. Reffelmann T, Hale SL, Li G and Kloner RA. Relationship between no reflow and infarct size as influenced by the duration of ischemia and reperfusion. Am J Physiol Heart Circ Physiol. 2002; 282: H766-72.

31. Basso $\mathrm{C}$ and Thiene $\mathrm{G}$. The pathophysiology of myocardial reperfusion: a pathologist's perspective. Heart. 2006; 92: 1559-62.

32. Williams FM. Neutrophils and myocardial reperfusion injury. Pharmacol Ther. 1996; 72: 1-12.

33. Moens AL, Claeys MJ, Timmermans JP and Vrints CJ. Myocardial ischemia/reperfusion-injury, a clinical view on a complex pathophysiological process. Int J Cardiol. 2005; 100: 179-90.

34. Arumugam TV, Okun E, Tang SC, Thundyil J, Taylor SM and Woodruff TM. Toll-like receptors in ischemiareperfusion injury. Shock. 2009; 32: 4-16.

35. Vinten-Johansen J. Involvement of neutrophils in the pathogenesis of lethal myocardial reperfusion injury. Cardiovasc Res. 2004; 61: 481-97.

36. Murohara T, Kamijikkoku S and Honda T. Increased circulating soluble intercellular adhesion molecule-1 
in acute myocardial infarction: a possible predictor of reperfusion ventricular arrhythmias. Crit Care Med. 2000; 28: 1861-4.

37. Heusch G. The Coronary Circulation as a Target of Cardioprotection. Circ Res. 2016; 118: 1643-58.

38. Qayumi AK, English JC, Godin DV, et al. The role of platelet-activating factor in regional myocardial ischemia-reperfusion injury. Ann Thorac Surg. 1998; 65: 1690-7.

39. Cour M, Gomez L, Mewton N, Ovize M and Argaud L. Postconditioning: from the bench to bedside. J Cardiovasc Pharmacol Ther. 2011; 16: 117-30.

40. Yahiro $E$, Ideishi $M$, Wang $L X$, et al. Reperfusion-induced arrhythmias are suppressed by inhibition of the angiotensin II type 1 receptor. Cardiology. 2003; 99: 61-7.

41. Maxwell SR and Lip GY. Reperfusion injury: a review of the pathophysiology, clinical manifestations and therapeutic options. Int J Cardiol. 1997; 58: 95-117.

42. Lee BH, Yi KY, Lee S and Yoo SE. Effects of KR-32570, a new sodium hydrogen exchanger inhibitor, on myocardial infarction and arrhythmias induced by ischemia and reperfusion. Eur J Pharmacol. 2005; 523: 101-8.

43. Lucchesi BR. Myocardial ischemia, reperfusion and free radical injury. Am J Cardiol. 1990; 65: 14I-23I.

44. Jeroudi MO, Hartley CJ and Bolli R. Myocardial reperfusion injury: role of oxygen radicals and potential therapy with antioxidants. Am J Cardiol. 1994; 73: 2B-7B.

45. Manning AS. Reperfusion-induced arrhythmias: do free radicals play a critical role? Free Radic Biol Med. 1988; 4: 305-16.

46. Biary N, Xie C, Kauffman J and Akar FG. Biophysical properties and functional consequences of reactive oxygen species (ROS)-induced ROS release in intact myocardium. J Physiol. 2011; 589: 5167-79.

47. Reimer KA, Murry CE and Richard VJ. The role of neutrophils and free radicals in the ischemic-reperfused heart: why the confusion and controversy? J Mol Cell Cardiol. 1989; 21: 1225-39.

48. Akar FG, Aon MA, Tomaselli GF and O'Rourke B. The mitochondrial origin of postischemic arrhythmias. $J$ Clin Invest. 2005; 115: 3527-35.

49. Hausenloy DJ and Yellon DM. New directions for protecting the heart against ischaemia-reperfusion injury: targeting the Reperfusion Injury Salvage Kinase (RISK)-pathway. Cardiovasc Res. 2004; 61: 448-60.

50. Buja LM. Myocardial ischemia and reperfusion injury. Cardiovasc Pathol. 2005; 14: 170-5.

51. Piper HM, Abdallah $\mathrm{Y}$ and Schafer $\mathrm{C}$. The first minutes of reperfusion: a window of opportunity for cardioprotection. Cardiovasc Res. 2004; 61: 365-71.

52. Lu HR, Yang P, Remeysen P, Saels A, Dai DZ and De Clerck F. Ischemia/reperfusion-induced arrhythmia in anaesthetized fats: a role of $\mathrm{Na}+$ and Ca2+ influx. Eur J Pharmacol. 1999; 365: 233-9.

53. del Monte F, Lebeche D, Guerrero JL, et al. Abrogation of ventricular arrhythmias in a model of ischemia and reperfusion by targeting myocardial calcium cycling. Proceedings of the National Academy of Sciences of the United States of America. 2004; 101: 5622-7.

54. Akar JG and Akar FG. Regulation of ion channels and arrhythmias in the ischemic heart. Journal of Electrocardiology. 2007; 40: S37-S41.

55. Gorgels A, Vos MA, Brugada P and Wellens HJ. The clinical relevance of abnormal automaticity and triggered activity. Cardiac arrhythmias: Where to go frome here? Mount Kisco, NY: Futura Publishing company, 1987, p. 147-69. 
56. Ravingerova T, Slezak J, Tribulova N, Dzurba A, Uhrik B and Ziegelhoffer A. Free oxygen radicals contribute to high incidence of reperfusion-induced arrhythmias in isolated rat heart. Life Sciences. 1999; 65: 1927 30.

57. Lakireddy V, Lakkireddy V, Bub G, et al. The kinetics of spontaneous calcium oscillations and arrhythmogenesis in the in vivo heart during ischemia/reperfusion. Heart rhythm : the official journal of the Heart Rhythm Society. 2006; 3: 58-66.

58. Aiello EA, Jabr RI and Cole WC. Arrhythmia and Delayed Recovery of Cardiac Action-Potential during Reperfusion after Ischemia - Role of Oxygen Radical-Induced No-Reflow Phenomenon. Circulation Research. 1995; 77: 153-62.

59. Brown DA and O'Rourke B. Cardiac mitochondria and arrhythmias. Cardiovasc Res. 2010; 88: 241-9.

60. Bell RM, Botker HE, Carr RD, et al. 9th Hatter Biannual Meeting: position document on ischaemia/ reperfusion injury, conditioning and the ten commandments of cardioprotection. Basic Res Cardiol. 2016; 111: 41.

61. Hausenloy DJ, Botker HE, Engstrom T, et al. Targeting reperfusion injury in patients with ST-segment elevation myocardial infarction: trials and tribulations. Eur Heart J. 2017; 38: 935-41.

62. Heusch G. Critical Issues for the Translation of Cardioprotection. Circ Res. 2017; 120: 1477-86.

63. Walsh SK, Hepburn CY, Kane KA and Wainwright CL. Acute administration of cannabidiol in vivo suppresses ischaemia-induced cardiac arrhythmias and reduces infarct size when given at reperfusion. British Journal of Pharmacology. 2010; 160: 1234-42.

64. Cheng L, Ma S, Wei L-X, et al. Cardioprotective and antiarrhythmic effect of U50,488H in ischemia/ reperfusion rat heart. Heart and Vessels. 2007; 22: 335-44.

65. Tsai CH, Su SF, Chou TF and Lee TM. Differential effects of sarcolemmal and mitochondrial K-ATP channels activated by 17 beta-estradiol on reperfusion arrhythmias and infarct sizes in canine hearts. Journal of Pharmacology and Experimental Therapeutics. 2002; 301: 234-40.

66. Das B, Sarkar C and Shankar PR. Pretreatment with sarafotoxin $6 c$ prior to coronary occlusion protects against infarction and arrhythmias via cardiomyocyte mitochondrial K-ATP channel activation in the intact rabbit heart during Ischemia/Reperfusion. Cardiovascular Drugs and Therapy. 2007; 21: $243-51$.

67. Imani A, Faghihi M, Sadr SS, Niaraki SS and Alizadeh AM. Noradrenaline Protects In Vivo Rat Heart Against Infarction and Ventricular Arrhythmias Via Nitric Oxide and Reactive Oxygen Species. Journal of Surgical Research. 2011; 169: 9-15.

68. Niccoli G, Kharbanda RK, Crea F and Banning AP. No-reflow: again prevention is better than treatment. Eur Heart J. 2010; 31: 2449-55.

69. Xiao Y-F, Sigg DC, Ujhelyi MR, Wilhelm JJ, Richardson ES and laizzo PA. Pericardial delivery of omega-3 fatty acid: a novel approach to reducing myocardial infarct sizes and arrhythmias. American Journal of Physiology-Heart and Circulatory Physiology. 2008; 294: H2212-H8.

70. Manning AS and Hearse DJ. Reperfusion-induced arrhythmias: mechanisms and prevention. $J$ Mol Cell Cardiol. 1984; 16: 497-518.

71. Manning A, Bernier M, Crome R, Little S and Hearse D. Reperfusion-induced arrhythmias: a study of the role of xanthine oxidase-derived free radicals in the rat heart. J Mol Cell Cardiol. 1988; 20: 35-45.

72. Ozer MK, Sahna E, Birincioglu M and Acet A. Effects of captopril and losartan on myocardial ischemia- 
reperfusion induced arrhythmias and necrosis in rats. Pharmacological Research. 2002; 45: 257-63.

73. van Gilst WH, de Graeff PA, Kingma JH, de Langen $\mathrm{CD}$ and Wesseling $\mathrm{H}$. Effects of diltiazem on reperfusion-induced arrhythmias in vitro and in vivo. J Mol Cell Cardiol. 1986; 18: 1255-66.

74. Das B and Sarkar C. Is the sarcolemmal or mitochondrial K-ATP channel activation important in the antiarrhythmic and cardioprotective effects during acute ischemia/reperfusion in the intact anesthetized rabbit model? Life Sciences. 2005; 77: 1226-48.

75. Demiryurek AT, Cakici I, Wainwright CL, Wadsworth RM and Kane KA. Effects of free radical production and scavengers on occlusion-reperfusion induced arrhythmias. Pharmacological Research. 1998; 38: 433-9.

76. Matejikova J, Kucharska J, Pinterova M, Pancza D and Ravingerova T. Protection Against IschemiaInduced Ventricular Arrhythmias and Myocardial Dysfunction Conferred by Preconditioning in the Rat Heart: Involvement of Mitochondrial K(ATP) Channels and Reactive Oxygen Species. Physiological Research. 2009; 58: 9-19.

77. Piot $\mathrm{C}$, Croisille $\mathrm{P}$, Staat $\mathrm{P}$, et al. Effect of cyclosporine on reperfusion injury in acute myocardial infarction. NEngl J Med. 2008; 359: 473-81.

78. Heusch G. CIRCUS: a kiss of death for cardioprotection? Cardiovasc Res. 2015; 108: 215-6.

79. Cung TT, Morel O, Cayla G, et al. Cyclosporine before PCl in Patients with Acute Myocardial Infarction. N Engl J Med. 2015; 373: 1021-31.

80. Ibanez B, Macaya C, Sanchez-Brunete V, et al. Effect of early metoprolol on infarct size in ST-segmentelevation myocardial infarction patients undergoing primary percutaneous coronary intervention: the Effect of Metoprolol in Cardioprotection During an Acute Myocardial Infarction (METOCARD-CNIC) trial. Circulation. 2013; 128: 1495-503.

81. Chen ZM, Pan HC, Chen YP, et al. Early intravenous then oral metoprolol in 45,852 patients with acute myocardial infarction: randomised placebo-controlled trial. Lancet. 2005; 366: 1622-32.

82. Riha H, Neckar J, Papousek F, et al. Suppression of Ischemic and Reperfusion Ventricular Arrhythmias by Inhalational Anesthetic-Induced Preconditioning in the Rat Heart. Physiological Research. 2011; 60: 70914.

83. Miura T, Ishimoto R, Sakamoto J, et al. Suppression of Reperfusion Arrhythmia by Ischemic Preconditioning in the Rat - Is It Mediated by the Adenosine Receptor, Prostaglandin, or Bradykinin Receptor. Basic Research in Cardiology. 1995; 90: 240-6.

84. Kleinbongard P, Amanakis G, Skyschally A and Heusch G. Reflection of Cardioprotection by Remote Ischemic Perconditioning in Attenuated ST-Segment Elevation During Ongoing Coronary Occlusion in Pigs: Evidence for Cardioprotection From Ischemic Injury. Circ Res. 2018; 122: 1102-8.

85. Rossello $X$ and Ibanez B. Infarct size reduction by targeting ischemic injury. Circ Res. 2018; 122: 1041-3.

86. Kloner RA, Dow JS and Bhandari A. First Direct Comparison of the Late Sodium Current Blocker Ranolazine to Established Antiarrhythmic Agents in an Ischemia/Reperfusion Model. J Cardiovasc Pharmacol Ther. 2011; 16: 192-6.

87. Napoli C, Liguori A, Chiariello M, Di leso N, Condorelli M and Ambrosio G. New-onset angina preceding acute myocardial infarction is associated with improved contractile recovery after thrombolysis. Eur Heart J. 1998; 19: 411-9. 
88. Ottani F, Galvani M, Ferrini D, et al. Prodromal angina limits infarct size. A role for ischemic preconditioning. Circulation. 1995; 91: 291-7.

89. Mewton N and Ovize M. Remote preconditioning and all-cause mortality. Lancet. 2013; 382: 579-80.

90. Wu ZK, livainen T, Pehkonen E, Laurikka J and Tarkka MR. Ischemic preconditioning suppresses ventricular tachyarrhythmias after myocardial revascularization. Circulation. 2002; 106: 3091-6.

91. Waltenberger J, Gelissen M, Bekkers SC, et al. Clinical pacing post-conditioning during revascularization after AMI. JACC Cardiovasc Imaging. 2014; 7: 620-6.

92. Sloth AD, Schmidt MR, Munk K, et al. Improved long-term clinical outcomes in patients with STelevation myocardial infarction undergoing remote ischaemic conditioning as an adjunct to primary percutaneous coronary intervention. Eur Heart J. 2014; 35: 168-75.

93. Botker HE, Kharbanda R, Schmidt MR, et al. Remote ischaemic conditioning before hospital admission, as a complement to angioplasty, and effect on myocardial salvage in patients with acute myocardial infarction: a randomised trial. Lancet. 2010; 375: 727-34.

94. Le Page S, Bejan-Angoulvant T, Angoulvant D and Prunier F. Remote ischemic conditioning and cardioprotection: a systematic review and meta-analysis of randomized clinical trials. Basic Res Cardiol. 2015; 110: 11.

95. Kleinbongard P, Skyschally A and Heusch G. Cardioprotection by remote ischemic conditioning and its signal transduction. Pflugers Arch. 2017; 469: 159-81.

96. Okamoto F, Allen BS, Buckberg GD, Bugyi H and Leaf J. Reperfusion conditions: importance of ensuring gentle versus sudden reperfusion during relief of coronary occlusion. J Thorac Cardiovasc Surg. 1986; 92: 613-20.

97. Heusch G. Postconditioning: old wine in a new bottle? J Am Coll Cardiol. 2004; 44: 1111-2.

98. Staat P, Rioufol G, Piot C, et al. Postconditioning the human heart. Circulation. 2005; 112: 2143-8.

99. Heusch G. Cardioprotection: chances and challenges of its translation to the clinic. Lancet. 2013; 381: 166-75.

100. Hahn JY, Song YB, Kim EK, et al. Ischemic postconditioning during primary percutaneous coronary intervention: the effects of postconditioning on myocardial reperfusion in patients with ST-segment elevation myocardial infarction (POST) randomized trial. Circulation. 2013; 128: 1889-96. 


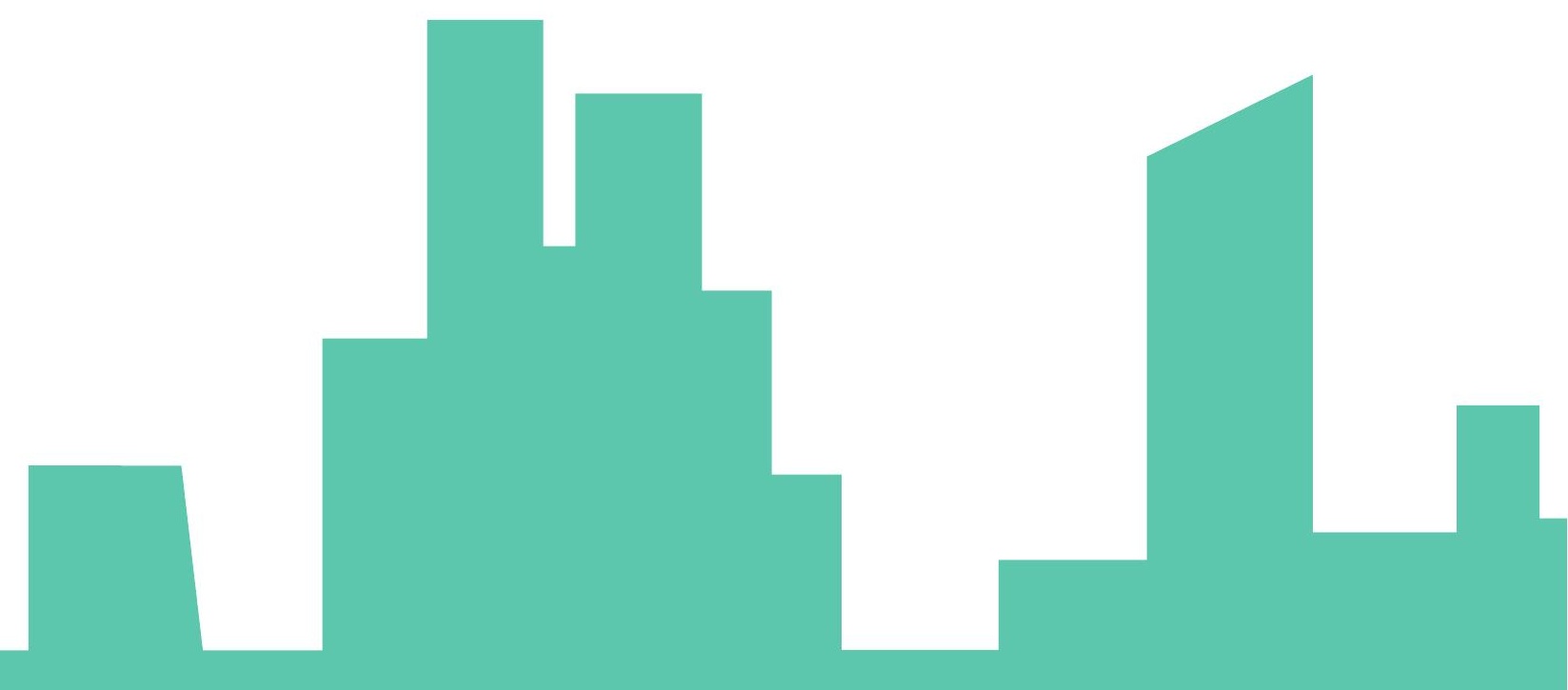




\section{Chapter 7}

Summary and general discussion

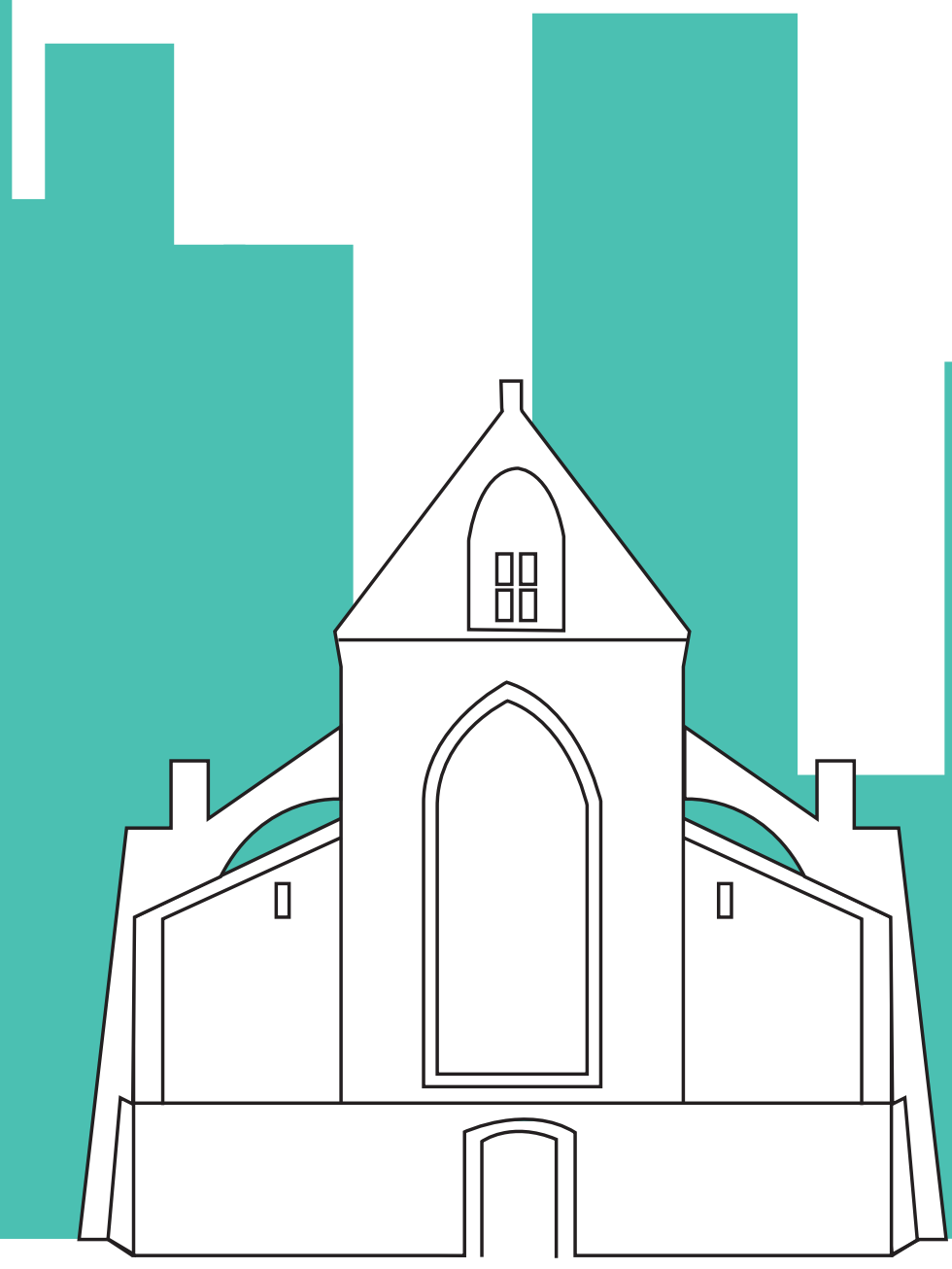




\section{Introduction}

Cardiovascular diseases such as acute ST-elevation myocardial infarction (STEMI) remain one of the main causes of death in industrialized countries ${ }^{1}$. Integration of new treatment modalities such as regionalized urgent transport and expedited hospital care paths for primary $\mathrm{PCl}$ have reduced STEMI mortality from $15 \%$ to about $3.5-5 \%^{2-4}$. These interventions reduce mortality through better, faster interruption of the STEMI, producing myocardial "salvage" measurable as smaller infarct size (IS) relative to the myocardial area at risk. Reduction of IS is also linked to reduction of morbidity from STEMI. Because morbidity, such as heart failure and arrhythmias, is still an important hindrance associated with AMI survival, reducing IS remains a key goal in current and future AMI care. Establishing quick and optimal reperfusion is an essential step in reducing infarct size. However, reperfusion is also referred to as a "double edged sword" where it can also cause additional damage, known as "lethal reperfusion injury" and in this way increases infarct size.

The objective of this thesis has been to study the mechanistic steps associated with STEMI intervention using pragmatic tools_-angiography and electrocardiographic monitoring - that are standard components of real time clinical care. Through a truly international collaboration we were able to access and include patients from clinical trials all of whom had angiographic and continuous ECG data available and analyzed in blinded independent expert core laboratories. Over 30024 hour holter recordings were manually analyzed beat by beat in at least 2 different leads to determine whether a beat had a ventricular of atrial origin and to distinguish between fusion beats and atrial beats. For all of these patients quantitative infarct size data was also available, either as SPECT or DE-CMR images, also analyzed in independent, blinded core laboratories.

Overall this thesis advances several decades of research observations into a more refined, quantitative "biosignature" of optimal reperfusion including sequential epicardial recanalization of the infarct artery, microvascular perfusion of the infarct zone, and cellular response of the ischemic territory to whole blood chemical exposure. The identification of ventricular arrhythmia "burst" as a surrogate marker of the cellular response in particular is the central and most unique knowledge conveyed in this thesis. Including this signal from "downstream" of even the microvascular infarct bed, this biosignature approach using practical real time surrogate markers has key relevance to both future research and clinical applications.

\section{Clinical and ECG features at the time of reperfusion}

The ECG changes occurring upon reperfusion have previously been studied by multiple investigators. The most frequently described ECG feature is the occurrence of at least $25 \%$ STsegment resolution within the first 60-90 min after reperfusion. The occurrence of ST-resolution within this time frame has shown to have a $97 \%$ positive predictive value for identifying successful reperfusion at both the epicardial and microvascular levels ${ }^{5-7}$. Another characteristic finding is the increase of ventricular premature beats (VPBs) with a long coupling interval, frequently resulting 
in accelerated idioventricular rhythms (AIVR). A positive predictive value as high as $94 \%$ of AIVR as a marker of reperfusion has been described by our and other groups ${ }^{5,7-10}$. However, our group also found that in over half of the study population these reperfusion arrhythmias were preceded by an increase before disappearance of chest pain, an increase in ST-elevation, before ST resolution and an additional increase in serum cardiac enzyme levels ${ }^{7}$ (fig 1). Therefore it was hypothesized that these findings could be due to reperfusion injury. Thus in the thrombolytic era, when nearly half of patients failed to achieve successful recanalization of the infarct artery after drug administration, reperfusion arrhythmias were considered a positive signal that the epicardial vessel had opened. In the era of primary $\mathrm{PCl}$, however, where more than $90 \%$ of infarct arteries are opened with TIMI 3 epicardial flow ${ }^{2}$, the implications of reperfusion arrhythmias have been identified as a novel, but negative, marker of tissue level response leading to cell death.
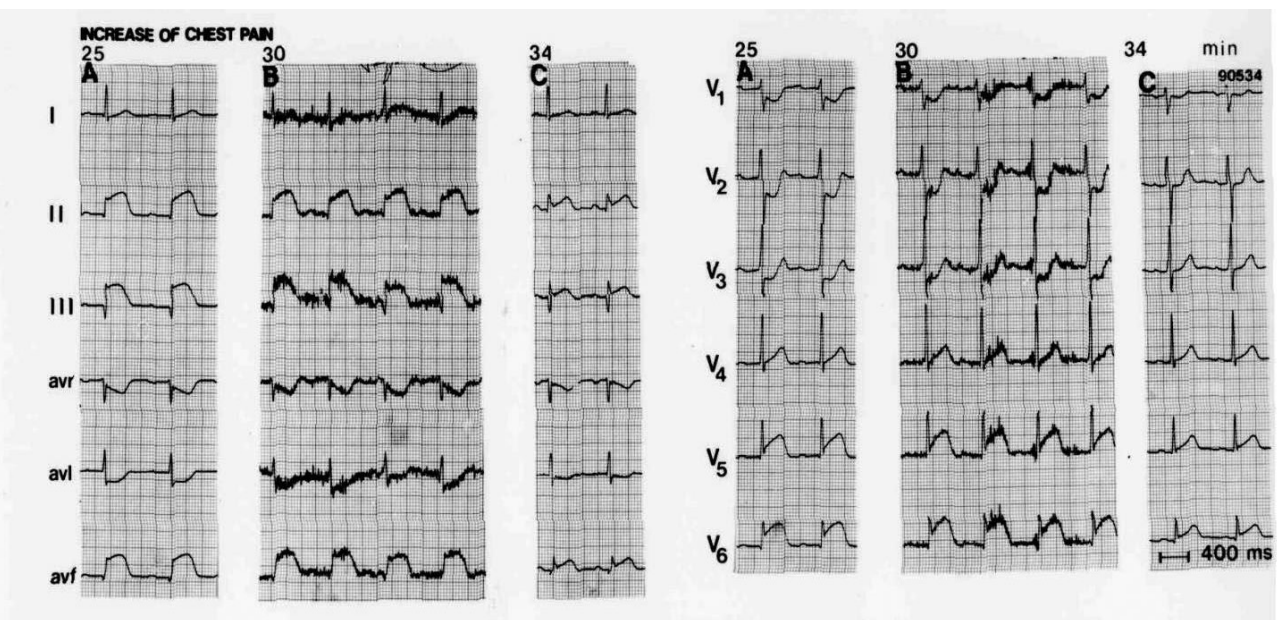

Figure 1:

12 lead ECG's recorded during the onset of reperfusion 25 (panel A), 30 (panel B) and 34 (panel C) minutes after start of fibrinolytic therapy. Panels A show an inferoposterolateral wall ST-elevation myocardial infarction. Panels B show baseline noise due to muscle motion artefacts caused by an increase in chest pain. Note the increase of ST-elevation. Panel 3 shows the disappearance of noise (chest pain resolves) and resolution of ST elevation

\section{Ventricular arrhythmias at the time of reperfusion}

Since the advent of recanalization techniques in AMI occurrence of ventricular arrhythmias (VA) upon reperfusion in both animal models and human patients with STEMI have long been recognized. Particularly in patients, however, their pathophysiological and prognostic significance have been difficult to study and remain ambiguous if not controversial ${ }^{11}$. Morphologically, these reperfusion VAs include ventricular premature beats with long coupling intervals and accelerated idioventricular rhythms (see figure 2 chapter 2 of this thesis). They start (almost) directly at the moment of reperfusion, appearing as temporary self-terminating "bursts" of spontaneous ventricular electrical activity, which are hemodynamically well tolerated, and have a QRS configuration, suggesting an origin within the reperfusion zone. ${ }^{2}$ In conjunction with fibrinolytic therapy, reperfusion VA were 
considered a beneficial event as a non-invasive marker of infarct artery recanalization ${ }^{12}$. In the more contemporary era of direct percutaneous coronary intervention $(\mathrm{PCl})$, in patients with established TIMI 3 flow, VA "bursts" were found to be associated with larger infarct size (IS) and worsened outcomes $^{10,13-15}$.

A

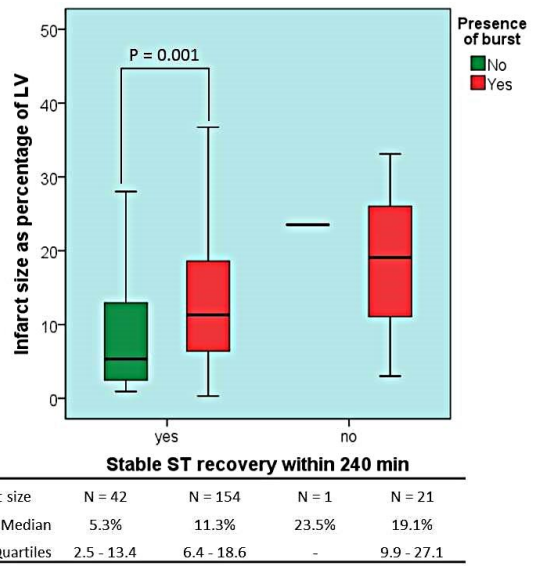

C

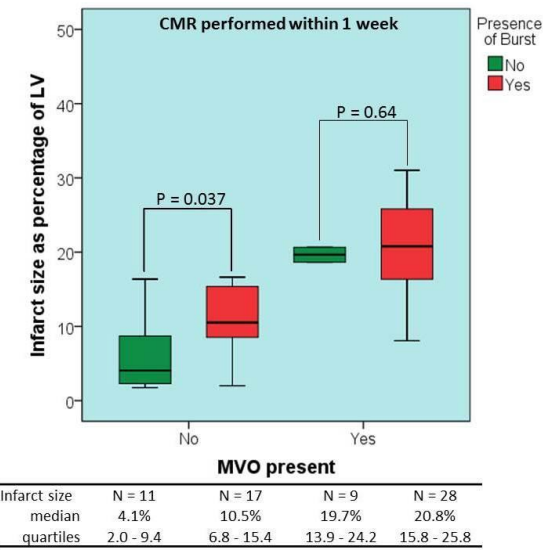

B

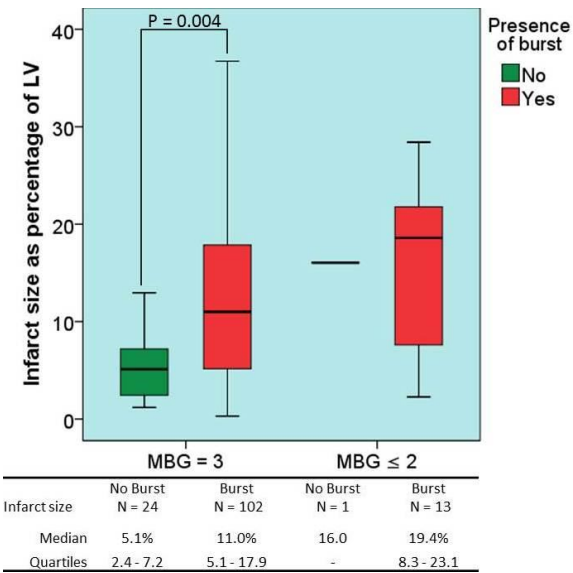

D

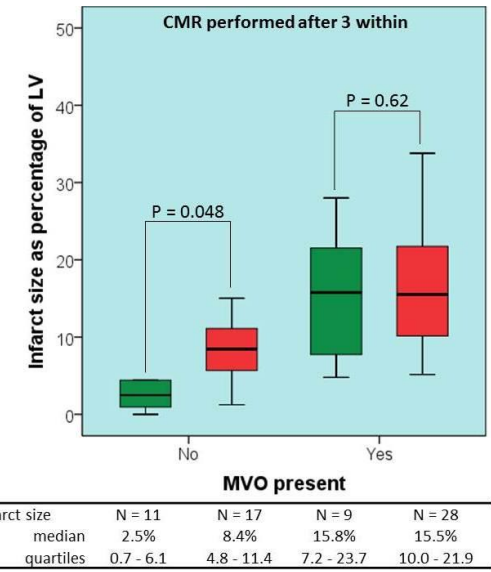

Figure 2: Differences between VA burst present or absent for final infarct size.

Box plots with corresponding medians and quartiles displaying the relation of VA burst and final infarct size (IS): in the presence or absence of (A) stable ST-recovery, (B) optimal myocardial blush grade (MBG 3), (C) MVO with IS one week after myocardial infarction, and (D) MVO with IS at 3 months after myocardial infarction.

\section{Epicardial and microvascular reperfusion}

In chapter $\mathbf{2}$ we studied whether VA bursts added information about IS in patients with TIMI 3 flow and brisk ST-recovery, e.g. in patients with otherwise optimal epicardial ${ }^{6,16}$. This study was the first to include both anterior and non-interior myocardial infarction (MI) VA burst analyzes and to correlate them with cardiac magnetic resonance imaging (CMR) to determine infarct size. As shown in fig $2 \mathrm{~A}$ there was a significantly smaller IS in the absence of VA burst consistent with our hypothesis that VA 
burst is a sign of additional damage that cannot be explained by suboptimal flow and is therefore likely related to an independent mechanism further "downstream" at the myocyte level. This was previously also shown by Majidi et al. in a population of 128 anterior AMI patients using SPECT to asses IS ${ }^{14}$. Our study not only confirmed this finding in a larger population but also included nonanterior MI and used CMR, the current gold standard to assess infarct size (IS).

In chapter $\mathbf{3}$ we studied subgroups of the PREPARE trial with and without VA burst arrhythmias in patients and with or without intact microvascular flow using angiographic myocardial blush grade, (MBG) after PCI. This population also included anterior and non-anterior $\mathrm{Ml}$ and correlated the findings with final infarct size determined by the gold standard CMR. A low MBG 0-1 is related to higher mortality, morbidity and larger infarct size when compared with the optimal score MBG $3^{17-19}$. Our data confirmed our hypothesis that VA bursts are of added value in assessing infarct size and were associated with significantly larger infarct size (increasing from 5.1 to 11\%), in spite of an optimal MBG grade (fig 2B).

In Chapter 4, another novel method was used to study the integrity of the myocardial microvascular bed, i.e. the identification of microvascular obstruction (MVO) using CMR. The presence of MVO is an established marker of larger IS, worse left ventricular ejection fraction (LVEF), left ventricular remodeling, and a higher incidence of cardiovascular complications ${ }^{20-23}$. Presence of MVO using CMR is usually assessed 3-7 days after the event and therefore not available during the acute stages of care. Nevertheless its predictive accuracy is superior to MBG that tends to underestimate the incidence of $\mathrm{MVO}^{24,25}$. Therefore to further test the robustness of our observations in chapter $\mathbf{3}$, we also studied another population of patients in the absence of MVO for the correlation of VA burst with larger IS. As shown in fig $2 \mathrm{C}$ and 2D, the correlation of VA burst with larger IS was highly significant again ( $4.1 \%$ vs. $10.5 \%$ and $2.5 \%$ vs $8.4 \%)$, providing confirmative evidence that VA bursts signal larger infarct size even with microvascular integrity. This also adds to the mechanistic evidence that the origin of the damage must therefore be even further downstream, i.e. at the myocellular level.

Figure 2 shows that the smallest IS is found in patients with TIMI 3 epicardial flow when the "biosignature" also includes fast ST-recovery, no MVO and, significantly, no VA burst. Absence vs presence of VA burst is associated with half the IS, implying that it is a mechanistic signal of potential clinical significance for both mortality morbidity after STEMI. Furthermore, that VA burst is present in the majority of patients (70-80\%) receiving primary PCI after STEMI implies that it could be a valuable target for therapeutics that reliably eliminate its source.

The four panels of figure 2 show a remarkable consistency that each of the mechanistic markers included in the "biosignature" approach subsequent to epicardial recanalization (ST segment recovery, angiographic myocardial blush or MVO by CMR) contribute significant information to correlations with IS. In the setting of suboptimal epicardial and microvascular reperfusion, VA bursts do not further stratify IS. This is consistent with the supposition that without both epicardial and 
microvascular flow, ischemic cell injury will proceed to complete infarction over the full distribution of the infarct artery, or the so-called area at risk.
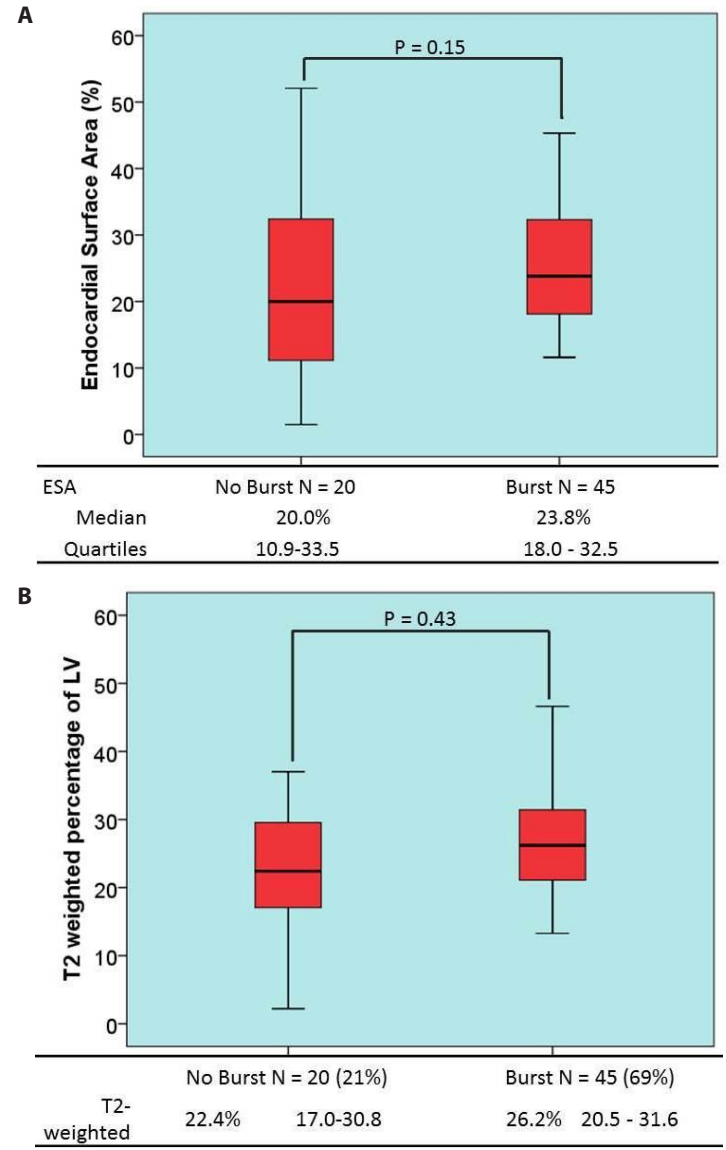

Figure 3: Difference between VA burst present or absent for area at risk

Box plots with corresponding medians and quartiles displaying the relation of VA burst and area at risk (AAR); assessed (A) using endocardial surface area (ESA), or (B) using T2-weighted CMR imaging with DE-CMR imaging

\section{Area at risk}

VA bursts, being a marker of larger IS, could also be related to a larger initial area at risk (AAR). AAR is a well-known determinant for final infarct size, next to factors such as ischemia duration, presence and extent of collateral flow and the success of revascularization attempt ${ }^{26-28}$. Because AAR is an important prognostic marker, its accurate measurement has been pursued using various imaging modalities, including SPECT imaging and, more recently, cardiovascular magnetic resonance imaging (CMR). The most commonly used and therefore considered to be the gold standard for AAR assessment is SPECT with technetium as the tracer. It provides information on zones with reduced perfusion regardless of anatomy and it accounts for collateral flow that can limit the ischemic area. 
However, the method has some important limitations. The perfusion defects that are attributed to the culprit artery may as well be increased or decreased depending on the distribution of the other coronary arteries ${ }^{29}$. In addition to the analytical limitations, the method is logistically challenging because it requires injection of the tracer before $\mathrm{PCl}$ and imaging needs to be performed within the first hours after the procedure. Such a sequence may interfere with patient care and may logistically be challenging outside office hours ${ }^{29}$. Furthermore, the patient is exposed to preferably avoidable radiation ${ }^{30}$.

Presently, the gold standard for final IS determination is DE-CMR because of its high imaging quality, accuracy, and reproducibility ${ }^{31}$. This technique enables accurate assessment of the lateral borders and of the transmural extent of the myocardial infarct ${ }^{26,32}$. Experimental studies have shown that the endocardial extent of (possible) necrosis is established at already 40 minutes after coronary occlusion. This approach has been used to determine the lateral boundaries of the AAR. The subsequent increases of IS is determined by the transmural wave front progression of ischemia from the endo- to the epicardial layers. Early revascularization stops this process and reduces final IS ${ }^{33,34}$. The use of ESA for AAR assessment is based on this "wavefront" mechanism of infarct formation. Good correlations with both angiographic, BARI and APPROACH, scores, SPECT, T2-weighted CMR imaging and pathology findings have been reported ${ }^{30,35-39}$. Furthermore, ESA has shown the highest correlation with near transmural infarcts, $R=0.93$, in comparison with other techniques for assessing $A A R^{40}$.

In chapter $\mathbf{5}$ we assessed whether VA burst was related to larger AAR as determined by CMR ESA . The result was that no statistical significant difference was found between AAR in the study groups with or without VA bursts (median 20.0 vs. 23.8\%) (fig 3A). This important finding adds additional insight that VA bursts do not simply originate from larger infarct artery territories per se (e.g. larger AAR), but indeed arise as a signal of cellular toxicity predicting larger final IS across a broad spectrum of AAR. Again, this supports the hypothesis of this thesis that VA burst signals a chemical injury at the cellular level after vascular perfusion has been restored, resulting in cellular death rather than cellular recovery.

Another method for assessing AAR using CMR is T2-weighted hyperenhanced imaging. Based on histopathological animal studies ${ }^{36,38,41-44}$ this method is considered to identify increased edema in the $A A R$ versus necrotic and non-ischemic tissue after reperfusion This method is currently suggested to best represent AAR by expert reviews and consensus society guidelines ${ }^{45-47}$. Therefore T2-weighted hyperenhanced imaging is frequently used to assess salvage in clinical acute myocardial infarction trials. However, disagreement exists within the cardiovascular imaging community whether the T2-weighted hyperintense area really corresponds with the $A A R^{48-54}$. Due to this controversy we only reported the results of ESA assessment in chapter $\mathbf{5}$. We did however observe a consistent relation between ESA and T2 weighted imaging (burst vs. no burst $26.2 \%$ vs $22.4 \%$; $p$ 0.43, fig 3B). 


\section{Pathophysiological relation between reperfusion injury and VA bursts}

In all our studies we observed that the presence of VA burst is associated with a significant doubling of IS ( $11.3 \%$ with burst vs $5.3 \%$ without, $11.0 \%$ vs $5.1 \%, 10.5 \%$ vs $4.1 \%, 8.4 \%$ vs $2.5 \%)$ in the setting of otherwise optimal epicardial and microvascular flow restoration by primary $\mathrm{PCl}$. It is important to realize the amount of infarct size due to reperfusion injury equals that of the preceding ischemic injury, and also that it affects the majority of patients with STEMI. This again implies that attention to therapeutics targeting this mechanism could have important clinical benefits to patients suffering STEMI.

\section{Cellular and clinical underpinning for VA bursts as a sign of reperfusion injury}

In chapter $\mathbf{6}$ we sought to investigate whether our hypothesis and findings could be the supported at the biocellular level by an extensive review of available literature on the cell biology of reperfusion injury, the pathophysiology of reperfusion arrhythmias at the cellular level and the basic and clinical trials focusing on preventing reperfusion injury. By reviewing this literature a clear pattern emerged showing a relation between apoptosis induced by reperfusion; through oxidative stress, intracellular calcium overload and mitochondrial permeability transition pore (MPTP) opening, and reperfusion arrhythmias, through by intracellular calcium overload aggravated by oxidative stress and mPTP opening. So the mechanism responsible for lethal reperfusion injury and the increase in IS, is the same as the mechanism causing the reperfusion arrhythmias).

The combination of the results found in chapter 2-5, the larger infarcts found in the presence of VA burst even in the presence of optimal epicardial and microvascular flow and absence of correlation with AAR, and the clear pathophysiological correlation of reperfusion arrhythmias and lethal reperfusion injury as described in chapter 6 leads to the conclusion that VA burst are a potential marker of lethal reperfusion injury and have important implications for future directions in both research and clinical care.

\section{VA burst, definition and remaining study aspects}

The phenomenon of ventricular arrhythmias at the moment of reperfusion is complex, consisting of ventricular ectopic activity, with different rates, durations and sites of origin. For the purpose of our analyses this complex phenomenon was reduced to a simple dichotomous marker, with a cut-off value being statistically determined as described by Majidi et $\mathrm{al}^{13}$. Importantly, as patients may have ongoing ventricular arrhythmias in conjunction with ischemia and cell death from STEMI prior to reperfusion, we encompass the quantification of VA bursts as outlier calculations comparing individual patient-related VA prior to immediately after the moment of reperfusion per se. This definition was found to be very useful to analyze the pathophysiology and the clinical significance of reperfusion arrhythmias. A number of aspects remain however unanswered such as: is the cutoff value used optimal?; what is the significance of different rates, durations and configurations of these arrhythmias? 
Also, although a clear relationship of VA burst exists with IS, the latter being linked to mortality, no direct proof is present as to what degree VA burst is associated with increased mortality or morbidity. However, to study these questions large, preferably prospectively designed databases with sufficiently long follow up are needed of patients with first $\mathrm{Ml}$, continuous rhythm monitoring and methods to accurately assess IS.

\section{Biosignature of optimal reperfusion}

In the clinical setting it is important to be informed early, within the first few hours after onset of acute myocardial infarction, about salvage of ischemic tissue, final infarct size and prognosis. For that purpose we propose the following model, termed "biosignature of optimal reperfusion". This concept is illustrated by a flowchart depicted in figure 4 starting with the duration of symptoms and ending with reperfusion injury. Optimal reperfusion and salvage is obtained if the final step in the flow chart is reached including absence of reperfusion arrhythmias. Significant salvage can only be obtained if patients present early enough for revascularization attempts to be effective, generally to be considered within 6 hours after the onset of ischemia ${ }^{26,28}$. Obtaining c epicardial revascularization (TIMI 3 flow) is a next prerequisite for optimal reperfusion. If unable to establish TIMI flow 3, the rest of the steps in the flowchart are inconsequential ${ }^{55-58}$. In case of TIMI 3 flow the presence of microvascular perfusion, quantified as myocardial blush grade (MBG), is essential: Optimal microvascular perfusion, MBG 3 compared to $M B G \leq 2$, is related with smaller IS and lower incidence of mortality and morbidity ${ }^{17,18}$. Although MVO using DE-CMR recording is superior in identifying the absence of optimal microvascular perfusion, obtaining this information within 24 hours of the event is logistically difficult ${ }^{24,25}$. Therefore MBG 3 was included in this model instead of MVO on DE-CMR. If optimal epicardial and microvascular perfusion has been established directly after the procedure, the next step is to determine whether ST-resolution of $>50 \%$ occurred within 240 minutes after last contrast and no re-elevation occurred using continuous ECG recording. Fast stable STresolution is an important marker of lower morbidity, mortality and smaller infarct size ${ }^{6,16,59}$. In the event of steady state optimal epicardial and microvascular perfusion in the hours following reperfusion, the final step is to take into account nutritive or toxic reintroduction of oxygenated blood flow as indicated by the occurrence of VA burst, being a sign of reperfusion injury ${ }^{60-62}$ as described in chapter 6 . If no optimal epicardial and microvascular perfusion is obtained than the occurrence of reperfusion arrhythmias becomes insignificant. In the absence of VA burst, the biosignature indicates that optimal reperfusion has been obtained resulting in small infarcts. Unfortunately VA burst still occurs in about $60-80 \%$ of patients ${ }^{13,14,63-66}$. This illustrates the importance of developing treatment methods that reduce reperfusion injury as indicated by the absence of VA burst.

Quantification of this model in large prospective registries, including its respective known and novel reperfusion injury biomarkers, may lead to improved early risk stratification in acute myocardial infarction 


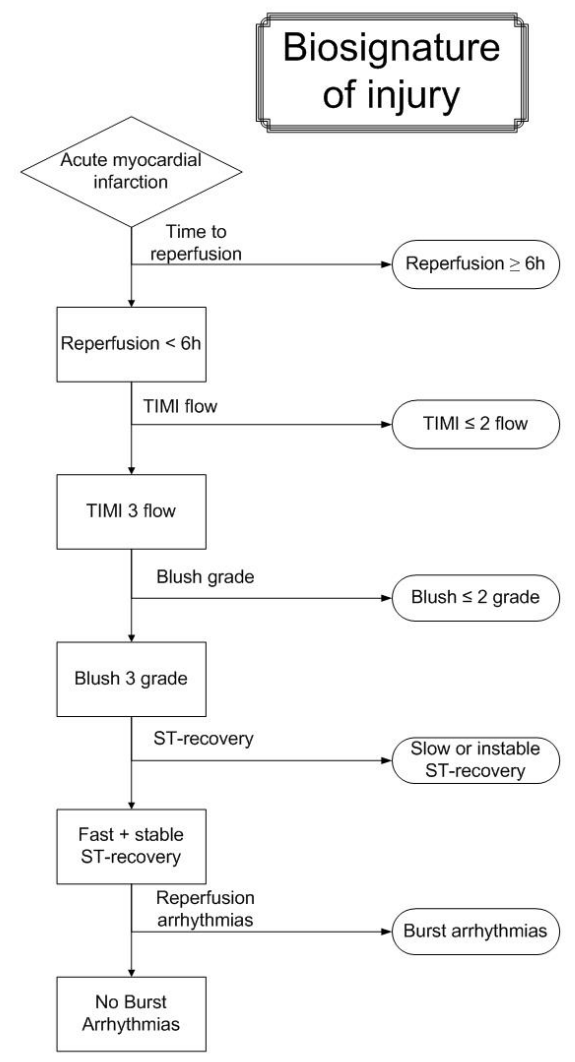

Figure 4: Biosignature of injury

\section{Clinical implications}

The most important conclusions of our study are that reperfusion VA burst are a marker of reperfusion injury and that reperfusion injury about doubles final infarct size. These findings should stimulate to assess VA bursts routinely in the clinical setting, use this novel biomarker next to already known clinical and electrical biomarkers to early identify final infarct size and to search for new modalities to reduce reperfusion injury. 


\section{Future perspectives}

Despite all advancements in the care for AMI, it is still an important cause of mortality and morbidity. The continuation of research in this field is therefore crucial and should focus on prevention as well as reducing resulting damage.

Lethal reperfusion injury is an area with a high potential to reduce the destructive effects of AMI. As described in Chapter $\mathbf{6}$ extensive research has focused on preventing reperfusion injury. However, most of the clinical trials have failed in spite of promising results in the preclinical setting or even after successful phase II trials, I believe that one important reason for failure, especially after successful phase II trials, could be the inclusion of patients with suboptimal reperfusion. As mentioned before, the consequence of reperfusion injury becomes inconsequential if there is suboptimal epicardial and microvascular reperfusion. Also patients with optimal reperfusion (with the absence of all biomarkers including the absence of VA burstof our biosignature of injury model) will dilute the study population.

The results found in chapters 2-5 show that VA burst is related to larger IS even in the situations of optimal epicardial and microvascular reperfusion. Therefore we concluded VA burst to be a sign of a different cause of myocellular injury. Chapter 6 reviews the current knowledge regarding the pathophysiology of lethal reperfusion injury and reperfusion arrhythmias and shows their pathophysiologic relation. Therefore, our findings suggest VA burst to have potential as a first and only biomarker for reperfusion injury and could be used in clinical trials aimed to reduce lethal reperfusion injury. Further research is needed to support this hypothesis. Current other markers used, such as ROS, only focus on one part in which reperfusion causes additional cell death but when using those researchers overlook the other pathways by which reperfusion induces cell death as shown in chapter $\mathbf{6}$. The pathways of reperfusion injury are numerous and only markers and interventions that illustrate in intervene in all these numerous pathways have the potential to be successful.

Furthermore, additional research should also focus on whether VA burst not only is a bimodal model but can also work as a multimodal model determining the amount of additional injury. It would be interesting to analyze whether multiple threshold levels to determine VA burst can be used and if a higher threshold is related to larger fatal reperfusion injury. 


\section{References}

1. WHO. The top 10 causes of death. 2018

2. Puymirat E, Simon T, Steg PG, Schiele F, Gueret P, Blanchard D, Khalife K, Goldstein P, Cattan S, Vaur L, Cambou JP, Ferrieres J, Danchin N. Association of changes in clinical characteristics and management with improvement in survival among patients with st-elevation myocardial infarction. JAMA: the journal of the American Medical Association. 2012;308:998-1006

3. Braunwald E. The rise of cardiovascular medicine. European heart journal. 2012;33:838-845, 845a

4. Ibanez B, James S, Agewall S, Antunes MJ, Bucciarelli-Ducci C, Bueno H, Caforio ALP, Crea F, Goudevenos JA, Halvorsen S, Hindricks G, Kastrati A, Lenzen MJ, Prescott E, Roffi M, Valgimigli M, Varenhorst C, Vranckx P, Widimsky P. 2017 esc guidelines for the management of acute myocardial infarction in patients presenting with st-segment elevation: The task force for the management of acute myocardial infarction in patients presenting with st-segment elevation of the european society of cardiology (esc). European heart journal. 2018;39:119-177

5. Hohnloser SH, Zabel M, Kasper W, Meinertz T, Just H. Assessment of coronary artery patency after thrombolytic therapy: Accurate prediction utilizing the combined analysis of three noninvasive markers. Journal of the American College of Cardiology. 1991;18:44-49

6. Krucoff MW, Croll MA, Pope JE, Pieper KS, Kanani PM, Granger CB, Veldkamp RF, Wagner BL, Sawchak ST, Califf RM. Continuously updated 12-lead st-segment recovery analysis for myocardial infarct artery patency assessment and its correlation with multiple simultaneous early angiographic observations. The American journal of cardiology. 1993;71:145-151

7. Doevendans PA, Gorgels AP, van der Zee R, Partouns J, Bar FW, Wellens HJ. Electrocardiographic diagnosis of reperfusion during thrombolytic therapy in acute myocardial infarction. The American journal of cardiology. 1995;75:1206-1210

8. Goldberg S, Greenspon AJ, Urban PL, Muza B, Berger B, Walinsky P, Maroko PR. Reperfusion arrhythmia: A marker of restoration of antegrade flow during intracoronary thrombolysis for acute myocardial infarction. American heart journal. 1983;105:26-32

9. Gorgels AP, Vos MA, Letsch IS, Verschuuren EA, Bar FW, Janssen JH, Wellens HJ. Usefulness of the accelerated idioventricular rhythm as a marker for myocardial necrosis and reperfusion during thrombolytic therapy in acute myocardial infarction. The American journal of cardiology. 1988;61:231-235

10. Engelen DJ, Gressin V, Krucoff MW, Theuns DA, Green C, Cheriex EC, Maison-Blanche P, Dassen WR, Wellens HJ, Gorgels AP. Usefulness of frequent arrhythmias after epicardial recanalization in anterior wall acute myocardial infarction as a marker of cellular injury leading to poor recovery of left ventricular function. The American journal of cardiology. 2003;92:1143-1149

11. Terkelsen CJ, Sorensen JT, Kaltoft AK, Nielsen SS, Thuesen L, Botker HE, Lassen JF. Prevalence and significance of accelerated idioventricular rhythm in patients with st-elevation myocardial infarction treated with primary percutaneous coronary intervention. The American journal of cardiology. 2009;104:1641-1646

12. Gorgels A, Vos MA, Brugada P, Wellens HJ. The clinical relevance of abnormal automaticity and triggered activity. Cardiac arrhythmias: Where to go frome here? Mount Kisco, NY: Futura Publishing company; 
1987:147-169.

13. Majidi M, Kosinski AS, Al-Khatib SM, Lemmert ME, Smolders L, van Weert A, Reiber JH, Tzivoni D, Bar FW, Wellens HJ, Gorgels AP, Krucoff MW. Reperfusion ventricular arrhythmia 'bursts' in timi 3 flow restoration with primary angioplasty for anterior st-elevation myocardial infarction: A more precise definition of reperfusion arrhythmias. Europace : European pacing, arrhythmias, and cardiac electrophysiology : journal of the working groups on cardiac pacing, arrhythmias, and cardiac cellular electrophysiology of the European Society of Cardiology. 2008;10:988-997

14. Majidi M, Kosinski AS, Al-Khatib SM, Lemmert ME, Smolders L, van Weert A, Reiber JH, Tzivoni D, Bar FW, Wellens HJ, Gorgels AP, Krucoff MW. Reperfusion ventricular arrhythmia 'bursts' predict larger infarct size despite timi 3 flow restoration with primary angioplasty for anterior st-elevation myocardial infarction. European heart journal. 2009;30:757-764

15. Remmelink M, Delewi R, Yong ZY, Piek JJ, Baan J, Jr. More pronounced diastolic left ventricular dysfunction in patients with accelerated idioventricular rhythm after reperfusion by primary percutaneous coronary intervention. The Journal of invasive cardiology. 2010;22:574-578

16. Krucoff MW, Croll MA, Pope JE, Granger CB, O'Connor CM, Sigmon KN, Wagner BL, Ryan JA, Lee KL, Kereiakes DJ, et al. Continuous 12-lead st-segment recovery analysis in the tami 7 study. Performance of a noninvasive method for real-time detection of failed myocardial reperfusion. Circulation. 1993;88:437-446

17. Hoffmann R, Haager P, Arning J, Christott P, Radke P, Blindt R, Ortlepp J, Lepper W, Hanrath P. Usefulness of myocardial blush grade early and late after primary coronary angioplasty for acute myocardial infarction in predicting left ventricular function. The American journal of cardiology. 2003;92:1015-1019

18. van 't Hof AW, Liem A, Suryapranata H, Hoorntje JC, de Boer MJ, Zijlstra F. Angiographic assessment of myocardial reperfusion in patients treated with primary angioplasty for acute myocardial infarction: Myocardial blush grade. Zwolle myocardial infarction study group. Circulation. 1998;97:2302-2306

19. Haager PK, Christott P, Heussen N, Lepper W, Hanrath P, Hoffmann R. Prediction of clinical outcome after mechanical revascularization in acute myocardial infarction by markers of myocardial reperfusion. Journal of the American College of Cardiology. 2003;41:532-538

20. Bekkers SC, Smulders MW, Passos VL, Leiner T, Waltenberger J, Gorgels AP, Schalla S. Clinical implications of microvascular obstruction and intramyocardial haemorrhage in acute myocardial infarction using cardiovascular magnetic resonance imaging. European radiology. 2010;20:2572-2578

21. Bogaert J, Kalantzi M, Rademakers FE, Dymarkowski S, Janssens S. Determinants and impact of microvascular obstruction in successfully reperfused st-segment elevation myocardial infarction. Assessment by magnetic resonance imaging. European radiology. 2007;17:2572-2580

22. Nijveldt R, Beek AM, Hirsch A, Stoel MG, Hofman MB, Umans VA, Algra PR, Twisk JW, van Rossum AC. Functional recovery after acute myocardial infarction: Comparison between angiography, electrocardiography, and cardiovascular magnetic resonance measures of microvascular injury. Journal of the American College of Cardiology. 2008;52:181-189

23. Wu KC, Zerhouni EA, Judd RM, Lugo-Olivieri CH, Barouch LA, Schulman SP, Blumenthal RS, Lima JA. Prognostic significance of microvascular obstruction by magnetic resonance imaging in patients with acute myocardial infarction. Circulation. 1998;97:765-772

24. Wong DT, Leung MC, Richardson JD, Puri R, Bertaso AG, Williams K, Meredith IT, Teo KS, Worthley MI, 
Worthley SG. Cardiac magnetic resonance derived late microvascular obstruction assessment post stsegment elevation myocardial infarction is the best predictor of left ventricular function: A comparison of angiographic and cardiac magnetic resonance derived measurements. The international journal of cardiovascular imaging. 2012;28:1971-1981

25. Vicente J, Mewton N, Croisille P, Staat P, Bonnefoy-Cudraz E, Ovize M, Revel D. Comparison of the angiographic myocardial blush grade with delayed-enhanced cardiac magnetic resonance for the assessment of microvascular obstruction in acute myocardial infarctions. Catheterization and cardiovascular interventions : official journal of the Society for Cardiac Angiography \& Interventions. 2009;74:1000-1007

26. Reimer KA, Jennings RB. The "wavefront phenomenon" of myocardial ischemic cell death. li. Transmural progression of necrosis within the framework of ischemic bed size (myocardium at risk) and collateral flow. Laboratory investigation; a journal of technical methods and pathology. 1979;40:633-644

27. Reimer KA, Jennings RB. The changing anatomic reference base of evolving myocardial infarction. Underestimation of myocardial collateral blood flow and overestimation of experimental anatomic infarct size due to tissue edema, hemorrhage and acute inflammation. Circulation. 1979;60:866-876

28. Reimer KA, Lowe JE, Rasmussen MM, Jennings RB. The wavefront phenomenon of ischemic cell death. 1. Myocardial infarct size vs duration of coronary occlusion in dogs. Circulation. 1977;56:786-794

29. Christian TF, Gibbons RJ, Clements IP, Berger PB, Selvester RH, Wagner GS. Estimates of myocardium at risk and collateral flow in acute myocardial infarction using electrocardiographic indexes with comparison to radionuclide and angiographic measures. Journal of the American College of Cardiology. 1995;26:388-393

30. Wagner A, Mahrholdt H, Holly TA, Elliott MD, Regenfus M, Parker M, Klocke FJ, Bonow RO, Kim RJ, Judd RM. Contrast-enhanced mri and routine single photon emission computed tomography (spect) perfusion imaging for detection of subendocardial myocardial infarcts: An imaging study. Lancet. 2003;361:374379

31. Kim RJ, Fieno DS, Parrish TB, Harris K, Chen EL, Simonetti O, Bundy J, Finn JP, Klocke FJ, Judd RM. Relationship of mri delayed contrast enhancement to irreversible injury, infarct age, and contractile function. Circulation. 1999;100:1992-2002

32. Wu E, Judd RM, Vargas JD, Klocke FJ, Bonow RO, Kim RJ. Visualisation of presence, location, and transmural extent of healed q-wave and non-q-wave myocardial infarction. Lancet. 2001;357:21-28

33. Maruoka Y, Tomoike H, Kawachi Y, Noguchi K, Nakamura M. Relations between collateral flow and tissue salvage in the risk area after acute coronary occlusion in dogs: A topographical analysis. British journal of experimental pathology. 1986;67:33-42

34. Mangion K, Corcoran D, Carrick D, Berry C. New perspectives on the role of cardiac magnetic resonance imaging to evaluate myocardial salvage and myocardial hemorrhage after acute reperfused st-elevation myocardial infarction. Expert review of cardiovascular therapy. 2016;14:843-854

35. Mewton N, Rapacchi S, Augeul L, Ferrera R, Loufouat J, Boussel L, Micolich A, Rioufol G, Revel D, Ovize $\mathrm{M}$, Croisille P. Determination of the myocardial area at risk with pre- versus post-reperfusion imaging techniques in the pig model. Basic research in cardiology. 2011;106:1247-1257

36. Garcia-Dorado D, Oliveras J, Gili J, Sanz E, Perez-Villa F, Barrabes J, Carreras MJ, Solares J, Soler-Soler J. 
Analysis of myocardial oedema by magnetic resonance imaging early after coronary artery occlusion with or without reperfusion. Cardiovascular research. 1993;27:1462-1469

37. Lonborg J, Engstrom T, Mathiasen AB, Vejlstrup N. Myocardial area at risk after st-elevation myocardial infarction measured with the late gadolinium enhancement after scar remodeling and t2-weighted cardiac magnetic resonance imaging. The international journal of cardiovascular imaging. 2012;28:1455-1464

38. Aletras AH, Tilak GS, Natanzon A, Hsu LY, Gonzalez FM, Hoyt RF, Jr., Arai AE. Retrospective determination of the area at risk for reperfused acute myocardial infarction with t2-weighted cardiac magnetic resonance imaging: Histopathological and displacement encoding with stimulated echoes (dense) functional validations. Circulation. 2006;113:1865-1870

39. Versteylen MO, Bekkers SC, Smulders MW, Winkens B, Mihl C, Winkens MH, Leiner T, Waltenberger JL, Kim RJ, Gorgels AP. Performance of angiographic, electrocardiographic and mri methods to assess the area at risk in acute myocardial infarction. Heart (British Cardiac Society). 2012;98:109-115

40. Bekkers SC, Backes WH, Kim RJ, Snoep G, Gorgels AP, Passos VL, Waltenberger J, Crijns HJ, Schalla S. Detection and characteristics of microvascular obstruction in reperfused acute myocardial infarction using an optimized protocol for contrast-enhanced cardiovascular magnetic resonance imaging. European radiology. 2009;19:2904-2912

41. Jennings RB, Schaper J, Hill ML, Steenbergen C, Jr., Reimer KA. Effect of reperfusion late in the phase of reversible ischemic injury. Changes in cell volume, electrolytes, metabolites, and ultrastructure. Circulation research. 1985;56:262-278

42. Jennings RB, Murry C, Reimer KA. Myocardial effects of brief periods of ischemia followed by reperfusion. Advances in cardiology. 1990;37:7-31

43. Whalen DA, Jr., Hamilton DG, Ganote CE, Jennings RB. Effect of a transient period of ischemia on myocardial cells. I. Effects on cell volume regulation. The American journal of pathology. 1974;74:381-397

44. Boxt LM, Hsu D, Katz J, Detweiler P, McLaughlin S, Kolb TJ, Spotnitz HM. Estimation of myocardial water content using transverse relaxation time from dual spin-echo magnetic resonance imaging. Magnetic resonance imaging. 1993;11:375-383

45. Stillman AE, Oudkerk M, Bluemke D, Bremerich J, Esteves FP, Garcia EV, Gutberlet M, Hundley WG, JeroschHerold M, Kuijpers D, Kwong RK, Nagel E, Lerakis S, Oshinski J, Paul JF, Underwood R, Wintersperger BJ, Rees MR. Assessment of acute myocardial infarction: Current status and recommendations from the north american society for cardiovascular imaging and the european society of cardiac radiology. The international journal of cardiovascular imaging. 2011;27:7-24

46. Schwitter J, Arai AE. Assessment of cardiac ischaemia and viability: Role of cardiovascular magnetic resonance. European heart journal. 2011;32:799-809

47. Perazzolo Marra M, Lima JA, Iliceto S. Mri in acute myocardial infarction. European heart journal. 2011;32:284-293

48. Wright J, Adriaenssens T, Dymarkowski S, Desmet W, Bogaert J. Quantification of myocardial area at risk with t2-weighted $\mathrm{cmr}$ : Comparison with contrast-enhanced $\mathrm{cmr}$ and coronary angiography. JACC. Cardiovascular imaging. 2009;2:825-831

49. Ganz W. The thrombolysis in myocardial infarction (timi) trial. The New England journal of medicine. 1985;313:1018 
50. Kim HW, Van Assche L, Jennings RB, Wince WB, Jensen CJ, Rehwald WG, Wendell DC, Bhatti L, Spatz DM, Parker MA, Jenista ER, Klem I, Crowley AL, Chen EL, Judd RM, Kim RJ. Relationship of t2-weighted mri myocardial hyperintensity and the ischemic area-at-risk. Circulation research. 2015;117:254-265

51. Croisille P, Kim HW, Kim RJ. Controversies in cardiovascular mr imaging: T2-weighted imaging should not be used to delineate the area at risk in ischemic myocardial injury. Radiology. 2012;265:12-22

52. Bulluck H, White SK, Frohlich GM, Casson SG, O'Meara C, Newton A, Nicholas J, Weale P, Wan SM, Sirker A, Moon JC, Yellon DM, Groves A, Menezes L, Hausenloy DJ. Quantifying the area at risk in reperfused stsegment-elevation myocardial infarction patients using hybrid cardiac positron emission tomographymagnetic resonance imaging. Circulation. Cardiovascular imaging. 2016;9:e003900

53. Bulluck H, White SK, Rosmini S, Bhuva A, Treibel TA, Fontana M, Abdel-Gadir A, Herrey A, Manisty C, Wan SM, Groves A, Menezes L, Moon JC, Hausenloy DJ.T1 mapping and t2 mapping at 3t for quantifying the area-at-risk in reperfused stemi patients. Journal of cardiovascular magnetic resonance : official journal of the Society for Cardiovascular Magnetic Resonance. 2015;17:73

54. Mangion K, Berry C. Advances in magnetic resonance imaging of the myocardial area at risk and salvage. Circulation. Cardiovascular imaging. 2016;9

55. Appelbaum E, Kirtane AJ, Clark A, Pride YB, Gelfand EV, Harrigan CJ, Kissinger KV, Manning WJ, Gibson CM. Association of timi myocardial perfusion grade and st-segment resolution with cardiovascular magnetic resonance measures of microvascular obstruction and infarct size following st-segment elevation myocardial infarction. Journal of thrombosis and thrombolysis. 2009;27:123-129

56. Brener SJ, Mehran R, Brodie BR, Guagliumi G, Witzenbichler B, Cristea E, Xu K, Lansky AJ, Stone GW. Predictors and implications of coronary infarct artery patency at initial angiography in patients with acute myocardial infarction (from the cadillac and horizons-ami trials). The American journal of cardiology. 2011;108:918-923

57. Gibson CM, Kirtane AJ, Morrow DA, Palabrica TM, Murphy SA, Stone PH, Scirica BM, Jennings LK, Herrmann HC, Cohen DJ, McCabe CH, Braunwald E. Association between thrombolysis in myocardial infarction myocardial perfusion grade, biomarkers, and clinical outcomes among patients with moderate- to high-risk acute coronary syndromes: Observations from the randomized trial to evaluate the relative protection against post-pci microvascular dysfunction and post-pci ischemia among antiplatelet and antithrombotic agents-thrombolysis in myocardial infarction 30 (protect-timi 30). American heart journal. 2006;152:756-761

58. Mehta RH, Harjai KJ, Cox D, Stone GW, Brodie B, Boura J, O'Neill W, Grines CL. Clinical and angiographic correlates and outcomes of suboptimal coronary flow inpatients with acute myocardial infarction undergoing primary percutaneous coronary intervention. Journal of the American College of Cardiology. 2003;42:1739-1746

59. Gibson CM, Karha J, Giugliano RP, Roe MT, Murphy SA, Harrington RA, Green CL, Schweiger MJ, Miklin JS, Baran KW, Palmeri S, Braunwald E, Krucoff MW. Association of the timing of st-segment resolution with timi myocardial perfusion grade in acute myocardial infarction. American heart journal. 2004;147:847-852

60. Ferrari R. Metabolic disturbances during myocardial ischemia and reperfusion. The American journal of cardiology. 1995;76:17B-24B

61. Yellon DM, Hausenloy DJ. Myocardial reperfusion injury. The New England journal of medicine. 
2007;357:1121-1135

62. Ferrari R, Balla C, Malagu M, Guardigli G, Morciano G, Bertini M, Biscaglia S, Campo G. Reperfusion damage- a story of success, failure, and hope. Circulation journal : official journal of the Japanese Circulation Society. 2017;81:131-141

63. Majidi M, Kosinski AS, Al-Khatib SM, Smolders L, Cristea E, Lansky AJ, Stone GW, Mehran R, Gibbons RJ, Crijns HJ, Wellens HJ, Gorgels AP, Krucoff MW. Implications of ventricular arrhythmia "bursts" with normal epicardial flow, myocardial blush, and st-segment recovery in anterior st-elevation myocardial infarction reperfusion: A biosignature of direct myocellular injury "downstream of downstream". European heart journal. Acute cardiovascular care. 2015;4:51-59

64. van der Weg K, Kuijt WJ, Bekkers SC, Tijssen JG, Green CL, Lemmert ME, Krucoff MW, Gorgels AP. Reperfusion ventricular arrhythmia bursts identify larger infarct size in spite of optimal epicardial and microvascular reperfusion using cardiac magnetic resonance imaging. European heart journal. Acute cardiovascular care. 2017:2048872617690887

65. van der Weg K, Kuijt WJ, Tijssen JG, Bekkers SC, Haeck JD, Green CL, Lemmert ME, de Winter RJ, Gorgels AP, Krucoff MW. Prospective evaluation of where reperfusion ventricular arrhythmia "bursts" fit into optimal reperfusion in stemi. International journal of cardiology. 2015;195:136-142

66. van der Weg K, Majidi M, Haeck JD, Tijssen JG, Green CL, Koch KT, Kuijt WJ, Krucoff MW, Gorgels AP, de Winter RJ. Ventricular arrhythmia burst is an independent indicator of larger infarct size even in optimal reperfusion in stemi. Journal of electrocardiology. 2016;49:345-352 


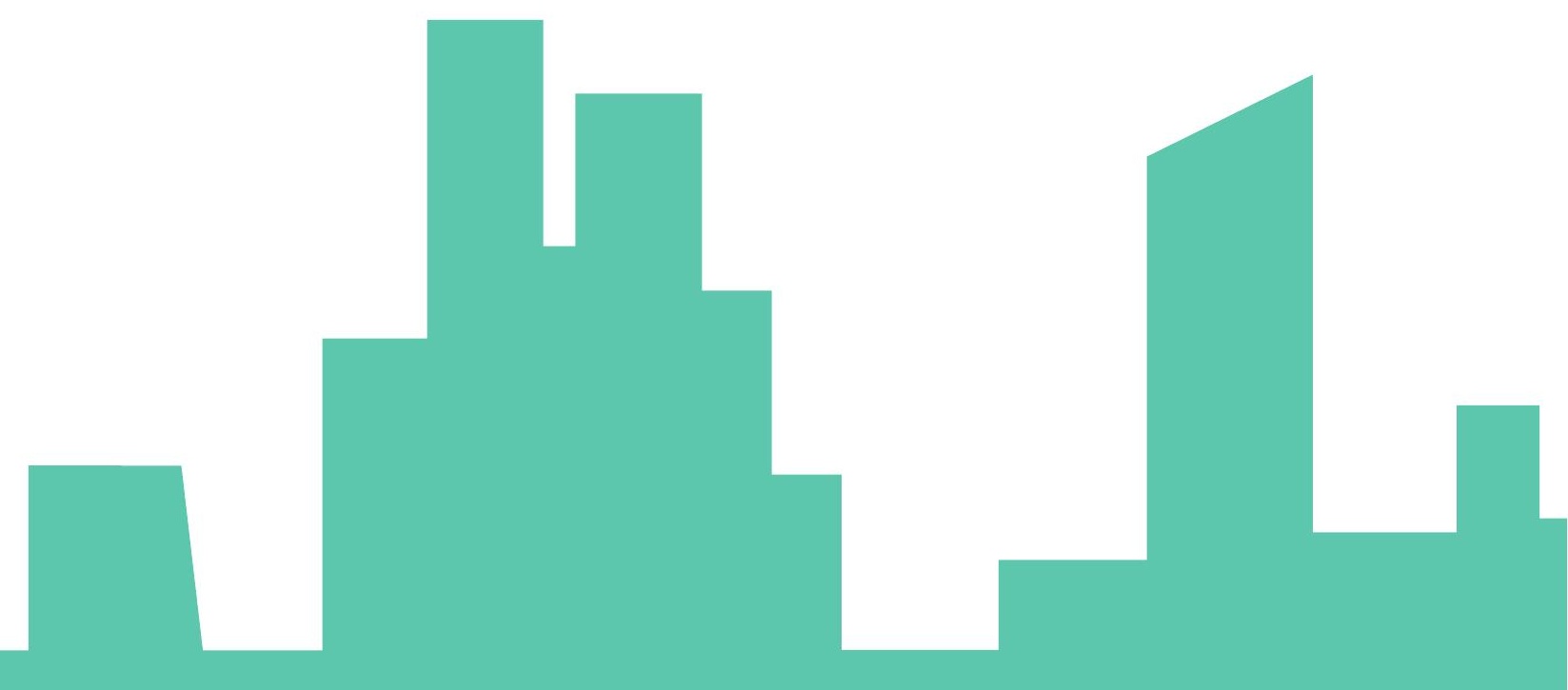




\section{Summary \\ Samenvatting \\ Dankwoord \\ Curriculum vitae \\ List of publications \\ Valorisation}

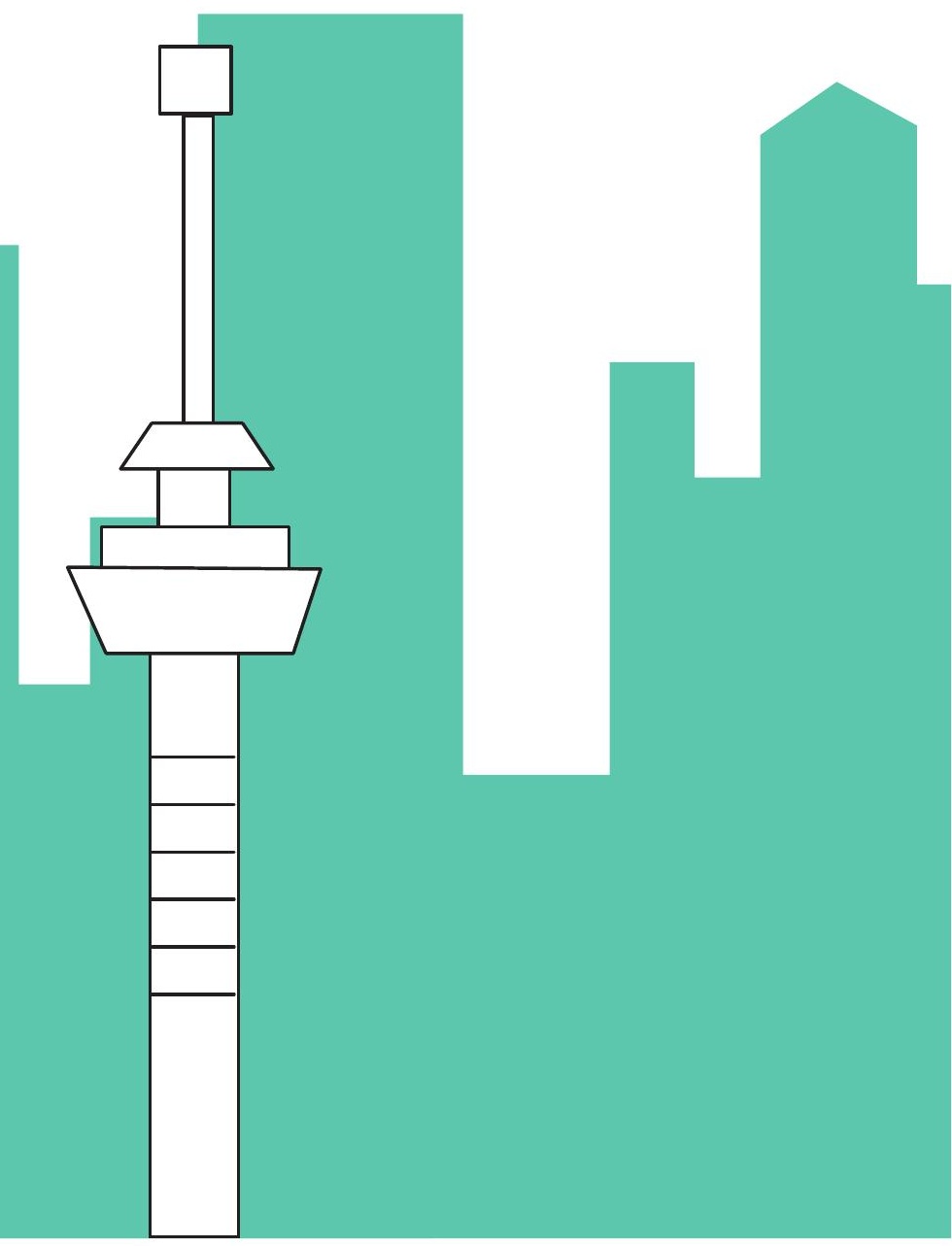




\section{Summary}

Even though direct mortality from acute myocardial infarction has dropped from $15 \%$ to $3,5-5 \%$, cardiovascular disease remains the main cause of mortality in Europe. Over the last century many therapeutic advances have been made that have successfully improved not only mortality but also morbidity. Still there is room for further improvement.

Percutaneous coronary intervention can deliver brisk reperfusion which reduces ischemic time and therefore the extent of cell death. However, reperfusion has also shown to induce extra cell death called reperfusion injury. So while it is essential to achieve reperfusion, the process also has an unfavorable side effect. Therefore a lot of research focusses on preventing reperfusion injury. Because of the complex pathophysiology of reperfusion injury there has not been much success in finding a solution. One of the factors that complicates this research is that a reliable marker for reperfusion injury is not yet available.

In this thesis we analyze the potential of reperfusion arrhythmias as a marker for reperfusion injury. In chapter $\mathbf{2}$ we analyzed whether the presence of a burst of ventricular arrhythmias (VA) was associated with larger myocardial infarction using cardiac MRI. For this purpose 196 patients from the PREPARE and MAST studies who had 24-hour, continuous, 12-lead Holter registration, started before primary percutaneous coronary intervention were analyzed. All patients had brisk TIMI (thrombolysis in myocardial infarction) 3 flow and stable ST-recovery. VA bursts were identified against subject-specific background VA rates using a previously published statistical outlier method. Infarct size was assessed using DE-CMR. VA bursts were present in 154/196 (79\%) of patients. VA bursts were associated with significantly larger infarct size in the population as a whole (median $11.3 \%$ vs $5.3 \% ; p=0.001$ ) and also when divided in non-anterior (median $9.9 \%$ vs $4.9 \% ; p=0.003$ ) and anterior myocardial infarction (median $21.4 \%$ vs $12.0 \% ; p=0.48$ ), the latter not reaching statistical significance due to the small subset of patients. From this we concluded that beyond the classical markers of "optimal" reperfusion such as TIMI 3 flow and stable ST-segment recovery, VA bursts occurring during the reperfusion phase are an early electrobiomarker of larger Infarct size.

After this we sought to analyze whether this relation was caused by suboptimal microvascular reperfusion. In chapter 3 we analyzed if VA burst's association with larger infarct size remained if we excluded patients who had a suboptimal myocardial blush grade (MBG) of 2 or less. A total of 126 STEMI patients were studied with $24 \mathrm{~h}$ continuous, 12-lead Holter monitoring. MBG was determined and VA bursts were identified against subject-specific background VA rates. Delayed-enhancement cardiovascular magnetic resonance imaging was used to determine infarct size. In the group with MBG 3 no significant differences were found for baseline characteristics between burst versus no burst (102 vs. 24). In those with optimal epicardial and microvascular reperfusion (TIMI 3, stable ST-recovery, and MBG 3), VA burst was associated with larger infarct size ( $N=102 / 126$; median 11.0 vs. $5.1 \% ; p=0.004$ ). In the event of MBG 3,VA bursts were associated with significantly larger infarct size. 
Chapter 4 further analyzed whether VA bursts remained associated with larger infarct size in the setting of optimal microvascular reperfusion determined by microvascular obstruction (MVO) on cardiac MRI. All 65 STEMI patients from the Maastricht ST elevation (MAST) study with brisk epicardial flow (TIMI 3) and complete ST recovery post-percutaneous coronary intervention were included. Using 24-hour Holter registrations from the time of admission, VA bursts were again identified against subject-specific Holter background VA rates using a statistical outlier method. MVO and final infarct size were determined using delayed enhancement cardiac MRI. MVO was present in 37/65 (57\%) of patients. Infarct size was significantly smaller in the group without MVO (median $9.4 \%$ vs. 20.5\%; $\mathrm{p}$ <.001). Infarct size in the group with MVO did not differ depending on VA burst ( $n=28 / 37$; median $20.8 \%$ vs. $19.7 \% ; p=0.64$ ). However, in the group without MVO, VA burst was associated with significantly larger IS ( $n=17 / 28$; median $10.5 \%$ vs. $4.1 \%$; $p=0.037$ ). In multivariable analyses, VA burst as well as anterior infarct location remained independent predictors of larger infarct size. Therefore we concluded that in the presence of suboptimal reperfusion with MVO by CMR, VA burst does not further define MI size. However, with optimal TIMI 3 reperfusion and optimal microvascular perfusion (i.e. no MVO), VA burst is associated with larger IS, indicating that VA burst is a marker of additional cell death.

Another explanation for the relation of VA burst with larger infarct size besides being a marker of reperfusion injury could have been that VA burst are a sign of larger area at risk. Therefore in chapter $\mathbf{5}$ we analyzed whether there was a difference in area at risk between the group with VA burst versus the group without VA burst. Included were 68 patients with ST-elevation myocardial infarction from the MAST study with 24-hour, continuous, 12-lead Holter monitoring initiated prior to primary percutaneous coronary intervention $(\mathrm{PCl}$ ) resulting in TIMI 3 flow post $\mathrm{PCI}$. VA bursts were again identified against subject-specific background VA rates using a previously validated statistical outlier method. Infarct size, and infarct endocardial surface area (ESA) were obtained using cardiac MRI at mean 4.9 days after admission. ESA is a method to determine area at risk. VA bursts were present in $69 \%$ (45/65) of patients. Infarct size was significantly smaller in the group without VA bursts (median $9.3 \%$ vs $17.0 \% ; p=0.025$ ). Infarct ESA did not significantly differ between the population with and without VA burst; median $24.3 \%$ vs $20.0 \% ; p=0.15$. As a result we concluded that VA bursts are a marker for larger infarct size independent of area at risk, assessed by surrogate markers. These findings support the hypothesis that VA bursts are a marker of reperfusion damage occurring downstream at myocellular level.

To further support our hypothesis that VA burst is a marker of reperfusion injury we reviewed the pathophysiology of reperfusion arrhythmias and their relation with pathophysiology of reperfusion injury. While both conditions are seen as separate processes, recent research has shown that reperfusion arrhythmias are related to larger infarct size. The pathophysiology of fatal reperfusion injury revolves around intracellular calcium overload and reactive oxidative species inducing apoptosis by opening of the mitochondrial protein transition pore. The pathophysiological basis for reperfusion arrhythmias is the same intracellular calcium overload as the one causing fatal 
reperfusion injury. Therefore both conditions should not be seen as separate entities but as one and the same process resulting in two different visible effects. Reperfusion arrhythmias could therefore be seen as a potential marker for fatal reperfusion injury. 


\section{Samenvatting}

Ondanks dat mortaliteit als een direct gevolg van een acuut hartinfarct is afgenomen van 15\% naar 3,5-5\% blijven hart- en vaatziekten de nummer 1 doodsoorzaak in Europa. De laatste eeuw zijn er veel ontwikkelingen geweest, waardoor niet alleen de mortaliteit maar ook de morbiditeit als gevolg van een hartinfarct zijn verbeterd. Er is desondanks nog zeker ruimte voor verbetering.

Het openen van een afgesloten kransslagader met een katheter tijdens de acute fase van een hartinfarct (ook wel percutane coronaire interventie of dotteren genoemd), zorgt voor snelle reperfusie (herstel van de doorstroming) van het eerdere ischemische (door afsluiting van de toevoerende kransslagader van zuurstof verstoken) gebied waardoor de ischemieduur afneemt en daardoor de hoeveelheid cellen die als een gevolg hiervan dood gaan. Echter is ook aangetoond dat reperfusie extra celdood kan veroorzaken, wat reperfusieschade wordt genoemd. Dus ondanks dat het essentieel is om reperfusie te verkrijgen, heeft dit proces ook een negatieve kant. Daarom is er veel onderzoek gaande om het heropenen van de kransslagader te combineren met farmaca of technieken waarmee reperfusieschade voorkomen kan worden. Vanwege de complexe pathofysiologie van reperfusieschade is er nog niet veel succes geweest op dit gebied. Een van de factoren die het onderzoek bemoeilijkt is dat er nog geen goede marker (meetbaar biologisch signaal) is voor reperfusieschade.

In dit proefschrift onderzoeken we de waarde van reperfusie aritmieën om als marker voor reperfusieschade te dienen. Tijdens het opengaan van het bloedvat treden namelijk bij het merendeel van de patiënten impulsen op uit het weer vers doorstroomde gebied in de hartkamers (ventrikels), die op het elektrocardiogram zichtbaar zijn als ventriculaire ritmen. Het betreft alleen optredende impulsen (ventriculaire extrasystolen) en in reeksen optredend en in een versneld tempo (geaccelereerde ventriculaire ritmen). Deze doven meestal na een aantal minuten weer uit en worden daarom een ontlading (burst) van ventriculaire aritmieën genoemd. In een eerdere studie van onze groep werd een statistische methode ontwikkeld om zo een burst te identificeren door deze te onderscheiden van willekeurig optredende ventriculaire ritmestoonissen.

In hoofdstuk 2 staat ons onderzoek beschreven naar het verband tussen het optreden van een burst van ventriculaire aritmieën en grotere hartinfarcten. Hiertoe werden 196 patiënten van zowel de PREPARE trial als de MAST studie geïncludeerd. Dezen hadden een 24 uurs holter met continue 12-afleidingen registratie die was gestart voor het ontstaan van reperfusie door middel van percutane coronaire interventie. Alle patiënten hadden snelle goed herstelde doorstroming van de afgesloten kransslagader (TIMI 3 flow) en een stabiel herstel van de ischemische tekenen op het elektrocardiogram (ST-elevatie). De infarctgrootte werd bepaald met behulp van magnetische beeldvorming van het hart (cardiale MRI of CMR). Burst van ventriculaire aritmieën waren aanwezig bij 154 van de 196 (79\%) patiënten. Het optreden van bursts van ventriculaire aritmieën ging gepaard met grotere infarcten dan bij patiënten waarbij geen bursts optraden. Dit gold zowel voor de gehele populatie (mediaan $11.3 \%$ vs $5.3 \% ; p=0.001$ ), als voor de subgroepen met niet-voorwand infarcten (mediaan $9.9 \%$ vs $4.9 \%$; 
$\mathrm{p}=0.003$ ) en infarcten van de voorwand (mediaan $21.4 \%$ vs $12.0 \% ; \mathrm{p}=0.48$ ). Bij de voorwandinfarcten werd geen siginifcant resultaat bereikt omdat het een kleine populatie betrof. Op basis van deze resultaten concludeerden we dat naast de klassieke markers van optimale reperfusie, zoals TIMI 3 flow en stabiel ST-segment herstel, bursts van ventriculaire aritmieën die ontstaan gedurende de reperfusie fase een vroege electrobiomarker zijn voor een groter hartinfarct.

$\mathrm{Na}$ dit onderzoek hadden we als doel om verder te analyseren of de relatie van een burst van ventriculaire aritmieën met een groter infarct misschien kwam doordat meer stroomafwaarts de kleine bloedvaatjes in de hartspier niet voldoende doorstroomd werden na heropening van de kransslagader (suboptimale microvasculaire reperfusie). Dit zou kunnen gebeuren door bv ischemische schade van deze microvasculatuur of door versleping van stolsels vanaf de afsluitingsplek meer stroomafwaarts. Dit kan zichtbaar gemaakt worden met röntgenfilms tijdens de dotterprocedure als het niet verschijnen van röntgencontrast in het gereperfundeerde gebied (afwezigheid van myocardiale blush, geclassificeerd als blush graad $\leq 2$ ). In hoofdstuk $\mathbf{3}$ onderzochten we of het verband tussen bursts van ventriculaire aritmieën en grotere infarcten bleef als we alle patiënten met een suboptimale myocardiale blush score (MBG) van 2 of minder excludeerden. Hiervoor werden 126 patiënten geïncludeerd. Cardiale MRI werd gebruikt om infarctgrootte te bepalen. In de groep met MBG 3 (intacte microvasculatuur) werden geen significante verschillen gevonden voor basiskarakteristieken tussen de groepen met en zonder burst (102 vs. 24 patiënten). In de groep met optimale epicardiale en microvasculaire reperfusie (TIMI 3, stabiel ST-segment herstel en MBG 3, was er een verband tussen het optreden van bursts van ventriculaire aritmieën en grotere hartinfarcten $(N=102 / 126$; mediaan 11.0 vs. $5.1 \% ; p=0.004$ ). Hieruit concludeerden we dat in de aanwezigheid van optimale MBG score $(M B G=3)$ burst van ventriculaire aritmieën waren geassocieerd met significant grotere infarcten. Dit betekent dus dat de oorzaak van ventriculaire aritmieën dus verder stroomafwaarts gezocht moest worden, d.w.z. ter hoogte van de hartspiercellen zelf .

Suboptimale microvasculaire reperfusie kan nog nauwkeuriger bepaald worden met behulp van cardiale MRI. Het wordt daar zichtbaar onder de naam microvasculaire obstructie (MVO). In hoofdstuk 4 wordt onderzocht of in de afwezigheid van MVO (intacte microvasculatuur) het optreden van bursts van ventriculaire aritmieen gepaard gaat met grotere hartinfarcten.. Alle 65 patiënten van de Maastricht ST-elevation (MAST) studie met snelle volledige epicardiale reperfusie (TIMI 3) en volledig ST-segment herstel na percutane coronaire interventie werden geïncludeerd. Zoals in de voorgaande studies werd met behulp van 24 uurs holter registraties, die werden gestart vanaf opname in het ziekenhuis, bursts van ventriculaire aritmieën herkend. MVO was aanwezig in 37 van de 65 patiënten (57\%). Hartinfarcten waren significant kleiner in de groep zonder MVO (mediaan 9.4\% vs. $20.5 \% ; \mathrm{p}<0.001)$. In de groep met MVO makte het voor de grootte van het hartinfarct niet uit of er wel of niet een burst van ventriculaire aritmieën was $(n=28 / 37$; mediaan $20.8 \%$ vs. $19.7 \%$; $p$ $=0.64$ ). In de groep zonder MVO daarentegen was er wel sprake van een significant verschil, waarbij de infarcten groter waren als er een burst van ventriculaire aritmieën was ( $n=17 / 28$; mediaan $10.5 \%$ vs. $4.1 \% ; p=0.037$ ). Bij multivariaat analyse bleven een burst van ventriculaire aritmieën en ook de 
aanwezigheid van een voorwandinfarct onafhankelijke voorspellers van een groter hartinfarct. Op basis van deze resultaten concludeerden we dat in de aanwezigheid van suboptimale reperfusie, waarbij MVO zichtbaar is op MRI afbeeldingen, een burst van ventriculaire aritmieën geen verdere aanwijzingen geeft over de grote van het infarct. Echter, als er zowel optimale epicardiale reperfusie (TIMI 3) als optimale microvasculaire reperfusie is (geen MVO), dan gaat de aanwezigheid van burst van ventriculaire aritmieën gepaard met een groter hartinfarct. Bursts als marker voor een groter infarct worden dus niet verklaard door beschadigde micovasculatuur, maar moeten hun oorzaak dus meer stroomafwaarts hebben; d.w.z. op het niveau van de hartspiercellen zelf.

Een andere verklaring voor de relatie van een burst van ventriculaire aritmieën en grotere hartinfarcten kan zijn dat het optreedt bij een groter ischemisch gebied dat gereperfundeerd wordt. Om dit te onderzoeken hebben we in hoofdstuk $\mathbf{5}$ bepaald of er een verschil is in de grootte van het ischemische gebied ( het risicogebied) tussen de groepen met en zonder een burst van ventriculaire aritmieën. Hiervoor werden 65 patiënten geïncludeerd van de MAST studie. Ook hier weer werden continue 12 afleidingen, 24-uurs holter registraties gemaakt startend voor de percutane coronaire interventie. Alle patiënten hadden volledige epicardiale reperfusie na de interventie (TIMI 3 flow) het aanvankelijke risicogebied (area at risk) en de uiteindelijke infarctgrootte (final infarct size) werden bepaald met cardiale MRI. De area at risk werd bepaald door de grootte van de ischemische binnenwand te bepalen omdat daar het infarct begint (endocardial surface area (ESA)). Bursts van ventriculaire aritmieën waren aanwezig bij 69\% (45/65) van de patiënten. De infarctgrootte was zoals eerder significant kleiner in de groep zonder bursts van ventriculaire aritmieën (mediaan $9.3 \%$ vs 17.0\%; $p=0.025$ ). Infarct ESA verschilde echter niet significant tussen beide groepen met en zonder bursts van ventriculaire aritmieën; mediaan $24.3 \%$ vs $20.0 \% ; p=0.15$. Op basis van deze resultaten concluderen wij dat bursts van ventriculaire aritmieën niet een uiting zijn van een aanvankelijk groter ischemisch gebied (area at risk), en omdat ze optreden bij een geopende kransslagader en intacte microvasculatuur dus. een marker zijn van schade die in de hartspiercellen (op myocellulair niveau) zelf plaatsvindt.

Om onze hypothese dat bursts van ventriculaire aritmieën een marker zijn van reperfusie schade verder te ondersteunen, hebben we een review geschreven over de pathofysiologische relatie tussen reperfusie-aritmieën en reperfusieschade op basis van bestaande literatuur. Beide processen werden voorheen gezien als gescheiden processen, maar recent onderzoek van onze groep heeft laten zien dat reperfusie-aritmieën gerelateerd zijn aan grotere hartinfarcten. De pathofysiologische basis van reperfusie- schade draait om een overbelasting van intracellulair calcium in combinatie met oxidatieve stress waardoor de mitochondriale eiwittransitie porie open gaat en er apoptose (geprogrammeerde celdood) ontstaat. De pathofysiologische basis van reperfusie-aritmieën wordt door dezelfde intracellulaire overbelasting van calcium gevormd. Om deze reden kunnen reperfusie-schade en reperfusie-aritmieën niet als twee gescheiden entiteiten gezien worden, maar als hetzelfde proces dat zich op twee verschillende manieren uit. Daarom kunnen reperfusiearitmieën gezien worden als een marker van reperfusieschade. 


\section{Dankwoord}

Het is alweer elf jaar geleden sinds ik begon aan mijn onderzoeksperiode bij Prof. Gorgels. Na al die jaren is nu eindelijk de tijd gekomen om het laatste en ook het leukste deel van mijn proefschrift te schrijven. De jaren zitten vol mooie herinneringen en ervaringen en in de komende pagina's zou ik graag iedereen die hieraan heeft bijgedragen willen bedanken.

Beste Ton, jij bent de eerste die ik wil bedanken. Vanaf het moment dat ik aan mijn derde jaar begon tot het laatste moment van dit proefschrift kon ik altijd bij je terecht met vragen en ondersteuning. Geen vraag was te gek en je wilde altijd meekijken, ook al was je op vakantie. De manier hoe je je patiënten benadert is voor mij altijd een voorbeeld geweest. Je benadert ze in hun geheel en kijkt verder dan alleen hun cardiale problematiek. Ik hoop zelf ook altijd deze brede kijk te behouden en verder te kijken dan het ene probleem waarvoor ze bij me langs komen. Naast de ondersteuning die je altijd hebt geboden op professioneel gebied, zag je ook altijd wanneer er andere dingen speelden en had je hiervoor begrip. Je was als een vaderfiguur voor me en ik ben heel blij en dankbaar dat jij mijn promotor bent geweest.

Dear Mitch, when I first started I hadn't even finished my MD, but you were willing to take on this journey with Ton and me. I would like to thank you for your support and all your advice. Your help was essential in combining the two researches at MUMC+ and AMC and further finalize the chapters of this thesis. You also made me feel welcome at Duke and my time in Durham was an amazing experience, thank you so much for that.

Beste Rob, met jouw hulp kon de PREPARE trial ook onderdeel van dit proefschrift uitmaken. Dank je wel voor je hulp en begeleiding tijdens dit proefschrift. Als ik aan jou denk komt altijd de herinnering boven aan het gesprek dat we in het zonnetje hadden tijdens de ACC in San Francisco. Een gesprek dat niet over de cardiologie ging maar over gewone dingen in het leven. Carrière is belangrijk maar minstens net zo belangrijk is familie en genieten van alle mooie dingen die er bestaan.

De leden van de beoordelingscommissie, Prof. H.J.G.M. Crijns (voorzitter), Prof. P.A.F.M. Doevendans, Prof. P.G.A. Volders, Prof. A.W.J. van 't Hof, en Dr. R Nijveldt wil ik hartelijk bedanken voor het kritisch beoordelen van mijn proefschrift. Voor het opponeren wil ik tevens Prof. H.J. Wellens, Prof R. Smeets en Prof. B. Mochtar bedanken.

Beste Bas Bekkers, jouw bijdrage aan de MAST studie is cruciaal geweest voor de studie. Door de vele uren die je eraan hebt gezeten gedurende meerdere jaren is het de mooie dataset geworden die het nu is. Tevens heb je altijd een grote bijdrage geleverd aan alle artikelen. Je was altijd een van de eersten die kritisch naar het artikel had gekeken ook al was het commentaar niet altijd even leuk om te krijgen. Mede door dit commentaar zijn de artikelen beter geworden en ik wil je voor al je inzet hierbij heel erg bedanken. 
Zonder de statistische ondersteuning die ik heb gehad was het niet mogelijk geweest de analyses uit te voeren en hiervoor zou ik graag Jan Tijssen en Cindy Green willen bedanken. Jan, zonder jouw hulp was het me nooit gelukt om de correlatie analyses uit te voeren. Je hielp niet alleen met het uitvoeren ervan maar ook bij het leren begrijpen wat je aan het analyseren was en waarom. Dit is niet alleen van onschatbare waarde geweest voor dit proefschrift, maar zal me mijn hele carrière nog heel veel geven. Hiervoor heel veel dank. Dear Cindy, you were willing to take on the task of performing the outlier detection method for all patients included in the MAST and PREPARE trial. I really enjoyed our collaboration and think it's an example to see how you combine your work as a statistician with your love for shoes and seeing bears.

Ik had dit onderzoek niet kunnen uitvoeren zonder de steun van de Wellens foundation. Ik wil hier prof. Wellens en de rest van de foundation enorm voor bedanken. De ervaring van het onderzoek en hiermee ook de periode in Amerika zijn een geweldige ervaring geweest niet alleen op wetenschappelijk gebied maar ook op persoonlijk gebied.

Miguel, samen met Bas heb jij de MAST studie opgezet en de patiënten geïncludeerd. Daarbij kon ik je altijd op zeer prettige wijze benaderen met praktische vragen over hoe dingen nou gaan in het promotieonderzoek, dankjewel hiervoor. Ook de tijd in New Orleans was erg gezellig.

Beste Frits, toen Ton en ik je benaderden om mee te schrijven aan de review was je gelijk bereid om mee te werken. Jouw kennis en praktische adviezen hebben de review gemaakt tot het mooie artikel dat het nu is en ik ook oorspronkelijk hoopte dat het kon worden waarvoor heel veel dank.

Josiane, de eerste stappen in het onderzoek heb ik onder begeleiding van Ton en jou gezet. Ik heb het altijd super leuk gevonden om met je te werken en de dagen in New Orleans vergeet ik nooit meer. Bourbon street in de avond waarbij wij al moe waren maar Ton nog energie had om door te gaan en natuurlijk het shoppen. Dank je wel voor de leuke tijd en benaderbaarheid.

During my time at Duke I had the privilege to work with some extraordinary people. Except for Mitch and Cindy there are 3 other people I would like to thank.

Dear Galen, you've been involved in the guidance of multiple young scientist for whom you're always available to discuss their theories, findings and problems. You gave your opinion but also helped us along to improve our theories. Sadly, you've passed away but you will always be remembered. Dear Renato, you've made me feel welcome from the first day at DCRI and always made sure to check-in if everything was going well. Your career is extremely inspiring and even more so is your interest in the people you work with. Thank you so much for all the talks that weren't only about research and academics but also about the things we value in life. Prof. Jennings, talking with you about my review and the pathophysiological processes involved was an honor. To test my hypothesis against your knowledge and experience and receive feedback 
made me better aware of opposing theories and improved my knowledge. Moreover, talking about how you've performed all your research and animal trials was remarkable.

Bas Kietselaer, tijdens mijn tijd bij cardioresearch kon ik je altijd benaderen voor vragen over hoe dat nu allemaal gaat met die grote studies en alles wat erbij komt kijken als we er met het team niet uit kwamen. Met koffie/thee was er altijd een antwoord en een leuk gesprek.

Lieke, Arlette, Aimee, Lizette, Nanda, Mireille en Suzanne, ik heb bij jullie een hele leuke tijd gehad bij cardioresearch. Er was altijd tijd voor een lach, wat thee en ondertussen hadden we tevreden patiënten en veel inclusies. Lieke, ik kijk nog altijd met veel plezier terug op onze paar dagen in Frankfurt. Ben er later nog meerdere keren geweest toen Nick er zat voor zijn werk en moest uiteraard terugkeren naar de dierentuin.

Beste An Moens, dankzij jouw inzet kon ik mijn onderzoek met de tijd bij cardioresearch combineren waardoor ik langer fulltime aan mijn onderzoek kon besteden. Ik kon je altijd om advies vragen en je ervaringen die je had opgedaan deelde je graag met me. Dank je wel voor alles, ik denk met een glimlach aan die tijd terug.

Beste Bas Mochtar, we hebben elkaar beter leren kennen mede doordat we beiden in het verleden in Rotterdam hadden gewoond en nu wonen we ironisch genoeg beiden in Laren. In alle jaren bent u er geweest als mentor en kon ik altijd de mooie momenten van het onderzoek, de geneeskunde en het leven met u delen maar ook de frustraties. De tijd van het promoveren is dadelijk afgesloten maar ik hoop dat onze gesprekken blijven bestaan.

Lieve Arie, Dorien, Nicole, Jessica en Jolanda, ik ben jullie heel dankbaar voor de leerzame maar vooral ook leuke tijd die ik bij jullie heb mogen doorbrengen in mijn eerste jaar van de huisartsenopleiding. Bij jullie leerde ik gewoon mezelf te zijn als dokter, dat een beetje recalcitrant zijn een goed iets is (en als het gaat over de opleiding dan mag je een beetje weglaten), dat grapjes zeker moeten kunnen, en van Arie leerder ik dingen over komkommers die ik nooit meer zal vergeten. Maar bovenal leerde ik hoe belangrijk het is om een leuk team te hebben waarmee je samenwerkt en dan komt alles wel goed. Ik hoop ooit later in een eigen praktijk dezelfde sfeer te hebben.

Lieve Joop, qua karakters waren we grote tegenpolen, waar jij rustig was stuiterde ik vrolijk door de praktijk. Ondanks deze verschillen liet je me gewoon de dokter zijn die ik ben en was je niet bezig een kopie van jezelf op te leiden. Dit is een uitzonderlijke kwaliteit en ik ben je heel erg dankbaar voor het leerzame laatste jaar van mijn opleiding bij jou. Lieve Monique, ik heb het het laatste jaar van mijn opleiding heel erg leuk met je gehad en ik kon altijd wel even bij je binnenwandelen voor een grapje of bij je terecht als ritsen/naden het begeven hadden. Naast alle gezelligheid en steun die je gaf ben je ook een top assistente en iedere huisarts die met jou werkt mag zich in zijn handen knijpen. 
Annemieke, Zain, Claudia, Isma, Melek, Nienke Bakker, Guusje, Rosanne, Tara, Ilse, Arendina, Sanne, Aimee, Marjon, Saskia, Climmy, Erika, Jens, Mandy, Laura A., Nienke Bergen, Roxanne, Mehmed, Zjwan, Laura en Leonie, heel erg bedankt voor de leuke terugkomdagen en de uitjes die erbij kwamen kijken. Leonie, het is toch grappig dat ik jou pas na vertrek uit Maastricht heb leren kennen en dat terwijl onze mannen samen in hetzelfde bestuur hebben gezeten. De gezamenlijke etentjes moeten we er zeker in houden. Zwjan, met jou kan ik altijd lachen maar ook de mindere dingen kunnen we met elkaar delen. Super leuk dat je nu een tweede kleine erbij krijgt, nog even volhouden met de opleiding, ja en amen knikken en dan ben je vrij en verlost van het instituut en draai na je laatste dag maar heel hard Wonderland van Oasis in de auto.

Graag wil ik ook alle collega's van de afdeling interne geneeskunde, longziekten en cardiologie van het Amstelland bedanken. De sfeer die daar heerst is ongekend en iedereen die denkt dat internisten suffe specialisten zijn heeft duidelijk nog nooit een dag in het Amstelland meegemaakt. Ook met de assistenten onderling was het altijd gezellig en dit werd maar weer benadrukt tijdens de afscheidsborrel van Cees afgelopen jaar. Annemieke, Audrey, Etienne, Clementine, Jasper, Jessy, Marieke, Suzanne, Viviane, Tessa, Michael, Susan, Britt, Eline, Kristian, Roeline, Dave en Fee heel erg bedankt voor de gezellige tijd. Fee, de dagjes strand en drankjes in de stad zijn altijd top geweest en hopelijk komen er nog meer.

Dear Danielle, I met you the second and longest time I spent at Duke. We instantly clicked and my time wouldn't have been the same if I hadn't met you; the sushi, shopping, cocktails, dinners and the sleepover. I'm so happy you got into med school and it won't be long before you start your residency. You're going to be an amazing doctor and if I'm ever Stateside or you're in Europe we should definitely get together. I suggest sushi and cocktails!!!

Lieve Ed, met jou, Kelly en Gwen heb ik een jaar een roeiboot mogen delen wat resulteerden in veel trainingen maar ook veel gezellige wedstrijd weekenden met $z^{\prime} n$ vieren. Na deze periode hebben we altijd contact gehouden of we nu in Amerika zaten of naar andere delen van Nederland verhuisden. Ik spreek je helaas niet meer zo vaak als ik zou willen maar als we afspreken is het altijd als vanouds en ik denk dat dat altijd zo zal blijven.

Lieve Marielle, jou heb ik eigenlijk pas leren kennen aan het einde van de geneeskunde opleiding. Samen hebben we op andere wijze een promotietraject bij de cardiologie doorgemaakt en als ik wat frustratie of juist iets heel erg leuks kwijt wilde kon ik daarvoor altijd bij je terecht. Daarnaast waren er natuurlijk de lunches en wijntjes waarbij dit gebeurde. Je opleidingsplek is meer dan verdiend en je gaat een geweldige cardiologe worden. Op nog vele lunches, wijntjes en bezoeken aan het ballet!

Lieve Joke, Anouk, Myrna, Roos, Sandra, Margot, Fred, en Pauline, onze mannen kiezen best wel leuke vriendinnen als ik het mag zeggen en we hebben daarin een hele leuke groep gekregen. Ondertussen is het zo dat we elkaar niet alleen zien als de mannen samen 
afspreken maar ook gewoon omdat wij er zin in hebben. Ik vind dit super en hierdoor zijn de oud en nieuw feestjes, etentjes en uiteraard de bruiloften alleen nog maar leuker. Lieve Pauline, jou heb ik ook zo leren kennen en ik vind het echt super dat je zo dichtbij bent komen wonen. Als er iets is kan ik je bellen of een voice bericht via Whatsapp sturen (wat je me hebt geleerd) en zo kan datgene dat ik echt even kwijt moet met je delen. Andersom kan je het ook bij mij en hoeven we voor elkaar de schone schijn niet op te houden. Je bent een super vriendin en op de vele drankjes die nog gaan komen. Er zijn nog heel veel tenten in het centrum die we moeten uitproberen. Lieve Fred, jou kende ik een beetje vanuit Saurus maar door de etentjes heb ik je beter leren kennen. Toen Joep en jij vlak bij ons kwamen wonen in Amsterdam was het helemaal makkelijk om wat te gaan drinken, naar de bios te gaan of een gesprek over de dakterrassen heen met elkaar te hebben. Helaas woon je nu niet meer zo dichtbij en hebben we het drukker gekregen maar de etentjes, borrels, shoppen en bios houden we erin alleen dan afgesproken via de app en niet meer over het dak geroepen.

Lieve Dana en Miranda, ik ken jullie via de volleybal,al vanaf toen we nog op de middelbare school zaten. Eigenlijk is sinds die tijd de vriendschap alleen maar verbeterd. Miran, jij woont nu in Denemarken en ik vind het heel dapper wat je hebt gedaan. Daan en ik moeten nog altijd langskomen en aangezien het bijna het nieuwe jaar is, is het mijn voornemen om dat nog in 2019 zeker te doen! Daan, je bent een top vriendin. Van het stappen in Rotterdam aan het einde van de middelbare school wat vervangen werd door het stappen in Maastricht tot het grote toppunt, onze reis door Vietnam. Die reis zit vol prachtige herinneren van het fietsen op een te kleine tandem, het kijken van het WK in oranje jurkjes, gekke hotelnamen, het binnenland in gaan voor olifanten, chocolade die niet te eten was, kleding laten maken, Halong Bay en zoveel meer. Gelukkig zijn er na die tijd alleen nog maar mooie herinneringen bijgekomen met jouw prachtige bruiloft en zoon. Komend jaar een reisje Denemarken en we houden natuurlijk onze sauna uitjes.

Lieve Mireille, soms kom je op onverwachte momenten hele leuke mensen tegen waarmee je gelijk bevriend raakt. Onze vriendschap is een voorbeeld hiervan. In die korte tijd ben je uitgegroeid tot een hele goede vriendin die ik altijd kan bellen om iets leuks mee af te spreken of heerlijk te kletsen. Van heerlijke ladies nights met Noor, wijntjes drinken en natuurlijk onze ogen uitkijken en lachen tijdens occasion avond in het Bonte Paard. Als de afgelopen 1,5 jaar een leidraad is voor de jaren die nog gaan komen dan gaan het heerlijke jaren worden. Volgende punt op de planning is een weekendje weg voor waterglijbanen met Noor er ook bij, al wil ik dat best upgraden naar Eurodisney! Ohwja we hadden ook nog een trip naar de Champagne streek in gedachten....

Lieve Noor, we leerden elkaar kennen als collega's op de SEH bij de interne geneeskunde in het Amstelland waar jij je spoed stage deed en nu zijn we weer collega's in Zeeburg. Er zijn van die mensen waarbij het moeilijk is om wat over te vertellen omdat als je aan ze denkt er te veel geweldige dingen zijn die je kan vertellen en je niet weet waar je moet beginnen; relaxen op terras/dakterras, winkelen, congressen, weekendjes weg, tutten, feesten en ons als gekken verkleden, gewoon wat 
drinken of decadent ergens wat drinken, naar het strand, naar concerten, meeblèren in de auto met de muziek, te veel om op te noemen. Waar het op neer komt is eigenlijk dat het niet uitmaakt wat we doen, ik kan met je lachen en huilen en hoop dat je nog heeeeeel veel jaren mijn vriendin blijft.

Lieve Natas, sinds de eerste dag bij onze allereerste onderwijsgroep in Maastricht zijn we vriendinnen en later werd je ook nog mijn overbuurmeisje (want we blijven altijd jong). In Maastricht hebben we heerlijke avonden in de kroeg gehad, maar ook hebben we precies dezelfde smaak qua series en films. Vele avonden werden dan ook met een wijntje doorgebracht terwijl we onze favoriete series of films keken of bespraken. Ik zal ook nooit die keer vergeten dat we stiekem naar een tweede film waren gesneakt, gewoon omdat we dat nog nooit hadden gedaan. Ohw en natuurlijk de Gossip Girl party voor onze verjaardag. We zien en spreken elkaar niet meer zo vaak als we vroeger deden maar altijd als we elkaar zien/spreken is het als vanouds ongeacht of er nu een week, maand of half jaar tussen heeft gezeten. Het wordt trouwens tijd dat er een nieuwe trilogie in de bios komt voor ons om naartoe te gaan.

Lieve Git, mijn leukste woning in Maastricht was de woning die ik naast jou had. Ik geloof dat er weinig dagen zijn geweest dat ik je niet heb gezien in die periode. Nieuwe aankopen werden standaard aan elkaar geshowd, kledingkasten werden samen uitgezocht, de logeerkat werd gedeeld en frustraties en verdriet konden we ook met elkaar delen. We hebben sindsdien meerdere keren telefonisch aan elkaar verzucht hoe graag we wel niet weer zouden willen dat wel naast elkaar woonden of op zijn minst in dezelfde stad (sorry mijn schuld). Op Nick na is er niemand die mijn promotietraject denk ik zo duidelijk heeft meegemaakt als jij. Het kon daarom niet anders dat jij een van mijn paranimfen zou zijn. Ik ben meerdere keren bij jou binnen gekomen om te vragen of jij kon lezen wat Ton bij een stuk had geschreven maar nog vaker werden periodes van studie onderbroken door even een periode ongegeneerd fanatiek mario kart spelen. Git, je bent een top vriendin en ik ben heel blij dat je ook op dit laatste moment van mijn promotie-onderzoek naast me staat.

Lieve Kirs, je bent al mijn vriendin sinds de eerste dag je bij mij in de klas kwam in groep 6 (25 november 1996). Er is niemand die mij zo goed kent als jij. We kunnen aan elkaars stemgeluid al horen hoe we elkaar voelen, of we onszelf goed proberen te houden en kunnen ook om de kleinste dingen lachen. Er zijn te veel herinneren om op te noemen en wat ook maar goed is want sommige dingen zijn al schaamtelijk genoeg voor ons tweeën (bewitched). Wat er ook is, hoe laat het ook is of waar we ook zijn, we zijn er altijd voor elkaar en kunnen altijd bij elkaar terecht. Je hoort dingen soms nog eerder dan Nick ze hoort en er gaat denk ik geen week voorbij dat we niet bellen (vaak meerdere keren). Je steunt me door dik en dun maar zegt het ook gewoon eerlijk als je het niet met me eens bent. Ik kon daarom niemand bedenken die ik op dit moment liever bij me zou hebben dan jij. Kirs, je bent mijn beste en oudste vriendinnetje en ik ben je zo dankbaar voor alle jaren die zijn geweest en alle jaren die nog gaan komen. 
Lieve zus, iedereen die ons een beetje kent weet dat we vroeger niet echt vredig met elkaar opschoten en papa en mama vele kopzorgen hebben bezorgd. Zelfs samen afwassen op de camping vonden ze geen verstandig plan meer. Gelukkig ligt die tijd volledig achter ons en is de relatie helemaal veranderd. Ik ben zo trots op wat je allemaal bereikt heb en het mooie gezin dat je samen met Pim hebt. Levi en Xev zijn pracht jongens, je hebt het toch maar even goed voor elkaar. Ik weet dat als er nu iets is ik altijd bij je terecht kan en we weten elkaar altijd te vinden. Ik ben heel blij dat jij mijn zusje bent.

Papa en mama, het is dan eindelijk klaar. Die promotie die zo lang duurde vindt vandaag zijn afronding. Jullie waren altijd geïnteresseerd en wilden altijd weten hoe het ervoor stond. Het probleem was alleen dat er een periode was dat het niet echt opschoot en toen is er maar de afspraak gekomen dat ik het jullie zou laten weten als er beweging in zat. Gelukkig kon ik jullie het afgelopen jaar heel vaak bellen met updates, zelfs updates waarvan jullie niet wisten dat het updates konden zijn. Ik kan vrij eigenwijs zijn en ben ook geen talent in het voor me houden van wat ik denk. Dit heeft het niet altijd makkelijk gemaakt voor jullie, maar weet dat jullie het super hebben gedaan. Mam, in de periodes dat ik het moeilijk had mocht ik je altijd bellen. Pap, sinds je met pensioen bent spreek ik je vaker dan mama en je doet dat toch maar knap met al die vrouwen om je heen. Ik ben heel blij met jullie als ouders en ik hoop dat jullie ook een beetje kunnen genieten van de verdediging. Het is me uiteindelijk gelukt.

Nick, lieverdje, het laatste en belangrijkste dankwoord is voor jou. We zijn nu al ruim 12,5 jaar samen en hebben samen veel meegemaakt. Door de jaren heen is onze relatie alleen maar sterker geworden en ik vertel je regelmatig hoe bijzonder ik het vind hoe gelukkig ik met je ben. Je kent me soms beter dan ik mezelf ken en wist bijvoorbeeld al veel eerder dan ik dat ik het meest gelukkig zou worden als huisarts. Toch heb je me de ruimte gegeven om zelf tot deze conclusie te komen. Ik weet dat het combineren van werk met onderzoek me niet altijd tot de gezelligste persoon heeft gemaakt maar toch heb je me altijd gesteund en me geleerd prioriteiten te stellen. Dank je wel voor alles, ik hou super veel van je en kijk uit naar alles wat nog gaat komen samen met jou wat het ook mag zijn. Ik heb nog wel een grote verlanglijst aan ervaringen die ik met je wil op doen om ons nog heel veel jaren bezig te houden. 


\section{Curriculum vitae}

Kirian van der Weg was born on the 23th of November 1986 in Rotterdam. She grew up in Berkel en Rodenrijs with her parent Caroline en Frits van der Weg and her sister Tamara. After graduating from Marnix Gymnasium in Rotterdam in 2005 she relocated to Maastricht to study Medicine at the faculty of Health, Medicine and life sciences at Maastricht University. During her second year she started in the honoursprogramme of the faculty focusing on medical research. It was that year she first came in contact with research supervised by prof. Gorgels of the department of cardiology. Though the topic of her research changed, she continued research supervised by prof. Gorgels which led to the start of her $\mathrm{PhD}$ research during her fourth year.

After getting her MD she spent 1,5 year focusing solely on research where she combined her PhD research with working as a sub-investigator on the CAROLINA, PEGASUS, RELYABLE, CANTOS, and TECOS trial. During this time she also spent a total of six months for her research at Duke Clinical Research Institute at Durham, North Carolina.

This period was followed by working as a cardiology resident at HAGA hospital and VU Medical Center. During this time she realized she wanted to pursue a different rout in medicine. To explore whether she wanted to specialize in internal medicine or family medicine she worked a year as a resident in internal medicine at Amstelland Hospital. It was there she discovered her passion for working with a diversity of patients of different ages and liked most aspects of them including all their quirks. Because of this she chose to become a general practitioner and spend the following three years as a GP in training at Erasmus University coming full circle back in Rotterdam.

In August 2018 she completed her training and became a qualified GP. During all this time she continued working on her $\mathrm{PhD}$ thesis.

Today, she currently works as a general practitioner in the region between Amsterdam, Utrecht and Amersfoort while rediding in Laren with her partner Nick. 


\section{Publications}

\section{International peer reviewed published publications}

van der Weg K, Prinzen F, Gorgels APM: Reperfusion cardiac arrhythmias and their relation to reperfusion induced cell death. European heart journal Acute cardiovascular care epublished ahead of print.

van der Weg K, Kuijt WJ, Bekkers S, Tijssen JGP, Green CL, Smulders MW, Lemmert ME, Krucoff MW, Gorgels APM: Bursts of reperfusion arrhythmias occur independently of area at risk size and are the first marker of reperfusion injury. International journal of cardiology 2018, 271:240-246.

van der Weg K, Kuijt WJ, Bekkers SC, Tijssen JG, Green CL, Lemmert ME, Krucoff MW, Gorgels AP: Reperfusion ventricular arrhythmia bursts identify larger infarct size in spite of optimal epicardial and microvascular reperfusion using cardiac magnetic resonance imaging. European heart journal Acute cardiovascular care 2018, 7(3):246-256.

van der Weg K, Majidi M, Haeck JD, Tijssen JG, Green CL, Koch KT, Kuijt WJ, Krucoff MW, Gorgels AP, de Winter RJ: Ventricular arrhythmia burst is an independent indicator of larger infarct size even in optimal reperfusion in STEMI. Journal of electrocardiology 2016, 49(3):345-352.

van der Weg K, Kuijt WJ, Tijssen JG, Bekkers SC, Haeck JD, Green CL, Lemmert ME, de Winter RJ, Gorgels AP, Krucoff MW: Prospective evaluation of where reperfusion ventricular arrhythmia "bursts" fit into optimal reperfusion in STEMI. International journal of cardiology 2015, 195:136-142.

Rovai D, Bayes de Luna A, Goldwasser D, Pons-Llado G, Carreras F, di Bella G, Pingitore A, van der Weg K, Gorgels A, Kim R: Q wave myocardial infarction of anteroseptal zone: a new classification. International journal of cardiology 2015, 180:44-45.

Norda S, van der Weg K, Vos R, Gorgels AP: Electrocardiographic prediction of lateral involvement in acute non-anterior wall myocardial infarction. Journal of electrocardiology 2015, 48(4):527-532.

Hassell ME, Bekkers SC, Loring Z, Van Hellemond I, Bouwmeester S, Van der Weg K, Maynard C, Gorgels AP, Wagner GS: The predictive value of an ECG-estimated Acute Ischemia Index for prognosis of myocardial salvage and infarct healing 3months following inferior ST-elevated myocardial infarction. Journal of electrocardiology 2013, 46(3):221-228. 
van der Weg K, Bekkers SC, Winkens B, Lemmert ME, Schalla S, Crijns HJ, Waltenberger J, Gorgels AP: Evaluation of the electrocardiogram in identifying and quantifying lateral involvement in nonanterior wall infarction using cardiovascular magnetic resonance imaging. Journal of electrocardiology 2012, 45(5):478-484.

Bouwmeester S, van Hellemond IE, Maynard C, Bekkers SC, van der Weg K, Wagner GS, Gorgels AP: The relationship between initial ST-segment deviation and final QRS complex changes related to the posterolateral wall in acute inferior myocardial infarction. Journal of electrocardiology 2011, 44(5):509-515.

Gorgels AP, van der Weg K: Posterior or lateral involvement in nonanterior wall infarction. What's in a name? Journal of electrocardiology 2010, 43(3):221. 


\section{Selection of Lectures and poster presentations:}

"Reperfusion arrhythmia "bursts" predict larger infarct size in STEMI patients undergoing primary percutaneous coronary intervention despite optimal epicardial and microvascular flow." Oral presentation ESC September 2013 in Amsterdam.

"Reperfusion bursts of ventricular arrhythmias are associated with larger infarct size in patients with acute myocardial infarction." Poster ACC March 2013 in San Francisco

"Reperfusion Ventricular Arrhythmia "Bursts" are a Potential Novel Biomarker for Reperfusion Injury at Myocellular Level in the Presence of Optimal Epicardial and Microvascular Angiographic Reperfusion." Lecture during the NVVC on October 4, 2012.

"The value of precordial leads in anterior and non-anterior wall infarction." lecture during the MALT meeting in Maastricht on February 2011

"The R in V1 in non-anterior wall infarction indicates lateral rather than posterior involvement. Results from ECG/MRI correlations" Poster ESC 2009 in Barcelona

"The R in V1 in non-anterior wall infarction indicates lateral rather than posterior involvement" Poster MMSRC 2009 in Maastricht

"The R in V1 in non-anterior wall infarction indicates lateral rather than posterior involvement. Results from ECG/MRI correlations" lecture during the MALT meeting in Schotland on February 2009 


\section{Valorisation}

This valorisation chapter describes how the knowledge derived from this thesis could contribute to the society. This thesis focuses on the relation of cardiac ventricular reperfusion arrhythmias and larger infarct size due to the mechanism of reperfusion injury. In this chapter the focus will be on how these results might be used in the future and the subsequent societal relevance of these findings.

\section{Societal relevance}

Mortality rates following acute myocardial infarction have significantly dropped in the past decades ${ }^{1,}$ 2. Paradoxically, the impact of myocardial infarction on society increases. Heart failure is a frequently occurring disease entity with myocardial infarction as one of its major causes. Over the last 10 years in the Netherlands medical costs for heart failure have doubled (455 million euro in 2007 vs 937 million euro in 2015), being responsible for $1,1 \%$ of the total Dutch health care budget ${ }^{3,4}$. This figure does not even include the costs for treatment of acute and chronic coronary artery disease. The burden on society further increases because more than $50 \%$ of people are still of working age when struck by myocardial infarction.

Reducing impact on society can be achieved by lowering incidence of coronary artery disease and by decreasing morbidity as a result of myocardial infarction. As mentioned in previous chapters, research has recently also been focusing on preventing reperfusion injury as it appears to be responsible for up to $50 \%$ of total infarct size. Based VA burst as an electrobiomarker of reperfusion injury. This is a frequently occurring complication of recanalized myocardial infarction, being observed in about $70 \%$ of cases in studies from our group ${ }^{5-11}$. Numerous treatment options have been tested but favorable results are still limited. This is partly due to the absence of a good (surrogate) marker for reperfusion injury making it difficult to distinguish between reperfusion and ischemic injury. Our method of VA burst as an early electrobiomarker could be of aid in solving this problem as it was found to be a marker of reperfusion injury rather than ischemic injury. When reperfusion injury could be prevented, infarct size will be reduced; morbidity (and mortality) might decrease resulting in increased quality of life and reduced medical costs.

Furthermore, VA burst as an electrobiomarker is a relatively inexpensive diagnostic tool being widely available and easily applicable. Our biosignature of injury as described in chapter 7 can further aid to identify patients who could be benefit most from preventing reperfusion injury. Because reperfusion injury does not occur in every patient following successful reperfusion, these patients can be identified early and be excluded in research, studying means of reducing this event, preventing in this way diluting the study population. 


\section{Target audience}

The results of this thesis are of interest for patients, physicians and researchers. Models stratifying patients according to infarct size to determine the most suited treatment protocol are widely used in daily practice. The addition of ventricular reperfusion arrhythmias as an electrobiomarker can further identify patients with larger infarcts especially in combination with the concept of biosignature of injury. These may help identify patients who can be discharged early and easier resume their daily life. This impacts patients as well as care professionals. It also impacts hospital management considering changes in discharge policy with consequences such as for ward capacity.

Also the medical industry might be interested in the advent of a reliable biomarker of reperfusion injury. Until now the main focus in treating patients with acute myocardial infarction is on reducing ischemia related myocardial cell death. Early recognition of myocardial ischemia and start of treatment by paramedics in the field, improved logistics to early open the culprit coronary artery by percutaneous coronary intervention, the disposal of supporting medication and development of rehabilitation programs led to preservation of cardiac function and quality of life. However it has also been recognized that the reperfusion process itself can cause additional cell death. In spite of an extensive body of research on reducing or preventing reperfusion injury over the past decades, attempts to reduce reperfusion injury were largely unsuccessful. Multiple factors impede the prevention or reduction of reperfusion injury. In this regard it has to be considered that reperfusion injury can only occur if recanalization of the epicardial culprit coronary artery and its downstream microvasculature is reestablished after a period of preceding ischemia. If this does not happen, attempts to reduce reperfusion injury will not be feasible. Furthermore, as mentioned above reperfusion injury does not occur in all patients with optimal recanalization, including the microvasculature. This implies dilution of study populations when studying interventions to reduce reperfusion injury. With the advent of an early electrobiomarker such as VA burst it will hopefully become possible to study means to reduce or prevent reperfusion injury in patient groups identified as such.

\section{Future directions}

VA burst have the potential to be used in clinical trials aiming at reducing or preventing reperfusion injury. Using the full biosignature of injury patients can be identified benefitting most. This is essential for the development of new methods to combat reperfusion injury. Up till now the absence of this approach has restrained research.

To further asses the usability of VA burst in clinical trials aimed at impacting reperfusion injury, a large independent multicenter trial is necessary to confirm our findings and analyze whether adjusting the threshold that determines the presence of VA burst further stratifies the extent of cell death caused by reperfusion injury. If such a trial is performed and confirms our hypothesis, VA burst could become approved as a valid surrogate biomarker for reperfusion injury. 
1. de Vreede-Swagemakers JJ, Gorgels AP, Dubois-Arbouw WI, et al. Out-of-hospital cardiac arrest in the 1990's: a population-based study in the Maastricht area on incidence, characteristics and survival. J Am Coll Cardiol. 1997; 30: 1500-5.

2. Johansson S, Rosengren A, Young K and Jennings E. Mortality and morbidity trends after the first year in survivors of acute myocardial infarction: a systematic review. $B M C$ Cardiovasc Disord. 2017; 17: 53.

3. Engelfriet PM, Hoogenveen RT, Poos MJJC, Blokstra A, van Baal PHM and Verschuren WMM. Hartfalen; epidemiologie, risicofactoren en toekomst. RIVM, 2012.

4. Slobbe LCJ, Ramjiawan VR and Giesbers H. kosten van ziekten 2015. Volksgezondheid en zorg, 2015.

5. Majidi M, Kosinski AS, Al-Khatib SM, Lemmert ME, Smolders L, van Weert A, Reiber JH, Tzivoni D, Bar FW, Wellens HJ, Gorgels AP, Krucoff MW. Reperfusion ventricular arrhythmia 'bursts' in timi 3 flow restoration with primary angioplasty for anterior st-elevation myocardial infarction: A more precise definition of reperfusion arrhythmias. Europace. 2008;10:988-997

6. Majidi M, Kosinski AS, Al-Khatib SM, Lemmert ME, Smolders L, van Weert A, Reiber JH, Tzivoni D, Bar FW, Wellens HJ, Gorgels AP, Krucoff MW. Reperfusion ventricular arrhythmia 'bursts' predict larger infarct size despite timi 3 flow restoration with primary angioplasty for anterior st-elevation myocardial infarction. European heart journal. 2009;30:757-764

7. Majidi M, Kosinski AS, Al-Khatib SM, Smolders L, Cristea E, Lansky AJ, Stone GW, Mehran R, Gibbons RJ, Crijns HJ, Wellens HJ, Gorgels AP, Krucoff MW. Implications of ventricular arrhythmia "bursts" with normal epicardial flow, myocardial blush, and st-segment recovery in anterior st-elevation myocardial infarction reperfusion: A biosignature of direct myocellular injury "downstream of downstream". European heart journal. Acute cardiovascular care. 2015;4:51-59

8. van der Weg K, Kuijt WJ, Bekkers S, Tijssen JGP, Green CL, Smulders MW, Lemmert ME, Krucoff MW, Gorgels APM. Bursts of reperfusion arrhythmias occur independently of area at risk size and are the first marker of reperfusion injury. International journal of cardiology. 2018;271:240-246

9. van der Weg K, Kuijt WJ, Bekkers SC, Tijssen JG, Green CL, Lemmert ME, Krucoff MW, Gorgels AP. Reperfusion ventricular arrhythmia bursts identify larger infarct size in spite of optimal epicardial and microvascular reperfusion using cardiac magnetic resonance imaging. European heart journal. Acute cardiovascular care. 2018;7:246-256

10. van der Weg K, Kuijt WJ, Tijssen JG, Bekkers SC, Haeck JD, Green CL, Lemmert ME, de Winter RJ, Gorgels AP, Krucoff MW. Prospective evaluation of where reperfusion ventricular arrhythmia"bursts" fit into optimal reperfusion in stemi. International journal of cardiology. 2015;195:136-142

11. van der Weg K, Majidi M, Haeck JD, Tijssen JG, Green CL, Koch KT, Kuijt WJ, Krucoff MW, Gorgels AP, de Winter RJ. Ventricular arrhythmia burst is an independent indicator of larger infarct size even in optimal reperfusion in stemi. Journal of electrocardiology. 2016;49:345-352 
